\title{
Interim Plutonium Stabilization Engineering Study
}
G. J. Sevigny
P. M. Molton
R. H. Gallucci
R. Nass
S.M.K. Garrett
K.J. Templeton
J.G.H. Geeting
A. J. Villegas
R. S. Goheen

August 1995

Prepared for the

U.S. Department of Energy

under Contract DE-AC06-76RLO 1830

Pacific Northwest Laboratory

Operated for the U.S. Department of Energy

by Battelle Memorial Institute

\section{Battelle}




\section{DISCLAIMER}

This report was prepared as an account of work sponsored by an agency of the United States Government. Neither the United States Government nor any agency thereof, nor Battelle Memorial Institute, nor any of their employees, makes any warranty, express or implied, or assumes any legal liability or responsibility for the accuracy, completeness, or usefulness of any information, apparatus, product, or process disclosed, or represents that its use would not infringe privately owned rights. Reference herein to any specific commercial prodúct, process, or service by trade name, trademark, manufacturer, or otherwise does not necessarily constitute or imply its endorsement, recommendation, or favoring by the United States Government or any agency thereof, or Battelle Memorial Institute. The views and opinions of authors expressed herein do not necessarily state or reflect those of the United States Government or any agency thereof.

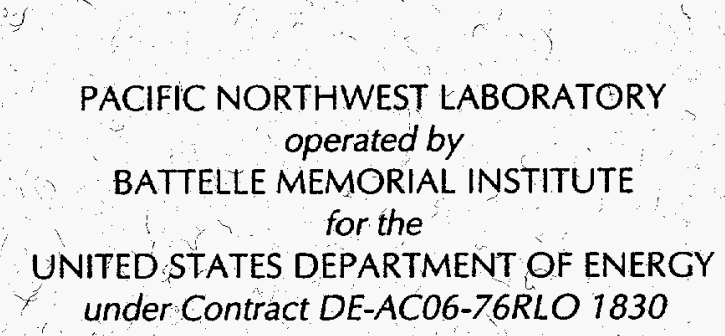

Printed in the United States of America

Available to DOE and DOE contractors from the

Office of Scientific and Technical Information, P.O. Box 62, Oak Ridge, TN 37831; prices available from (615) 576-8401.

Available to the public from the National Technical Information Service, U.S. Department of Commerce, 5285 Port Royal Rd., Springfield, VA 22161 


\section{DISCLAIMER}

Portions of this document may be illegible in electronic image products. Images are produced from the best available original document. 


\section{Plutonium Finishing Plant}

\section{Interim Plutonium Stabilization \\ Engineering Study}
G. J. Sevigny
R. H. Gallucci
S.M.K. Garrett
J.G.H. Geeting
R. S. Goheen
P. M. Molton
R. Nass ${ }^{(a)}$
K. J. Templeton
A. J. Villegas

August 1995

Prepared for the U.S. Department of Energy under Contract DE-AC06-76RLO 1830

Pacific Northwest Laboratory

Richland, Washington 99352

(a) Nuclear Fuel Services, Inc. 


\begin{abstract}
This report provides the results of an engineering study that evaluated the available technologies for stabilizing the plutonium stored at the Plutonium Finishing Plant located at the Hanford Site in southeastern Washington. Further processing of the plutonium may be required to prepare the plutonium for interim ( $<50$ years) storage. Specifically this document provides the current plutonium inventory and characterization, the initial screening process, and the process descriptions and flowsheets of the technologies that passed the initial screening. The conclusions and recommendations also are provided. The information contained in this report will be used to assist in the preparation of the environmental impact statement and to help decision makers determine which is the preferred technology to process the plutonium for interim storage.
\end{abstract}





\section{Summary}

The Plutonium Finishing Plant (PFP), located at the Hanford Site in southeastern Washington, and operated by the Westinghouse Hanford Company (WHC) for the U.S. Department of Energy (DOE), contains plutonium-bearing material from $40+$ years of processing plutonium for weapons production, research needs, and reactor fuel. In 1989 the plant was shut down, and DOE now wants to prepare these residues for storage. However, further processing will be required to stabilize many of these materials for interim storage $(<50$ years).

This engineering study was performed by the Pacific Northwest Laboratory (PNL) for WHC to evaluate the currently available and known technologies at Hanford and elsewhere for processing plutonium-bearing materials into a stable form. The inventory of plutonium-bearing materials stored in various vaults at the PFP was received from WHC in an unclassified form for use in this study. Table S.1 summarizes that inventory. PNL staff conducted the study by compiling information on the technologies that would be considered, performing an initial screening, developing process descriptions, and subcontracting with an independent review team to evaluate and rank the processes. This independent review team consisted of representatives from the national laboratories and industry who are considered to be experts in the subject matter.

Once PNL completed its analysis, the independent review team began a review of the technologies that passed the initial screening. Specifically, the goals of the independent review were to ensure that the appropriate set of technologies was considered, to identify any technologies that may have been overlooked by PNL, and to identify any significant issues relating to the technologies considered.

The process for conducting the independent technical review involved the following activities:

- a presentation on specific technical information on each candidate technology by PNL staff to the independent review team

- a screening of the technologies that were initially identified to establish the applicable technologies

- a rating of the feasible alternatives against a predetermined set of criteria. These criteria consisted of technical feasibility, effluent and by-product disposition, worker safety, cost, and time required for implementing the technology and processing the plutonium. Note that the cost data are very, very preliminary and that a rigorous procedure for estimating costs was not applied in a consistent manner.

Based upon its findings, the independent review team identified the preferred technologies for each waste stream (i.e., liquid or solid effluents) as summarized in Table S.2. These technologies were, in general, preferred based on meeting the criteria of availability, flexibility, and technical maturity. 
Table S.1. PFP Residue Treatment Needs

\begin{tabular}{|c|c|c|c|c|}
\hline \multirow[b]{2}{*}{ Resides } & \multicolumn{4}{|c|}{ Inventory } \\
\hline & Total Wt. (kg) & Mass Pu (kg) & No. of Items & Pu Mass (\%) \\
\hline \multicolumn{5}{|l|}{ Solutions: } \\
\hline Nitrate & 3498 & $289^{(a)}$ & 318 & 10.1 \\
\hline Chlorides & 220 & 3.3 & 28 & 1.3 \\
\hline Organics & 22 & 3.5 & 2 & 0.13 \\
\hline Other & 1320 & 62 & 120 & 2.4 \\
\hline \multicolumn{5}{|l|}{ Solids: } \\
\hline Pu Oxides & 6622 & $1224^{(a)}$ & 4817 & 48 \\
\hline $\begin{array}{l}\text { High-Fired } \\
\text { Low-Fired }\end{array}$ & $\begin{array}{l}1631 \\
4991\end{array}$ & $\begin{array}{l}301^{(\mathbf{b})} \\
923^{(\mathbf{b})}\end{array}$ & $\begin{array}{l}1288 \\
3524\end{array}$ & \\
\hline Metal/Alloy & 1040 & $770^{(a)}$ & 499 & 30 \\
\hline Combustibles & 62 & & 32 & \\
\hline Process Residue & 1374 & 154 & 1480 & 6.1 \\
\hline Polycubes & 187 & 31 & 224 & 1.2 \\
\hline Fluorides & 15 & 3 & 14 & 0.12 \\
\hline Total & & 2539.5 & 7281 & 99.35 \\
\hline \multicolumn{5}{|c|}{$\begin{array}{l}\text { Note: Some plutonium values are based on ratios of item weight/total weight times total } \\
\text { plutonium. Individual plutonium weights were not available. } \\
\text { (a) Nitrate solutions, plutonium oxides, metals, and alloys account for }-90 \% \text { of total } \\
\text { inventory. } \\
\text { (b) Assumes high-fired/low-fired oxide split for plutonium mass is the same as total weight. }\end{array}$} \\
\hline
\end{tabular}

The following recommendations are also made by the independent review team.

1. The benefits of removing americium-241 from the stored plutonium material need to be further assessed. It is not clear if the reduction in occupational exposure will outweigh the costs considering the additional waste processing required, process complexity, and future ingrowth of americium-241 during the 50-year storage period. 
Table S.2. Preferred Technologies for PFP Residue Treatment

\begin{tabular}{|c|l||}
\hline Waste Stream & \multicolumn{1}{|c|}{ Preferred Technologies } \\
\hline \hline Solutions: & \\
\hline Aqueous & $\begin{array}{l}\text { Thermal treatment (calcination), ion- } \\
\text { exchange with thermal treatment }\end{array}$ \\
\hline Organic & $\begin{array}{l}\text { No reasonable technology identified; } \\
\text { molten salt oxidation is most promising }\end{array}$ \\
\hline Solids: & $\begin{array}{c}\text { Continuous Calciner } \\
\text { Muffle Furnace for special applications }\end{array}$ \\
\hline Oxides, Fluorides Residues & $\begin{array}{l}\text { Repackage } \\
\text { Muffle furnace for special applications, } \\
\text { e.g., fines, turnings }\end{array}$ \\
\hline Metals, Alloys & $\begin{array}{l}\text { No reasonable technology identified; } \\
\text { molten salt oxidation is most promising. }\end{array}$ \\
\hline Polycubes/Combustibles
\end{tabular}

2. The preferred processes should be developed and finalized on an expedited basis. In addition, the development of the molten salt oxidation process followed by plutonium oxide recovery should be expedited. This process was the only technology identified that had multi-purpose applicability to this treatment problem.

3. There is an apparent lack of acceptable processes for treating the organic liquids, combustible solids, and polycubes. The molten salt process should be further reviewed for these waste streams.

4. The waste streams should be processed by a strategy that gives priority to major safety concerns first. Thus, the liquids should be treated early followed by the organic solids and low-fired plutonium oxide. The second consideration is the quantity of material needing stabilization, which suggests a need for early processing of the oxides. The priority for early treatment of organic solids is frustrated by the current lack of good, demonstrated technology.

5. The potential of direct repackaging of the metals and high-fired oxides should be examined. These waste streams represent approximately $40 \%$ of the mission need. 



\section{Acknowledgments}

The authors of this report would like to thank the independent review team members for commenting on the flowsheets, preparing Section 6.0, and providing the majority of the recommendations. The independent review team consisted of Lyle Zahn, from Nuclear Fuel Services, Inc.; Langdon Holton, from the Pacific Northwest Laboratory (PNL); Martin Muller, from the Los Alamos National Laboratory; and Wally Sumner, from the Westinghouse Savannah River Company. These individuals were concerned, patient, and independent. The group performed as a good team even though they had diverse views. The result was a thorough review and ranking of processes for stabilizing the plutonium-bearing material. Robbie Tidwell and Terry Hosaka of PNL also provided invaluable help in setting up the review meeting and providing a quality written record.

The authors also thank Nancy Stratton, editor; Barb Eaton, publications assistant; and Jean Cheyney, Pat Young, and Joan Slavens, text processors. These people provided guidance and worked long hours to complete this document, which had many different authors.

Additionally, the authors thank the staff at PNL, such as Andrew Prichard, Jack Ryan, and Jeff Surma, who provided technical advice on some of the technologies and material disposition options. Finally, the authors thank Iral Nelson for his reviews and comments on the study mission in the context of providing support for the environmental impact statement and Mike Schlender for managing the project and providing direction. 



\section{Acronyms}

$\begin{array}{ll}\text { ALARA } & \text { as low as reasonably achievable } \\ \text { Am } & \text { americium } \\ \text { ANL } & \text { Argonne National Laboratory } \\ \text { ANN } & \text { aluminum nitrate nonahydrate } \\ \text { ARF } & \text { airborne release fraction } \\ \text { CAW } & \text { current acid waste } \\ \text { CCl } & \text { carbon tetrachloride } \\ \text { CEPOD } & \text { catalyzed electrochemical plutonium-oxide dissolution (process) } \\ \text { CMPO } & \text { octyl(phenyl)-N,N-diisobutylcarbamoylmethylphosphine oxide } \\ \text { DBP } & \text { dibutyl phosphate } \\ \text { D\&D } & \text { decontaminate and decommission } \\ \text { DF } & \text { decontamination factor } \\ \text { DOE } & \text { U.S. Department of Energy } \\ \text { dP } & \text { delta pressure } \\ \text { EDTA } & \text { ethylenediaminetetraacetate } \\ \text { EIS } & \text { environmental impact statement } \\ \text { FFTF } & \text { Fast Flux Test Facility } \\ \text { FUETAP } & \text { formed under elevated temperatures and pressures } \\ \text { GTM } & \text { generic TRUEX model } \\ \text { HEPA } & \text { high-efficiency particulate air filter } \\ \text { HGMS } & \text { high gradient magnetic separation } \\ \text { HLW } & \text { high-level waste } \\ \text { IAEA } & \text { International Atomic Energy Agency } \\ \text { INEL } & \text { Idaho National Engineering Laboratory } \\ \text { KfK } & \text { Kernforschungszentrum Karlsruhe } \\ \text { LANL } & \text { Los Alamos National Laboratory } \\ \text { LLW } & \text { low-level waste } \\ \text { LLWTF } & \text { Low-Level Waste Treatment Facility } \\ \text { LOI } & \text { loss on ignition } \\ \text { LWR } & \text { light water reactor } \\ \text { MACTEC } & \text { MAC Technical Services Company } \\ \text { MBP } & \text { monobutyl phosphate } \\ \text { MSE } & \text { molten salt extraction } \\ \text { MSO } & \text { molten salt oxidation } \\ \text { MT } & \text { miscellaneous-treatment gloveboxes } \\ \text { NPH } & \text { normal paraffinic hydrocarbon } \\ \text { O/A } & \text { organic to aqueous } \\ \text { ORNL } & \text { Oak Ridge National Laboratory } \\ \text { OXAL } & \text { oxalate } \\ \text { PFP } & \text { Plutonium Finishing Plant } \\ & \end{array}$




$\begin{array}{ll}\text { PNL } & \text { Pacific Northwest Laboratory } \\ \text { Pu } & \text { plutonium } \\ \text { PUREX } & \text { Plutonium Uranium Extraction (Process) } \\ \text { PR } & \text { plutonium recovery } \\ \text { PRF } & \text { Plutonium Recovery Facility } \\ \text { PRT } & \text { pre-reduction tank } \\ \text { PVC } & \text { polyvinylchloride } \\ \text { RADTU } & \text { radioactive acid digestion test unit } \\ \text { RF } & \text { respirable fraction } \\ \text { RMC (line) } & \text { remote mechanical "C" } \\ \text { SAR } & \text { safety analysis review } \\ \text { SRL } & \text { Savannah River Laboratory } \\ \text { TBP } & \text { tributyl phosphate } \\ \text { TCE } & \text { trichloroethylene } \\ \text { TRU } & \text { transuranic } \\ \text { TRUEX } & \text { Transuranic Extraction (Plant) } \\ \text { TRUSAF } & \text { Transuranic Waste Storage and Assay Facility } \\ \text { WAK } & \text { Wiederaufarbeitungsanlage Karlsruhe } \\ \text { WHC } & \text { Westinghouse Hanford Company } \\ \text { WIPP } & \text { Waste Isolation Pilot Plant }\end{array}$




\section{Contents}

Abstract $\ldots \ldots \ldots \ldots \ldots \ldots \ldots \ldots \ldots \ldots \ldots \ldots \ldots \ldots \ldots \ldots \ldots$ iii

Summary $\ldots \ldots \ldots \ldots \ldots \ldots \ldots \ldots \ldots \ldots \ldots \ldots \ldots \ldots \ldots \ldots \ldots$

Acknowledgments $\ldots \ldots \ldots \ldots \ldots \ldots \ldots \ldots \ldots \ldots \ldots \ldots \ldots \ldots \ldots \ldots$ ix

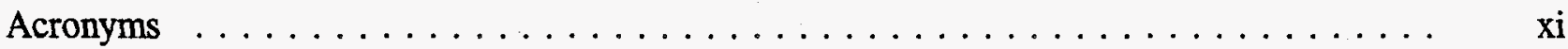

1.0 Introduction $\quad \ldots \ldots \ldots \ldots \ldots \ldots \ldots \ldots \ldots \ldots \ldots \ldots \ldots \ldots \ldots \ldots$

2.0 Plutonium-Bearing Material Inventory and Characterization $\ldots \ldots \ldots \ldots \ldots$

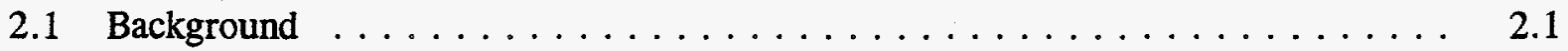

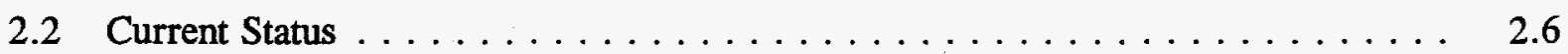

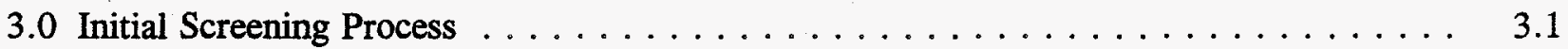

4.0 General Descriptions of the Stabilization Technology Flowsheets $\ldots \ldots \ldots$. . . . . 4.1

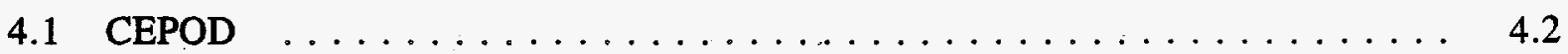

$4.1 .1 \quad$ Process Description $: \ldots \ldots \ldots \ldots \ldots \ldots \ldots \ldots$

4.1.2 Effluents and Products Generated $\ldots \ldots \ldots \ldots \ldots$

4.2 Silver Persulfate $\ldots \ldots \ldots \ldots \ldots \ldots \ldots \ldots \ldots \ldots \ldots \ldots \ldots \ldots$

4.2.1 Process Description $\ldots \ldots \ldots \ldots \ldots \ldots \ldots \ldots \ldots$

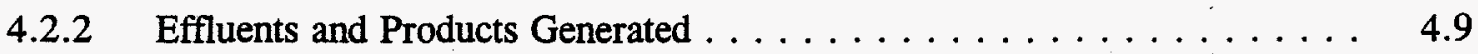

4.3 Acid Digestion $\ldots \ldots \ldots \ldots \ldots \ldots \ldots \ldots \ldots \ldots \ldots$

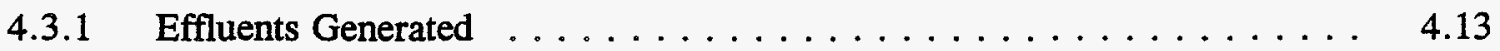

$4.3 .2 \quad$ Nuclear Criticality Safety $\ldots \ldots \ldots \ldots \ldots \ldots \ldots \ldots \ldots \ldots$

4.3.3 Final Product Description $\ldots \ldots \ldots \ldots \ldots \ldots \ldots \ldots \ldots$ 
4.4 Solvent Extraction $\ldots \ldots \ldots \ldots \ldots \ldots \ldots \ldots \ldots \ldots \ldots \ldots$

$4.4 .1 \quad$ Process Description $\ldots \ldots \ldots \ldots \ldots \ldots \ldots \ldots \ldots \ldots$

$4.4 .2 \quad$ Effluent Final Disposition $\ldots \ldots \ldots \ldots \ldots \ldots \ldots \ldots \ldots$

$4.4 .3 \quad$ Equipment $\ldots \ldots \ldots \ldots \ldots \ldots \ldots \ldots \ldots \ldots \ldots$

4.5 Oxalate Acid Precipitation Using the Remote Mechanical " $\mathrm{C}$ " Line . . . . . . . . 4.21

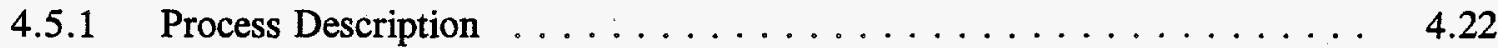

4.5 .2 Flow Diagram $\ldots \ldots \ldots \ldots \ldots \ldots \ldots \ldots \ldots \ldots \ldots \ldots \ldots$

$4.5 .3 \quad$ Cost Estimates $\ldots \ldots \ldots \ldots \ldots \ldots \ldots \ldots \ldots \ldots \ldots \ldots \ldots$

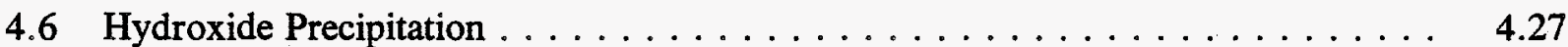

$4.6 .1 \quad$ Process Description $\ldots \ldots \ldots \ldots \ldots \ldots \ldots \ldots \ldots \ldots \ldots \ldots \ldots$

$4.6 .2 \quad$ Flow Diagram $\ldots \ldots \ldots \ldots \ldots \ldots \ldots \ldots \ldots \ldots \ldots \ldots$

$4.6 .3 \quad$ Cost Estimates $\ldots \ldots \ldots \ldots \ldots \ldots \ldots \ldots \ldots \ldots \ldots \ldots . \ldots \ldots \ldots$

4.7 Plutonium Reclamation Facility $\ldots \ldots \ldots \ldots \ldots \ldots \ldots \ldots \ldots \ldots \ldots \ldots$

4.7.1 Process Description $\ldots \ldots \ldots \ldots \ldots \ldots \ldots \ldots \ldots \ldots$

$4.7 .2 \quad$ Flow Diagram $\ldots \ldots \ldots \ldots \ldots \ldots \ldots \ldots \ldots \ldots \ldots$

$4.7 .3 \quad$ Cost Estimates $\ldots \ldots \ldots \ldots \ldots \ldots \ldots \ldots \ldots \ldots \ldots \ldots \ldots$

4.8 Ion Exchange $\ldots \ldots \ldots \ldots \ldots \ldots \ldots \ldots \ldots \ldots \ldots \ldots \ldots \ldots$

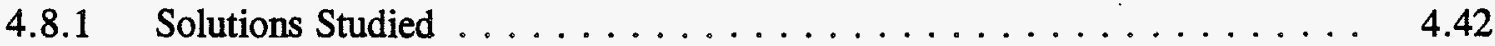

4.8.2 Equipment Requirements $\ldots \ldots \ldots \ldots \ldots \ldots \ldots \ldots \ldots \ldots . \ldots \ldots$

4.8 .3 Process Description $\ldots \ldots \ldots \ldots \ldots \ldots \ldots \ldots \ldots \ldots$

4.8 .4 Summary $\ldots \ldots \ldots \ldots \ldots \ldots \ldots \ldots \ldots \ldots \ldots \ldots$ 
4.9 Furnace - Oxides $\ldots \ldots \ldots \ldots \ldots \ldots \ldots \ldots \ldots \ldots \ldots \ldots \ldots \ldots \ldots \ldots \ldots$

4.9.1 Process Description $\ldots \ldots \ldots \ldots \ldots \ldots \ldots \ldots \ldots \ldots .4 .49$

4.9.2 Equipment Description $\ldots \ldots \ldots \ldots \ldots \ldots \ldots \ldots \ldots \ldots \ldots .4 .51$

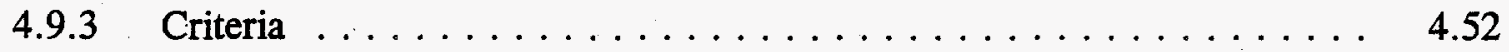

4.10 Muffle Furnace - Polycubes and Combustibles $\ldots \ldots \ldots \ldots \ldots \ldots \ldots .4 .54$

4.10.1 Process Description $\ldots \ldots \ldots \ldots \ldots \ldots \ldots \ldots \ldots \ldots \ldots .55$

4.10 .2 Equipment Description $\ldots \ldots \ldots \ldots \ldots \ldots \ldots \ldots \ldots .4 .57$

4.10 .3 Criteria $\ldots \ldots \ldots \ldots \ldots \ldots \ldots \ldots \ldots \ldots \ldots \ldots \ldots \ldots .59$

4.11 Muffle Furnace - Metals and Alloys, and Sand, Slag, and Crucibles $\ldots \ldots \ldots 4.62$

4.11 .1 Process Description $\ldots \ldots \ldots \ldots \ldots \ldots \ldots \ldots \ldots \ldots .64$

4.11.2 Equipment Description $\ldots \ldots \ldots \ldots \ldots \ldots \ldots \ldots \ldots \ldots .63$

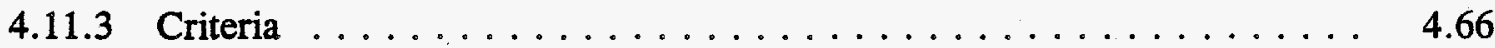

4.12 Molten Salt Oxidation $\ldots \ldots \ldots \ldots \ldots \ldots \ldots \ldots \ldots \ldots \ldots \ldots \ldots \ldots \ldots$

4.12.1 Process Description $\ldots \ldots \ldots \ldots \ldots \ldots \ldots \ldots \ldots \ldots . \ldots \ldots$

4.12.2 Facilities and Equipment Required $\ldots \ldots \ldots \ldots \ldots \ldots \ldots \ldots \ldots .72$

4.12 .3 Schedule $\ldots \ldots \ldots \ldots \ldots \ldots \ldots \ldots \ldots \ldots \ldots \ldots \ldots, 4.72$

4.12.4 End Product Description $\ldots \ldots \ldots \ldots \ldots \ldots \ldots \ldots \ldots \ldots .72$

4.12.5 Effluents and By-Products $\ldots \ldots \ldots \ldots \ldots \ldots \ldots \ldots \ldots \ldots .72$

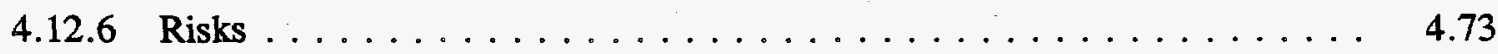

4.12 .7 Costs $\ldots \ldots \ldots \ldots \ldots \ldots \ldots \ldots \ldots \ldots \ldots \ldots \ldots \ldots \ldots .44$

4.12 .8 Comments $\ldots \ldots \ldots \ldots \ldots \ldots \ldots \ldots \ldots \ldots \ldots \ldots \ldots .74$

4.12 .9 Nitrate Solutions $\ldots \ldots \ldots \ldots \ldots \ldots \ldots \ldots \ldots \ldots \ldots .75$ 
4.12 .10 HEPA Filters $\ldots \ldots \ldots \ldots \ldots \ldots \ldots \ldots \ldots \ldots \ldots \ldots$

4.12 .11 Combustibles $\ldots \ldots \ldots \ldots \ldots \ldots \ldots \ldots \ldots \ldots \ldots \ldots \ldots$

4.12 .12 Polycubes $\ldots \ldots \ldots \ldots \ldots \ldots \ldots \ldots \ldots \ldots \ldots \ldots$

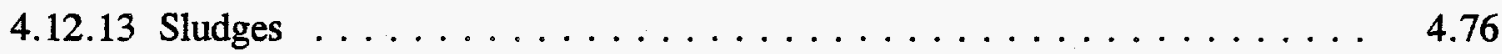

4.12 .14 Oils and Organics $\ldots \ldots \ldots \ldots \ldots \ldots \ldots \ldots \ldots \ldots$

4.12 .15 Graphite $\ldots \ldots \ldots \ldots \ldots \ldots \ldots \ldots \ldots \ldots \ldots \ldots$

4.12.16 Fluorine-Bearing Materials $\ldots \ldots \ldots \ldots \ldots \ldots \ldots \ldots$

4.13 Vertical Calciner $\ldots \ldots \ldots \ldots \ldots \ldots \ldots \ldots \ldots \ldots$

4.13.1 Direct Denitration Process $\ldots \ldots \ldots \ldots \ldots \ldots \ldots \ldots . \ldots \ldots$

4.13.2 Facilities and Equipment Required $\ldots \ldots \ldots \ldots \ldots . \ldots \ldots$

4.13.3 Effluents Generated $\ldots \ldots \ldots \ldots \ldots \ldots \ldots \ldots \ldots \ldots$

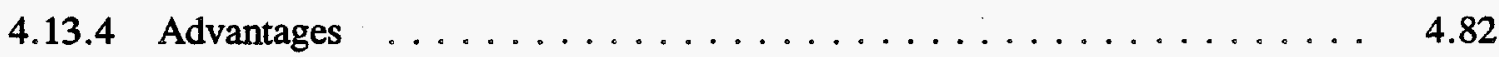

4.13 .5 Disadvantages $\ldots \ldots \ldots \ldots \ldots \ldots \ldots \ldots \ldots \ldots$

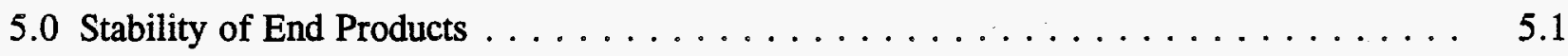

6.0 Technical Review of PFP Residue Waste Treatment Alternatives $\ldots \ldots \ldots . \ldots . \ldots$

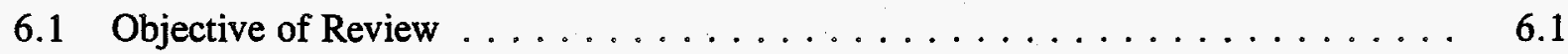

6.2 Review Process $\ldots \ldots \ldots \ldots \ldots \ldots \ldots \ldots \ldots \ldots \ldots \ldots \ldots \ldots$

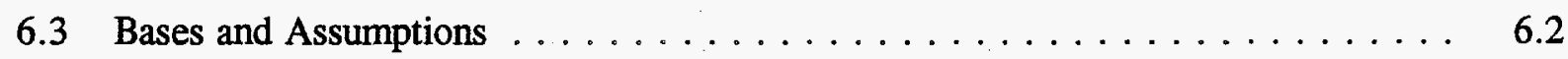

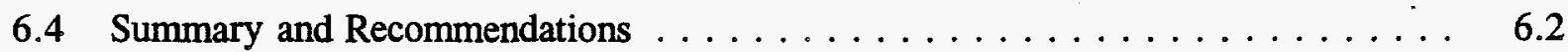

6.5 Description of the PFP Treatment Scope $\ldots \ldots \ldots \ldots \ldots \ldots$

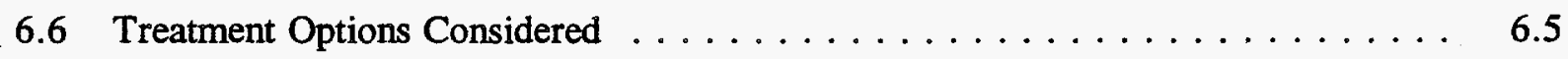




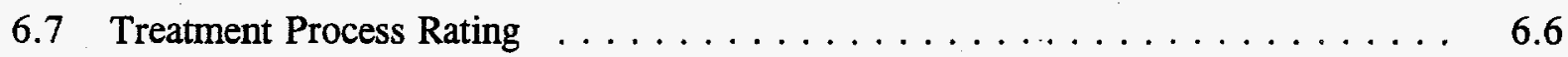

6.7 .1 Treatment Process Rating Criteria $\ldots \ldots \ldots \ldots \ldots \ldots \ldots$

6.7 .2 Results From Weighting Analyses $\ldots \ldots \ldots \ldots \ldots . \ldots \ldots$

6.8 Unresolved Issues $\ldots \ldots \ldots \ldots \ldots \ldots \ldots \ldots \ldots \ldots \ldots \ldots \ldots \ldots$

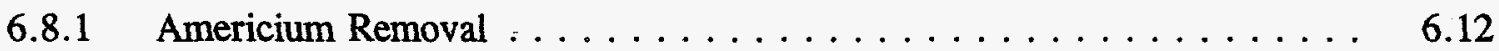

6.8.2 Uncertainties for 50 -Year Storage Criteria $\ldots \ldots \ldots \ldots \ldots \ldots . \ldots \ldots$

6.8.3 Repackaging of Metals and Oxides ... . . . . . . . . 6.14

6.8 .4 Worker Exposure $\ldots \ldots \ldots \ldots \ldots \ldots \ldots \ldots \ldots \ldots \ldots \ldots$

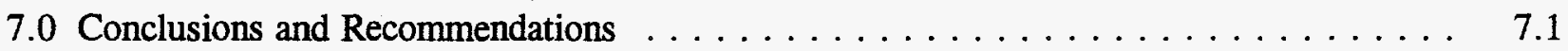

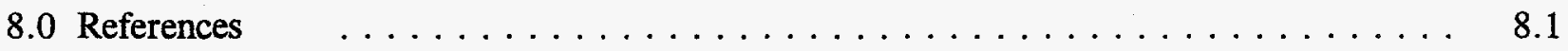

Appendix A - Description of Technologies $\ldots \ldots \ldots \ldots \ldots \ldots \ldots \ldots \ldots$

Appendix B - Basis for Numerical Rating of PFP Residue Processing Alternatives . . . . . . B.1 


\section{Figures}

4.1 CEPOD Flow Diagram $\ldots \ldots \ldots \ldots \ldots \ldots \ldots \ldots \ldots \ldots \ldots$

4.2 Silver Persulfate Flow Diagram $\ldots \ldots \ldots \ldots \ldots \ldots \ldots \ldots \ldots$

4.3 Acid Digestion Process Flow Diagram $\ldots \ldots \ldots \ldots \ldots \ldots \ldots \ldots \ldots$

4.4 TRUEX Process Flow Diagram $\ldots \ldots \ldots \ldots \ldots \ldots \ldots \ldots \ldots \ldots \ldots \ldots$

4.5 Schematic of TRUEX Processing Plant $\ldots \ldots \ldots \ldots \ldots \ldots \ldots \ldots$

4.6 RMC Line Floor Diagram $\ldots \ldots \ldots \ldots \ldots \ldots \ldots \ldots \ldots \ldots \ldots \ldots$

4.7 Oxalate Acid Precipitation Using the RMC Line $\ldots \ldots \ldots \ldots \ldots \ldots$

4.8 Oxalate Precipitation Using Existing RMC Line $\ldots \ldots \ldots \ldots \ldots \ldots$

4.9 Cutaway of the Plutonium Reclamation Facility $\ldots \ldots \ldots \ldots \ldots$

4.10 Floor Diagram of MT-5 Glovebox $\ldots \ldots \ldots \ldots \ldots \ldots \ldots$

4.11 Proposed Hydroxide Precipitation With $\mathrm{MgO} \ldots \ldots \ldots \ldots \ldots . \ldots \ldots$

4.12 Building $236-Z$ Floor Plans $\ldots \ldots \ldots \ldots \ldots \ldots \ldots \ldots \ldots \ldots \ldots$

4.13 Hydrolysis Flow Diagram $\ldots \ldots \ldots \ldots \ldots \ldots \ldots \ldots \ldots$

4.14 Dissolution Process $\ldots \ldots \ldots \ldots \ldots \ldots \ldots \ldots \ldots \ldots \ldots \ldots$

4.15 Primary Effluent Material Flow Diagram $\ldots \ldots \ldots \ldots \ldots . \ldots \ldots$

4.16 Flow Diagram for Chloride Solution Ion Exchange Process $\ldots \ldots \ldots \ldots$. . . . . 4.44

4.17 Flow Diagram for Nitrate Solution Ion Exchange Process $\ldots \ldots \ldots \ldots \ldots$

4.18 Flow Diagram for "Other Solutions" Ion Exchange Process $\ldots \ldots \ldots \ldots$. . . . . 4.46

4.19 Flow Diagram of the Furnace Process for Calcinating Oxides $\ldots \ldots \ldots$. . . . . 4.50

4.20 Flow Diagram of the Muffle Furnace Process - Polycubes and Combustibles $\ldots \ldots$. . 4.56 
4.21 Flow Diagram for the Muffle Furnace Process - Metals and Alloys, and Sand, Slag and Crucibles $\ldots \ldots \ldots \ldots \ldots \ldots \ldots \ldots \ldots \ldots \ldots \ldots \ldots . \ldots \ldots$

4.22 Molten Salt Oxidation Flow Diagram $\ldots \ldots \ldots \ldots \ldots \ldots \ldots \ldots \ldots \ldots .71$

4.23 Vertical Calciner Flow Diagram $\ldots \ldots \ldots \ldots \ldots \ldots \ldots \ldots \ldots \ldots \ldots . .60$ 


\section{Tables}

S.1 PFP Residue Treatment Needs $\ldots \ldots \ldots \ldots \ldots \ldots \ldots \ldots \ldots \ldots \ldots$ vi

S.2 Preferred Technologies for PFP Residue Treatment $\ldots \ldots \ldots \ldots \ldots$ vii

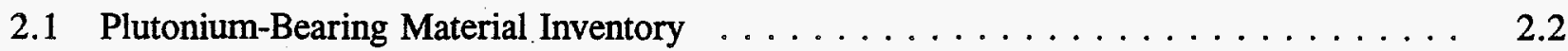

2.2 Constants of Relevant Plutonium and Americium Isotopes $\ldots \ldots \ldots \ldots \ldots \ldots$

2.3 Isotopic Distribution of Plutonium at PFP Based on Inventory Records and Estimates $\ldots \ldots \ldots \ldots \ldots \ldots \ldots \ldots \ldots \ldots \ldots \ldots \ldots \ldots \ldots \ldots \ldots$

3.1 Preliminary Criteria for Evaluation of Technologies to Process PFP Materials . . . . 3.2

3.2 Preliminary Definitions for the PFP Stabilization Criteria $\ldots \ldots \ldots \ldots \ldots$

3.3 Identified Technologies for Solutions $\ldots \ldots \ldots \ldots \ldots \ldots \ldots \ldots \ldots$

3.4 Identified Technologies for Solids $\ldots \ldots \ldots \ldots \ldots \ldots \ldots \ldots \ldots \ldots \ldots \ldots \ldots$

4.1 Volumes, Masses, and Process Times for CEPOD Flowsheet Effluents $\ldots \ldots \ldots$

4.2 Volumes, Masses, and Process Times from Persulfate Flowsheet Effluents . . . . . . 4.10

4.3 Feed Inventory for Acid Digestion Process $\ldots \ldots \ldots \ldots \ldots \ldots \ldots \ldots \ldots$

4.4 Calcined Residue Compositions $\ldots \ldots \ldots \ldots \ldots \ldots \ldots \ldots \ldots \ldots \ldots \ldots$

4.5 Solvent Extraction Feed from the CEPOD and Silver Persulfate Processes $\ldots \ldots \ldots$

4.6 Solvent Extraction Processing of CEPOD Plutonium-Bearing Effluent $\ldots \ldots \ldots$. . . 4.17

4.7 Solvent Extraction Processing of Silver Persulfate Plutonium-Bearing Effluent $\ldots \ldots$

4.8 Estimated Cost and Area of TRUEX Process Plant $\ldots \ldots \ldots \ldots \ldots \ldots \ldots$

4.9 Tanks Sizes Required for an 8 -Hour Run $\ldots \ldots \ldots \ldots \ldots . \ldots \ldots$

4.10 Glovebox Dimensions and Functions $\ldots \ldots \ldots \ldots \ldots \ldots \ldots \ldots \ldots$

4.11 Proposed Inventory to be Stabilized by Hydroxide Precipitation $\ldots \ldots \ldots \ldots \ldots$ 
4.12 Summary for Magnesium Precipitation $\ldots \ldots \ldots \ldots \ldots \ldots \ldots \ldots \ldots . .31$

4.13 Proposed Inventory Items to be Stabilized in PRF $\ldots \ldots \ldots \ldots \ldots \ldots \ldots \ldots . .33$

4.14 Development of Cost Estimates for Plutonium Stabilization Using the PRF $\ldots \ldots \ldots 4.38$

4.15 Solutions Suitable for Ion Exchange $\ldots \ldots \ldots \ldots \ldots \ldots \ldots \ldots \ldots \ldots .4 .42$

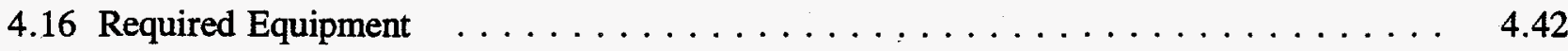

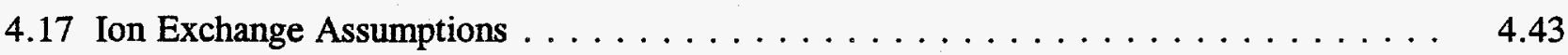

4.18 Solution Categories and Process Flow $\ldots \ldots \ldots \ldots \ldots \ldots \ldots \ldots \ldots \ldots .4 .47$

4.19. Thermal Treatment - Oxide Effluent Stream Descriptions $\ldots \ldots \ldots \ldots \ldots \ldots \ldots$

4.20 Ramp-Up Rates for Polystyrene Thermal Treatment $\ldots \ldots \ldots \ldots \ldots \ldots \ldots \ldots 4.57$

4.21 Muffle Furnace - Combustible Effluent Stream Descriptions $\ldots \ldots \ldots \ldots \ldots \ldots .60$

4.22 Muffle Furnace - Polycubes Effluent Stream Descriptions $\ldots \ldots \ldots \ldots \ldots \ldots .61$

4.23 Muffle Furnace - Residue Effluent Stream Descriptions $\ldots \ldots \ldots \ldots \ldots \ldots .4 .67$

4.24 Muffle Furnace - Metals and Alloys Stream Descriptions $\ldots \ldots \ldots \ldots \ldots \ldots .4 .68$

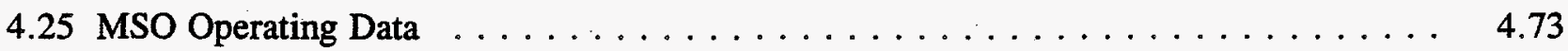

4.26 Equipment Description and Costs $\ldots \ldots \ldots \ldots \ldots \ldots \ldots \ldots \ldots \ldots \ldots .78$

4.27 Flows for Nitrate Solutions $\ldots \ldots \ldots \ldots \ldots \ldots \ldots \ldots \ldots \ldots \ldots \ldots \ldots \ldots$

4.28 Flows for Organic Solutions $\ldots \ldots \ldots \ldots \ldots \ldots \ldots \ldots \ldots \ldots \ldots \ldots . .61$

4.29 Flows for Filtrate Solutions $\ldots \ldots \ldots \ldots \ldots \ldots \ldots \ldots \ldots \ldots \ldots \ldots . .41$

4.30 Flows for Chloride Solutions $\ldots \ldots \ldots \ldots \ldots \ldots \ldots \ldots \ldots \ldots \ldots . .62$

4.31 Vertical Calciner Operating Duration $\ldots \ldots \ldots \ldots \ldots \ldots \ldots \ldots \ldots \ldots . .62$

5.1 Approximate Hazards from Release of Plutonium Metals and Oxides $\ldots \ldots \ldots \ldots .2$

5.2 Consequence Value Table for Theft/Diversion of SNM $\ldots \ldots \ldots \ldots \ldots \ldots .3$ 
6.1 Preferred Technologies for PFP Residue Treatment . . . . . . . . . . . . . 6.2

6.2 PFP Residue Treatment Needs $\ldots \ldots \ldots \ldots \ldots \ldots \ldots \ldots \ldots \ldots$

6.3 Alternative Process Evaluations $\ldots \ldots \ldots \ldots \ldots \ldots \ldots \ldots \ldots \ldots \ldots \ldots \ldots$

6.4 Definitions for the PFP Stabilization Criteria $\ldots \ldots \ldots \ldots \ldots \ldots \ldots \ldots$

7.1 Preferred Technologies for PFP Residue Treatment $\ldots \ldots \ldots \ldots \ldots \ldots$ 


\subsection{Introduction}

The Plutonium Finishing Plant (PFP), which is located at the Hanford Site in southeastern Washington, contains plutonium-bearing materials that have accumulated from years of plutonium processing activities for weapons production. The PFP was shut down in 1989, and the U.S. Department of Energy (DOE) wishes to prepare the material for interim storage ( $<50$ years). However, further processing will be required to stabilize many of these materials before placing them in storage vaults.

The Pacific Northwest Laboratory (PNL) conducted an engineering study for the Westinghouse Hanford Company (WHC), which operates the PFP for DOE, to evaluate the currently available and known technologies at Hanford and elsewhere for processing plutonium-bearing materials into a stable form. The materials in question are based on the current inventory at the PFP, excluding the material to be treated in the interim, miscellaneous laboratory standards, and some Fast Flux Test Facility (FFTF) unirradiated fuel rods. This report provides the results of the PNL study. Specifically, the report includes 1) the initial criteria used by PNL to evaluate the technologies, 2) the summary descriptions of the plutonium-bearing material, 3) the results of PNL's initial technology screening to limit the number being combined in process flowsheets for a final ranking, 4) the combinations of technologies into flowsheets for treating the plutonium-bearing material, and 5) a ranking of the flowsheets by an independent review team. The independent review team consisted of representatives from the national laboratories who are considered experts in the subject matter.

Based on this evaluation, a set of reasonable processing alternatives will be selected to be included in an environmental impact statement (EIS), which is to be prepared by MAC Technical Services Company (MACTEC). Together, the EIS and this study will be used to provide recommendations for the selection of known engineering technologies that could be used to stabilize plutonium-bearing materials stored in the PFP.

This report is divided into the following sections. Section 2.0 provides background information, the current inventory, and the characterization data of the plutonium-bearing material in the PFP. Section 3.0 describes the initial screening process used by PNL, and Section 4.0 provides flowsheets and descriptions for each technology that passed the initial screening process. Next, the proposed storage criteria for the final plutonium end product are discussed in Section 5.0. Section 6.0 lists the independent review team's findings and concerns. Overall conclusions and recommendations are provided in Section 7.0, and references are listed in Section 8.0. Appendix A contains brief descriptions of each technology considered by PNL for processing the material. Finally, Appendix B contains the ranking conducted by the independent review team for the process flowsheets and the logic behind the ranking. 


\subsection{Plutonium-Bearing Material Inventory and Characterization}

Staff from PNL received the inventory listing (Table 2.1) of plutonium-bearing materials stored in various vaults at the PFP from WHC in an unclassified form for use in this study. Additional information was obtained from other laboratory reports and safety documents. The inventory information was then reorganized and summarized. Chemical characterization information does not exist or was not provided for many items, so averages and approximations were used for the technology evaluations. The wide variety of materials and few chemical characterization data limited the amount of detail in some of the process evaluations.

The basic material types and bulk weights used in this study are shown in Table 2.1. The bulk weight category in the table shows the combined weight of the plutonium-bearing material and the packages containing the material. In most cases, the net weights were not significantly different from the bulk weights. Net weights were used when they were available, such as for the solutions. However, the bulk weights were used for the solids in most cases. The plutonium values, in many cases, were based on ratios of the item weight/total weight times the total plutonium weight. Detailed information was not generally available. The table includes material to be stabilized under the interim actions, and the items are denoted by a small " $h$ " on the right side of the table. The table does not include unirradiated FFTF fuel stored at the PFP as no stabilization treatment is currently being considered.

The plutonium currently stored at the PFP was produced in nuclear reactors, then reprocessed using a number of techniques. The plutonium is a mixture of isotopes depending on the original reactor environment, time since last processing, and type of reprocessing treatment used. The potential radiological hazard of plutonium depends significantly on the abundance of particular isotopes present. Each isotope represents a different hazard because of its specific activity and decay mechanism. Table 2.2 shows that half-life and specific activity of plutonium isotopes. One issue in processing the plutonium-bearing material is the removal of americium-241 to reduce the dose rate during storage. The removal decision requires an appreciation of the variation in plutonium isotopic ratios found in the stored materials and how they may have originated. Average americium-241 percentages were used in this study for effluent calculations. Worker dose rates were not calculated; they will be determined in another task supporting the EIS.

\subsection{Background}

The DOE's original mission for the PFP was to supply plutonium metal for national defense. Plutonium metal was processed at the PFP and shipped in large quantities during the 1950s and 1960s. Virtually all of this plutonium is characterized as containing nominally $6 \%$ or less of the plutonium-240 isotope. Similar metal production was conducted for several years in the 1980 s. 
Table 2.1. Plutonium-Bearing Material Inventory

\begin{tabular}{|c|c|c|c|c|c|c|c|c|c|c|c|c|}
\hline min: & EAT. & & meas & wux (nn) & $\begin{array}{l}\text { MET AVE. } \\
\text { KOMITEM }\end{array}$ & $\begin{array}{c}\text { Mot } \\
\text { Woinht ton }\end{array}$ & PU ko & $P U-240$ & Avo Am or & $M \omega^{3}$ & & Motos \\
\hline Nitrate colutions & & Index no & ittam & & & & & & & & & \\
\hline Monconformine & 100 & 76.77 & 108 & 6078 & 11 & 1186 & 11.60 & & & and $0.4 \mathrm{M} \mathrm{KO} 03$ & 14 itemes high $\mathrm{CA}$ & \\
\hline M.ticic Acid Solutions & Fo1 & & 102 & 4856 & 11 & 1122 & 137.80 & 137.80 & & 5 molar & & donitrats \\
\hline Pu-DU Solution & 140 & 102,103 & 52 & 129.8 & ii) & 572 & 70.25 & & Witrats from & mleboratery & & $d$ \\
\hline Purinu Salutions & 560 & 114 & 7 & 350 & 11) & 71 & 8.48 & & \multicolumn{2}{|c|}{ Witrat from HEQ } & & d \\
\hline PuEl Solution & 770 & 122,123 & 42 & 2100 & i1 & 482 & 56.74 & & \multicolumn{3}{|c|}{$180 \mathrm{3} 38$ itoms from HEQ 4 from AML } & d \\
\hline \multirow[t]{3}{*}{ Pu-Th Solution } & 180 & 128,127 & 8 & 450 & 11 & 89 & 12.18 & & 1975 & 5 trom Argome & 4 trom PIIL & $d$ \\
\hline & & & 318 & 13760.8 & & 3490 & 298.00 & & & & & \\
\hline & & & & & & & & & & & & \\
\hline \multicolumn{13}{|l|}{ Chloride Solutions } \\
\hline \multirow[t]{2}{*}{ HeC Solutions } & 102 & $78,80,171$ & 20 & 805 & 11. & 220 & 3.30 & & & & 2 Molat & 1 \\
\hline & \multicolumn{12}{|c|}{ Other Solutions: } \\
\hline Constic Solurion & F04 & 82 & 16 & 720 & 11 & 178 & 27.72 & $11.4 \mathrm{x}$ & & & some catonates & \\
\hline \multirow{2}{*}{ Filtrate } & 105 & $25,28,81$ & 104 & 7445 & 11 & 1144 & 34.32 & $6.5 \mathrm{~K}$ & \multicolumn{2}{|c|}{ 3. solution $\mathrm{m}$ tis $\mathrm{Pu}$} & \multicolumn{2}{|l|}{ Equipment cleon-out } \\
\hline & & actototal & 120 & 8165 & & 1320 & 82 & & & & & \\
\hline & & & & & & & & & & & & \\
\hline & & & & & & & & & & & & \\
\hline \multicolumn{13}{|l|}{ Organie Solutions } \\
\hline Qil and Qrearics & 103 & 81 & 2 & 220 & 11 & 22 & 3.46 & & & & TEP. Lerd oil, CEAB & \\
\hline & & & & & & & & & & & & \\
\hline \multicolumn{13}{|l|}{ Oxides } \\
\hline Oxides Low Fired & 601 & ell but $8,16,1$ & 2663 & 3812.7 & 1.44 & 3812.7 & & & & & & $c, b$ \\
\hline Oxider Low Firod & EOI & $8,18,1$ & 25 & 5.9 & 0.24 & 5.8 & & & & & & h \\
\hline Oxides High Fired & $c 02$ & & 687 & 707.3 & 1.25 & 707.3 & & & & & & $c$ \\
\hline Oxider with $\mathrm{B}_{\mathrm{B}}$ & 003 & & 4 & 3.1 & 0.78 & 3.1 & & & & & & GH, G \\
\hline Encepsulated Pu Compounds & 630 & & 8 & 4 & 0.07 & 4 & 0.368 & & & & & 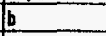 \\
\hline Pu-Du compounde & $C A 0$ & 84,86 & 414 & 591.4 & 1.43 & 581.4 & & & & & & WH \\
\hline Pu-DU Compoinds & C40. & 10 & 1 & 0.8 & 0.60 & 0.8 & & & & & & h \\
\hline Pu-DU Low Find Oxides & CA1 & & 58 & 114 & 1.97 & 114 & & & & & & WH \\
\hline Pu-DU High Firod & C43 & & 200 & 1789.4 & 0.87 & 179.4 & & & & & & E \\
\hline Pu-BUU Compounds & C650 & & 38 & 33.4 & 0.80 & 33.4 & & & & & & by \\
\hline Pur-NU Low Fired Qxidas & C51 & & 40 & 116.2 & 2.40 & 115.2 & & & & & & c \\
\hline Pu-Nu High Fired Oxidas & 052 & & 171 & 287.1 & 1.80 & 287.1 & & & & & & $\epsilon$ \\
\hline PuEU Compounde & $c 70$ & & 278 & 303 & 1.10 & 303 & & & & 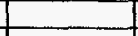 & & by \\
\hline 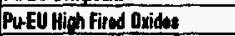 & c72 & & 344 & 456.8 & 1.33 & 468.9 & & & & & & $c$ \\
\hline \multirow{3}{*}{ Puth Compound } & CBO & & 8 & 8.2 & 1.37 & 8.2 & & & & & & e \\
\hline & & & & & & & & & & & & \\
\hline & & & 4017 & 8622 & & 6622 & 1224 & & & & & \\
\hline
\end{tabular}


Table 2.1. (contd)

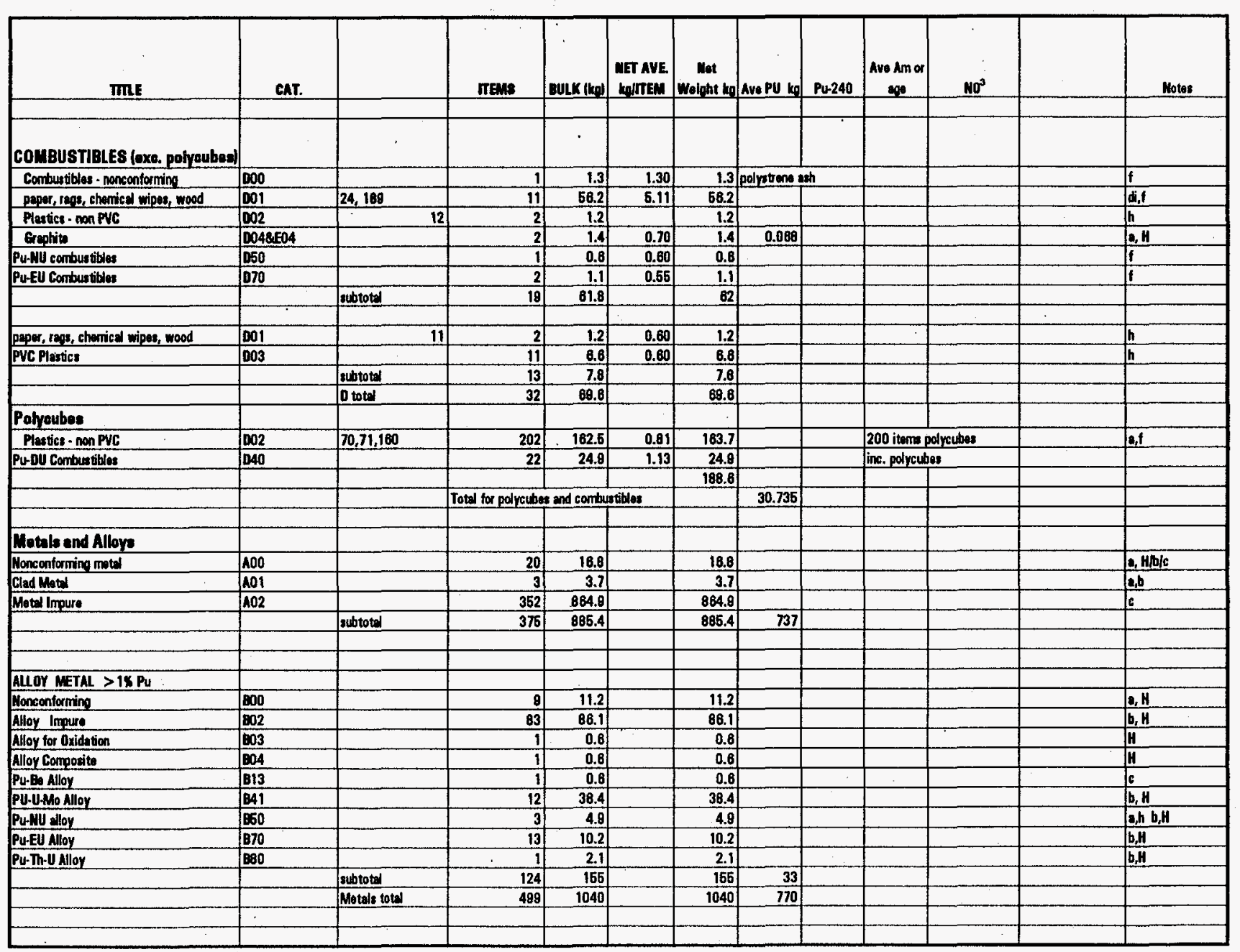


Table 2.1. (contd)

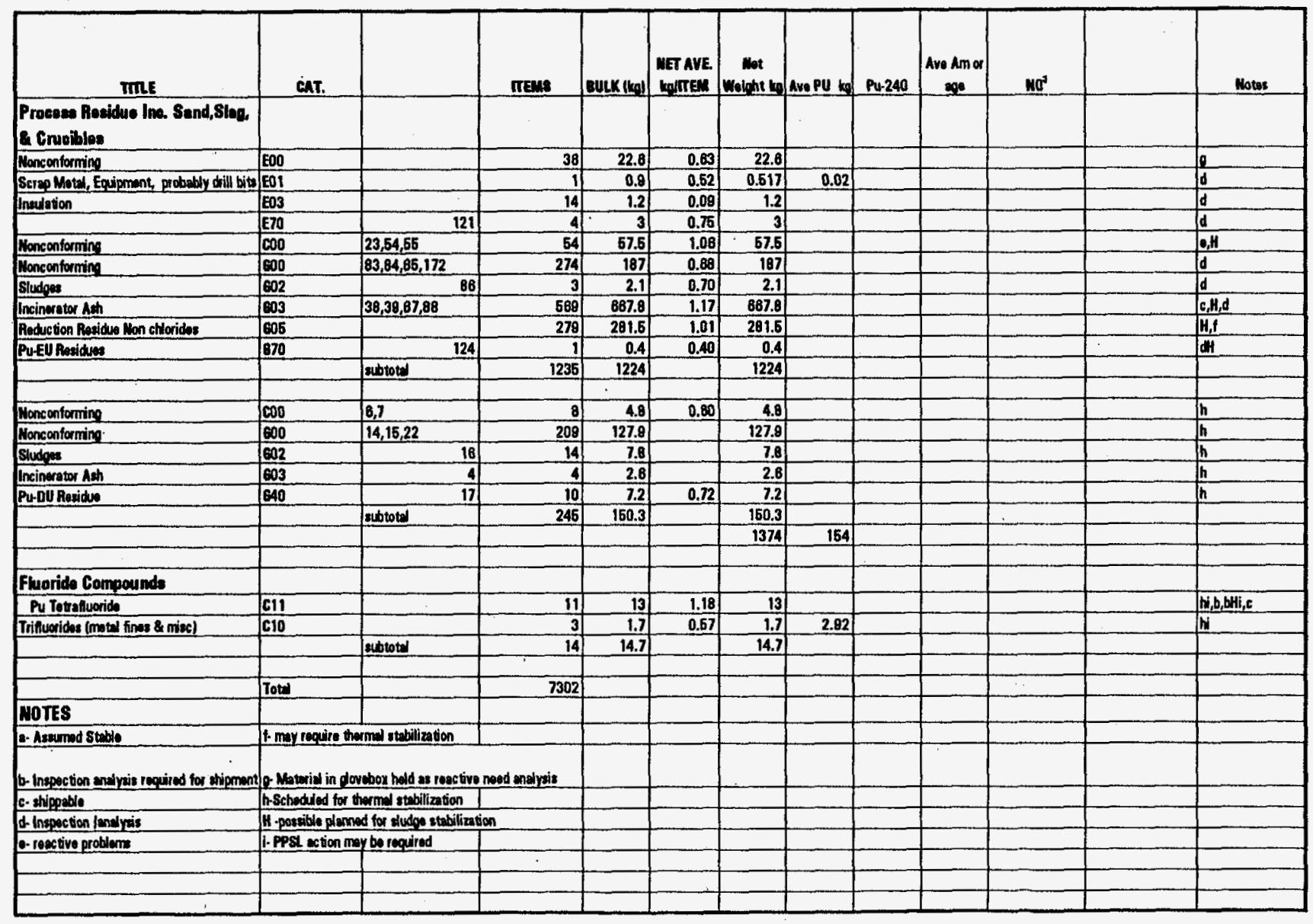


Table 2.2. Constants of Relevant Plutonium and Americium Isotopes (Eckerman and Jeffrey 1993)

\begin{tabular}{||c|c|c||}
\hline Isotope & $\begin{array}{c}\text { Half-Life } \\
\text { (yr) }\end{array}$ & $\begin{array}{c}\text { Specific } \\
\text { Activity (Ci/g) }\end{array}$ \\
\hline \hline${ }^{238} \mathrm{Pu}$ & 87.4 & 17.1 \\
\hline${ }^{239} \mathrm{Pu}$ & 24,065 & 0.0621 \\
\hline${ }^{240} \mathrm{Pu}$ & 6,537 & 0.228 \\
\hline${ }^{241} \mathrm{Pu}$ & 14.4 & 103 \\
\hline${ }^{242} \mathrm{Pu}$ & 376,300 & 0.00392 \\
\hline${ }^{241} \mathrm{Am}$ & 432.2 & 3.43 \\
\hline
\end{tabular}

In the 1960s, PFP plutonium processing changed (Crowe and Szewpruch 1994). Demands for plutonium metal declined while research in power reactor technology indicated that plutonium oxide could be used as a fuel. Later research demonstrated how to use plutonium oxide as a fuel for breeder reactors. The predominant product form from PFP changed from a single metallic piece weighing about $2 \mathrm{~kg}$ to a fine, powdery oxide. Demands for the oxide powder increased from grams for research to thousands of kilograms for reactor fuel. In the late 1960s and 1970s, the PFP processed almost all of the plutonium oxide used in the United States, including thousands of kilograms for FFTF reactor cores.

Production strategies for the oxide dictated scheduling between metal production campaigns (Crowe and Szewpruch 1994). They also included some overproduction to allow for process losses, outof-specification products, and unanticipated requests for kilogram quantities of plutonium oxide. Storage of production overrun material became common.

The completion of the Plutonium Reclamation Facility (PRF) in the 1960s provided the PFP with plutonium scrap recovery capability (Crowe and Szewpruch 1994). Plutonium scrap from military applications as well as from commercial and breeder reactor research was returned to the Hanford Site for the recovery of plutonium. Because the Hanford Site was the DOE scrap-management site and the envisioned supply site for DOE breeder reactor fuel, the PFP received virtually all plutonium scrap with greater than $6 \%$ plutonium- 240 content from both domestic and foreign sources. This scrap, which had a wide variety of chemical and physical forms, was added to the growing inventory of plutonium metal and oxide stored at the PFP.

During the 1960s and 1970s, other changes occurred that ultimately impacted isotopic composition of the plutonium stored at the PFP (Crowe and Szewpruch 1994). The declining demand for plutonium metal caused N Reactor production to change from nominal 6\% plutonium-240 to nominal $12 \%$ plutonium-240. The $12 \%$ plutonium-240 material was used for breeder reactor research for the FFTF 
cores. Commercial nuclear reactors and some government experimental reactors produced plutonium with higher plutonium-240 content. Changes in production demands and capabilities at other DOE sites caused large segments of the DOE inventory to be relocated. The inventory was shipped to PFP because of available storage space and anticipated breeder reactor program needs. Plutonium handling or processing of $15 \%$ to $18 \%$ plutonium- 240 material was not uncommon, and some small lots in excess of $40 \%$ plutonium- 240 were processed at the PFP. Today, this material is part of the current inventory of thousands of containers in storage vaults.

\subsection{Current Status}

The current plutonium inventory consists of a collection of individual items, not a continuous spectrum of a single product line (Crowe and Szewpruch 1994). The plutonium in each inventory container is unique because of its creation in a particular reactor environment and its chronological history of processing and storage. Individual containers may have similar plutonium isotopic distributions because of a common history, a common process blend lot, or a pure coincidence.

The present plutonium inventory at PFP comprises (Crowe and Szewpruch 1994) more than 8000 items including FFTF unirradiated fuel. This study addresses 7302 items. Accountability methods and records requirements over the years have changed. This situation has resulted in an inventory database that ranges from detailed isotopic information for some items to only the total plutonium weight and an indication of plutonium-240 content for others. The present PFP plutonium isotopic inventory shown in Table 2.3 was derived from current inventory records. For cases in which the database did not contain isotopic information, the special nuclear material accountability personnel provided an estimate of the total inventory of each isotope. Next, past laboratory data and hard copy records were used to determine an estimate of the isotopic content of each package. Estimates and professional judgment were used to assign isotopic values to materials of common origin or process lot. The plutonium inventory was then separated into groups based on the percent of plutonium-240. The groups typically spanned a 3\% range. For this report, the groups have not been connected to the inventory in Table 2.1 , which gives an idea of the large variation and reasons to use average americium values. 
Table 2.3. Isotopic Distribution of Plutonium at PFP Based on Inventory Records and Estimates ${ }^{(\text {a) }}$

\begin{tabular}{|c|c|c|c|c|c|c|c|c|}
\hline $\begin{array}{c}\text { Range } \\
\left(\%^{240} \mathrm{Pu}\right)\end{array}$ & Mass (g) & $\begin{array}{l}\text { Number } \\
\text { of Items }\end{array}$ & $\begin{array}{l}{ }^{238} \mathbf{P u}{ }^{(b)} \\
(\% \mathrm{Pu})\end{array}$ & $\begin{array}{l}{ }^{239} \mathbf{P u}^{(\mathbf{b})} \\
(\% \mathrm{Pu})\end{array}$ & $\begin{array}{l}{ }^{240} \mathrm{Pu}^{(\mathrm{b})} \\
(\% \mathrm{Pu})\end{array}$ & $\begin{array}{l}{ }^{241} \mathbf{P u}^{(\mathbf{b})} \\
(\% \mathrm{Pu})\end{array}$ & $\begin{array}{l}{ }^{242} \mathbf{P u}^{(\mathbf{b})} \\
(\% \mathrm{Pu})\end{array}$ & $\begin{array}{l}{ }^{241} \mathrm{Am}^{(\mathrm{b})} \\
(\% \mathrm{Pu})\end{array}$ \\
\hline$<3.99$ & $8.17 E+03$ & 23 & 0.00 & 96.89 & 3.04 & 0.05 & 0.00 & 0.02 \\
\hline $\begin{array}{l}4.00 \text { to } \\
6.99\end{array}$ & $1.49 \mathrm{E}+06$ & 3202 & 0.01 & 93.43 & 6.04 & 0.25 & 0.04 & 0.16 \\
\hline $\begin{array}{l}7.00 \text { to } \\
9.99\end{array}$ & $6.38 \mathrm{E}+04$ & 419 & 0.01 & 91.10 & 8.35 & 0.43 & 0.10 & 0.61 \\
\hline $\begin{array}{l}10.00 \text { to } \\
12.99\end{array}$ & $4.77 \mathrm{E}+05$ & 2195 & 0.07 & 86.68 & 11.88 & 0.93 & 0.19 & 0.73 \\
\hline $\begin{array}{l}13.00 \text { to } \\
15.99\end{array}$ & $1.09 \mathrm{E}+05$ & 235 & 0.52 & 81.05 & 14.92 & 2.39 & 1.15 & 2.50 \\
\hline $\begin{array}{l}16.00 \text { to } \\
18.99\end{array}$ & $1.30 \mathrm{E}+06$ & 1440 & 0.16 & 81.17 & 17.01 & 1.11 & 0.57 & 1.68 \\
\hline$>19.00$ & $2.25 \mathrm{E}+05$ & 572 & 0.27 & 73.68 & 22.62 & 1.87 & 1.65 & 2.45 \\
\hline Total & $3.65 \mathrm{E}+06$ & 8086 & NA & NA & NA & NA & NA & NA \\
\hline \multicolumn{9}{|c|}{$\begin{array}{l}\text { (a) Source: Crowe and Szewpruch } 1994 . \\
\text { (b) The percent plutonium (\% Pu) is calculated on a per-gram-plutonium basis. The total for a } \\
\text { row is greater than } 100 \% \text { because the contribution of the americium- } 241 \text { mass. } \\
\text { NA = Not Applicable. }\end{array}$} \\
\hline
\end{tabular}




\subsection{Initial Screening Process}

The initial screening process was performed by independent consultant Lyle Zahn and PNL staff who wrote the technology descriptions. The group screened the technologies using criteria developed based on previous plutonium treatment evaluations and input from WHC. Previous evaluations included treatment alternatives of Rocky Flats plutonium-bearing material, separated plutonium disposition options compiled by the Lawrence Livermore National Laboratory, and the original EIS prepared by WHC. The criteria encompass the major issues of concern at PFP and include performing the work in a few years while minimizing risks to the workers and the environment. Additional criteria consist of the following: 1) a new building should not be necessary, 2) the final product should be stable for 50 years, and 3) the processing technology chosen should be developed or easily developed. The evaluation criteria for the initial screening are shown in Table 3.1, and further definition of the criteria is given in Table 3.2. Note that the screening was performed based on individual groupings of the plutonium-bearing material. Several reasons for disqualifying a technology are provided on the right side of Table 3.1 .

Tables 3.3 and 3.4 summarize the results of the initial screening technologies available for stabilizing plutonium-bearing material. The technologies that were accepted include pretreatment and stabilization technologies. The pretreatment technologies or unit operations are used to prepare the material for feed to the stabilization process and/or to remove americium and other undesirable chemicals from the plutonium-bearing material. The stabilization processes are the operations that produce the final product form for storage. The final product, in almost all cases, is a high-fired plutonium oxide. The technology descriptions, including the justification for initial acceptance or rejection, are provided in Appendix A and include the same topics described in the evaluation criteria (Table 3.1). The options of "no treatment" and "shipping to another site" are not discussed as technology options, although those options will be considered in the final evaluation of flowsheets and the EIS. Technologies that did not meet the minimum requirements in the evaluation criteria based on literature surveys, personal interviews, and engineering judgment are only described in enough detail to justify their rejection from further study. The process of briquetting and sintering should be considered for all powder materials. The primary product from stabilization activities will be plutonium oxide, not plutonium metal, as described in Section 5.0. However, the storage of metal is not precluded. 
Table 3.1. Preliminary Criteria for Evaluation of Technologies to Process PFP Materials

\begin{tabular}{||l|l||}
\hline \multicolumn{1}{|c|}{ Criteria } & \multicolumn{1}{|c|}{ Reasons for Disqualification } \\
\hline \hline Technical Feasibility (technology maturity) & Will not be available for 2 years \\
\hline $\begin{array}{l}\text { Effluents/By-products } \\
\text { (minimize volumes, hazards) }\end{array}$ & \\
\hline Effluents Covered/SAR & \\
\hline Energy Resource & Product volume exceeds storage capacity \\
\hline Weapon Potential & Readily combustible or reactive \\
\hline End Product Volume & Does not meet regulatory compliance \\
\hline End Product Stability & \\
\hline $\begin{array}{l}\text { Environmental and Public Risk } \\
\text { Routine } \\
\text { Accident }\end{array}$ & Requires new building/facilities \\
\hline $\begin{array}{l}\text { Worker Risk } \\
\text { Routine } \\
\text { Accident }\end{array}$ & Duration greater than 5 years \\
\hline $\begin{array}{l}\text { Cost } \\
\text { (construction, operations and D\&D) }\end{array}$ & \\
\hline $\begin{array}{l}\text { Operating Duration } \\
\text { Public Acceptance }\end{array}$ & \\
\hline \hline
\end{tabular}


Table 3.2. Preliminary Definitions for the PFP Stabilization Criteria

\begin{tabular}{|c|c|}
\hline Criteria & Preliminary Definition \\
\hline $\begin{array}{l}\text { Technical Feasibility } \\
\text { (maturity of technology) }\end{array}$ & $\begin{array}{l}\text { A technology that is considered to be technically feasible is one that can be } \\
\text { implemented within } 2 \text { years assuming that the technology has been demonstrated } \\
\text { to work on a pilot-scale operation or larger for actinide processing, or that an } \\
\text { available technology can be modified to process the PFP materials within } \\
2 \text { years. This also includes the reliability and ease of maintenance in a glovebox } \\
\text { or canyon environment. }\end{array}$ \\
\hline $\begin{array}{l}\text { Effluents/By-products } \\
\text { (minimize volume, hazard) }\end{array}$ & $\begin{array}{l}\text { Minimizing the effluents/by-products (other than the end product) considers the } \\
\text { volume of effluents generated and their hazardous nature. For instance, a proc- } \\
\text { ess may have an effluent stream with a high volume, but with a low hazard; or a } \\
\text { low volume, but with a high hazard. }\end{array}$ \\
\hline Effluents Covered/SAR & $\begin{array}{l}\text { One of the assumptions for this study is that many effluents are already identi- } \\
\text { fied in the existing SAR. If the effluents generated by the process are not } \\
\text { within the constraints identified in the existing SAR, the existing SAR may need } \\
\text { to be updated to reflect the new effluent streams generated by the process. } \\
\text { Modifications and acceptance are judged as minor to severe. }\end{array}$ \\
\hline Energy Resource & $\begin{array}{l}\text { The energy resource considers the potential of the end state product to be used } \\
\text { in future energy making activities (i.e., ability to fabricate with minimal proc- } \\
\text { essing into reactor fuel). }\end{array}$ \\
\hline Weapon Potential & $\begin{array}{l}\text { The weapon potential considers the potential of endstate product to be used in } \\
\text { weapon making without extensive reprocessing. }\end{array}$ \\
\hline End Product Volume & $\begin{array}{l}\text { The end product volume considers the storage requirements needed for storing } \\
\text { the processed PFP material. For example, vitrifying the PFP materials may } \\
\text { increase the volume significantly, creating the possible need for more storage } \\
\text { capacity within the PFP facility. }\end{array}$ \\
\hline End Product Stability & $\begin{array}{l}\text { The stability of the end product is considered in terms of handling and storage. } \\
\text { Stability is to be defined based on Department of Transportation regulations, the } \\
\text { Waste Isolation Pilot Plant (WIPP) acceptance criteria and other sources to be } \\
\text { defined. The end product must not exhibits combustive or reactive } \\
\text { characteristics. }\end{array}$ \\
\hline $\begin{array}{l}\text { Environmental and Public Risk } \\
\text { Routine } \\
\text { Accident }\end{array}$ & $\begin{array}{l}\text { Risk scenarios for routine and accident situations are considered for environ- } \\
\text { mental and public exposures. }\end{array}$ \\
\hline $\begin{array}{l}\text { Worker Risk } \\
\text { Routine } \\
\text { Accident }\end{array}$ & $\begin{array}{l}\text { Risk scenarios for routine and accident situations are considered for occupa- } \\
\text { tional exposures. }\end{array}$ \\
\hline $\begin{array}{l}\text { Cost } \\
\text { (construction, operations and D\&D) }\end{array}$ & $\begin{array}{l}\text { Life cycle cost includes those costs for constructing, operating, and } \\
\text { decommissioning/decontaminating of the process. For the purposes of this } \\
\text { study, it is assumed that the operating costs of the process are included in the } \\
\text { daily operations of the PFP. }\end{array}$ \\
\hline Operating Duration & $\begin{array}{l}\text { The maximum operating duration time to process the PFP materials to a stable } \\
\text { form has not been established. The duration time will help determine the feasi- } \\
\text { bility of the process. }\end{array}$ \\
\hline Public Acceptance & Public acceptance considers the current public perception of a chosen process. \\
\hline
\end{tabular}


Table 3.3. Identified Technologies for Solutions

\begin{tabular}{|c|c|c|c|c|}
\hline $\begin{array}{l}\text { Initial Screening of Identified Technologies Applicable to } \\
\text { Special Nuclear Materials Disposition }\end{array}$ & $\begin{array}{l}\text { Nitrate } \\
\text { Solutions }\end{array}$ & $\begin{array}{l}\text { Chloride } \\
\text { Solutions }\end{array}$ & $\begin{array}{l}\text { Other } \\
\text { Aqueous }\end{array}$ & Organic \\
\hline Direct Denitration (calcination) & $\mathbf{S}-\mathbf{A}$ & $\mathbf{S}-\mathbf{A}$ & S-A & S-A \\
\hline Direct Denitration (sugar) & $\mathbf{P}-\mathbf{R}$ & NA & NA & NA \\
\hline Hydroxide Precipitation & $\mathbf{P}-\mathbf{A}$ & $\mathbf{P}-\mathbf{A}$ & $\mathbf{P}-\mathbf{A}$ & $\mathbf{N A}$ \\
\hline Oralate Precipitation - RMC & $\mathbf{P}-\mathbf{A}$ & $\mathbf{P}-\mathbf{R}$ & $\mathbf{P}-\mathbf{R}$ & $\mathbf{P}-\mathbf{R}$ \\
\hline Solvent Extraction (PRF) & $\mathbf{P}-\mathbf{A}$ & $\mathbf{P}-\mathbf{R}$ & $\mathbf{P}-\mathbf{R}$ & $\mathbf{P}-\mathbf{R}$ \\
\hline Solvent Extraction - new & $\mathbf{P}-\mathbf{A}$ & $\mathbf{P}-\mathbf{A}$ & $\mathbf{P}-\mathbf{A}$ & P-R \\
\hline Ion Exchange & $\mathbf{P}-\mathbf{A}$ & $\mathbf{P}-\mathbf{A}$ & $\mathbf{P}-\mathbf{A}$ & $\mathbf{P}-\mathbf{R}$ \\
\hline Microwave Drying & $\mathbf{S - R}$ & P-R & $\mathbf{P}-\mathbf{R}$ & P-R \\
\hline Blend with HLW Feed to the Hanford Waste Vitrification Project & P-R & $\mathbf{P}-\mathbf{R}$ & $\mathbf{P}-\mathbf{R}$ & P-R \\
\hline Grout for WIPP & S-R & $\mathbf{S}-\mathbf{R}$ & S-R & S-R \\
\hline Vitrify for Storage/WIPP Transfer & S-R & $\mathbf{S - R}$ & S-R & S-R \\
\hline Supercritical Fluid & NA & NA & NA & $\mathbf{P}-\mathbf{R}$ \\
\hline Wet Air Oxidation & NA & NA & NA & $\mathbf{P}-\mathbf{R}$ \\
\hline Peroxide Precipitation & $\mathbf{P}-\mathbf{A}$ & $\mathbf{P}-\mathbf{R}$ & $\mathbf{P}-\mathbf{R}$ & P-R \\
\hline Freeze Dry and Evaporate & $\mathbf{P}-\mathbf{R}$ & $\mathbf{P}-\mathbf{R}$ & $\mathbf{P}-\mathbf{R}$ & $\mathbf{P}-\mathbf{R}$ \\
\hline High Energy Plasma & S-R & S-R & S-R & S-R \\
\hline Sol-Gel Process & S-R & $\mathbf{S}-\mathbf{R}$ & S-R & S-R \\
\hline Membrane Technologies & $\mathbf{P} \cdot \mathbf{R}$ & $\mathbf{P}-\mathbf{R}$ & $\mathbf{P}-\mathbf{R}$ & $\mathbf{P}-\mathbf{R}$ \\
\hline Vacuum Evaporation & $\mathbf{P}-\mathbf{A}$ & $\mathbf{P}-\mathbf{A}$ & $\mathbf{P}-\mathbf{A}$ & NA \\
\hline Ammonium Nitrate Neutralization & $\mathbf{P}-\mathbf{R}$ & P-R & $\mathbf{P}-\mathbf{R}$ & $\mathbf{P}-\mathbf{R}$ \\
\hline Seeded Magnetic Separation & P-R & $\mathbf{P}-\mathbf{R}$ & P-R & P-R \\
\hline Chloride Precipitation & NA & $\mathbf{P}-\mathbf{A}$ & NA & NA \\
\hline Hydrolysis & NA & NA & NA & $\mathbf{P}-\mathbf{R}$ \\
\hline Thermal Treatment & S-A & $\mathbf{S}-\mathbf{A}$ & S-A & S-A \\
\hline Phase Separation & NA & NA & NA & P-R \\
\hline Ozone Treatment & NA & NA & NA & $\mathbf{P}-\mathbf{R}$ \\
\hline CEPOD and Electrolysis & NA & $\mathbf{P}-\mathbf{R}$ & NA & $\mathbf{P}-\mathbf{R}$ \\
\hline Absorption & $\mathbf{P}-\mathbf{R}$ & P-R & P-R & P-R \\
\hline Direct WIPP Disposal & S-R & S-R & S-R & S-R \\
\hline $\begin{array}{l}\mathbf{S}=\text { Storage/Stabilization. } \\
\mathbf{P}=\text { Pretreatment/Purification. } \\
\mathbf{N A}=\text { Not Applicable. } \\
\mathbf{A}=\text { Accept. } \\
\mathbf{R}=\text { Reject. }\end{array}$ & & & & \\
\hline
\end{tabular}


Table 3.4. Identified Technologies for Solids

\begin{tabular}{|c|c|c|c|c|c|c|}
\hline & Oxides & $\begin{array}{c}\text { Sand, Slag, and } \\
\text { Crucibles } \\
\text { (Some Free Ca) }\end{array}$ & $\begin{array}{c}\text { Metals } \\
\text { and } \\
\text { Alloys }\end{array}$ & $\begin{array}{l}\text { Combustibles } \\
\text { (Other than } \\
\text { Polycubes) } \\
\end{array}$ & Polycubes & $\begin{array}{l}\text { Miscellaneous } \\
\text { Fluoride } \\
\text { Compounds } \\
\end{array}$ \\
\hline $\begin{array}{l}\text { Thermal Treatment/ } \\
\text { Stabilization }\end{array}$ & S-A & S-A & S-A & S-A & S-A & S-A \\
\hline $\begin{array}{l}\text { Existing MT-4 Distillation } \\
\text { Process (with modifications) }\end{array}$ & S-A & $\mathbf{S}-\mathbf{A}$ & S-A & S-A & S-A & S-A \\
\hline $\begin{array}{l}\text { High-Gradient Magnetic } \\
\text { Separation }\end{array}$ & P-R & P-R & P-R & P-R & P-R & P-R \\
\hline Silver Persulfate Leach & NA & P-A & NA & $\mathbf{P}-\mathbf{R}$ & $\mathbf{P}-\mathbf{R}$ & P-R \\
\hline CEPOD & P-A & P-A & NA & $\mathbf{P}-\mathbf{R}$ & P-R & P-A \\
\hline $\begin{array}{l}\text { HF/Nitric Acid Dissolution } \\
\text { (includes aluminum nitrate } \\
\text { nonhydrate addition) }\end{array}$ & $\mathbf{P}-\mathbf{R}$ & P-A & P-R & P-R & $\mathbf{P}-\mathbf{R}$ & P-R \\
\hline Grout & S-R & S-R & S-R & $S-R$ & S-R & S-R \\
\hline Vitrify for Storage/WIPP & S-R & S-R & S-R & S-R & S-R & S-R \\
\hline Molten Salt Oxidation & S-A & S-A & S-A & S-A & S-A & S-A \\
\hline Direct Discard for WIPP & S-R & S-R & S-R & S-R & S-R & S-R \\
\hline Screening & S-A & P-A & NA & NA & NA & $\mathbf{P}-\mathbf{R}$ \\
\hline Zone Melting & S-R & S-R & S-R & S-R & S-R & $S-R$ \\
\hline Acid Digestion & NA & NA & NA & P-A & P-A & NA \\
\hline $\begin{array}{l}\text { Grind Under Liquid } \\
\text { Nitrogen, Leach }\end{array}$ & NA & NA & NA & NA & $\mathbf{P}-\mathbf{R}$ & NA \\
\hline Hydrolysis & NA & NA & NA & P-A & $\mathbf{P}-\mathbf{R}$ & P-R \\
\hline $\begin{array}{l}\text { Mufine Furnace (being } \\
\text { installed) }\end{array}$ & S-A & S-A & S-A & S-A & S-A & S-A \\
\hline $\mathrm{ACT}^{*} \mathrm{DE}^{*} \mathrm{CON}$ & NA & $\mathbf{P}-\mathbf{R}$ & NA & NA & NA & $\mathrm{P}-\mathrm{R}$ \\
\hline \multicolumn{7}{|l|}{$\begin{array}{l}S=\text { Storage/Stabilization. } \\
\mathrm{P}=\text { Pretreatment/Purification. } \\
\mathrm{NA}=\text { Not Applicable. } \\
\mathrm{A}=\text { Accept. } \\
\mathrm{R}=\text { Reject. }\end{array}$} \\
\hline
\end{tabular}




\subsection{General Descriptions of the Stabilization Technology Flowsheets}

This section contains process flow diagrams as well as detailed technology descriptions prepared based on the technologies accepted in the initial screening process. The flowsheet descriptions contain information on the time required to process a specific waste stream and the quantities of effluents. The information and reference material used for the process descriptions were taken from Appendix A. Note that the cost data are very, very preliminary, and that the procedures for estimating costs were not applied consistently for each technology.

This information was compiled and presented to the independent review team to consider and rank. The review team then commented on the flowsheets presented, and modifications to the flowsheets were made. The review team's comments and rankings are discussed in Section 6.0. The flowsheets presented to the independent review team included the following technologies for each inventory form:

\section{Nitrate Solutions}

Direct denitration (vertical calciner) Oxalate precipitation/thermal treatment Peroxide precipitation/thermal treatment Hydroxide precipitation/thermal treatment Ion exchange/thermal treatment

\section{Chloride Solutions}

Thermal treatment (vertical calciner) Solvent extraction/thermal treatment Ion exchange/thermal treatment Hydroxide precipitation/thermal treatment Chloride precipitation/thermal treatment

\section{Other Solutions}

Thermal treatment (vertical calciner)

Ion exchange/thermal treatment

Hydroxide precipitation/thermal treatment

\section{Organic Solutions}

Thermal treatment (vertical calciner)

Molten salt oxidation

\section{Oxides}

Thermal treatment (muffle furnace) CEPOD/solvent extraction/vertical calciner Silver persulfate leach/solvent extraction/ vertical calciner

Molten salt oxidation

\author{
Process Residue \\ Thermal treatment (muffle furnace) \\ CEPOD/solvent extraction/vertical calciner \\ Silver persulfate leach/solvent extraction/ \\ thermal treatment \\ Molten salt oxidation \\ $\mathrm{HF} / \mathrm{HNO}_{3}$ dissolution/solvent extraction/ \\ thermal treatment \\ Metals and Alloys \\ Thermal oxidation (muffle furnace) \\ $\mathrm{HF} / \mathrm{HNO}_{3}$ dissolution/solvent extraction/ \\ thermal treatment \\ Molten salt oxidation \\ Combustibles \\ Thermal treatment (modified muffle furnace) \\ Molten salt oxidation \\ Acid digestion/thermal treatment \\ Hydrolysis
Polycubes
Thermal treatment (modified muffle furnace)
Molten salt oxidation
Acid digestion/thermal treatment
Fluoride Compounds
Thermal treatment (modified muffle furnace)
Molten salt oxidation
Acid digestion/thermal treatment.


Some of the general assumptions used to develop the process flowsheets are listed below:

\section{Waste Disposal Requirements}

The waste disposal requirements are based on WIPP criteria, the Code of Federal Regulations, and recently developed criteria for the tank farms.

- low-level waste (LLW) is less than $100 \mathrm{nCi} / \mathrm{g}$

- tank farms will accept only neutralized waste with $<1.3 \mathrm{E}-02 \mathrm{~g} / \mathrm{L}$ plutonium-239 equivalent

- draft WIPP storage requirements for plutonium equivalent.

\section{General Inventory Assumptions}

The inventory assumptions are based on process history and current storage and operating guidelines. The information was obtained from reports and WHC staff at PFP.

- liquid containers contain $8.5 \mathrm{~L}$ of solution

- chloride content of solids is negligible

- plutonium average isotopic ratio is $85 \%$ plutonium- $239,14 \%$ plutonium-240, $1 \%$ plutonium-241

- americium-241 is $1.5 \%$ of total plutonium mass

- items planned for interim stabilization were not considered

- processing rate based on $24 \mathrm{~h} / \mathrm{d}, 5 \mathrm{~d} / \mathrm{wk}, 60 \%$ on-line efficiency.

\subsection{CEPOD}

The Catalyzed Electrochemical Plutonium Oxide Dissolution (CEPOD) process would be used to leach plutonium oxides from solids. The goal of the process is volume reduction and removal of nonplutonium impurities. The process does not work on plutonium metal, although materials that contain plutonium metal could be oxidized in a furnace and then processed via CEPOD. However, there does not appear to be any advantage in processing plutonium-metal-bearing materials in this way, so only plutonium-oxide-bearing materials are considered for this flowsheet. The waste categories that would be applicable to CEPOD are the low-fired oxides (C01, C03, C30, C40, C41, C50, C51, C70, C80) and the process residues (C00, G00, G02, G03, G05, G40, G70). Items that are scheduled for thermal stabilization are not included. The high-fired oxides are not considered, as the dissolution kinetics are 
generally slower for these materials relative to low-fired oxides. Further, there seems to be little incentive to treat these materials using CEPOD as the high-fired oxides are already in a very stable form.

Since the product stream from CEPOD is not a suitable form for long-term storage, an additional treatment step is required. There are a number of options available to treat the liquid product, which would be composed primarily of nitric acid, silver, and dissolved plutonium oxide, with some other soluble ions from the waste. However, it was assumed that the product stream would be directly calcined using the vertical calciner or similar apparatus for the purposes of studying potential treatment process strategies. The effect of sending the stream through a solvent extraction step before calcining was also investigated.

An existing CEPOD dissolver is located in storage at the 236-Z Plant, which could be used to treat PFP wastes. The CEPOD dissolver would require approximately $0.5 \mathrm{~m}^{3}$ of floorspace within the glovebox. The CEPOD dissolver is approximately $1.2 \mathrm{~m}$ high but requires additional clearance space for opening the unit to load the solids and access the electrodes. Therefore, Glovebox HC-7 is recommended for the location of the CEPOD dissolver.

CEPOD, as designed, requires manual loading of the solids. Manual loading would increase the dose to the workers operating the dissolver. The solution and solids are removed through the bottom of the unit by activating a valve, which could be operated remotely. The solids would be captured by a filter, then washed to remove residual solution, dried, and packaged for storage. The solution would be sent to the next processing step.

The process of stripping plutonium from the liquid stream (e.g., solvent extraction, ion exchange) would allow some degree of recycling. Recycling the liquid stream back to the CEPOD dissolver would reduce the volume of anolyte solution added to CEPOD, which would, therefore, reduce the volume of effluents from the process. However, there would be problems in recycling if there were significant quantities of dissolved ions in the liquid stream. High concentrations of dissolved ions could reduce the efficiency of the CEPOD process by reducing the $\mathrm{Ag}(\mathrm{II})$ ions to $\mathrm{Ag}(\mathrm{I})$ before they could react with the plutonium oxide.

Stripping the plutonium from the CEPOD product stream would increase the purity of the final product. Sending the product stream directly to calcination results in the inclusion of silver final form, as well as any other dissolved impurities from the waste. Solvent extraction could also be used to separate americium from plutonium; however, americium separation is not an issue at this time.

\subsubsection{Process Description}

Two flowsheets were designed to determine potential effluent and product volumes from a process that utilizes CEPOD (Figure 4.1). The first one uses a solvent extraction step to strip plutonium from the aqueous product, followed by calcination of the plutonium product. In the second flowsheet, the CEPOD product is sent directly to calcination. In both of these flowsheets, the final product is a 


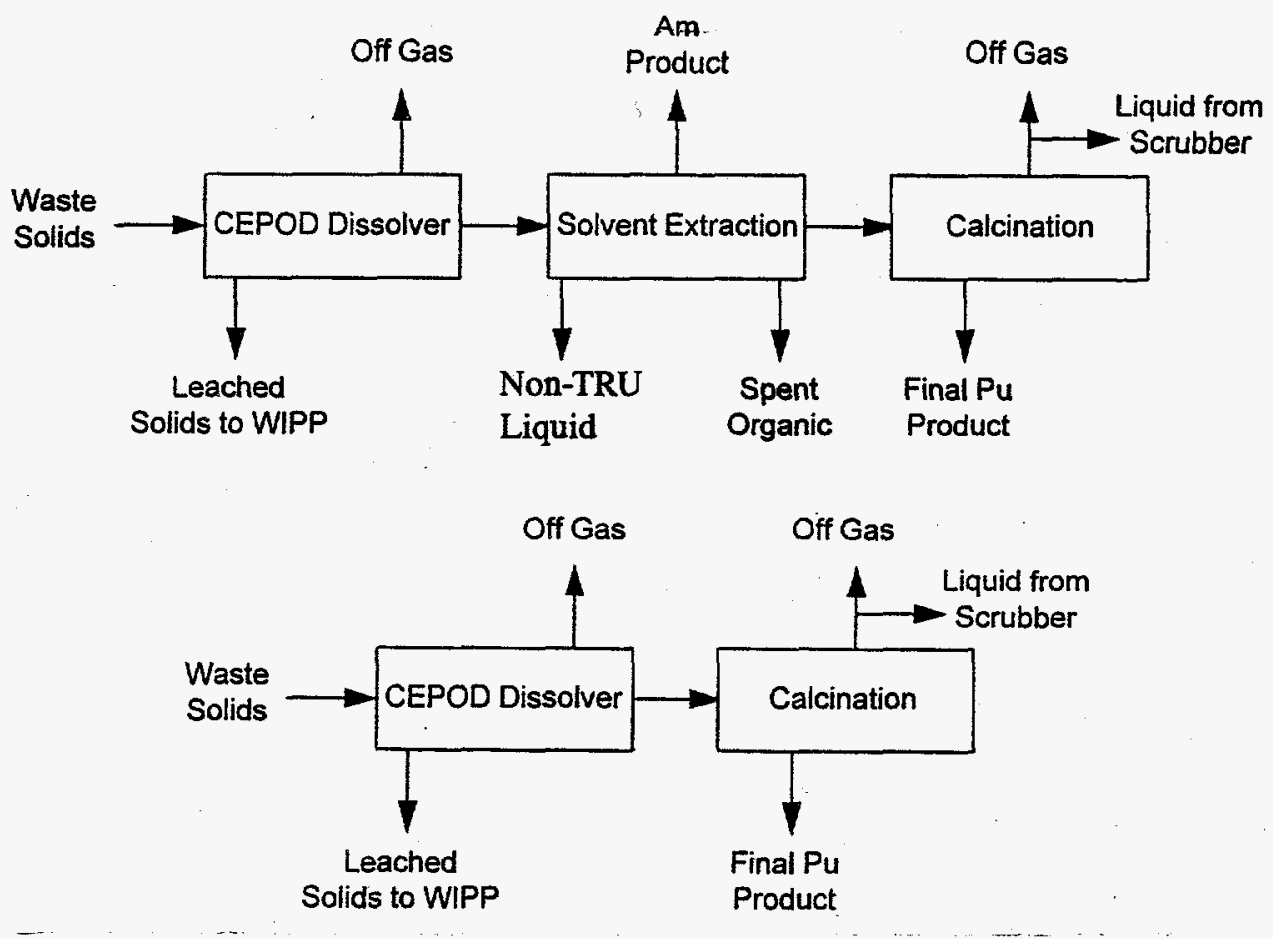

Figure 4.1. CEPOD Flow Diagram

plutonium oxide compound, with some degree of impurities. Because of the uncertainties associated with the PFP waste compositions, several assumptions were made to generate effluent volumes, process times, etc.

It is assumed that the solids that will be treated do not contain a significant amount of chlorine. Furthermore, it is assumed that the treated materials all compose relatively fine particles (on the order of $1 \mathrm{~mm}$ ), and that all the plutonium in the solids is in an oxide form.

A $99 \%$ removal efficiency in 2 hours at 20 amps is assumed. This removal efficiency should be readily achievable for waste materials that contain only plutonium oxides and are composed of small particles. Any deviation from this would significantly reduce the efficiency of the process. The flowsheet uses one dissolution vessel that holds $11 \mathrm{~L}$ of anolyte solution and can effectively handle $1 \mathrm{~kg}$ of plutonium or $2.5 \mathrm{~kg}$ of total solids per batch, whichever is greatest. The anolyte solution is $0.5 \underline{\mathrm{M}} \mathrm{AgNO}_{3}$ and $4 \underline{\mathrm{M}} \mathrm{HNO}_{3}$. After the reaction is complete, the solids are filtered from the solution using a stainless steel filter. The solids are water-washed to remove any residual solution. It is assumed that the amount of washing water used is minimal with respect to the other solution volumes and is not included in the final total. The solids are then dried, packaged, and sent to the central waste storage complex.

Other compounds from the solids will be present in the solution after processing in addition to plutonium oxide. Americium is assumed to be dissolved to the same extent as the plutonium. However, 
without more detailed information about the waste composition it is impossible to predict the extent of other components in the solution. Past CEPOD tests on ash and other plutonium-bearing residues have shown that a majority of the solids do not dissolve. It is assumed for this study that the mass of other dissolved components from the solids is negligible.

The process consumes $\mathrm{NO}_{3}{ }^{-}$at the cathode, generating $\mathrm{NO}_{x}$ gas. It is estimated that approximately $0.5 \underline{\mathrm{M}}$ of $\mathrm{NO}_{3}{ }^{-}$are consumed per mole of $\mathrm{e}^{-}$passing through the cell. It is also assumed that the primary gas product is nitrogen oxide. From the processing time and current passed through the cell, a nitrogen oxide gas flow rate can be calculated. The equation used is as follows (Wash 1993):

$$
\frac{\mathrm{dm}}{\mathrm{dt}}=\frac{\mathrm{I}}{\mathrm{nF}}
$$

where $\mathrm{dm} / \mathrm{dt}$ is the rate of electrons entering the cell, $\mathrm{I}$ is the current, $\mathrm{n}$ is the equivalent per mole of electrons, and F is Faraday's Constant. The calculations seem to result in a somewhat lower value for nitrogen oxide production than was expected based on experimental data, although it is not far from the theoretical maximum value. It should not be considered as a conservative estimate. The consumption of $\mathrm{NO}_{3}^{-}$means that fresh solution must be added to the cathode compartment. To calculate the amount of solution added, it is assumed that $12 \mathrm{M} \mathrm{HNO}_{3}$ would be added to replace the consumed $\mathrm{NO}_{3}^{-}$. It is also assumed that the concentration in the cathode is never allowed to drop below $7 \underline{\mathrm{M}} \mathrm{HNO}_{3}$, as concentrations lower than $5 \underline{\mathrm{M}}$ can result in hydrogen gas generation. The $\mathrm{NO}_{\mathrm{x}}$ would be sent into the existing venting system.

The liquid product from CEPOD would then be sent to the next processing step. The flowsheet and calculations used to determine effluent volumes, equipment sizes, etc., for the solvent extraction system are described in a subsequent section. The opportunity exists for solution recycle if the plutonium is stripped from the anolyte solution. Therefore, it is assumed for the case where a solvent extraction step followed CEPOD that there would be a $50 \%$ reduction in the volume of the anolyte solution. A large concentration of soluble ions from the waste could hinder recycling. However, it is felt that (based on the best available information on the waste) that a $50 \%$ recycle is a reasonable assumption.

Plutonium-bearing liquids, whether from CEPOD directly or from the solvent extraction process, are then sent to a calcination step. A generic calciner is assumed, which has the following properties: 1) liquids are fed into the calciner at a rate of $3 \mathrm{~L} / \mathrm{h} ; 2$ ) all water, $\mathrm{HNO}_{3}$, and $\mathrm{NO}_{3}{ }^{-}$end up in the off gas; and 3) all other compounds end up in the solid product as an oxide. It is assumed that no small solid particles would escape through the off gas. In calculating $\mathrm{NO}_{\mathrm{x}}$ generation from the calciner, it is assumed that any $\mathrm{NO}_{3}^{-}$not in the form $\mathrm{HNO}_{3}$ would end up in the off gas as nitrogen oxide.

As the off gas would contain $\mathrm{HNO}_{3}$, it would be necessary to treat the off-gas stream leaving the calciner. Therefore, it is assumed that there is a condenser and scrub step after the calciner to remove $\mathrm{HNO}_{3}$. It is also assumed that $100 \%$ of the $\mathrm{HNO}_{3}$ would be condensed from the off gas, along with $90 \%$ of the water. All other components of the off gas are assumed to be vented to the environment. 
All liquid effluent streams, which include the condensed off gas from the calciner and the non-TRU raffinate from the solvent extraction process, are assumed to be sent to the tank farms. As liquids pumped into the tanks must be $\mathrm{pH} 12$, it is assumed that liquids generated by the flowsheets were

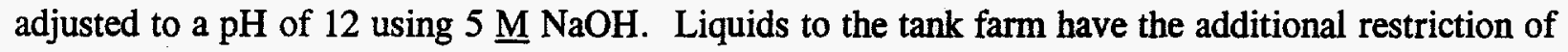
having less than $1.3 \mathrm{E}-03 \mathrm{~g} / \mathrm{L}$ of plutonium-239 equivalent. In the flowsheet that includes solvent extraction, a small amount of plutonium ends up in the americium product stream, which is sent to the tank farms. If the plutonium concentration in this stream were greater than the allowable concentration, then the stream would be diluted to the acceptable plutonium concentration.

\subsubsection{Effluents and Products Generated}

Table 4.1 outlines the volumes, masses, and process times of the products and effluents from the described flowsheets. As can be seen, there is a tradeoff between using and not using solvent extraction in terms of time required for calcination and the amount of liquid wastes pumped to the tank farm. This situation is due to solvent extraction producing a smaller plutonium-bearing stream, which would be calcined, at the expense of producing a larger liquid stream that, as it contains some plutonium and other radionuclides, would be sent to the tank farm. In addition, the total mass of stored plutoniumbearing material would be reduced if solvent extraction was used.

Table 4.1. Volumes, Masses, and Process Times for CEPOD Flowsheet Effluents

\begin{tabular}{|l|r|r||}
\hline Volumes, Masses, and Process Times & $\begin{array}{c}\text { Without Solvent } \\
\text { Extraction }\end{array}$ & $\begin{array}{c}\text { With Solvent } \\
\text { Extraction }\end{array}$ \\
\hline \hline Volumes and masses & 51 & 51 \\
\hline Solids to WIPP (\# of 55 gal. drums) & 25,000 & 86,000 \\
\hline Liquids to Tank Farm (L) & 1,170 & 1,130 \\
\hline Plutonium-Bearing Solids (kg) & 68 & 68 \\
\hline NO Formed (kg) & 3,900 & 770 \\
\hline Total Off Gas (kg) & & 4,000 \\
\hline \hline Process Time for Low-Fired Oxides (h) & 7,300 & 1,800 \\
\hline CEPOD & & \\
\hline Calcination & 960 & 960 \\
\hline \hline Process Time for Process Residues (h) & 1,800 & 440 \\
\hline CEPOD & & \\
\hline Calcination & \multicolumn{3}{|c|}{} \\
\hline
\end{tabular}




\subsection{Silver Persulfate}

The silver persulfate process would be used to leach plutonium oxides from solids. The goals of the process are volume reduction and the removal of non-plutonium impurities. The process does not work on plutonium metal, although materials that contain plutonium metal could be oxidized in a furnace and then processed via silver persulfate. However, it does not seem to serve any advantage to process plutonium-metal-bearing materials in this way, so only plutonium-oxide-bearing materials are considered for this flowsheet. The waste categories that would be applicable to the silver persulfate process are the low-fired oxides (C01, C03, C30, C40, C41, C50, C51, C70, C80) and the process residues $(\mathrm{C} 00, \mathrm{G} 00, \mathrm{G} 02, \mathrm{G} 03, \mathrm{G} 05, \mathrm{G} 40, \mathrm{G} 70)$. Items that are scheduled for thermal stabilization are not included. The high-fired oxides are not considered, as the dissolution kinetics are generally slower for high-fired oxides. As the high-fired oxides are already in a very stable form, there seems little incentive to treat these materials using silver persulfate.

Since the product stream from the silver persulfate process is not a suitable form for long-term storage, an additional treatment step is required. There are a number of options available to treat the liquid product, which would be composed primarily of nitric acid, silver, and dissolved plutonium oxide, with some other soluble ions from the waste. For the purposes of studying potential treatment process strategies, it is assumed that the product stream would be directly calcined using the vertical calciner or similar apparatus. The effect of sending the stream through a solvent extraction step prior to calcining was also investigated.

The silver persulfate process would require minimal glovebox space. The process could be done in one large beaker or numerous small ones, with the scale having little effect as long as good agitation is maintained. Therefore, the equipment required would be the reaction vessels, mechanical impellers for agitation of the solution, and equipment for filtering the solids from the solution. For the two 8-L reaction vessels assumed for these flowsheets, it is estimated that the process would require no more than approximately $0.8 \mathrm{~m}^{2}$ of floorspace in a glovebox.

The silver persulfate process would require manual loading of the solids into the reaction vessel, unless some mechanism could be designed to load the vessel remotely. This process would increase the dose to the workers operating the process. Draining the solution after the reaction is complete would increase the dose to the workers if done manually. It would, however, be easy to design a reaction vessel with a bottom drain that could have a remotely activated valve. The solids would be captured by a filter, then washed to remove residual solution, dried, and packaged for storage. The solution would be sent to the next processing step.

Some compounds from the solids other than plutonium oxide will be present in the solution after processing. Americium is assumed to be dissolved to the same extent as the plutonium. However, without more detailed information about the waste it is impossible to predict the mass of other components in the solution. Past experimental work has shown that for materials similar to the materials in the PFP inventory, the majority of the mass is not dissolved. It is assumed for this study that the mass of other dissolved components from the solids is negligible. 
Stripping the plutonium from the silver persulfate product stream would increase the purity of the final product. Sending the product stream directly to calcination results in the inclusion of the silver from silver persulfate in the final form, as well as any other dissolved impurities from the waste. Solvent extraction could also be used to separate americium from plutonium; however, there is no incentive to separate the americium from the plutonium at this time.

\subsubsection{Process Description}

Two flowsheets were designed to determine potential effluent and product volumes from a process that utilizes the silver persulfate process (Figure 4.2). The first flowsheet uses a solvent extraction step to strip plutonium from the aqueous product, followed by calcination of the plutonium product. In the second flowsheet, the silver persulfate product is sent directly to calcination. In both of these flowsheets, the final product is a plutonium oxide compound, with some degree of impurities. Because of the uncertainties associated with the PFP waste compositions, several assumptions were made to generate effluent volumes, process times, and so forth.

It is assumed that the solids that will be treated do not contain a significant amount of chloride. Furthermore, it is assumed that the treated materials are all composed of relatively fine particles (on the order of $1 \mathrm{~mm}$ ), and that all the plutonium in the solids is in an oxide form.

A $99 \%$ removal efficiency in 2 hours is assumed. Data are limited and show a wide range of efficiencies for different waste materials. However, a $99 \%$ removal efficiency is achievable if the waste
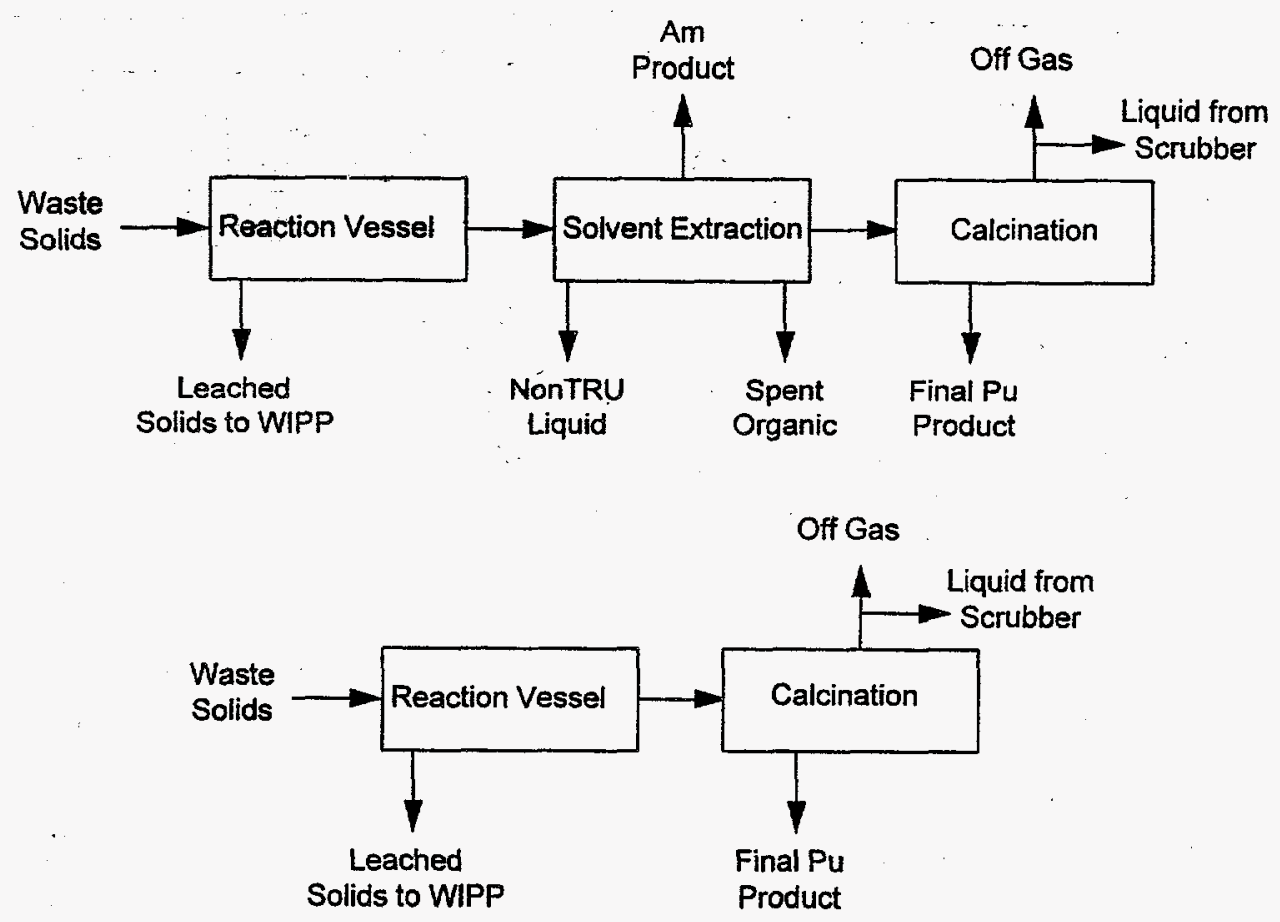

Figure 4.2. Silver Persulfate Flow Diagram 
material conforms as per the assumptions listed above. The flowsheet uses two 8- $\mathrm{L}$ reaction vessels, which are filled no more than $2 / 3$ full of solution. The solution is $0.5 \underline{\mathrm{M} \mathrm{K}} \mathrm{S}_{2} \mathrm{O}_{8}$ and $0.2 \underline{\mathrm{M}} \mathrm{AgNO}_{3}$. Ten parts of solution are used per 1 part solids. This combination results in approximately $10 \mathrm{~L} / \mathrm{batch}$ of solution and $1 \mathrm{~kg} / \mathrm{batch}$ of solids. The vessels are continuously stirred, probably using a mechanical impeller. After the reaction is complete, the solids are filtered from the solution, using a stainless steel filter. The solids are water-washed to remove any residual solution. It is assumed that the amount of washing water used is minimal with respect to the other solution volumes, and it was not included in the final total. The solids are dried, packaged, and sent to the central waste storage complex. The liquid is sent to the next processing step.

Plutonium-bearing liquids, whether from the silver persulfate process directly or from the solvent extraction process, are then sent to a calcination step. A generic calciner is assumed, which has the following properties: 1) liquids are fed into the calciner at a rate of $3 \mathrm{~L} / \mathrm{h} ; 2$ ) all water, $\mathrm{HNO}_{3}$, and $\mathrm{NO}_{3}{ }^{-}$end up in the off gas; and 3) all other compounds end up in the solid product as an oxide. It is assumed that no small solid particles would escape through the off gas. In calculating $\mathrm{NO}_{\mathrm{x}}$ generation from the calciner, it is assumed that any $\mathrm{NO}_{3}{ }^{-}$not in the form $\mathrm{HNO}_{3}$ would end up in the off gas as nitrogen oxide.

As the off gas would contain $\mathrm{HNO}_{3}$, it would be necessary to treat the off-gas stream leaving the calciner. Therefore, it is assumed that there is a condenser and scrub step after the calciner to remove $\mathrm{HNO}_{3}$. It is also assumed that $100 \%$ of the $\mathrm{HNO}_{3}$ would be condensed from the off gas, along with $90 \%$ of the water. All other components of the off gas are assumed to be vented to the environment.

All liquid effluent streams are assumed to be sent to the tank farms. The streams that fall under this category are the condensed off gas from the calciner and the non-TRU raffinate from the solvent extraction block. As liquids pumped into the tanks must be caustic, it is assumed that liquids generated by the flowsheets were adjusted to a $\mathrm{pH}$ of 12 using $5 \underline{\mathrm{M} \mathrm{NaOH}}$.

\subsubsection{Effluents and Products Generated}

Table 4.2 outlines the volumes, masses, and process times of the products and effluents from the described flowsheets. Liquids to the tank farm have the additional restriction of having less than 1.3 E-02 g/L of plutonium-239 equivalent. In the flowsheet that includes solvent extraction, a small amount of plutonium ends up in the americium product stream, which is sent to the tank farms. If the plutonium concentration in this stream is greater than the allowable concentration, then the stream is adjusted to the acceptable plutonium concentration.

\subsection{Acid Digestion}

Acid digestion is a chemical oxidation process for converting organic wastes to gaseous effluents and stable solid residues. Typical waste materials such as polyvinylchloride (PVC), polyethylene, paper and other cellulosic materials, ion exchange resins, and all types of rubber (neoprene, latex, 
Table 4.2. Volumes, Masses, and Process Times from Persulfate Flowsheet Effluents

\begin{tabular}{|c|c|c|}
\hline Volumes, Masses, and Process Times & $\begin{array}{l}\text { Without Solvent } \\
\text { Extraction }\end{array}$ & $\begin{array}{c}\text { With Solvent } \\
\text { Extraction }\end{array}$ \\
\hline Solids to WIPP (\# of 55 gal. drums) & 55 & 55 \\
\hline Liquids to Tank Farm (L) & 55,700 & 160,000 \\
\hline Plutonium-Bearing Solids (kg) & 1,108 & 1,095 \\
\hline Total Off Gas (kg) & 6,900 & 1,600 \\
\hline \multicolumn{3}{|l|}{ Process Time for Low-Fired Oxides (h) } \\
\hline Silver Persulfate & 10,300 & 10,300 \\
\hline Calcination & 16,600 & 4,200 \\
\hline \multicolumn{3}{|l|}{ Process Time for Process Residues (h) } \\
\hline Silver Persulfate & 2,500 & 2,500 \\
\hline Calcination & 4,000 & 1,000 \\
\hline
\end{tabular}

hypalon) are digested in a medium of sulfuric acid heated to $-250^{\circ} \mathrm{C}$. Typical volume reduction factors range between 10:1 and 100:1 depending on the combustible waste feed.

Figure 4.3 is a flowsheet of an acid digestion process with a material balance based on processing $100 \mathrm{~kg} / \mathrm{d}$ combustible waste provided. Wastes are sorted to remove non-combustible materials and then shredded to approximately $3 \mathrm{~cm}$ in diameter. These wastes are fed to the acid digester, constructed of titanium or glass, at an approximate rate of $4 \mathrm{~kg} / \mathrm{h}$. The sulfuric acid carbonizes and partially oxidizes the waste, but the primary oxidant is nitric acid, which is added continuously to the digester at a rate proportional to the waste addition. Because acid digestion is a combustion process, it has the same basic requirements as other combustion or incineration processes regarding preparation of feed materials, containment, off-gas cleanup, and process control. Two scrubbers are used to recover acids in the off gas that are sent to the acid fractionator and recycled.

There are three primary effluents: two off-gas effluents and one solid residue effluent. The first off-gas effluent is from the scrubber and is composed mainly of carbon dioxide, air, and water. The second off-gas stream is from the acid fractionator and is composed of water, $\mathrm{HNO}_{3}$, and $\mathrm{HCl}$. The solids residue effluent is composed of sulfate of plutonium, calcium, zinc, iron, titanium metal salts, and silicon oxide. Past testing has shown that no measurable plutonium is found in either off-gas steam. 


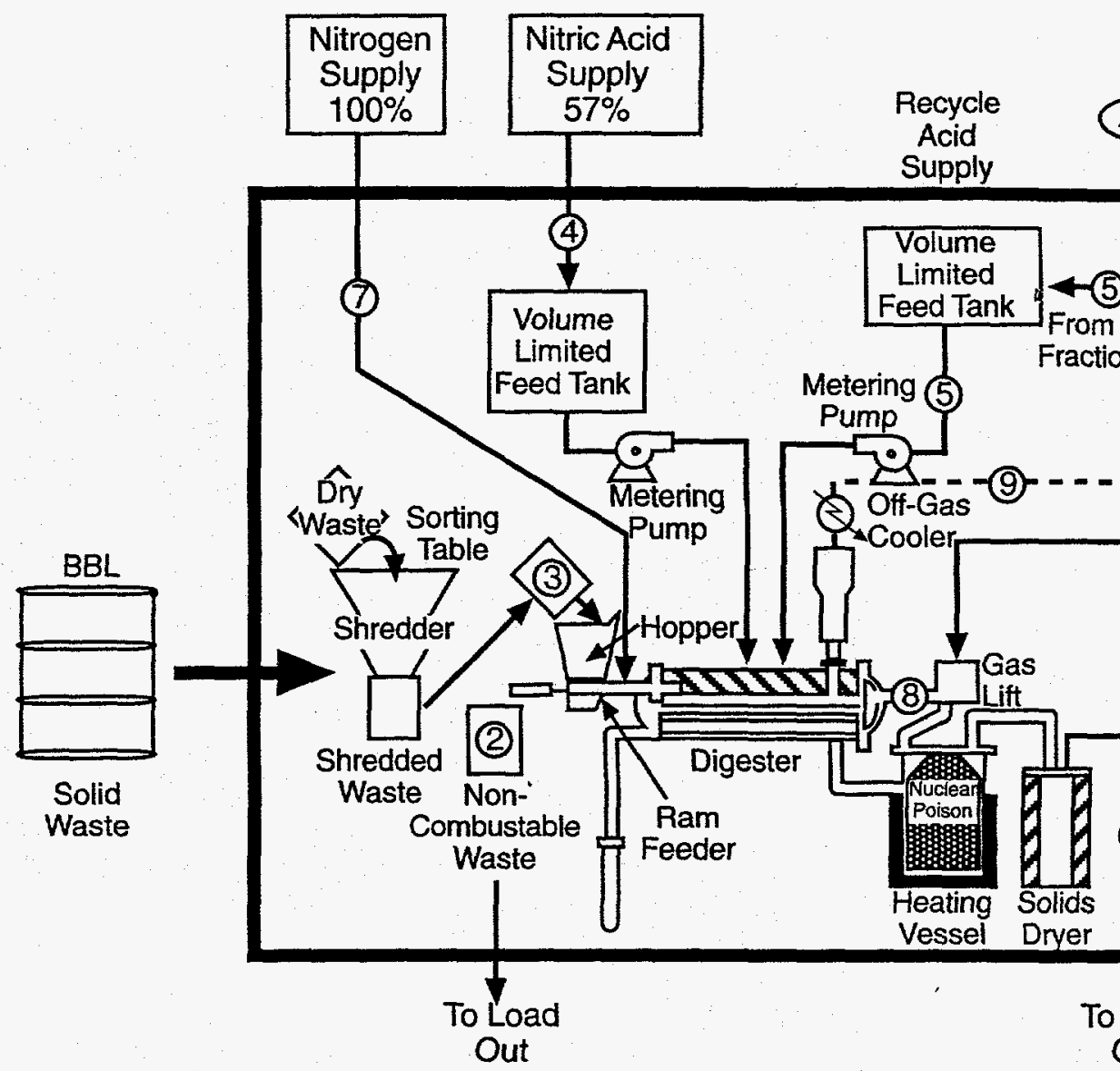

\begin{tabular}{|c|c|c|c|c|c|c|c|c|c|}
\hline Line Number & 1 & 2 & 3 & 4 & 5 & 6 & 7 & 8 & \\
\hline Description & $\begin{array}{l}\text { Drummed } \\
\text { Waste }\end{array}$ & $\begin{array}{l}\text { Noncomb. } \\
\text { Waste }\end{array}$ & $\begin{array}{c}\text { Combustible } \\
\text { Waste }\end{array}$ & Nitric Acid & Recycle Acid & Gas Lift Air & $\begin{array}{l}\text { Nitrogen } \\
\text { Jet }\end{array}$ & $\begin{array}{l}\text { Digester } \\
\text { Liquid }\end{array}$ & $\begin{array}{l}\text { Dige } \\
\text { Off- }\end{array}$ \\
\hline Rate Units & $\mathrm{Kg} / \mathrm{d}$ & $\mathrm{Kg} / \mathrm{d}$ & $\mathrm{Kg} / \mathrm{d}$ & $\mathrm{Kg} / \mathrm{d}$ & $\begin{array}{l}\mathrm{Kg} / \mathrm{d} \\
\text { (L/d) }\end{array}$ & $\mathrm{Kg} / \mathrm{d}$ & $\mathrm{Kg} / \mathrm{d}$ & $L / \min$ & \\
\hline $\begin{array}{l}\text { Quantity } \\
\text { or Rate }\end{array}$ & 126 & 20 & $106^{*}$ & 316 & $761 \quad(544)$ & 526 & 49 & Recirc. & \\
\hline $\begin{array}{c}\text { Pressure } \\
\text { Gauge }\end{array}$ & 0 & 0 & 0 & 0 & 20 psig & 5 psig & 250 psig & 0 & -7 in \\
\hline $\begin{array}{c}\text { Temperature } \\
\left({ }^{\circ} \mathrm{C}\right)\end{array}$ & 25 & 25 & 25 & 25 & 70 & 25 & 25 & 230 & \\
\hline \multicolumn{10}{|l|}{$\begin{array}{c}\text { Composition } \\
(w+\%)\end{array}$} \\
\hline & & & & & & & & & So \\
\hline & & Glass $=35 \%$ & $85 \%$ Paper & $\mathrm{HNO}_{3}=57 \%$ & $\mathrm{H}_{2} \mathrm{SO}_{4}=40 \%$ & $\mathrm{~N}_{2}=75 \%$ & $N_{2}=100 \%$ & $\mathrm{H}_{2} \mathrm{SO}_{4}=91 \%$ & $\mathrm{H}_{2} \mathrm{O}=$ \\
\hline & & Metal $=65 \%$ & $\begin{array}{c}\text { Polyethylene } \\
10 \%\end{array}$ & $\mathrm{H}_{2} \mathrm{O}=43 \%$ & $\mathrm{HNO}_{3}=12 \%$ & $\mathrm{O}_{2}=23 \%$ & & $\mathrm{H}_{2} \mathrm{O}=9 \%$ & $\mathrm{H}_{2} \mathrm{SC}$ \\
\hline & & & $5 \%$ PVC & & $\mathrm{H}_{2} \mathrm{O}=48 \%$ & $A r=1 \%$ & & & \\
\hline & & & (6\% Ash) & & & & & & \\
\hline & & & & & & & & & NO= \\
\hline & & & & & & & & & $\mathrm{CO}_{2}=$ \\
\hline & & & & & & & & & $\mathrm{N}_{2}=$ \\
\hline & & & & & & & & & $\mathrm{O}_{2}=$ \\
\hline
\end{tabular}

* Basis: $100 \mathrm{~kg} / \mathrm{d}$ of combustibles (Ash free).

Figure 4.3. Acid 


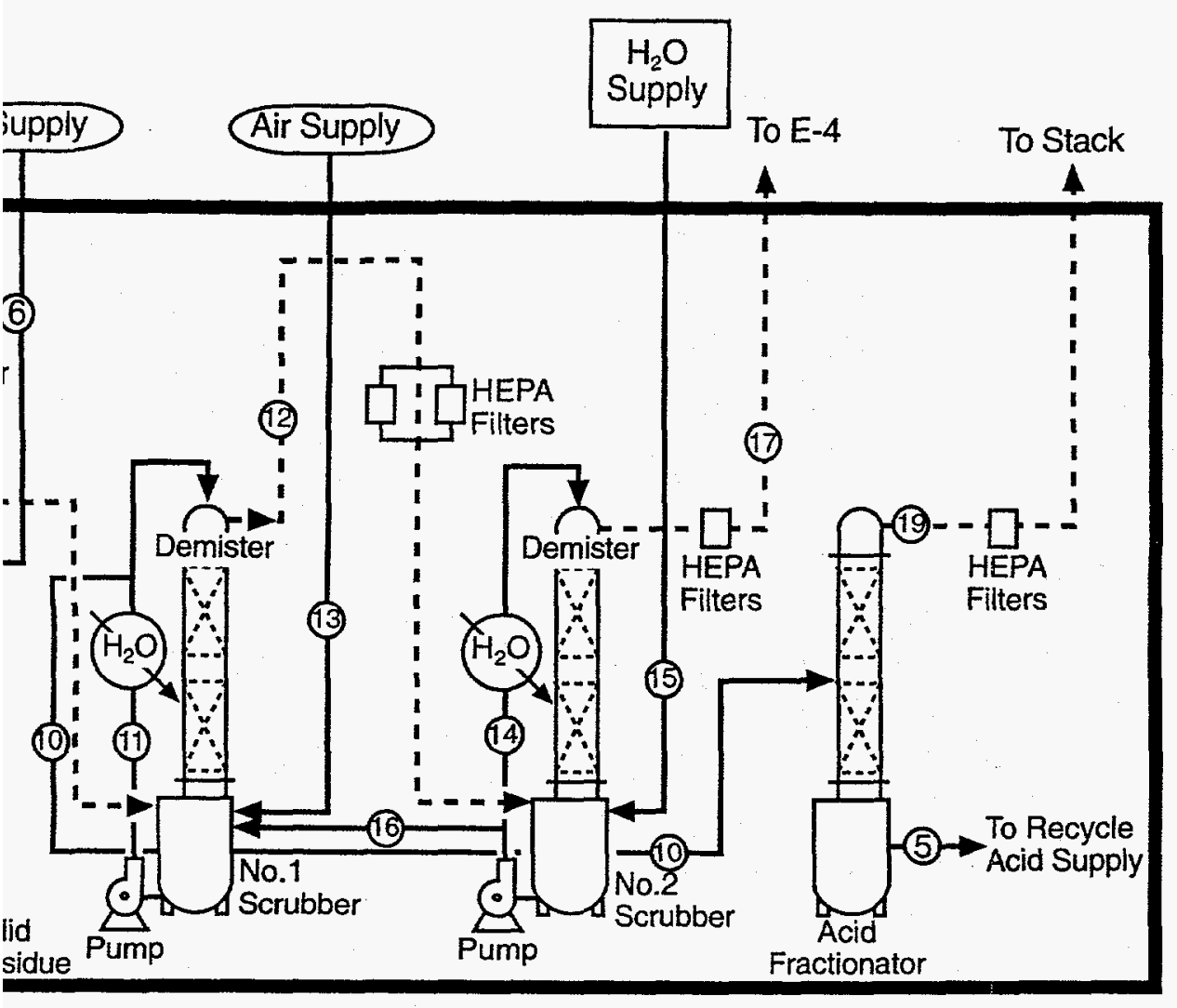

\section{d}

\begin{tabular}{|c|c|c|c|c|c|c|c|c|c|}
\hline 10 & 11 & 12 & 13 & 14 & 15 & 16 & 17 & 18 & 19 \\
\hline $\begin{array}{c}\text { No.1 Scrub. } \\
\text { Disch. }\end{array}$ & $\begin{array}{l}\text { No.1 Scrub. } \\
\text { Recirc. }\end{array}$ & $\begin{array}{c}\text { No.1 Scrub } \\
\text { Off-Gas }\end{array}$ & $\begin{array}{c}\text { Dilution } \\
\text { Air }\end{array}$ & $\begin{array}{c}\text { No. } 2 \text { Scrub } \\
\text { Recirc. }\end{array}$ & $\begin{array}{l}\text { No.2 Scrub } \\
\text { Water add. }\end{array}$ & $\begin{array}{c}\text { No.2 Scrub. } \\
\text { Disch. }\end{array}$ & $\begin{array}{c}\text { No.2 Scrub. } \\
\text { Off-Gas } \\
\end{array}$ & $\begin{array}{c}\text { Solid } \\
\text { Residue }\end{array}$ & $\begin{array}{l}\text { Fractionator } \\
\text { Off-Gas }\end{array}$ \\
\hline $\begin{array}{l}\mathrm{Kg} / \mathrm{d} \\
(\mathrm{d} d)\end{array}$ & L/min & $\mathrm{Kg} / \mathrm{d}$ & $\mathrm{Kg} / \mathrm{d}$ & $L / \min$ & $\mathrm{Kg} / \mathrm{d}$ & $\mathrm{Kg} / \mathrm{d}$ & $\mathrm{Kg} / \mathrm{d}$ & $\mathrm{Kg} / \mathrm{d}$ & $\mathrm{Kg} / \mathrm{d}$ \\
\hline $1,634 \quad(1,362)$ & 20 & 1,110 & 400 & 20 & 517 & 552 & 1,075 & 15 & 873 \\
\hline $20 \mathrm{psig}$ & $20 \mathrm{psig}$ & -9 in of $\mathrm{H}_{2} \mathrm{O}$ & 0 & $20 \mathrm{psig}$ & 0 & 20 psig & -20 in. of $\mathrm{H}_{2} \mathrm{O}$ & 0 & -15 in. of $\mathrm{H}_{2} \mathrm{O}$ \\
\hline 70 & 40 to 70 & 40 & 25 & 30 & 20 & 30 & 30 & 30 & $104^{\circ} \mathrm{C}$ \\
\hline $\mathrm{H}_{2} \mathrm{O}=69 \%$ & & & & & & & & & $\mathrm{NHO}_{3}=12.3 \%$ \\
\hline $\mathrm{H}_{2} \mathrm{SO}_{4}=18 \%$ & & $\mathrm{NO}=2.7 \%$ & $N_{2}=75 \%$ & & $\mathrm{H}_{2} \mathrm{O}=100 \%$ & $\mathrm{HNO}_{3}=6.7 \%$ & $\mathrm{CO}_{2}=17.3 \%$ & $\mathrm{CaSO}_{4}$ & $\mathrm{HCl}=0.2 \%$ \\
\hline $\mathrm{HNO}_{3}=12 \%$ & & $\mathrm{CO}_{2}=16.8 \%$ & $\mathrm{O}_{2}=23 \%$ & & & $\mathrm{H}_{2} \mathrm{O}=92.2 \%$ & $\mathrm{~N}_{2}=70.3 \%$ & $\mathrm{SiO}_{2}$ & $\mathrm{H}_{2} \mathrm{O}=87.5 \%$ \\
\hline $\mathrm{HCl}=0.1 \%$ & & $A r=1.1 \%$ & $A r=1 \%$ & & & $\mathrm{H}_{2} \mathrm{SO}_{4}=0.7 \%$ & $\mathrm{O}_{2}=8.3 \%$ & $\mathrm{ZnSO}_{4}$ & \\
\hline & & $\mathrm{O}_{2}=9.4 \%$ & & & & $\mathrm{HCl}=0.2 \%$ & $\mathrm{NO}=1.1 \%$ & $\mathrm{Fe}_{2}\left(\mathrm{SO}_{4}\right)_{3}$ & \\
\hline & & $\mathrm{HCl}=0.1 \%$ & & & & & $\mathrm{H}_{2} \mathrm{O}=1.7 \%$ & $\mathrm{~T}\left(\mathrm{SO}_{4}\right)_{2}$ & \\
\hline & & $\mathrm{H}_{2} \mathrm{O}=1.5 \%$ & & & & & $\mathrm{Ar}=1.1 \%$ & & \\
\hline & & $\mathrm{N}_{2}=68.1 \%$ & & & & & & & \\
\hline & & $\mathrm{SO}_{2}=0.3 \%$ & & & & & & & \\
\hline
\end{tabular}

tion Process Flow Diagram 
The inventory of combustible waste feed appropriate for treatment by the acid digestion process is given in Table 4.3.

\subsubsection{Effluents Generated}

The following effluents are based upon treating $258.2 \mathrm{~kg}$ of solid combustibles (Allen and Ely 1980): Solids Residue: $38.7 \mathrm{~kg} \mathrm{CaSO}_{4}, \mathrm{SiO}_{2}, \mathrm{ZnSO}_{4}, \mathrm{Fe}_{2}\left(\mathrm{SO}_{4}\right)_{3}, \mathrm{Ti}_{2}\left(\mathrm{SO}_{4}\right)_{3}$; Scrubber Off Gas: $2774 \mathrm{~kg} \mathrm{CO}=17.3 \%, \mathrm{~N}_{2}=70.3 \%, \mathrm{O}_{2}=8.3 \%, \mathrm{NO}=1.1 \%, \mathrm{H}_{2} \mathrm{O}=1.7 \%, \mathrm{Ar}=1.1 \%$; Acid Fractionator Off Gas: $2252 \mathrm{~kg} \mathrm{HNO}_{3}=12.3 \%, \mathrm{HCl}=0.2 \%, \mathrm{H}_{2} \mathrm{O}=87.5 \%$.

The hold up in the digester vessel is approximately $500 \mathrm{~L}$ assuming the 0.76 -m-diameter by $1.5-\mathrm{m}$-long digester is two-thirds full during operation. The concentration of plutonium in the digester is dependent on the concentration in the waste coming in and the frequency with which the residues are withdrawn from the digester. Assuming a $2.5-\mathrm{kg} / \mathrm{h}$ feed rate, $8 \mathrm{~h} / \mathrm{d}$, and assuming the residue is removed from the digester daily, approximately $2.4 \mathrm{~kg}(0.02 \mathrm{M})$ plutonium may be expected in the digester.

\subsubsection{Nuclear Criticality Safety}

RADTU was designed for nuclear criticality safety using a combination of restricted dimensions; fixed, unleachable neutron poisons; solid reflection barriers; and administrative controls (Cecille and Simon 1983).

The digestion vessel is considered to be the limiting component of the system, since this is where plutonium is mixed with moderator and where it can accumulate. Both WHC, using KENO Monte Carlo computer codes, and the Rockwell Hanford Company, using MONK5 Monte Carlo code, confirmed that the minimum critical mass for the digester was greater than $8 \mathrm{~kg}$ fissile.

Table 4.3. Feed Inventory for Acid Digestion Process

\begin{tabular}{|l|r|r|}
\hline \multicolumn{1}{|c|}{ Feed } & Net wt (kg) & Pu (kg) \\
\hline \hline Combustibles & 69.6 & NA \\
\hline Polycubes & 188.6 & NA \\
\hline Total & 258.2 & 30.7 \\
\hline NA = Not Available. \\
\hline
\end{tabular}




\subsubsection{Final Product Description}

The residue resulting from acid digestion of combustible waste materials primarily consists of sulfates and oxides of the inert "filler" materials in the wastes themselves. The residue accumulates in the digester acid and must be separated from the acid by filtering or by distilling the sulfuric acid. The resulting dried residue is similar in volume to that resulting from direct incineration of combustible wastes. Differential thermal analysis of the residue has shown it to be inert with no self-sustaining reactions occurring when the residue was heated to $800^{\circ} \mathrm{C}$ in the presence of air.

The process residue is dried in a heating pot at $400^{\circ} \mathrm{C}$. Based on Figure 4.3 and the plutonium inventory from the combustible feed, after treating the entire combustible feed stock the residue is expected to contain $47.9 \mathrm{~kg} \mathrm{Pu}\left(\mathrm{SO}_{4}\right)_{2}$ and $38.7 \mathrm{~kg}$ of the following: $\mathrm{CaSO}_{4}, \mathrm{SiO}_{2}, \mathrm{ZnSO}_{4}, \mathrm{Fe}_{2}\left(\mathrm{SO}_{4}\right)_{3}$, $\mathrm{Ti}_{2}\left(\mathrm{SO}_{4}\right)_{3}$. $\mathrm{Pu}\left(\mathrm{SO}_{4}\right)_{2}, \mathrm{CaSO}_{4}, \mathrm{SiO}_{2}$, and $\mathrm{Ti}_{2}\left(\mathrm{SO}_{4}\right)_{3}$ are stable salts and will not decompose if calcined. $\mathrm{ZnSO}_{4}$ and $\mathrm{Fe}_{2}\left(\mathrm{SO}_{4}\right)_{3}$ decompose to metal oxides at $600^{\circ} \mathrm{C}$ and $480^{\circ} \mathrm{C}$, respectively.

The process residue is then calcined in the muffle furnace to stabilize the $\mathrm{ZnSO}_{4}$ and $\mathrm{Fe}_{2}\left(\mathrm{SO}_{4}\right)_{3}$. Assuming equal weights of $\mathrm{CaSO}_{4}, \mathrm{SiO}_{2}, \mathrm{ZnSO}_{4}, \mathrm{Fe}_{2}\left(\mathrm{SO}_{4}\right)_{3}, \mathrm{Ti}\left(\mathrm{SO}_{4}\right)_{2}$ before calcination, the compositions found in Table 4.4 are expected in the calcined residue.

A total of $6.7 \mathrm{~kg}$ of $\mathrm{SO}_{2}$ and $1.7 \mathrm{~kg} \mathrm{O}_{2}$ are expected in the muffle furnace off gas.

\subsection{Solvent Extraction}

The process description, effluent stream disposition, and equipment required for the solvent extraction process are described in this section.

Table 4.4. Calcined Residue Compositions

\begin{tabular}{|l|c|}
\hline Composition & Weight (kg) \\
\hline \hline $\mathrm{Pu}\left(\mathrm{SO}_{4}\right)_{2}$ & 47.9 \\
\hline $\mathrm{CaSO}$ & \\
\hline $\mathrm{SiO}_{2}$ & 7.7 \\
\hline $\mathrm{ZnO}$ & 7.7 \\
\hline $\mathrm{Fe}_{2} \mathrm{O}_{3}$ & 3.9 \\
\hline $\mathrm{Ti}_{2}\left(\mathrm{SO}_{4}\right)_{3}$ & 3.1 \\
\hline Total & 7.7 \\
\hline
\end{tabular}




\subsubsection{Process Description}

A possible TRUEX process flowsheet ${ }^{(\mathrm{a})}$ is shown in Figure 4.4. A TRU-containing aqueous waste solution is fed to the extraction section, where the TRU components are extracted into the organic phase. The flowsheet is designed so that the raffinate that exits this section is a LLW stream. The loaded solvent is then scrubbed with a dilute nitric acid solution ( 0 to $0.50 \underline{\mathrm{M}})$. This dilution reduces the nitric acid concentration and some of the inert constituents in the organic phase that are extracted with the TRU elements, yet does not significantly lower the concentration of TRU elements in the loaded solvent. In the first strip section, americium and rare earth fission products are stripped by contacting the solvent with dilute nitric acid $(0.2$ to $0.05 \underline{\mathrm{M}})$. In the second strip section, the organic is contacted with ascorbic acid $(0.1 \underline{\mathrm{M}})$ and nitric acid $(0$ to $0.05 \underline{\mathrm{M}})$ to remove plutonium from the solvent. In a typical solvent cleanup section, the organic is contacted with a $0.25 \underline{\mathrm{M} \mathrm{Na}} \mathrm{CO}_{3}$ wash solution for removal of hydrolytic and radiolytic degradation products from the TRUEX process sol

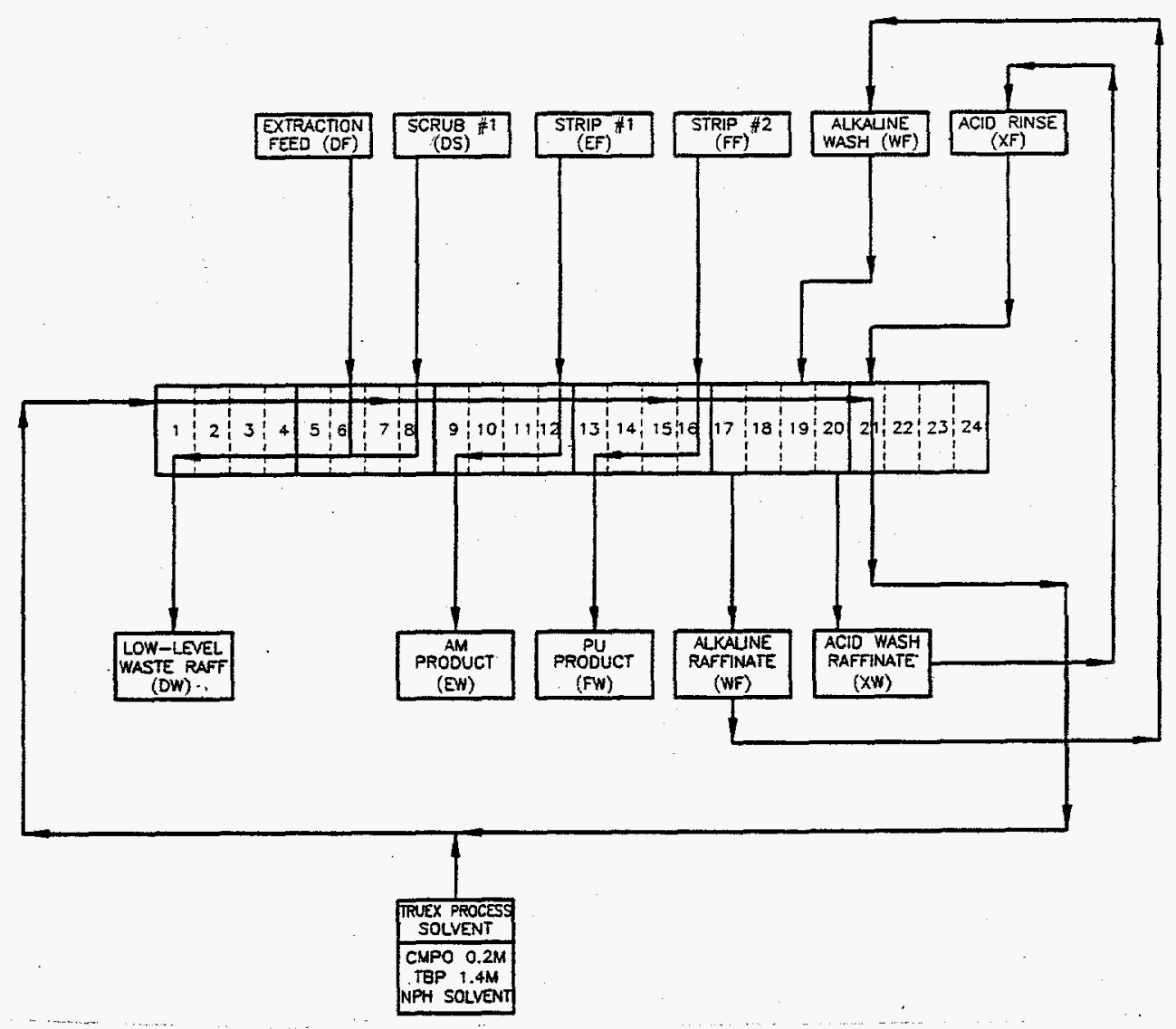

Figure 4.4. TRUEX Process Flow Diagram

(a) The TRUEX process is recommended to allow for partial recycle of the feed raffinate (LLW raffinate as shown in Figure 4.4) back to the CEPOD anolyte. If recycle of the CEPOD anolyte is not a priority, then the PUREX process is recommended. 
vent. Any uranium that is extracted into the solvent is also removed in this section of the process. The carbonate wash may be followed by a dilute acid rinse ( $\left.\sim 0.1 \underline{\mathrm{M}} \mathrm{HNO}_{3}\right)$ to remove any residual carbonate from the solvent. Following the acid rinse, the solvent can be recycled back to the extraction section.

Table 4.5 provides the nominal composition of the plutonium-bearing effluents from the CEPOD and silver persulfate processes, either one of which may provide feed to the solvent extraction process. The CEPOD plutonium-bearing effluent may be sent directly to the solvent extraction process without any feed adjustments. The silver persulfate plutonium-bearing effluent will require the addition of $4775 \mathrm{~L}$ of $15 \mathrm{M} \mathrm{HNO}_{3}$ (3850 L for process "A" and $925 \mathrm{~L}$ for process "B") to raise the concentration of $\mathrm{HNO}_{3}^{-}$to an acceptable level. Tables 4.6 and 4.7 which provide the nominal solvent extraction influent and effluent compositions and volumes, and are based on Table 4.5.

The primary benefit of running solvent extraction is the removal of metal salts, which will greatly reduce the level of impurities in the final product. Another benefit of solvent extraction treatment of the CEPOD effluent (anolyte) is that it may be recycled. The presence of $\mathrm{SO}_{4}{ }^{2-}$ in the silver persulfate effluent hinders the extraction of actinides because this anion tends to hold the actinides in the aqueous phase. However, based on D values (concentration in the organic phase/concentration in the aqueous phase) calculated by the Generic TRUEX Model, the separation is certainly possible.

Table 4.5. Solvent Extraction Feed from the CEPOD and Silver Persulfate Processes

\begin{tabular}{|c|c|c|c|c|}
\hline & \multicolumn{2}{|c|}{ CEPOD Effluent (M) } & \multicolumn{2}{|c|}{ Silver Persulfate Effluent (M) } \\
\hline & $\underline{\underline{\mathrm{A}}}$ & $\underline{\underline{B}}$ & $\underline{\underline{\underline{A}}}$ & $\underline{\underline{\mathrm{B}}}$ \\
\hline $\mathrm{Pu}$ & 0.17 & 0.08 & 0.08 & 0.04 \\
\hline $\mathrm{Ag}^{+}$ & 0.5 & 0.5 & 0.2 & 0.2 \\
\hline $\mathrm{NO}_{3}^{-}$ & 4.5 & 4.5 & 0.2 & 0.2 \\
\hline $\mathrm{H}^{+}$ & 4.0 & 4.0 & 1.0 & 1.0 \\
\hline $\mathrm{SO}_{4^{-}}^{-}$ & 0.0 & 0.0 & 1.0 & 1.0 \\
\hline $\mathrm{K}^{+}$ & 0.0 & 0.0 & 1.0 & 1.0 \\
\hline Vol (K L) & 22 & 5.3 & 50 & 12 \\
\hline
\end{tabular}


Table 4.6. Solvent Extraction Processing of CEPOD Plutonium-Bearing Effluent

\begin{tabular}{|c|c|c|c|}
\hline Influent & Nominal Composition & \multicolumn{2}{|c|}{ Volume (L) } \\
\hline & & $\underline{\mathrm{A}}$ & $\underline{B}$ \\
\hline \multirow[t]{4}{*}{ Feed } & $4 \mathrm{M} \mathrm{HNO}_{3}$ & $22,000^{(a)}$ & 5,300 \\
\hline & Pu: (A) $0.17 \underline{\mathrm{M}}$, (B) $0.08 \mathrm{M}$ & & \\
\hline & $0.5 \underline{\mathrm{M}} \mathrm{Ag}$ & & \\
\hline & $\mathrm{U}, \mathrm{Am}$, metal salts & & \\
\hline Scrub & $0.0-0.5 \mathrm{M} \mathrm{HNO}_{3}$ & 2,200 & 530 \\
\hline Strip 1 & $0.02-0.05 \mathrm{M} \mathrm{HNO}_{3}$ & 11,000 & 2,650 \\
\hline \multirow[t]{2}{*}{ Strip 2} & $0.0-0.05 \mathrm{M} \mathrm{HNO}_{3}$ & 5,500 & 1,330 \\
\hline & 0.1 M Ascorbic Acid & & \\
\hline Alkaline Wash & $0.25 \mathrm{M} \mathrm{NaCO}_{3}$ & 5,500 & 1,330 \\
\hline Acid Rinse & $0.05-0.1 \mathrm{M} \mathrm{HNO}_{3}$ & 5,500 & 1,330 \\
\hline \multirow[t]{2}{*}{ Effluent } & Nominal Composition & \multicolumn{2}{|c|}{ Volume (L) } \\
\hline & & $\underline{\mathrm{A}}$ & $\underline{\mathrm{B}}$ \\
\hline \multirow[t]{3}{*}{ LLW Raffinate } & $0.74 \mathrm{M} \mathrm{HNO}_{3}$ & 24,200 & 5,830 \\
\hline & $0.45 \mathrm{M} \mathrm{Ag}$ & & \\
\hline & $\sim 100 \%$ metal salts & & \\
\hline \multirow[t]{2}{*}{ Americium Product } & $0.14 \mathrm{M} \mathrm{HNO}_{3}$ & 11,000 & 2,650 \\
\hline & $>99.9 \% \mathrm{Am}$ & & \\
\hline \multirow[t]{4}{*}{ Plutonium Product } & $0.004 \mathrm{M} \mathrm{HNO}_{3}$ & 5,500 & 1,330 \\
\hline & $\mathrm{Pu}:$ (A) $0.68 \mathrm{M}$, (B) $0.32 \underline{\underline{\mathrm{M}}}$ & & \\
\hline & $<0.1 \% \mathrm{Am}$ & & \\
\hline & trace U & & \\
\hline \multirow[t]{2}{*}{ Alkaline Wash Raffinate } & $0.25 \mathrm{M} \mathrm{NaCO}_{3}$ & $5,500^{(2)}$ & $1,330^{(a)}$ \\
\hline & $-100 \% U$ & & \\
\hline Acid Rinse Raffinate & $0.05-0.1 \mathrm{M} \mathrm{HNO}_{3}$ & $5,500^{(a)}$ & $1,330^{(a)}$ \\
\hline \multirow[t]{3}{*}{ Spent Solvent } & $0.2 \mathrm{M} \mathrm{CMPO}^{1}$ & 20 & 20 \\
\hline & $1.4 \mathrm{M} \mathrm{TBP}{ }^{2}$ & & \\
\hline & $\mathrm{NPH}^{3}$ & & \\
\hline \multicolumn{4}{|c|}{$\begin{array}{l}\text { (a) Values will be less if streams are recycled. } \\
\text { A = From processing low-fired oxides. } \\
B=\text { From processing process residues. } \\
1 \text { = N-octyl(phenyl)-N, N-diisobutylcarbamoylmethylphosphine oxide. } \\
2 \text { = Tributylphosphate. } \\
3 \text { = Normal paraffinic hydrocarbon. }\end{array}$} \\
\hline
\end{tabular}


Table 4.7. Solvent Extraction Processing of Silver Persulfate Plutonium-Bearing Effluent

\begin{tabular}{|c|c|c|c|}
\hline Influent & Nominal Composition & \multicolumn{2}{|c|}{ Volume (L) } \\
\hline & & $\underline{A}$ & $\underline{\mathrm{B}}$ \\
\hline Feed Adjustment & $15 \mathrm{M} \mathrm{HNO}_{3}$ & 3,850 & 925 \\
\hline \multirow[t]{5}{*}{ Feed } & $2 \underline{\mathrm{M} \mathrm{HNO}_{3}}$ & 50,000 & 12,000 \\
\hline & Pu: (A) $0.04 \mathrm{M}$, (B) 0.02 & & \\
\hline & $0.2 \mathrm{M} \mathrm{Ag}$ & & \\
\hline & $1.0 \mathrm{M} \mathrm{SO}_{4}$ & & \\
\hline & $\mathrm{U}, \mathrm{Am}$, metal salts & & \\
\hline Scrub & $0.0-0.5 \mathrm{M} \mathrm{HNO}_{3}$ & 5,000 & 1200 \\
\hline Strip 1 & $0.02-0.05 \underline{\mathrm{M}} \mathrm{HNO}_{3}$ & 25,000 & 6,000 \\
\hline \multirow[t]{2}{*}{ Strip 2} & $0.0-0.05 \underline{\underline{\mathrm{M}} \mathrm{HNO}_{3}}$ & 12,500 & 3,000 \\
\hline & $0.1 \underline{\mathrm{M}}$ Ascorbic Acid & & \\
\hline Alkaline Wash & $0.25 \mathrm{M} \mathrm{NaCO}_{3}$ & 12,500 & 3,000 \\
\hline Acid Rinse & $0.05-0.1 \mathrm{M} \mathrm{HNO}_{3}$ & 12,500 & 3,000 \\
\hline Effluent & Nominal Composition & \multicolumn{2}{|c|}{ Volume $(\mathrm{L})$} \\
\hline \multirow[t]{4}{*}{ LLW Raffinate } & $0.74 \mathrm{M} \mathrm{HNO}_{3}$ & 55,000 & 13,200 \\
\hline & $0.18 \mathrm{M} \mathrm{Ag}$ & & \\
\hline & $0.91 \mathrm{M} \mathrm{SO}_{4}$ & & \\
\hline & $\sim 100 \%$ metal salts & & \\
\hline \multirow[t]{2}{*}{ Americium Product } & $0.14 \underline{\mathrm{M}} \mathrm{HNO}_{3}$ & 25,000 & 6,000 \\
\hline & $>99.9 \%$ Am & & \\
\hline \multirow[t]{4}{*}{ Plutonium Product } & $0.004 \underline{\mathrm{M} \mathrm{HNO}}_{3}$ & 12,500 & 3,000 \\
\hline & Pu: (A) $0.16 \underline{\mathrm{M}}$, (B) $0.08 \underline{\mathrm{M}}$ & & \\
\hline & $<0.1 \%$ Am & & \\
\hline & trace U & & \\
\hline \multirow[t]{2}{*}{ Alkaline Wash Raffinate } & $0.25 \underline{\mathrm{M} \mathrm{NaCO}}$ & 12,500 & 3,000 \\
\hline & $\sim 100 \% \mathrm{U}$ & & \\
\hline Acid Rinse Raffinate & $0.05-0.1 \mathrm{M} \mathrm{HNO}_{3}$ & 12,500 & 3,000 \\
\hline \multirow[t]{3}{*}{ Spent Solvent } & $0.2 \mathrm{M}$ CMPO & 50 & 50 \\
\hline & $1.4 \mathrm{M}$ TBP & & \\
\hline & NPH & & \\
\hline
\end{tabular}




\subsubsection{Effluent Final Disposition}

The plutonium product stream will require calcination to stabilize the plutonium as an oxide. The remaining aqueous streams from the solvent extraction process may be sent to the tank farms after neutralization. The solvent extraction effluents from the CEPOD process will require approximately $4400 \mathrm{~kg}$ of $\mathrm{NaOH}$ to raise the $\mathrm{pH}$ to 12 , while the solvent extraction effluents from the silver persulfate process will require approximately $5340 \mathrm{~kg}$ of $\mathrm{NaOH}$.

\subsubsection{Equipment}

Table 4.8 provides the estimated area and cost for the TRUEX processing equipment using centrifugal contactors based on Argonne National Laboratory's (ANL's) Generic TRUEX Model (GTM). The cost estimate includes equipment only. The components and equipment located in the hot and cold processing areas are identified in Figure 4.5. Components and equipment in the cold processing area are accessible so that installation and maintenance work can be performed directly. Components and equipment within the hot processing area are located in a glovebox.

The flow rates listed are based upon the 18,000 hours processing time and the CEPOD and silver persulfate effluent volumes. The contractor diameters listed are of sufficient size to process the rates as given.

Table 4.8. Estimated Cost and Area of TRUEX Process Plant

\begin{tabular}{||l|c|c|}
\hline & SX of CEPOD Effluent & SX of Ag Persulfate Effluent \\
\hline \hline Contactor Area & $31.1 \mathrm{ft}^{2}$ & $35.3 \mathrm{ft}^{2}$ \\
\hline Total Hot Area & $176.9 \mathrm{ft}^{2}$ & $223.4 \mathrm{ft}^{2}$ \\
\hline Total Cold Area & $125.1 \mathrm{ft}^{2}$ & $217.6 \mathrm{ft}^{2}$ \\
\hline Total Processing Area & $302.0 \mathrm{ft}^{2}$ & $441.0 \mathrm{ft}^{2}$ \\
\hline & Cost of CEPOD SX (M \$) & Cost of Ag Persulfate SX (M \$) \\
\hline \hline Contactor & 0.98 & 1.10 \\
\hline Balance of Equipment & 1.41 & 1.70 \\
\hline Plant Total & 2.39 & 2.80 \\
\hline Contactor Diameter & $3.0 \mathrm{~cm}$ & $4.0 \mathrm{~cm}$ \\
\hline Contactor Hold Up & $1.0 \mathrm{~L}$ & $2.4 \mathrm{~L}$ \\
\hline Feed Flow Rate & $1.5 \mathrm{~L} / \mathrm{h}$ & $7.36 \mathrm{~L} / \mathrm{h}$ \\
\hline
\end{tabular}




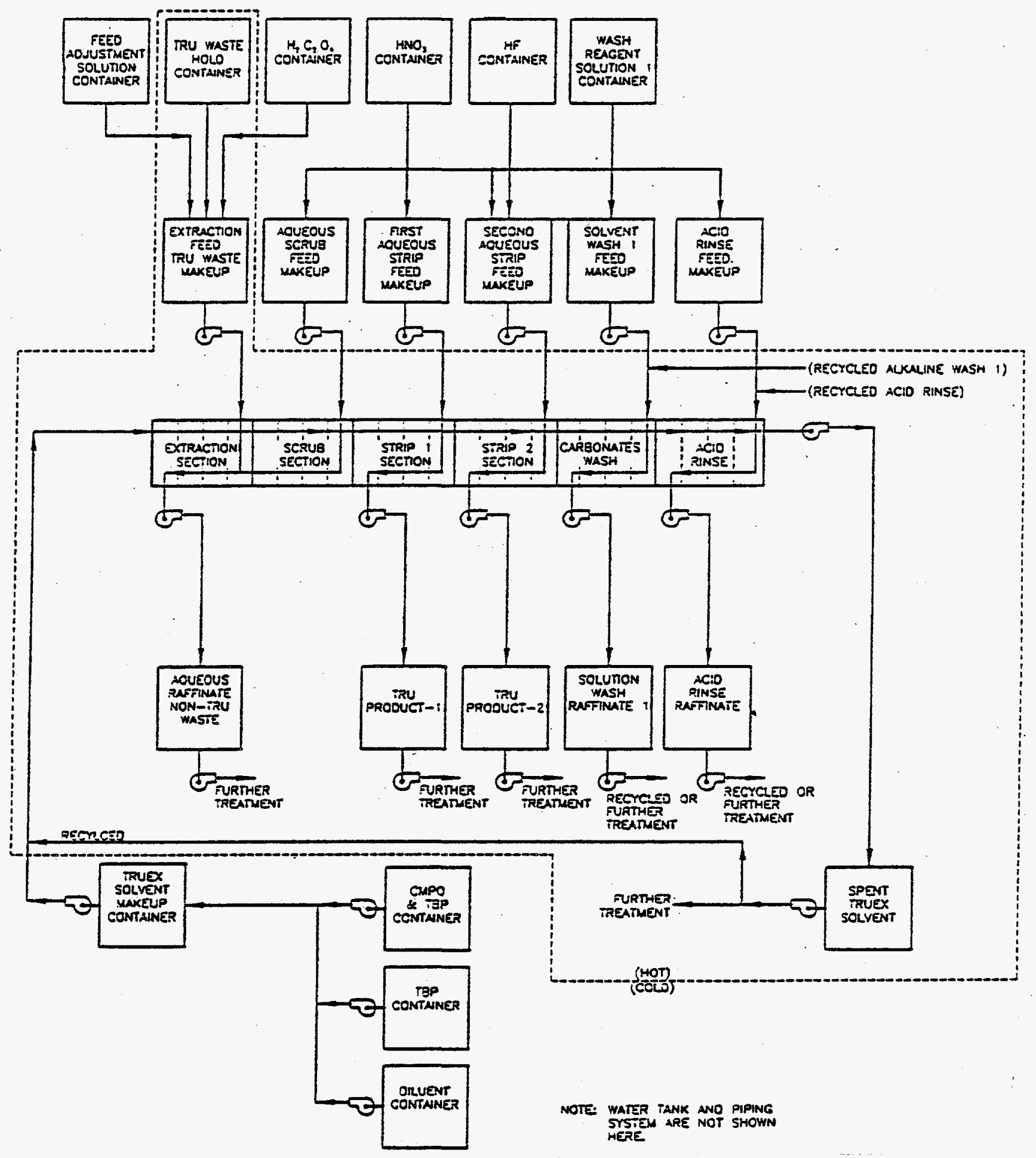

Figure 4.5. Schematic of TRUEX Processing Plant 
Table 4.9 provides tank sizes required for an 8-hour run. The CEPOD processing column provides tanks sizes based upon a feed flow rate of $1.5 \mathrm{~L} / \mathrm{h}$, while the silver persulfate column is based upon a feed flow rate of $3.4 \mathrm{~L} / \mathrm{h}$. Tanks that may contain radiochemicals have a critically safe diameter of 6 in. Cold chemical tanks have no restriction on their dimensions.

\subsection{Oxalate Acid Precipitation Using the Remote Mechanical "C" Line}

Flow diagrams were developed to provide a conceptual analysis for stabilizing plutonium nitrate solutions using the existing unit operations located in the Remote Mechanical "C" (RMC) line. The

Table 4.9. Tanks Sizes Required for an 8-Hour Run

\begin{tabular}{|c|c|c|}
\hline Waste Stream & $\begin{array}{c}\text { CEPOD Processing } \\
\text { Size (L) }\end{array}$ & $\begin{array}{c}\text { Ag Persulfate } \\
\text { Processing Size (L) }\end{array}$ \\
\hline \multicolumn{3}{|l|}{ Influents } \\
\hline TRU Waste Container & 13 & 30 \\
\hline Extraction Feed & 15 & 35 \\
\hline Scrub & 2 & 5 \\
\hline Strip 1 & 8 & 18 \\
\hline Strip 2 & 4 & 9 \\
\hline Solvent Wash 1 & 4 & 9 \\
\hline Acid Rinse & 4 & 9 \\
\hline Feed Adjustment & 3 & 7 \\
\hline $\begin{array}{l}\text { Solvent Makeup } \\
\text { Container }\end{array}$ & 1 & 2 \\
\hline \multicolumn{3}{|l|}{ Effluents } \\
\hline Non-TRU Raffinate & 18 & 40 \\
\hline TRU Product-1 & 8 & 18 \\
\hline TRU Product-2 & 4 & 9 \\
\hline Wash Raffinate & 4 & 9 \\
\hline Acid Raffinate & 4 & 9 \\
\hline TRUEX Solvent & 5 & 11 \\
\hline
\end{tabular}


oxalate precipitation technology could process only the following nitrate solutions: F00, F01, F40, F50, F70, and F80 for a total net mass of $3498 \mathrm{~kg}$ and a total plutonium mass of $257 \mathrm{~kg}$. The development of the flow diagrams are based on information provided in Appendix A, Oxalate Precipitation, and the PFP training manual.

The former fluorination unit, which is still installed in the RMC line, is not considered in this engineering analysis. The original purpose of this fluorination unit was for the production of plutonium metal. The present analysis is only concerned with the stabilization of the plutonium nitrate solutions to a plutonium oxide. For this analysis, the primary unit operations include the following:

- precipitation - addition of peroxide to adjust the plutonium valence oxidation state, and the addition of oxalic acid to obtain a plutonium oxalate using the existing reaction vessels

- filtering - separation of the crystalline plutonium oxalate from the aqueous solution using the existing drum filter

- calcination - heating of the precipitate to decompose the plutonium oxalate.

\subsubsection{Process Description}

The present analysis assumed that oxalate precipitation would be completed using the existing facilities located in the RMC facility. A floor diagram for the RMC line is provided in Figure 4.6.

The operations are conducted in five "wet" gloveboxes where plutonium solutions are present (HC-4, HC-7, HC-9B, HC-17P, and HA-46), and in 4 "dry" gloveboxes where plutonium oxide powders are present (HC-1, HC-2, HC-10, and HC-11).

Hood HC-227T and Glovebox HC-227S are part of the plutonium solution load-in/load-out facility for the PFP in room 227. This facility provides the plutonium to be sent to the RMC line. Table 4.10 shows the dimensions and functions of the gloveboxes considered in this engineering analysis.

Glovebox HC-17 contains a 16.5-L glass pre-reduction tank (PRT) that receives the solution from HC-4. Lines of nitric acid and hydrogen peroxide lead to the PRT to adjust the acidity, valence, and plutonium valence and concentration. Another 16.5-L tank, referred to as the "transfer head tank, " is located below the PRT. This tank receives solution from the PRT by gravity feed, then continuously pumps the solution to a 3.9-L reaction vessel in Glovebox HC-9B.

Glovebox HC-9B contains the following equipment starting from the top of the glovebox down (gravity feed): reactor tank, vacuum drum filter, calciner, recycle feeder, banjo valve (deactivated), fluorinator (deactivated) condensate receiver tank, vacuum receiver tank, overflow tank, and two pumps. 


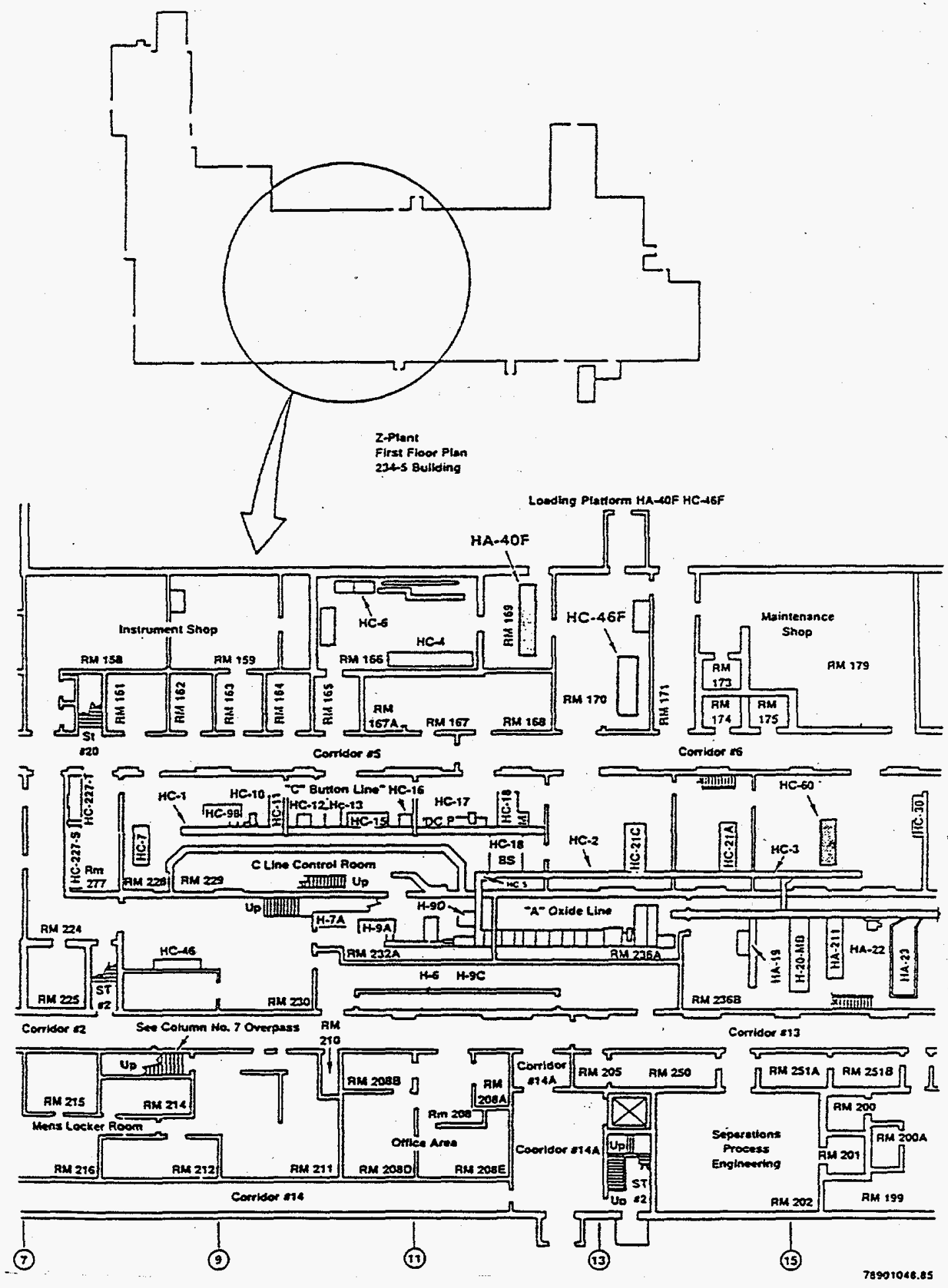

Figure 4.6. RMC Line Floor Diagram 
Table 4.10. Glovebox Dimensions and Functions

\begin{tabular}{|c|c|c|c|c|}
\hline Glovebox & Width (cm) & Depth (cm) & Height (cm) & Function \\
\hline $\mathrm{HC}-4$ & 475 & 58 & 194 & Solution staging \\
\hline HC-6 & 179 & 76 & 159 & Solution way station \\
\hline $\mathrm{HC}-7$ & 244 & 122 & 305 & Solution treatment \\
\hline $\begin{array}{l}\text { HC-9B } \\
\text { Upper } \\
\text { Middle } \\
\text { Lower } \\
\text { Total } \\
\end{array}$ & $\begin{array}{l}229 \\
\text { Same } \\
\text { Same } \\
\text { Same }\end{array}$ & $\begin{array}{l}86 \\
\text { Same } \\
\text { Same } \\
\text { Same }\end{array}$ & $\begin{array}{l}114 \\
129 \\
132 \\
376\end{array}$ & $\begin{array}{l}\text { Oxalate precipitation, } \\
\text { vacuum filtration, } \\
\text { calcination and deacti- } \\
\text { vated fluorination }\end{array}$ \\
\hline $\mathrm{HC}-1$ & 2393 & 41 & 86 & Conveyor \\
\hline $\mathrm{HC}-2$ & 1372 & 41 & 86 & Conveyor \\
\hline $\mathrm{HC}-10$ & 70 & 48 & 68 & Weighing \\
\hline $\mathrm{HC}-11$ & 215 & 70 & 68 & Powder pan storage \\
\hline
\end{tabular}

The reactor tank is a 3.9-L, stainless steel tank with an agitator and an overflow pipe leading to the vacuum drum filter pan. Oxalic acid from the chemical makeup room is added to the reactor tank along with the plutonium nitrate solution in Glovebox HC-7 to precipitate plutonium oxalate. The estimated flowrate of the plutonium nitrate solution feed from Glovebox HC-7 is $10 \mathrm{~L} / \mathrm{h}$. Oxalic acid $(0.94 \mathrm{M})$ has an estimated feed rate of $5 \mathrm{~L} / \mathrm{h}$ into the reactor. Slurry overflows into a slurry path of the drum filter mechanism. This mechanism consists of a receiver pan with a rotating drum filter dipping into the slurry pan by vacuum onto the filter. The filtrate is pumped out to the vacuum receiver tank. Solids are scraped off the drum filter by a doctor blade and fall into the calciner at an estimated rate of $15 \mathrm{~L} / \mathrm{h}$. The filtrate solution has an estimated plutonium concentration of $0.5 \mathrm{~g} / \mathrm{L}$ and would have to be reworked to remove the remaining plutonium, most likely using hydroxide precipitation (see Section 4.6). Figure 4.7 illustrates the precipitation process.

The screw calciner is a 206-cm-long stainless steel trough with a 10-cm-diameter, stainless steel conveyor screw running down the center. The calciner has three 3500-watt electric resistance heaters strapped to the outside of the trough. The oxygen in the atmosphere combines with the plutonium oxalic to form a plutonium oxide at a flow rate of $2500 \mathrm{~g} / \mathrm{h}$. The fluorinator located below the calciner has been deactivated. The plutonium oxide would be passed through this fluorinator to allow the plutonium oxide to be canned into food cans. To ensure complete calcination, the fluorinator may be activated to serve as a second stage calcination unit. 


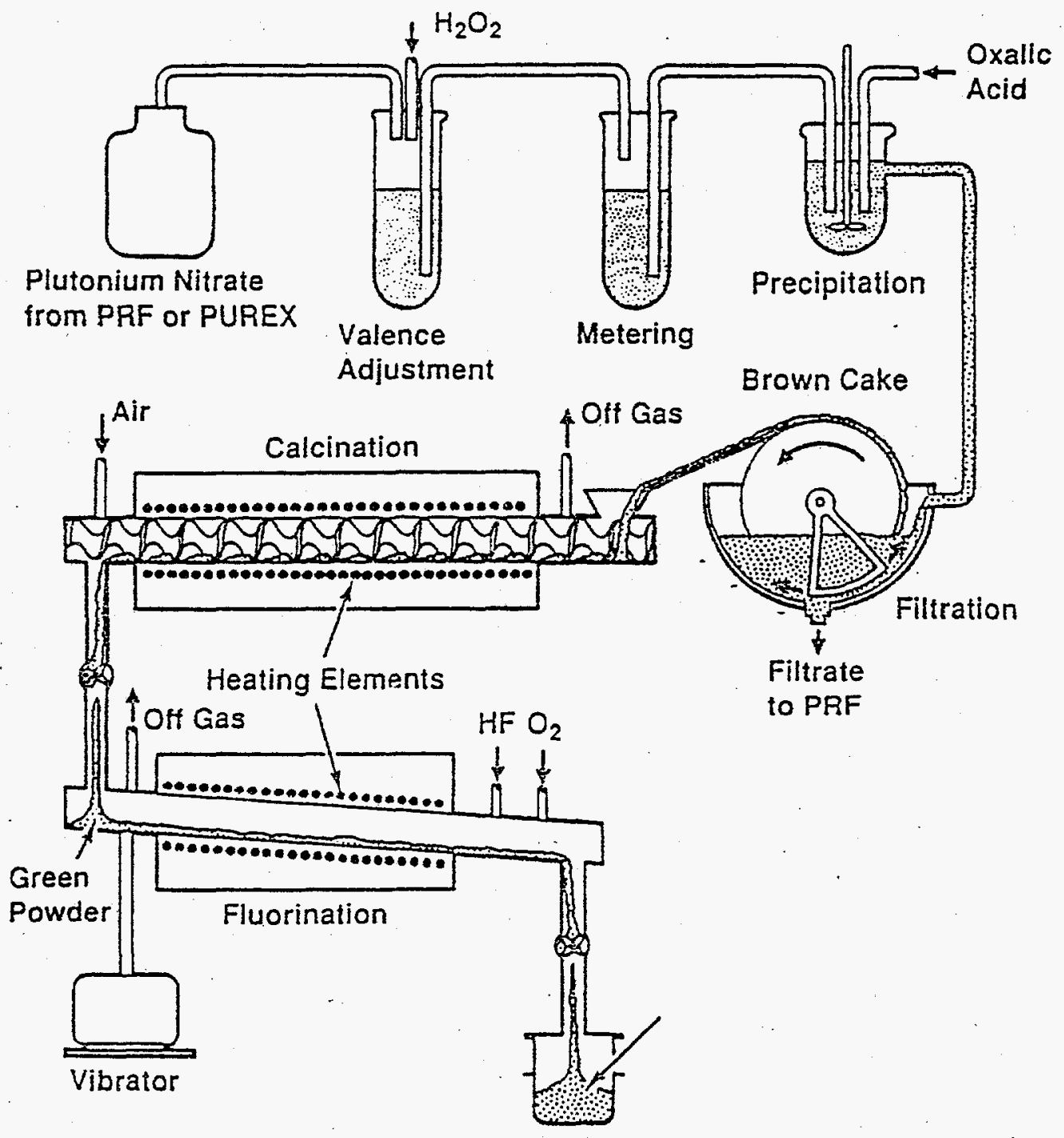

Figure 4.7. Oxalate Acid Precipitation Using the RMC Line

\subsubsection{Flow Diagram}

The development of the material flow diagram using oxalate precipitation is based on the inventory listed in Section 4.5 and equipment capacities. The operation time assumes that the process operates $24 \mathrm{~h} / \mathrm{d}, 5 \mathrm{~d} / \mathrm{wk}, 52 \mathrm{wk} / \mathrm{yr}$ at an efficiency of $60 \%$. The material flow diagram (Figure 4.8 ) developed highlights the primary influents and effluents.

The estimated volume to be processed is $2700 \mathrm{~L}$ with an estimated specific gravity of 1.3 . The time required to process this volume is estimated to be 300 hours. This time estimate was based on a system that is operating on a continuous basis. In reality, the time required to process the inventory may be much higher because of the following: 


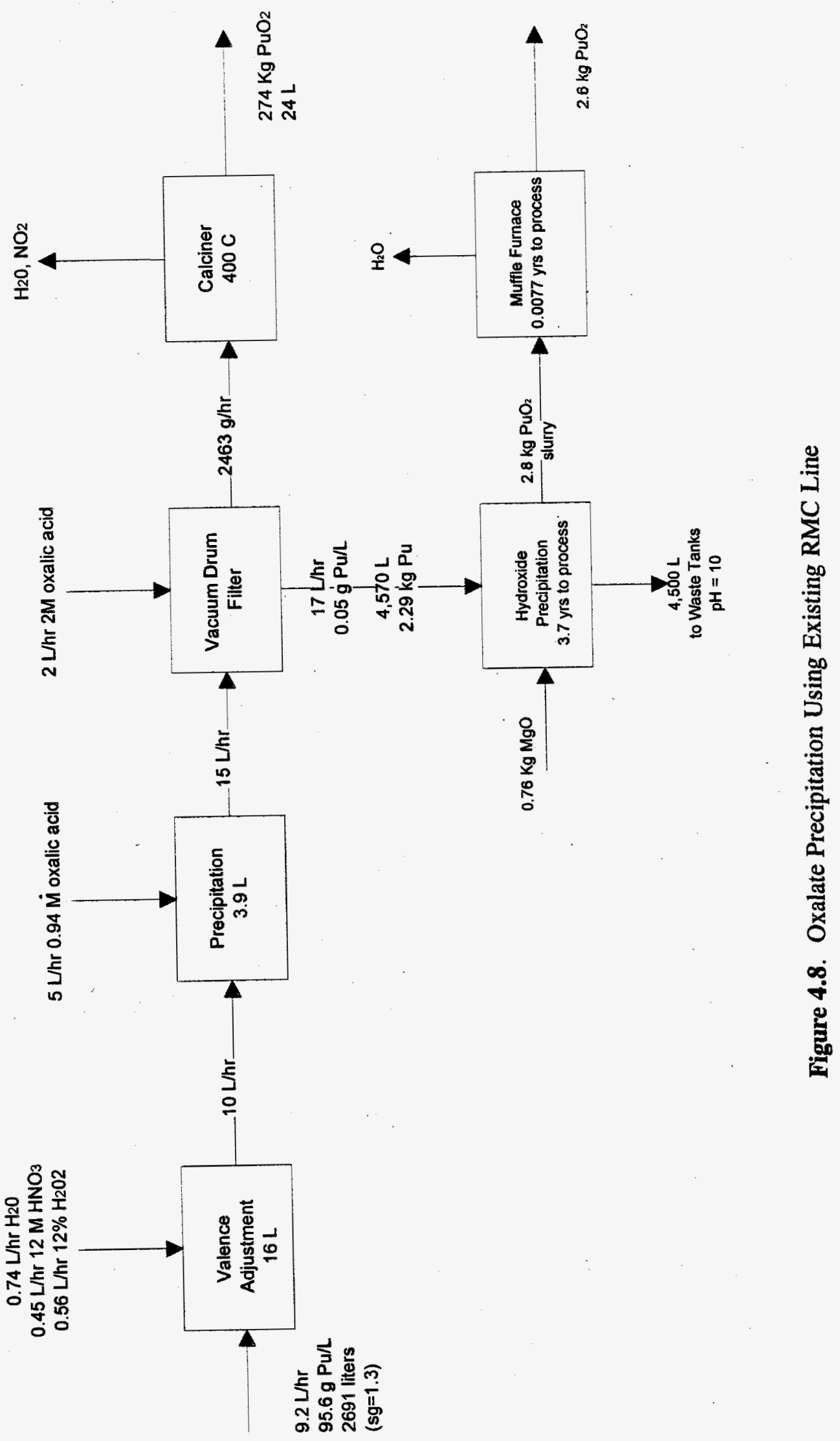


1. The system requires a start-up time to fill up the reactors and adjust the reagent feeds to achieve a steady state system.

2. The original system was designed to accept a purified plutonium nitrate solution. The solutions considered in the inventory (see Section 4.5) contain impurities such as uranium that may interfere with the calcination of the precipitate. In addition, the feed concentration varies with the solution type.

Assuming that the oxalate precipitation is already at steady state, and that the impurities and concentration variation do not interfere with processing, approximately $270 \mathrm{~kg}$ of plutonium oxide powder is produced. The primary effluent produced is the filtrate from the vacuum drum filter. Approximately $4600 \mathrm{~L}$ of an aqueous solution with a plutonium concentration of $0.5 \mathrm{~g} / \mathrm{L}$.

The filtrate stream would be processed using hydroxide precipitation to obtain a plutonium oxide precipitate and then thermally stabilized using the muffle furnace as described in Section 4.6. The operation time for the precipitation step assumes that the process operates $24 \mathrm{~h} / \mathrm{d}, 5 \mathrm{~d} / \mathrm{wk}, 52 \mathrm{wk} / \mathrm{yr}$ at an efficiency of $60 \%$. The operation time for the muffle furnace assumes that 2 batches/d can be processed at $500 \mathrm{~g} / \mathrm{batch}$. Based on the filtrate volume from the vacuum drum filter, $0.76 \mathrm{~kg} \mathrm{MgO}$ would be required to stoichiometrically precipitate the plutonium from the filtrate. The time required for the precipitation step is estimated to be 3.7 years. The estimated volume of liquid to be sent to the waste tanks is $4500 \mathrm{~L}$ at a pH of 10 . The remaining precipitate is assumed to consist of $50 \%$ liquid and $50 \%$ plutonium hydroxide by volume. The estimated precipitate mass is $2.8 \mathrm{~kg}$.

Based on the process rate of the muffle furnace, it is estimated that 0.0077 years would be required to stabilize the plutonium to an oxide form. The estimated mass of the dry plutonium is $2.6 \mathrm{~kg}$.

\subsubsection{Cost Estimates}

No cost estimates were made for this process.

\subsection{Hydroxide Precipitation}

The inventory that hydroxide precipitation could process includes nitrate solutions and chloride solution. Specific category items are listed in Table 4.11. The development of the flow diagram is based on information provided in Appendix A, Hydroxide Precipitation, and the PFP operator training manual.

For this engineering analysis, the primary unit operations that were evaluated consisted of the following: 
Table 4.11. Proposed Inventory to be Stabilized by Hydroxide Precipitation

\begin{tabular}{|l|l|c|c|}
\hline \multicolumn{1}{|c|}{ Title } & \multicolumn{1}{|c|}{ Category } & \multicolumn{1}{|c|}{$\begin{array}{c}\text { Total Net Mass } \\
\text { (kg) }\end{array}$} & $\begin{array}{c}\text { Total Pu Mass } \\
\text { (kg) }\end{array}$ \\
\hline \hline Nitrate Solutions & F00, F01, F40, F50, F70, F80 & 3500 & 260 \\
\hline Chloride Solutions & F02 & 220 & 35 \\
\hline
\end{tabular}

- precipitation - the addition of a hydroxide reagent (magnesium oxide for this analysis) to obtain a metal hydroxide ${ }^{(a)(b)(c)}$

- liquid/solid separation - separation of the plutonium-hydroxide precipitate from aqueous solution

- thermal treatment - thermal treatment of the precipitate to evaporate the remaining liquids and reduce the plutonium hydroxide to an oxide form using a muffle furnace identified in

Section 4.9 .

\subsubsection{Process Description}

Hydroxide precipitation would be performed using the existing facilities located in the PRF, specifically the miscellaneous treatment gloveboxes located on the fourth floor. A cutaway of the PRF and a floor diagram of Glovebox MT-5 are provided in Figures 4.9 and 4.10, respectively.

There are currently a number of reagents that could be used for hydroxide precipitation, such as sodium hydroxide or ferrous hydroxide. A more detailed description of hydroxide precipitation is provided in Appendix A. The flow diagrams presented to the independent review team used magnesium oxide as the reagent to precipitate plutonium hydroxide. Magnesium oxide is a dry powder with a specific gravity of 3.65. Magnesium oxide reacts to form a magnesium hydroxide as an intermediate species. The magnesium then reacts with plutonium nitrate or plutonium chloride to form plutonium hydroxide. Precipitation occurs at a $\mathrm{pH}$ of 10 . The precipitate formed consists of a granular material that is easier to filter than other precipitates using other reagents. One drawback to using magnesium is that magnesium may be activated in the presence of americium; in addition, it is slower than other reagents. Table 4.12 summarizes the results obtained using magnesium oxide as a reagent to precipitate plutonium hydroxide.

(a) PFP operator training manual.

(b) WHC internal memo, "Process Proposal to Stabilize Plutonium-Bearing, Nitrate-Based Materials and Residue."

(c) Personal communication: Antonia Villegas, PNL, with Michael Palmer, LANL, July 12, 1994. 


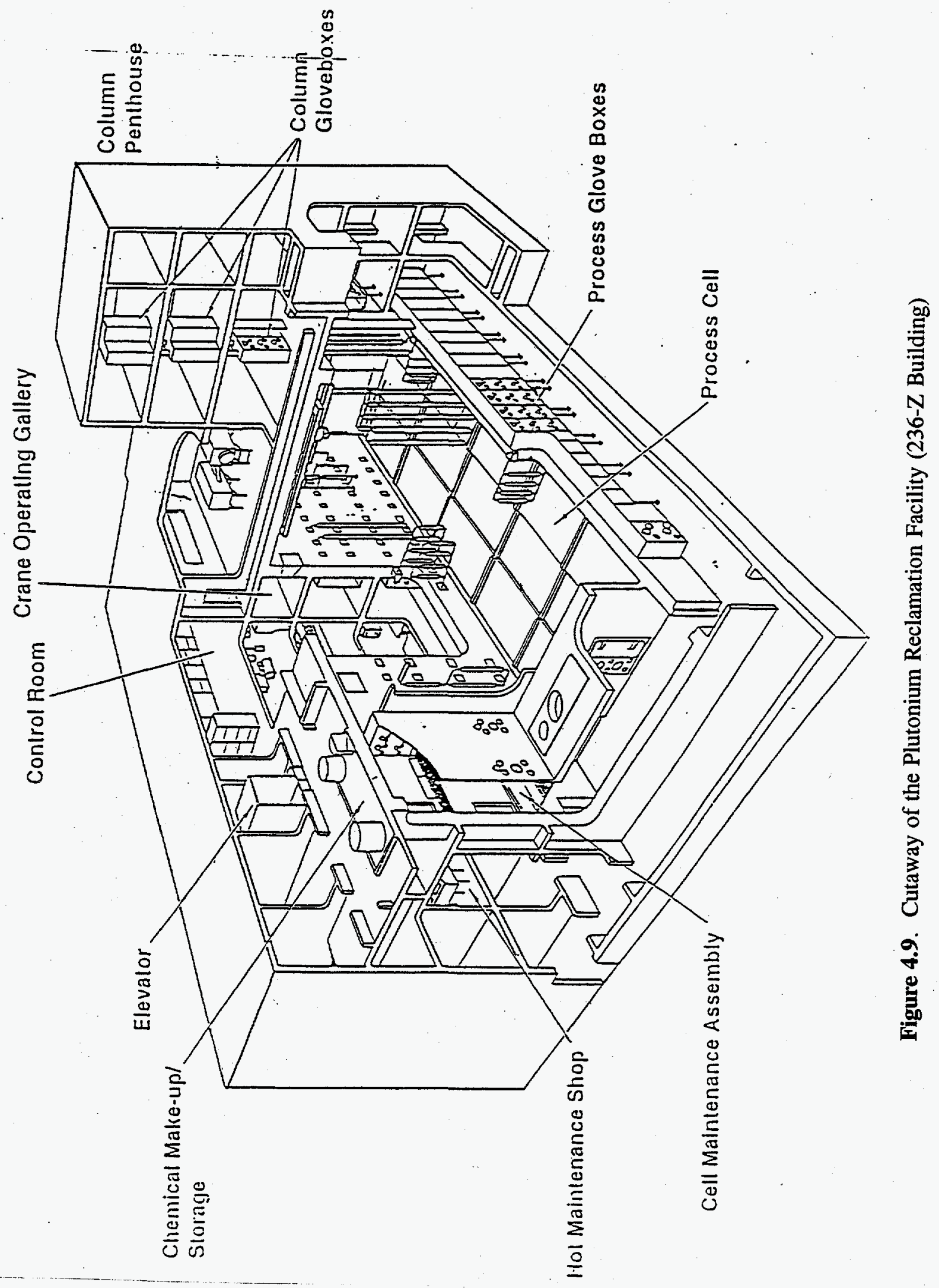




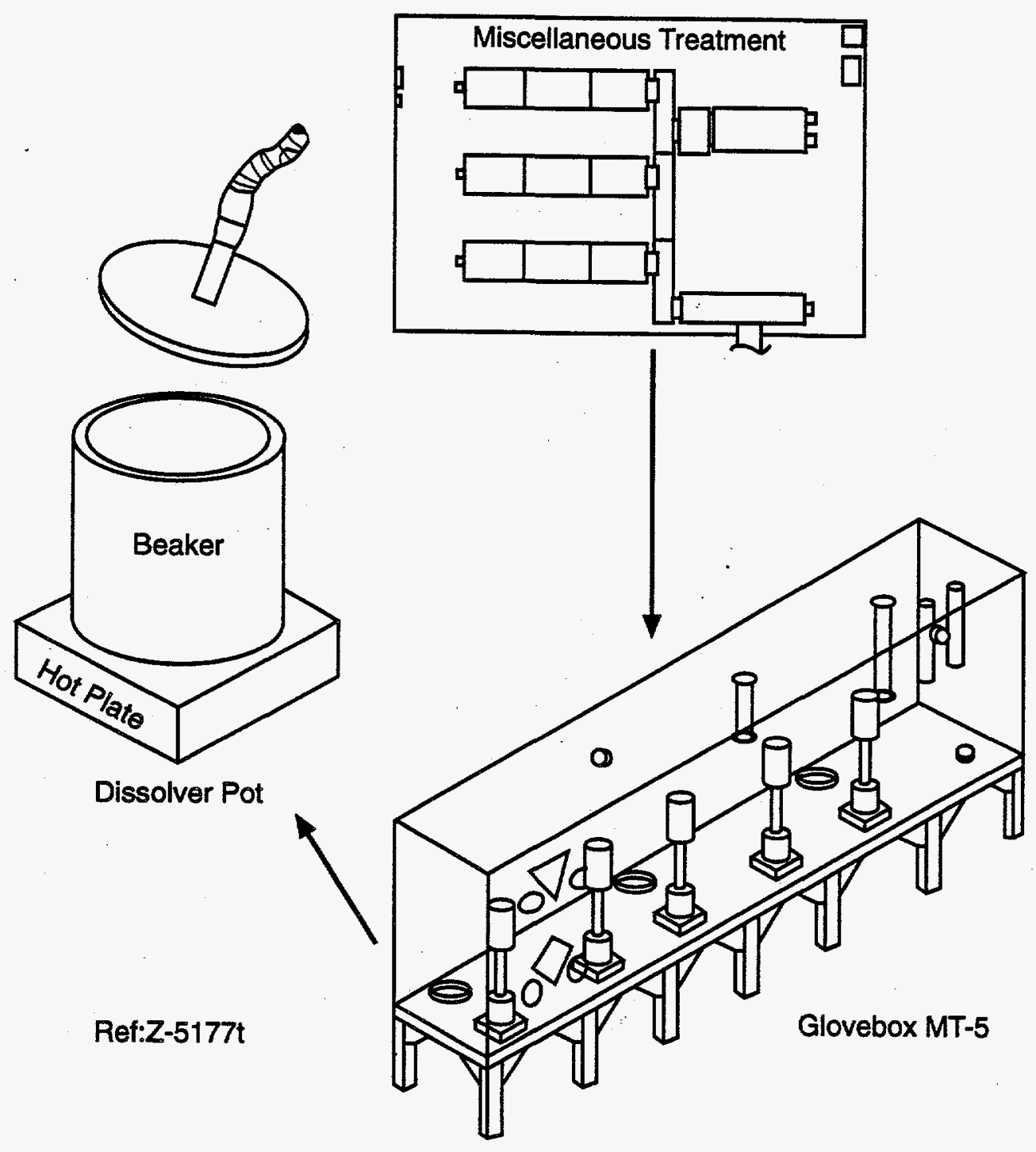

$\$ 9410070.5$

Figure 4.10. Floor Diagram of MT-5 Glovebox 
Table 4.12. Summary for Magnesium Precipitation

\begin{tabular}{||l|c|c|c|c|c||}
\hline \multirow{2}{*}{\multicolumn{1}{|c|}{ Title }} & \multicolumn{2}{|c|}{ Influent Items } & \multicolumn{3}{c|}{ Effluent Items } \\
\cline { 2 - 6 } & $\begin{array}{c}\text { Net Weight } \\
(\mathbf{k g})\end{array}$ & $\begin{array}{c}\text { Average } \\
\text { Total Pu } \\
\text { Weight (kg) }\end{array}$ & $\begin{array}{c}\text { Liquid } \\
\text { Waste } \\
\text { Volume (L) }\end{array}$ & $\begin{array}{c}\text { Wet Precipitate } \\
\text { Weight (PuO }+\mathbf{H}_{2} \text { 0) } \\
(\mathbf{k g})\end{array}$ & $\begin{array}{c}\text { Volume } \\
\text { Stabilized Dry } \\
\text { PuO }^{2} \text { (L) }\end{array}$ \\
\hline $\begin{array}{l}\text { Nitrate Solutions (F00, } \\
\text { F01, F40, F50, F70, F80) }\end{array}$ & 3500 & 260 & 2300 & 320 & 290 \\
\hline HCl Solutions (F02) & 220 & 35 & 160 & 42 & 40 \\
\hline \hline Totals & 3700 & 290 & 2400 & 360 & 330 \\
\hline
\end{tabular}

The existing digestion vessels located in Glovebox MT-5 would be used to precipitate the plutonium hydroxide. These digestion vessels are of a critically safe design. Glovebox MT-5 has a system that siphons liquids to the waste tanks, assuming that the liquids meet the waste acceptance criteria. The waste acceptance criteria for liquids must have a plutonium concentration of less than $0.13 \mathrm{~g} / \mathrm{L}$, and a pH of less than 12. For this analysis, it is assumed that the liquids meet the waste acceptance criteria.

There are several methods that might be used to separate the solids and liquids. Settling should be used to separate the primary liquid from the solids. The liquids would be siphoned directly to the waste tanks. An inline filter, consisting of a filter paper, would be installed in the siphoning system to entrain any solids.

The liquid remaining -in the solids would be removed by drying or evaporation using the muffle furnace. A description of the muffle furnace is provided in Section 4.10. For this engineering analysis, it is assumed that the precipitate is processed through the muffle furnace to obtain a stable plutonium oxide. The solids and paper from the in-line filter also would be processed using the muffle furnace.

\subsubsection{Flow Diagram}

The development of the material flow using hydroxide precipitation is based on the inventory listed in Table 4.11. The operation time assumes that the process operates $24 \mathrm{~h} / \mathrm{d}, 5 \mathrm{~d} / \mathrm{wk}, 52 \mathrm{wk} / \mathrm{yr}$ at an efficiency of $60 \%$. A material flow diagram was developed that highlights the primary effluents from this process in Figure 4.11.

For this analysis, it is assumed that the solutions can be precipitated at a rate of $1 \mathrm{~L} / 3 \mathrm{~h}$. This includes the siphoning of liquids to the waste tanks, and removal of the filter paper. The muffle furnace assumes a process rate of $500 \mathrm{~g} / \mathrm{batch}, 2$ batches $/ \mathrm{d}$. 


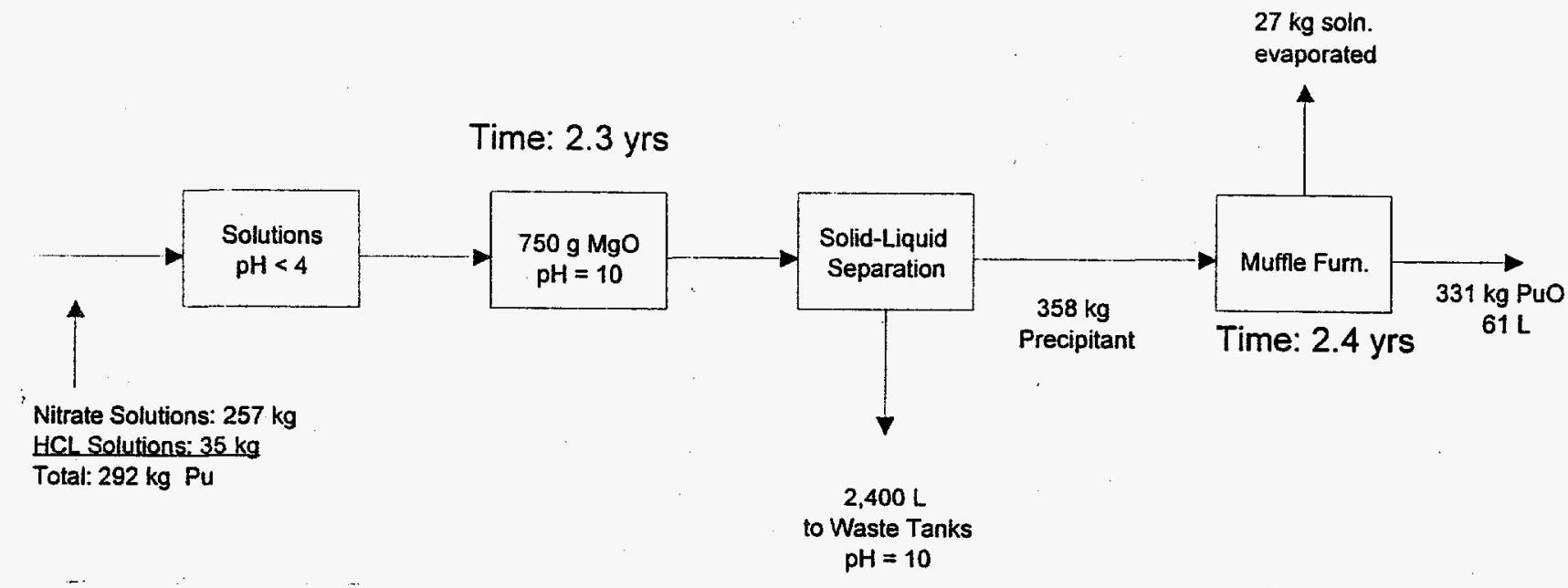

Figure 4.11. Proposed Hydroxide Precipitation With MgO

It is not possible to estimate the amount of reagent required to ensure complete reaction because the plutonium concentration of the chloride and nitrate solutions is not known; therefore, the quantity of magnesium oxide required was based on the stoichiometric amount required to react with the plutonium listed in the inventory. Based on the inventory, $750 \mathrm{~kg}$ of magnesium oxide would be required to stoichiometrically precipitate the plutonium from the solutions. The time required for the precipitation step is estimated to be a total of 2.3 years. The estimated volume of liquid to be sent to the waste tanks is $2400 \mathrm{~L}$ at a pH of 10 . The remaining precipitate is assumed to consist of $50 \%$ liquid and $50 \%$ plutonium hydroxide by volume. The estimated precipitate mass is $331 \mathrm{~kg}$.

Based on the process rate of the muffle furnace, it is estimated that 2.4 years is required to stabilize the plutonium to an oxide form. Approximately $27 \mathrm{~kg}$ of solution is evaporated, the remaining material consists of $311 \mathrm{~kg}$ plutonium oxide with a volume of $61 \mathrm{~L}$.

\subsubsection{Cost Estimates}

The estimated cost for direct labor assumes a labor rate of $\$ 75 / \mathrm{h}$. Four individuals are required to operate this system, two for the precipitation step and two to operate the muffle furnace. Based on the total time required, it is estimated that $\$ 4.4$ million is required in direct labor cost to operate this system. 


\subsection{Plutonium Reclamation Facility}

Flow diagrams were developed to provide a conceptual analysis for stabilizing plutonium using existing and additional unit operations in the PRF. ${ }^{(a)}$ The inventory that the PRF would process include the same low-fired oxides and process residues that are to be processed by the CEPOD process, as well as metals and alloys. Table 4.13 provides a listing of proposed inventory items to be stabilized using operations in the PRF.

The existing solvent extraction system used in the PRF was not considered in this engineering analysis. The primary purpose of the existing solvent extraction system was to remove any impurities using the tributylphosphate (TBP) solvent extraction process to obtain pure plutonium solutions that could be further processed to plutonium metal. For this analysis, the ion exchange process identified in Section 4.8 was evaluated for additional processing of the plutonium nitrate solution to remove any specific ions that may interfere with the stabilization of the plutonium.

The primary unit operations that were evaluated include

- hydrolysis - to burn off any organic or cellulose and decomposing any unstable compounds or nitric acid

- dissolution - solid items are dissolved in $12 \underline{\mathrm{M}} \mathrm{HNO}_{3}$ and $0.35 \underline{\mathrm{M}} \mathrm{HF}$ ("B" acid)

- centrifugation - to separate the plutonium nitrate solution from undissolved solids

- ion exchange - to remove americium and/or targeted ions

- vertical calciner - to evaporate the nitric solution and convert the plutonium to a stable oxide form.

Table 4.13. Proposed Inventory Items to be Stabilized in PRF

\begin{tabular}{||c|l|c|c|}
\hline Title & \multicolumn{1}{|c|}{ Category } & Total Mass (kg) & Total Pu Mass (kg) \\
\hline \hline Low-Fired Oxides & $\begin{array}{l}\text { C01, C03, C30, C40, C41, C50, C70, } \\
\text { C80 }\end{array}$ & 4985 & 918 \\
\hline Metals and Alloys & $\begin{array}{l}\text { A00, A01, A02, B00, B02, B03, B04, } \\
\text { B13, B41, B50, B70, B80 }\end{array}$ & 1040 & 770 \\
\hline Process Residue & C00, G00, G02, G03, G05, G40, G70 & 1196 & 105 \\
\hline
\end{tabular}

(a) The development of the flow diagram was based on information provided in Appendix A (PRF) and the PFP Operating Manual. 


\subsubsection{Process Description}

The PRF is located in Building 236-Z of the PFP. A cutaway of the PRF was provided in Figure 4.9. A large portion of the PRF facility is dedicated to support a canyon that contains the original solvent extraction columns. For this engineering study, the majority of the stabilization process would occur in the miscellaneous-treatment gloveboxes (MT) located on the fourth floor of the PRF. A schematic of the floor diagrams that provide the location of the gloveboxes is provided in Figure 4.12.

Plutonium recoverable material is stabilized to prevent the formation of excessive hydrogen or nitrated organic compounds. Solutions containing more than $20 \%$ organic material and $\mathrm{HNO}_{3}$ are hydrolyzed in Glovebox HC-60. Hydrolysis is accomplished by adding $\mathrm{NaOH}$ to the material. A flow diagram for the hydrolysis process is provided in Figure 4.13. Plutonium is then recovered by dissolving the solid material in $\mathrm{HNO}_{3}, \mathrm{HF}, \mathrm{Al}\left(\mathrm{NO}_{3}\right)_{3}$ and $\mathrm{NaF}$. The most common dissolution solution is reagent is $12 \underline{\mathrm{M} \mathrm{HNO}} \mathrm{H}_{3}$ and $0.35 \mathrm{M} \mathrm{HF}$ (B-acid). The aluminum nitrate nonhydrate (ANN) is added later to complex the fluoride and minimize the evolution of HF into the glovebox and ventilation system (see Figure 4.14). The dissolution process occurs in dissolver pots located in Glovebox MT-5. The dissolver equipment consists of hot plates, metal beakers, and condensers. Each dissolver is equipped with a nitrogen sparge ring to agitate material during dissolution. Each dissolver pot has an individual temperature controller. The gases and vapor that are generated during the boiling process rise through flex hoses connecting to the pot dissolvers to the reflux condensers. The vapors from the boiling acid are condensed and flow back into the dissolver pot in a continuous cycle.

After the dissolution process, the plutonium-bearing solution is separated from the solids that remain in the dissolver pot. Solids removal is achieved by decanting and filtering when the dissolver pots are emptied in Glovebox MT-5 and by centrifuging the solution in Glovebox MT-6. After dissolution and centrifugation, the residual solid heel is rinsed, then packaged for disposal. The solid heel is assumed to contain insignificant amounts of plutonium.

It may be desirable to remove specific contaminants such as americium-241 to reduce worker risk, or to remove contaminants that may interfere with further stabilization. This removal may be accomplished by solvent extraction or ion exchange. For the purposes of this study, it is assumed that the plutonium-bearing solution may be processed with an ion exchange column placed in Glovebox MT-3. A detailed description of the ion exchange process is provided in Section 4.8 and Appendix A. The solution enters the ion exchange unit where the plutonium is captured onto the resin. Once the resin has been saturated with plutonium, the resin is rinsed with dilute nitric acid. This rinse is not contaminated with plutonium and is sent directly to the waste tanks. The plutonium is recovered in an aqueous form using dilute nitric acid to elute the resin bed. The eluant has a concentration of approximately $18 \mathrm{~g} / \mathrm{L} \mathrm{Pu}$. Finally, the column is reconditioned to prepare the resin bed to accept more plutonium. The plutonium-bearing solution can now be processed using the vertical calciner to obtain a more pure plutonium oxide.

Plutonium-bearing nitric solutions can be processed using a vertical calciner to directly convert the solutions to a plutonium oxide without the formation of intermediate plutonium compounds. The 

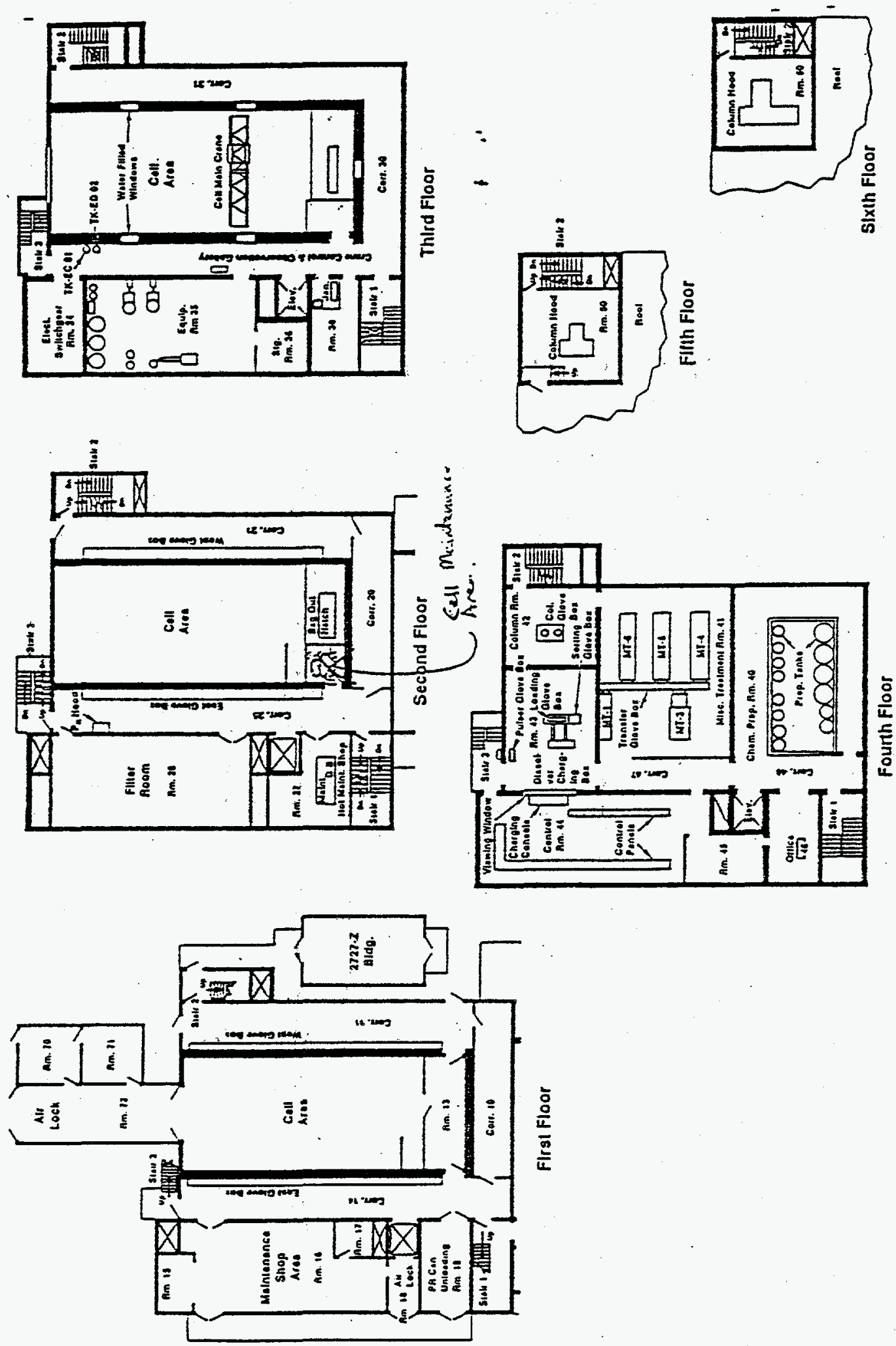

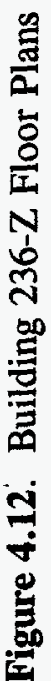




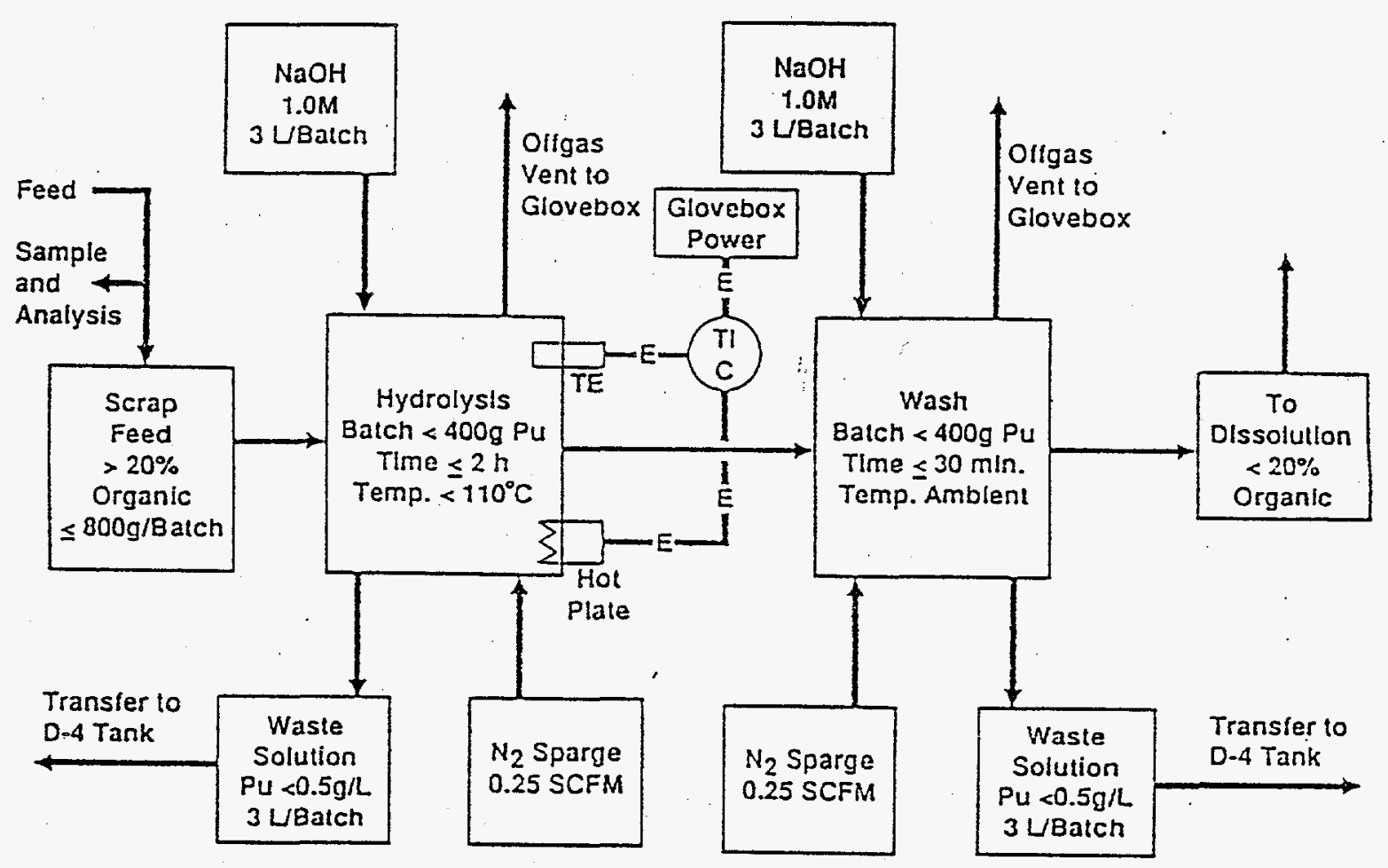

Figure 4.13. Hydrolysis Flow Diagram

plutonium nitrate solution is heated in an air atmosphere to evaporate the water and nitric acid, leaving a solid plutonium oxide particle. The product is a dry powder. For the purpose of this analysis, it is assumed that the vertical calciner will be placed in Glovebox MT-4. Additional detail pertaining to the operational aspects of the vertical calciner is provided in Appendix A.

\subsubsection{Flow Diagram}

For this conceptual engineering study, is assumed that the inventory does not need to be processed through hydrolysis because the material is primarily composed of solids and metals. Therefore, the inventory may be sent directly to dissolution. A spreadsheet was developed based on estimated equipment capacities to determine the various flow rates and cost from each of the unit operations. The cost estimates are based on the direct labor required to operate the process and to decontaminate the gloveboxes after the stabilization has been completed. Costs do not include equipment purchase cost, upgrade requirements, training, or consumables. The results from the spreadsheet calculations are provided in Table 4.14. Based on the results of the spreadsheet, a material flow diagram that highlights the primary effluents was developed (see Figure 4.15).

The dissolution process consists of 5 dissolver pots/batch in the Glovebox MT-5 with a total batch capacity of $3 \mathrm{~L} / \mathrm{h}$. The total mass of plutonium entering the dissolution process is $1800 \mathrm{~kg}$. The solid material is dissolved to obtain a plutonium concentration of $100 \mathrm{~g} \mathrm{pu} / \mathrm{L}$. The primary emission from 


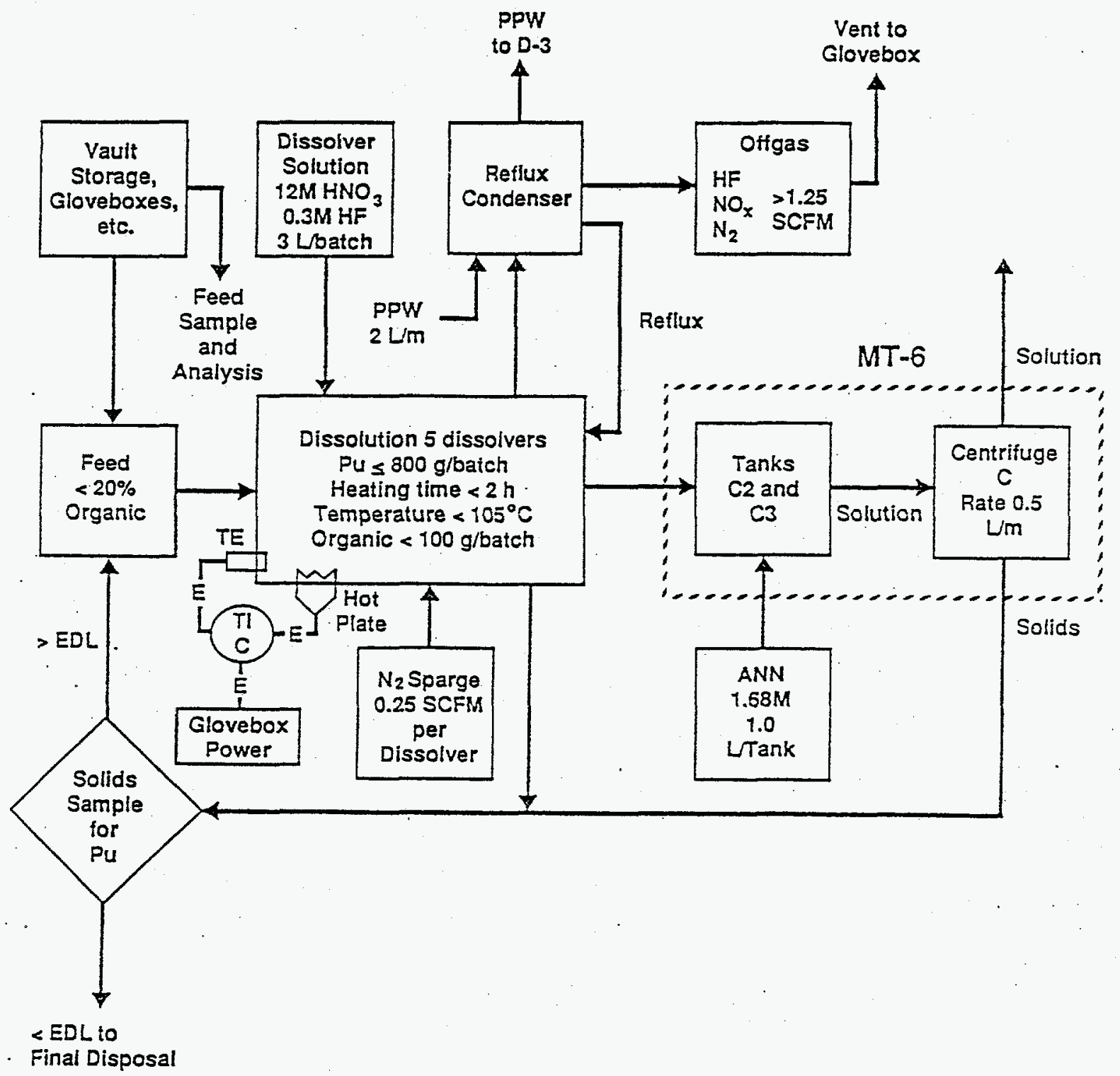

Figure 4.14. Dissolution Process

this process is NOx that is refluxed back to the pot. Processing the inventory through the dissolution process takes approximately 3.2 years and generates $18,000 \mathrm{~L}$ of solution.

The plutonium solution generated from dissolution is then processed by a centrifuge located in the Glovebox MT-6. The centrifuge has an operating capacity of $0.5 \mathrm{~L} / \mathrm{h}$. It is assumed that $0.5 \%$ of the volume, $90 \mathrm{~L}$, is attributed to the remaining solid heel from dissolution and can be sent to disposal. The remaining $99.5 \%$ of the volume, $17,840 \mathrm{~L}$, is attributed to the plutonium-bearing solution. The time required to process the solutions is 0.2 years. 
Table 4.14. Development of Cost Estimates for Plutonium Stabilization Using the PRF

\begin{tabular}{|c|c|c|}
\hline \multicolumn{3}{|l|}{ Hydrolysis Process } \\
\hline \multicolumn{3}{|l|}{ Not applicable to this engineering analysis } \\
\hline \multicolumn{3}{|l|}{ Dissolution Process } \\
\hline Input Pu Mass (kg) & 1,800 & Process residue + low-fired oxides + metals and alloys \\
\hline Output $\mathrm{Pu}$ Concentration Desired (g/L) & 100 & \\
\hline Output Volume (L) & 18,000 & \\
\hline Time to Process (yr) & 3.2 & ( $2 \mathrm{~h} / 3 \mathrm{~L}$ batch) \\
\hline Output $\mathrm{HNO}_{3} \mathrm{M}$ & 10 & \\
\hline Output $\mathrm{Pu}$ Concentration $(\mathrm{g} / \mathrm{L})$ & 100 & \\
\hline Operating Labor Cost (\$) & $4,200,000$ & (2 people @ \$75/h) \\
\hline \multicolumn{3}{|l|}{ Centrifuge Process } \\
\hline Input Pu Mass (kg) & 1,800 & \\
\hline Input Volume (L) & 18,000 & \\
\hline Output Liquid Volume (L) & 18,000 & (99.5\% input volume) \\
\hline Output Solid Volume (L) & 90 & ( $0.5 \%$ input volume) \\
\hline Output Pu Mass (kg) & 1,8000 & \\
\hline Time to Process (yr) & 0.20 & $(0.5-\mathrm{L} / \mathrm{min})$ \\
\hline Operating Labor Cost (\$) & 260,000 & (2 people @ $\$ 75 / \mathrm{h})$ \\
\hline \multicolumn{3}{|l|}{ Ion Exchange Process } \\
\hline Input Volume (L) & 18,000 & \\
\hline Input Pu mass (kg) & 1,800 & \\
\hline Output $\mathrm{Pu}$ solution volume $(\mathrm{L})$ & 100,000 & $\left(18 \mathrm{~g} / \mathrm{L}, 0.45 \mathrm{M} \mathrm{HNO}_{3}\right)$ \\
\hline Wash and Recondition Cycles & 1,500 & Maximum loading: $1199 \mathrm{~g} \mathrm{Pu}$ \\
\hline Output Volume to Tanks (L) & 120,000 & (\# cycles [wash volume + recondition resin volume]) \\
\hline Americium Output to Tanks (kg) & 27 & $(A m-241$ mass $=1.5 \% \times$ Pu mass, $\mathrm{kg})$ \\
\hline Time (yr) & 1.6 & (Input volume $3 \mathrm{~L} / \mathrm{h}$ ) \\
\hline Operating Labor Cost (\$) & $2,100,000$ & (Assume 2 people @ \$75/h) \\
\hline \multicolumn{3}{|l|}{ Thermal Treatment Process } \\
\hline Input Pu Mass (kg) & 1,800 & \\
\hline Input Volume (L) (no iox) & 18,000 & \\
\hline Input Volume $(L)$ (w/iox) & 100,000 & \\
\hline
\end{tabular}


Table 4.14. (contd)

\begin{tabular}{|c|c|c|}
\hline Output Mass $\left(\mathrm{NO}_{\mathrm{x}}\right.$ (no iox) & 12,000 & \\
\hline Output Mass $\left(\mathrm{NO}_{\mathrm{x}}\right)(\mathrm{kg})(\mathrm{w} / \mathrm{iox})$ & 280,000 & \\
\hline Output Mass $\mathrm{PuO}_{2}(\mathrm{~kg})$ & 3,000 & \\
\hline Output Volume $\mathrm{PuO}_{2}(\mathrm{~L})$ & 180 & \\
\hline Time (calcine) (yr) (no iox) & 0.80 & $6 \mathrm{~L} / \mathrm{h}$ \\
\hline Time (calcine) (yr) (w/iox) & 4.4 & $500 \mathrm{~g} /$ batch, $2 /$ batches $/ \mathrm{d}$ \\
\hline Operating Labor Cost (no iox) (\$) & $1,000,000$ & $(2$ people @ $\$ 75 / \mathrm{h})$ \\
\hline Operating Labor Cost (w/iox) (\$) & $5,800,000$ & (2 people @ $\$ 75 / \mathrm{h})$ \\
\hline \multicolumn{3}{|c|}{ Total Direct or Labor Operational Cost Estimates } \\
\hline Low End (M\$) & 5.5 & (Dissolution + centrifuge + calcine) \\
\hline High End (M\$) & 10 & (Dissolution + centrifuge + ion exchange + calcine) \\
\hline \multicolumn{3}{|c|}{ Estimated Glovebox Decontamination Costs } \\
\hline Low End (\$) & 45,000 & (3 gloveboxes @ $\$ 15,000 /$ box, no disposal or packaging) \\
\hline High End (\$) & 150,000 & (5 gloveboxes $@ \$ 15,000 / \mathrm{box}$, no disposal or packaging) \\
\hline
\end{tabular}

Next, a choice must be made to determine if americium should be removed from the solutions. Americium can be removed using ion exchange or by solvent-extraction. For the purposes of this engineering analysis, it is assumed that americium is removed using ion exchange, although solventextraction may provide similar or better results. If there is no need to remove americium from the solutions, the solutions may be sent from the centrifuge directly to a vertical calciner.

If there is a need to remove americium from the solution to reduce the worker risk of radiation exposure, it is assumed that it is accomplished by ion exchange. For this engineering analysis, it is assumed that the quantity of americium removed from the solution is $1.5 \%$ of the plutonium that has decayed to americium-241. The ion exchange process considered captures the plutonium on a resin, allowing the americium and other contaminants to pass through. The output from this process includes a stream containing americium, other contaminants, and rinse solutions that may be sent to the waste tanks, which are assumed to meet the acceptance criteria. This stream has an estimated volume of $120,000 \mathrm{~L}$ and a maximum of $27 \mathrm{~kg}$ of americium. The other primary stream contains the plutonium at a concentration of $18 \mathrm{~g} / \mathrm{L}$ with a volume of $100,000 \mathrm{~L}$. The ion exchange columns are assumed to be located in Glovebox MT-3.

One alternative for the ion exchange process to remove the americium from the solution is to use a resin specifically to recover americium rather than plutonium. This alternate may eliminate the need to purify the plutonium stream further than is needed and possibly reduce the volume sent to the vertical calciner. 


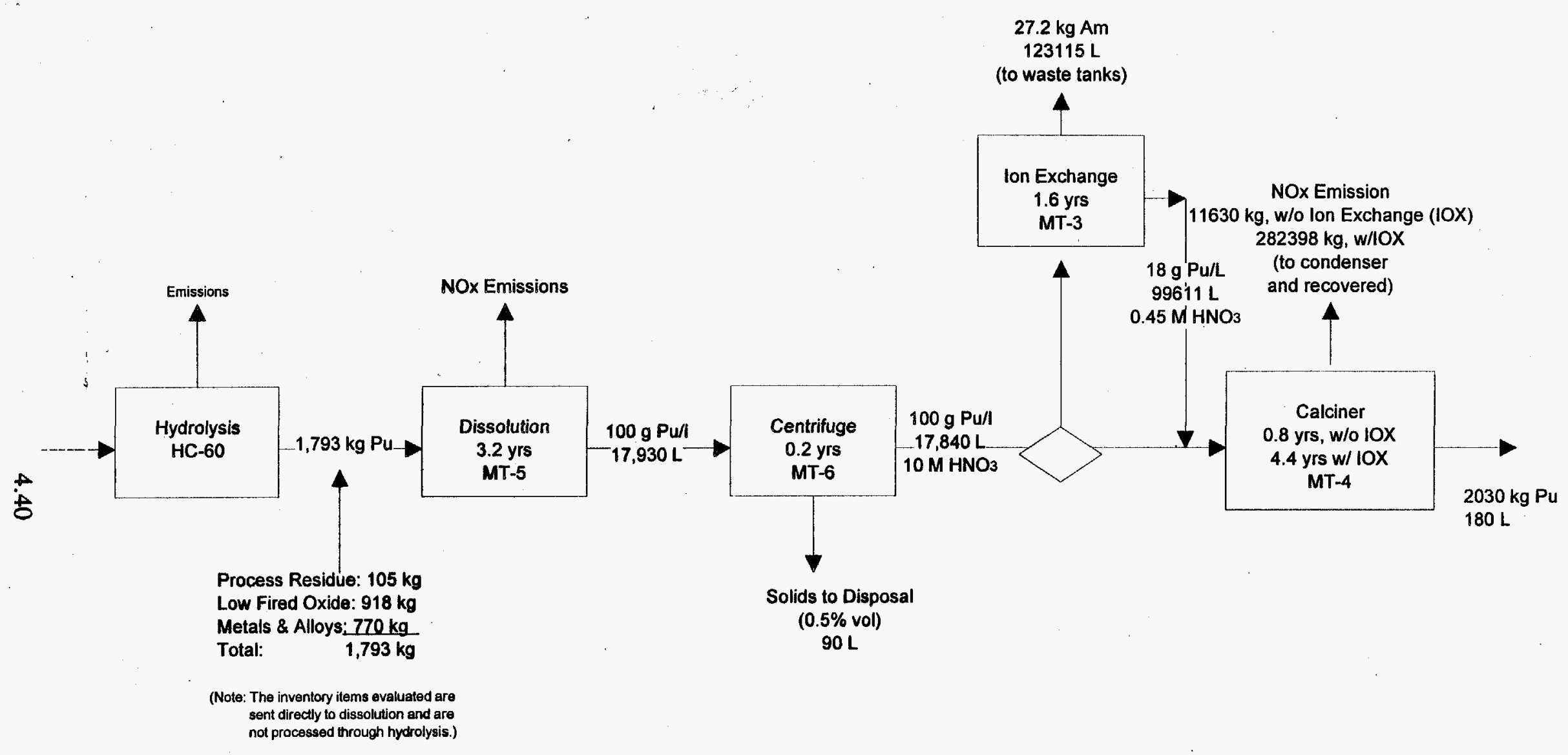

Note: Number of significant figures shown are for computational accuracy only and does not imply that level of precision.

Figure 4.15. Primary Effluent Material Flow Diagram 
The direct denitration converts plutonium nitrate directly to plutonium oxide without the formation of an intermediate plutonium compound. The result is a dry, plutonium oxide powder. The direct denitration considered in this study is a vertical calciner that has a process rate of $4 \mathrm{~L} / \mathrm{h}$. Based on this rate, the time required to process $18,000 \mathrm{~L}$ of solution directly from the centrifuge process is 1.2 years, whereas the time required to process $100,000 \mathrm{~L}$ of solution directly from the ion exchange process is 4.4 years. The mass of plutonium oxide would be the same, $2000 \mathrm{~kg}$, but the plutonium oxide processed through the ion exchange resin bed would not contain americium. The majority of nitrogen oxides emitted from the calcining unit are assumed to be recovered using condensers.

\subsubsection{Cost Estimates}

The cost estimates developed for this analysis are for direct labor cost to operate a unit process and for glovebox decontamination. These costs do not include equipment purchases, consumables, utilities, or disposal costs. The cost estimates assume a labor rate of $\$ 75 / \mathrm{h}$ per person. For this analysis, two individuals are required to operate each unit process $24 \mathrm{~h} / \mathrm{d}, 5 \mathrm{~d} / \mathrm{wk}$, for the duration of the stabilization process. After stabilization has been completed, it is assumed that the gloveboxes will be decontaminated for future use. Details of the cost estimates are provided in Table 4.14. The direct labor costs are estimated to range from $\$ 5.5$ million without using ion exchange up to $\$ 10.5$ million using ion exchange.

The cost estimates to decontaminate a glovebox are based on the NRC study to decontaminate and decommission (D\&D) a glovebox contaminated with americium-241 (Short 1988). Each glovebox costs approximately $\$ 15,000$ to decontaminate. This cost does not include packaging and disposal. It is estimated that 3 to 5 gloveboxes will need to be decontaminated after stabilization is completed. The decontamination cost ranges from $\$ 45,000$ up to $\$ 150,000$.

\subsection{Ion Exchange}

Ion exchange technology has been used for the last 30 years to purify and concentrate plutonium. For this study, the ion exchange technology was evaluated for purification, because the solutions considered for ion exchange are initially concentrated. In fact, after processing these solutions through ion exchange, the concentration of plutonium is considerably lower. Purification of plutonium is considered for two reasons: 1) to increase the stability of the final form and 2) to reduce worker risk associated with the americium present in the impure plutonium. Ion exchange will remove all impurities, including americium.

The following describes the solutions considered for ion exchange, the required equipment, and the process flow descriptions for each solution category. In addition, the disadvantages and advantages of ion exchange are summarized based on the established criteria. 


\subsubsection{Solutions Studied}

The ion exchange technology can process the nitrate solutions, chloride solutions, and other solutions that are categorized on the PFP inventory. Nitrate solutions comprise the F00, F01, F40, F50, F70, and F80 solutions. Chloride solutions comprise the F02 solution. Other solutions consist of the F04 and F05 solutions. Table 4.15 lists the solutions, total grams of plutonium, and total liters for each category.

\subsubsection{Equipment Requirements}

The ion exchange process requires the equipment listed in Table 4.16. The equipment description was largely abstracted from E. C. Vogt's (1983) document. This equipment has 1.3-cm-thick Pyrex glass walls with stainless steel flanges. A 100 mesh, stainless steel screen that is mounted on each flange is recommended for resin support. Currently, a glovebox in the PFP exists that was designed for the ion exchange process. This glovebox, MT-3, is in room 41 of Building 236-Z. Glovebox MT3 is currently out of service and would require repair or replacement.

Table 4.15. Solutions Suitable for Ion Exchange

\begin{tabular}{||l|l|l|l||}
\hline Solution Category & \multicolumn{1}{|c|}{$\begin{array}{c}\text { Specific } \\
\text { Solutions }\end{array}$} & \multicolumn{1}{|c|}{$\begin{array}{c}\text { Total } \\
\text { Plutonium (g) }\end{array}$} & $\begin{array}{c}\text { Total } \\
\text { Volume (L) }\end{array}$ \\
\hline \hline Nitrate Solutions & $\begin{array}{l}\text { F00, F01, F40, } \\
\text { F50, F70, F80 }\end{array}$ & $2.6 \mathrm{E}+05$ & $2.7 \mathrm{E}+03$ \\
\hline Chloride Solutions & F02 & $3.5 \mathrm{E}+04$ & $1.7 \mathrm{E}+02$ \\
\hline Other Solutions & F04, F05 & $6.2 \mathrm{E}+04$ & $1.0 \mathrm{E}+03$ \\
\hline
\end{tabular}

Table 4.16. Required Equipment

\begin{tabular}{|c|l|c|}
\hline Location & \multicolumn{1}{|c|}{ Tank } & Capacity (L) \\
\hline \hline MT-3 & Feed Receiver Tank, TK-150 & 13.9 \\
\hline & Pump Tank, TK-151 & 16.7 \\
\hline & Ion Exchange Columns, TK-152 and new column & 33.3 \\
\hline & Product Tank, TK-153 & 33.3 \\
\hline & Waste Tanks, TK-154 \& TK-155 & 33.3 \\
\hline MT-5 & Product Receiver Tank, TK-133 & 16.8 \\
\hline
\end{tabular}


If Glovebox MT-3 proves to be unusable, Glovebox 235-B-1 on the main floor of Building 234-5 Z is another potential option if the transfer of ownership is granted to PFP operations. The dimensions of 235-B-1 are $76 \mathrm{~cm}$ wide, $3 \mathrm{~m}$ tall, and $6 \mathrm{~m}$ long. The main modification that would be required for this glovebox is the addition of approximately $9 \mathrm{~m}$ of piping. This piping would connect the glovebox to the drainage tunnel that leads to waste tank D-8. The glovebox sections also need to be realigned and secured to seal the glovebox. Alignment will require the removal of the I-beam at the top of the glovebox. Finally, it is recommended that two ion exchange columns be used to capture the breakthrough streams.

\subsubsection{Process Description}

The process proposed for the candidate solutions is anion exchange using Reillex HPQ resin or a similar material. The ionic species absorbed is a hexanitrate complex of plutonium (IV). There are three solution categories considered for ion exchange. The same set of assumptions apply for each solution category. These assumptions are listed in Table 4.17.

Table 4.17. Ion Exchange Assumptions

\begin{tabular}{|c|c|}
\hline & Ascumptions \\
\hline \multirow[t]{9}{*}{ Ion exchange Process } & Column is $15 \mathrm{~cm}$ in diameter and $1.8 \mathrm{~m}$ tall \\
\hline & $1.3 \mathrm{~kg} / \mathrm{L}$ density of all solutions \\
\hline & Assume $\mathrm{Pu}(\mathrm{IV})$ and no adjustment is required \\
\hline & Two columns necessary to catch breakthrough \\
\hline & Assume $3 \mathrm{~L} / \mathrm{h}$ flow rate to ensure saturation at all binding sites \\
\hline & All feed is adjusted to $7.2 \mathrm{M} \mathrm{HNO}_{3}$ \\
\hline & Assume 24 hours, $5 \mathrm{~d} / \mathrm{wk}$, and $60 \%$ operational \\
\hline & Product feed is stabilized in vertical calciner and processed as nitrate solution \\
\hline & Waste solution is $<0.01 \mathrm{~g} \mathrm{Pu} / \mathrm{L}$ (this assumption is dependent on the impurities present in the solution) \\
\hline \multirow[t]{8}{*}{ Resin Properties } & Resin occupies half the column capacity, i.e., $16.65 \mathrm{~L}$ \\
\hline & Assume $80 \%$ loaded at breakthrough as conservative measure \\
\hline & Elution is $90 \%$ effective for Reillex HPQ resin (Navratil 1979) \\
\hline & Four bed volumes required to elute Reillex HPQ resin (Marsh 1989) \\
\hline & Lewatit MP-500-FK resin has maximum loading capacity of $100 \mathrm{~g} \mathrm{Pu} / \mathrm{L}$ (Marsh 1989) \\
\hline & $\begin{array}{l}\text { Assume Reillex HPQ resin performs the same as Lewatit MP-500-FK resin since both are macroporous } \\
\text { organic resins }\end{array}$ \\
\hline & Plutonium sorbed will not be significantly affected after the first elution cycle \\
\hline & Resin will not degrade or require replacement \\
\hline
\end{tabular}


The ion exchange process occurs in four phases (Vogt 1983): loading the resin, washing the resin, elution, and reconditioning of the resin. Figures $4.16,4.17$, and 4.18 display the flow diagrams for each of the solution categories.

\section{Loading}

It is assumed that plutonium in the feed solutions is already in the IV oxidation state. The feed is also adjusted to $7.2 \mathrm{M} \mathrm{HNO}_{3}$ before processing. The solution is fed to the ion exchange column, TK-152, at $3 \mathrm{~L} / \mathrm{h}$. This flow rate was assumed to ensure total saturation of all the binding sites on the resin. The resin, Reillex HPQ, is assumed to occupy half of the column volume which is $16.65 \mathrm{~L}$.

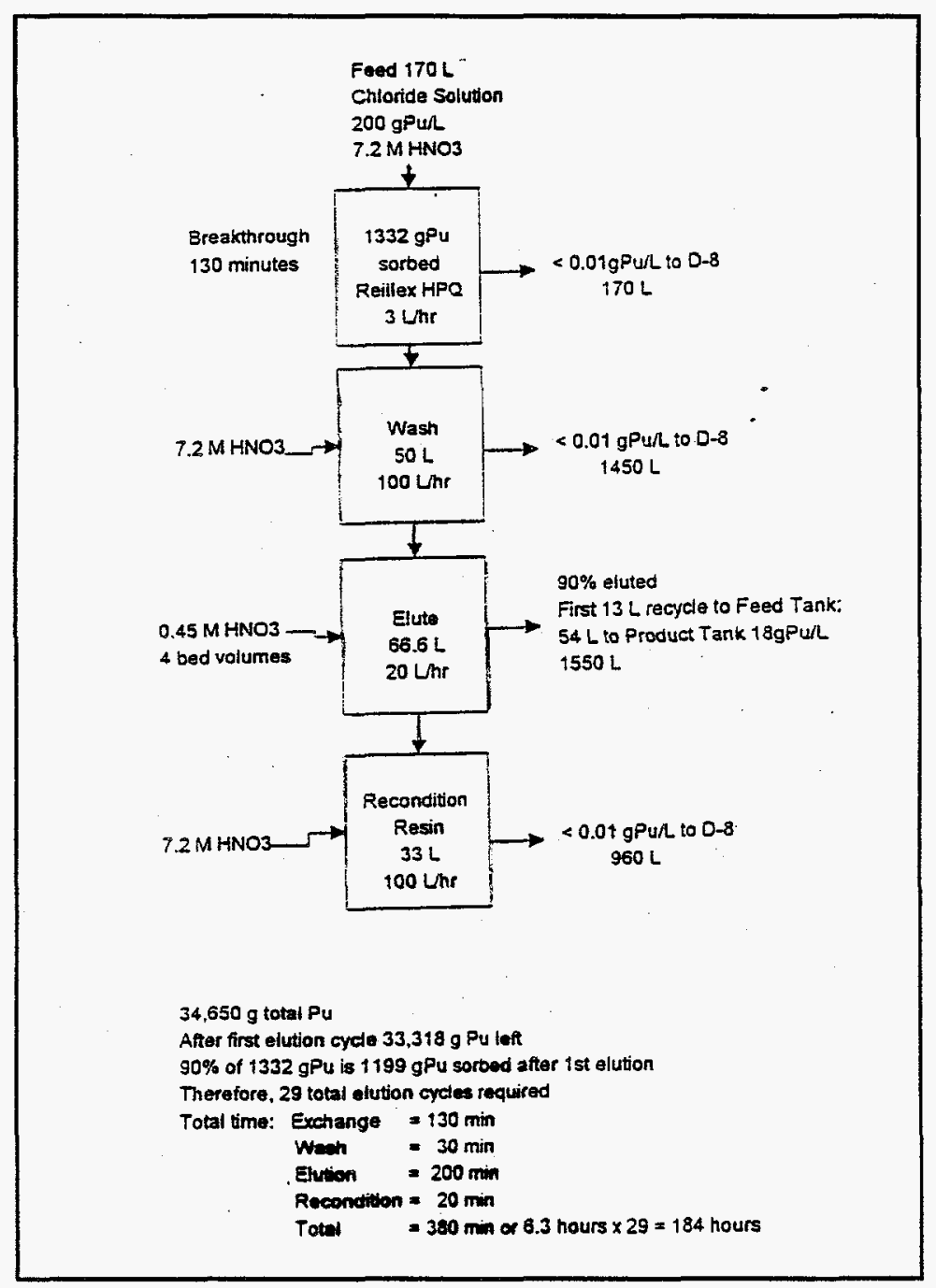

Figure 4.16. Flow Diagram for Chloride Solution Ion Exchange Process 


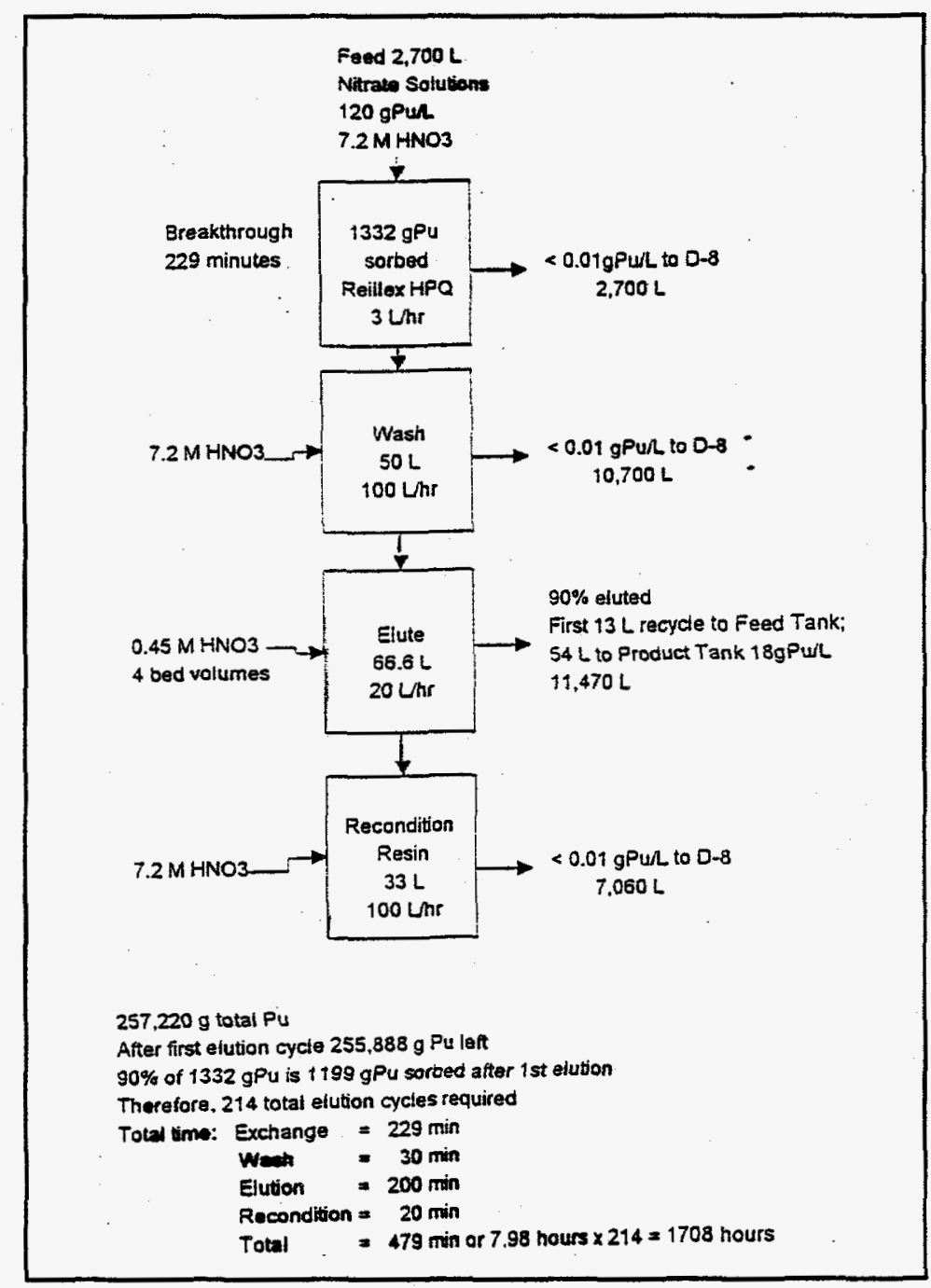

Figure 4.17. Flow Diagram for Nitrate Solution Ion Exchange Process

The waste solution that contains the impurities and less than $0.01 \mathrm{~g} \mathrm{Pu} / \mathrm{L}$ is assumed to be equal to the total volume of feed solution. This waste solution will be collected in waste tanks TK-154 and TK-155 for eventual collection in tank D-8. Tank D-8 collects all waste that will be disposed of in the tank farms. The concentration of plutonium exiting the column may vary depending on the impurities in solutions, especially the presence of fluorides.

The Reillex HPQ resin can bind $1.33 \mathrm{E}+03 \mathrm{~g}$ plutonium before breakthrough. It is recommended that a second ion exchange column be added to the process to catch any breakthrough solution. It is assumed that the resin is $80 \%$ loaded at breakthrough. 


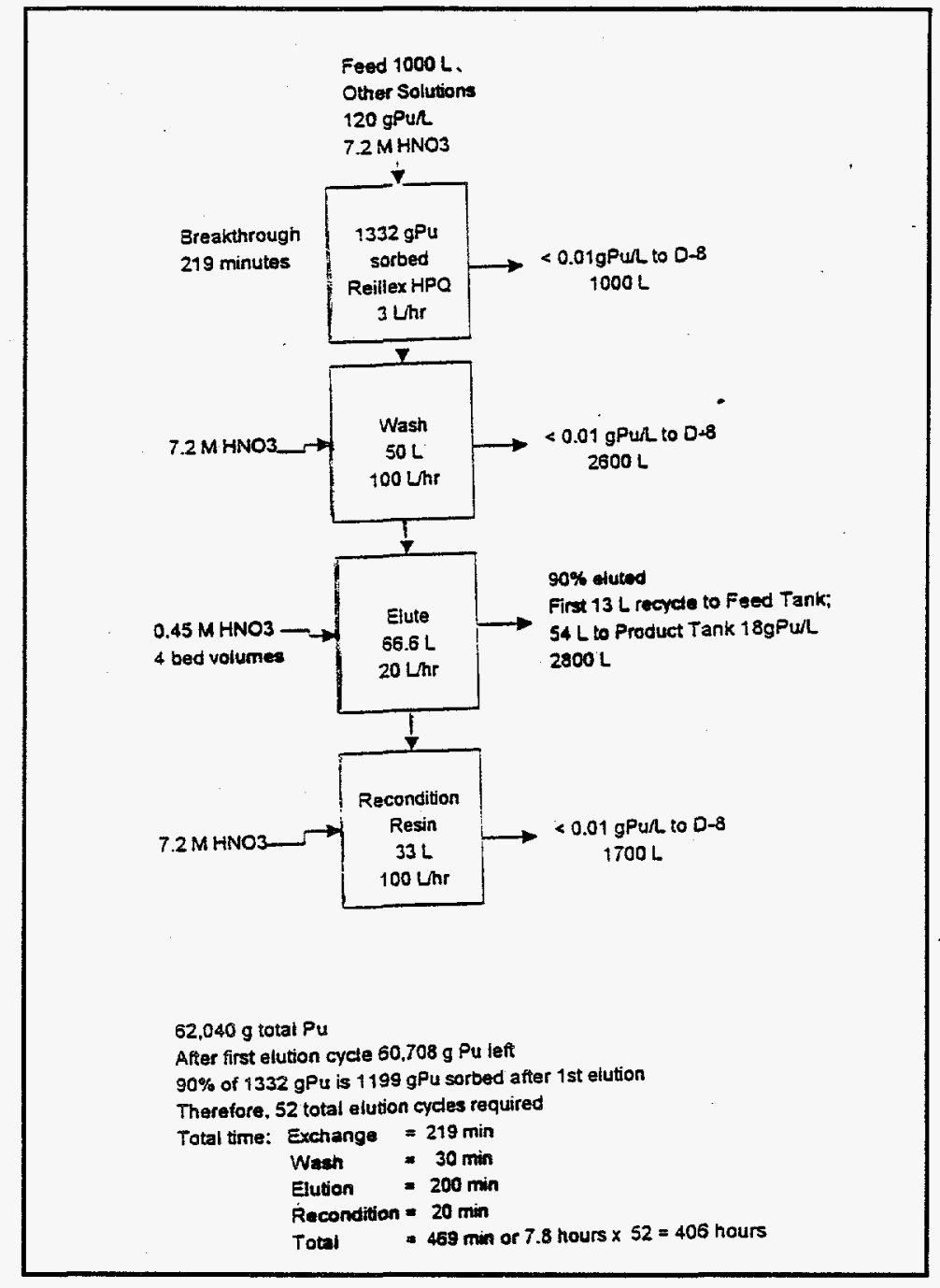

Figure 4.18. Flow Diagram for "Other Solutions" Ion Exchange Process

\section{Wash}

To wash any impurities that may have bound to the resin, $50 \mathrm{~L}$ of $7.2 \underline{\mathrm{M} \mathrm{HNO}} \mathrm{HN}_{3}$ are fed to the column at $100 \mathrm{~L} / \mathrm{h}$. The pump tank, TK-151, is responsible for feeding the wash into the column. The effluent is collected in the waste tanks and transferred to tank D-8 for subsequent transfer to the tank farms.

\section{Elution}

Sixty-six liters of $0.45 \underline{\mathrm{M}} \mathrm{HNO}_{3}$ are pumped into the column at $20 \mathrm{~L} / \mathrm{h}$. To completely elute plutonium, four bed volumes (Marsh 1989), or $66.6 \mathrm{~L}$, are required. It is assumed the $90 \%$ of the plutonium is successfully eluted from the resin (Navratil 1979). The first $13 \mathrm{~L}$ of effluent will be recycled 
to the feed tank, and the remaining $54 \mathrm{~L}$ will be transferred to the product tank, TK-153. The concentration of the product stream is $18 \mathrm{~g} \mathrm{Pu} / \mathrm{L}$. This product stream will be sent to the vertical calciner where it will be converted to plutonium oxide.

The number of elution cycles required for each solution was determined by assuming that after the first elution cycle, the $10 \%$ remaining on the resin after each cycle would not affect the number of required cycles.

\section{Reconditioning the Resin}

Thirty-three liters of $7.2 \mathrm{M} \mathrm{HNO}_{3}$ are pumped onto the resin at $100 \mathrm{~L} / \mathrm{h}$ before the next loading. The effluent is collected in the waste tanks and transferred to tank D-8 for subsequent disposal in the tank farms. It is assumed that the resin will not need to be replaced during the process.

\section{Solution Categories}

The general process discussed above is applicable for the nitrate, chloride, and other solutions. The specific feed, waste, and product characteristics are detailed in Table 4.18. The time required for ion exchange only, and ion exchange plus vertical calciner are also provided.

Table 4.18. Solution Categories and Process Flow

\begin{tabular}{|l|r|r|c||}
\hline & $\begin{array}{c}\text { Nitrate } \\
\text { Solutions }\end{array}$ & $\begin{array}{c}\text { Chloride } \\
\text { Solutions }\end{array}$ & $\begin{array}{c}\text { Other } \\
\text { Solutions }\end{array}$ \\
\hline \hline Feed Volume (L) & 2,700 & 170 & 1,000 \\
\hline Feed Concentration (g Pu/l) & 120 & 210 & 120 \\
\hline Breakthrough (min) & 230 & 130 & 220 \\
\hline Waste Solution Volume (L) & 20,000 & 2,600 & 5,300 \\
\hline Product Volume (L) & 11,000 & 1,600 & 2,800 \\
\hline Total Plutonium (g) & 260,000 & 35,000 & 62,000 \\
\hline Total Americium-240 in Waste Solution (g) & 3,900 & 520 & 930 \\
\hline Elution Cycles & 210 & 30 & 50 \\
\hline Time (wk) & 20 & 3 & 6 \\
\hline Total Time with Vertical Calciner (wk) & 60 & 10 & 10 \\
\hline
\end{tabular}




\subsubsection{Summary}

Ion exchange is a process that has been proven and demonstrated for the last 30 years. The underlying issue associated with this process is how pure the final product needs to be, and whether the worker risk associated with the americium justifies the use of ion exchange. If ion exchange was implemented, the final product will have no impurities, including americium which would reduce worker risk for the 50-year storage period. Besides this main issue, there are several disadvantages and advantages with the ion exchange process:

\section{Advantages}

- technology exists and has been demonstrated

- equipment exists, or can be readily modified

- cost is less than other purifying technologies

- operational duration is extremely low

- routine worker risk is low

- final product is pure, thus considered more stable.

\section{Disadvantages}

- verification of process may be required

- accidental worker risk could be high, e.g., self-sustaining exothermic reaction

- does not handle insoluble streams

- plutonium concentration is reduced

- high volume of waste streams are produced

- spent resin treatment/disposal is unclear

- public perception is negative concerning the purification of plutonium

- public perception to worker dose is negative.

Ion exchange is a fast, inexpensive process suitable for purifying the product, if purification is the main objective. However, the process does have some negative perceptions associated with it because 
of accidental worker risk and the public's mistrust of purifying plutonium. The high volumes of product and waste streams are also considerations that need further evaluation.

\subsection{Furnace - Oxides}

The process, equipment, and criteria for using furnaces, other than the currently installed muffle furnaces, to calcinate oxides are described in this section. The furnaces, configured similar to the muffle furnaces, provide a much more rapid ramp-up capability.

\subsubsection{Process Description}

The overall process is depicted in Figure 4.19. A container of low-fired plutonium oxide is sealed into a glovebox (HM-20MB). The material is then placed into a tared "boat" that is weighed on an electronic scale located in the glovebox. The boat is a container for the oxide while it is being fired in the furnace. The weight of the oxide is recorded, and the boat is transferred to Glovebox HA-21I through a conveyer glovebox.

The boat and oxide are then placed in one of two furnaces and the door is closed. A rotameter is adjusted to remove the off gas from the furnace at a rate of 3.4 to $3.5 \mathrm{~m}^{3} / \mathrm{h}$. The off gas is removed via the 110 -Torr vacuum system.

Once the rotameter is set, the furnace heating cycle is started. The operator ensures that the emergency stop button is in the up (pulled out) position and that the furnace door is closed. The operator then selects the correct cycle program on the controller for the feed material being processed and depresses the manual start switch.

The oxides are assumed to contain an insignificant amount of organic materials. Therefore, the temperature is ramped up to $1000^{\circ} \mathrm{C}$ in less than 15 minutes and maintained at that temperature for 1 hour. The controller then shuts off power to the furnace and allows it to cool. It takes roughly $51 / 2$ hours for the furnace to cool to $200^{\circ} \mathrm{C}$. Total process time per batch is 6.75 hours.

After the furnace has cooled to below $200^{\circ} \mathrm{C}$, the exhaust rotameter is shut off, and the furnace door is opened. The boat is removed using a boat handling tool. The boat, along with the plutoniumbearing product, is placed in a desiccator located in Glovebox HA-21I to further cool. After the product has cooled to roughly room temperature (about 1 hour), the boat is removed from the desiccator and transferred to Glovebox HM-20MB via the connecting conveyor. If needed (for the oxides), the product is ground up using a mortar and pestle in Glovebox HM-20MB and then is sieved in the sieve shaker if larger chunks of the product exist. The product is collected in a separate container (slip lid can), which is stored in a separate desiccator located in Glovebox HM-20MB, until the container is filled. A sample of the product is taken, and a loss-on-ignition (LOI) analysis is performed. The 


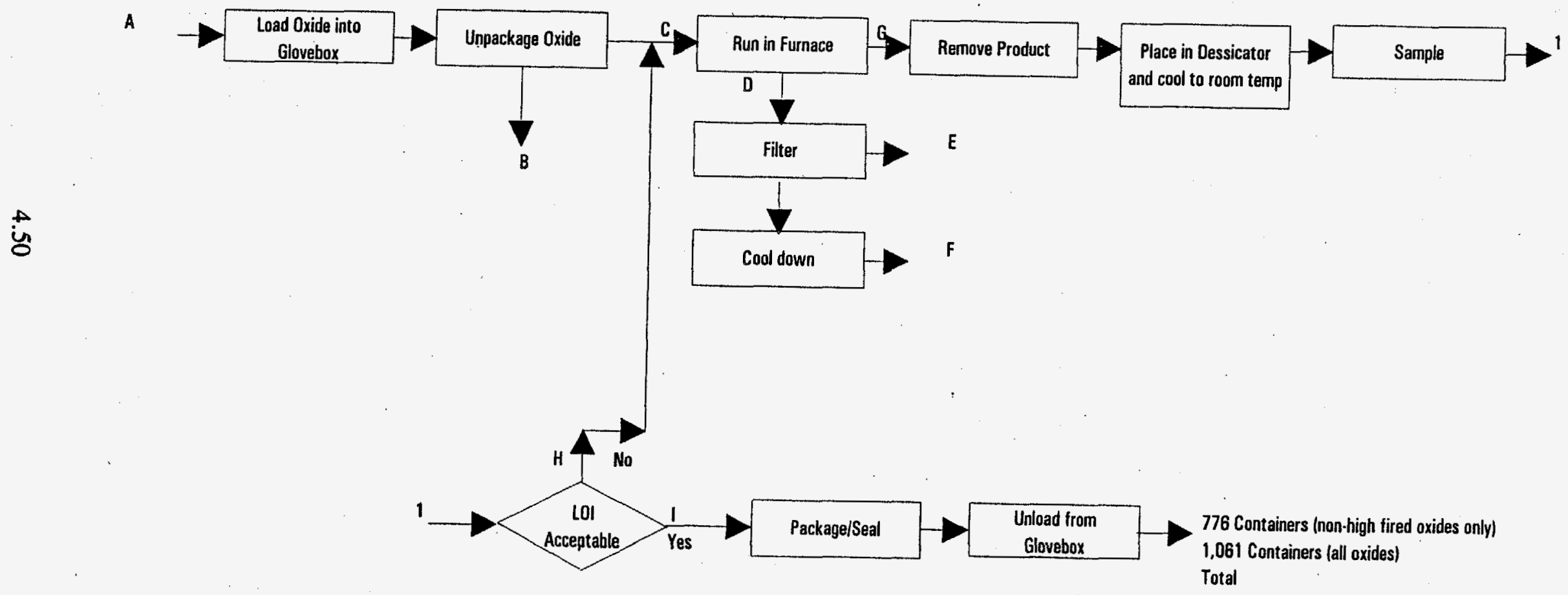

Figure 4.19. Flow Diagram of the Furnace Process for Calcinating Oxides 
product remains in the desiccator while awaiting LOI results. If the LOI is less than $1 \%$, the product is weighed, canned, packaged, and sent to the vaults for storage. Any product greater than $1 \%$ LOI is recycled through the furnaces

\subsubsection{Equipment Description}

This section contains a brief description of the equipment used in the oxide calcining process.

- Glovebox HA-21I - Glovebox HA-21I is located on the west side of room 235 in 234-5Z Building.

- Glovebox HM-20MB - Items are passed back and forth between Gloveboxes HA-21I and HM-20MB via a connecting conveyor. Glovebox HM-20MB will house the sieve shaker, one desiccator, and one Mettler balance.

- Furnace - The furnace is a custom-made unit from Materials Research Furnaces or a Thermolyne Model F46248CM. The operating temperatures range up to over $3000^{\circ} \mathrm{C}$ or up to $1700^{\circ} \mathrm{C}$, respectively. Quoted ramp-up times for $1000^{\circ} \mathrm{C}$ are 10 and 40 minutes, respectively.

- Boats - The boats are constructed of Schedule 10 stainless steel and have a capacity of 1500 to $3000 \mathrm{~g}$. Boats may be constructed of Inconel 600 because of the high operating temperatures.

- Vacuum Line - The 1.3-cm exhaust line from each furnace ties into the plant's 110-Torr vacuum system. The exhaust air passes through a ceramic filter followed by an air heat exchanger and a rotameter. The rotameter is adjusted manually to throttle the flow rate. The ceramic filters have a delta pressure (dP) gage to indicate if the filter becomes plugged. The $\mathrm{dP}$ is checked before starting a heating cycle. The exhaust line is made from Inconel 600 to withstand the high temperatures because stainless steel becomes embrittled and suffers extensive scaling at temperatures over $800^{\circ} \mathrm{C}$.

- Heat Exchanger - The hot exhaust stream flows through a 1.3-cm-diameter Inconel tubing coil mounted inside a $15-\mathrm{cm}$-diameter aluminum pipe that is open at both ends for convective cooling flow.

- Ceramic Filter - A stainless steel cartridge with ceramic filter media is installed in the exhaust line to filter out suspended particles in the off gas.

- Desiccator - Desiccator cabinets are constructed of stainless steel with tempered glass door and sides. The cabinet is fitted with a front opening, positive-latch door with a neoprene gasket. A manual relief valve allows for chamber pressure equalization. Outside dimensions are $32 \mathrm{~cm}$ long by $32 \mathrm{~cm}$ wide by $31 \mathrm{~cm}$ high. 
The desiccant is silica gel contained in a small canister that can be recharged. Each canister has an indicating window that changes color when the desiccant needs recharging (drying). The furnace controllers can be programmed so that the canisters can be recharged. Recharging consists of heating the desiccant up to $175^{\circ} \mathrm{C}$ for $11 / 2$ hours.

- Mesh Sieve and Shaker - A fairly uniform particle size is required to ensure that samples taken for LOI are representative. If no large chunks of product are present after processing, sieving may not be required. If the particle size distribution is large, a four-mesh sieve and sieve shaker is used to screen the product after it has cooled. A mortar and pestle may also be used to break up larger chunks. The sieve is installed in an enclosed shaker in Glovebox HM-20MB. The sieve plates are purged with argon before sieving to displace moist glovebox air.

- Scale - The scale is an electric Mettler balance. A scale will be located in both Glovebox HA-21I, to weigh feed items prior to processing, and in Glovebox HM-20MB, to weigh items prior to packaging.

\subsubsection{Criteria}

The criteria used to determine whether this technology is acceptable are described below.

- Technical Feasibility - The furnaces could be constructed, installed, and tested in a 2-year period.

- Effluents/By-products - One container and the plastic used for sealing into the glovebox per container, filter wash and filtrate (1 to $3 \mathrm{~L}$ per campaign), and off gas. The off gas should consist mainly of water because the plutonium oxide has been thermally treated previously as indicated in Table 4.19.

- Energy Resources - Same as other high-fired oxides (see polycubes).

- Weapons Potential - The resultant product is a high-fired oxide with possible impurities that would be difficult to digest with acids and would require processing to convert to a metal. The product may contain plutonium isotopes not useful in weapon production.

- End Product Volume - Thermal treatment results in the minimum volume for the product. However, since the plutonium oxide has been thermally treated previously, it is believed there should be little to no change in volume. There would be a minimum of $315 \mathrm{~g}$ of plutonium oxide per batch. A total of 776 containers is estimated for the non-high-fired oxides, and 1061 containers are estimated for all oxides.

- End Product Stability - The product will be chemically inert and will have an LOI of less than $1 \%$ before it is packaged. 
Table 4.19. Thermal Treatment - Oxide Effluent Stream Descriptions (numbers are rounded to two significant digits)

\begin{tabular}{|l|l|c|c|c|c|c|c|c|c|c|c|}
\hline & & & & & & & & \\
\hline
\end{tabular}


- Environmental Risk - The environmental risk is minimal; see worker risk.

- Worker Risk: Explosion - There is minimal risk from explosion. The plutonium oxide has been thermally treated previously and, therefore, should contain no organic materials. Also, the furnace will be operated at slightly negative pressure compared to the glovebox. It is assumed the chance of occurrence is less than the chance of an explosion in the high-level waste (HLW) calciner, which is estimated $6 \mathrm{E}-07$.

Routine - There should be no special exposure to personnel during normal operations.

- Costs - The system construction cost includes the cost of the furnaces at roughly $\$ 30 \mathrm{~K}$. Modifications to the glovebox would also be required.

The systems operations cost is relatively minimal: a maximum crew of 2 people, around the clock, for a minimum of 831 operational days at 4 batches/d. Personnel costs, at $\$ 100 \mathrm{~K} /$ person/yr, are estimated at about $\$ 2 \mathrm{M}$.

The D\&D costs should be minimal. The waste generated during D\&D would be the equipment in the gloveboxes and the gloveboxes themselves.

- Operation Duration - Assuming an average of 4 batches $/ \mathrm{d}$ and $1500 \mathrm{~g}$ of material per batch, the non-high-fired oxides would take 831 days, or 3.3 years. All oxides would take 1103 days, or 4.4 years.

- Public Acceptance - Public acceptance has been high for the interim action.

- Flexibility - The only restrictions on input are criticality issues and the amount of organics present (must be less than $2 \%$ ).

- Materials Covered - The furnaces could handle the combustibles, oxides, sand slag and crucibles, and metals and alloys. The ramp-up times for the non-oxide materials would be similar to the ramp-up times given for the muffle furnaces. There are furnaces available that can ramp up to $1000^{\circ} \mathrm{C}$ in 10 to 40 minutes, but also allow for 8 ramp-up and dwell times to allow for treatment of various materials.

\subsection{Muffle Furnace - Polycubes and Combustibles}

A process description, equipment description, and criteria are discussed briefly below for treating polycubes and combustibles. Both materials are assumed to have high quantities of organic material. The process is based on the interim action muffle furnaces being used in tandem. The first furnace would be used for pyrolysis, and the off gas would be routed directly to the second furnace, which would be used as an afterburner. There would be no filters between the two furnaces. The process described in this section is not optimal. The process described uses the interim action equipment to 
ensure availability. Afterburners for both furnaces were considered, but the idea was rejected because of the heat that such burners would add to the glovebox. A more optimal system would use two muffle furnaces with afterburners.

\subsubsection{Process Description}

A container with a plutonium-bearing polystyrene cube or combustible materials is sealed into Glovebox HC-21A to begin the process (Figure 4.20). The polystyrene cubes are crushed so the material can be spread over the bottom of the boat. The material then is placed into a tared "boat" that is weighed on an electronic scale located in the glovebox. The boat is a container for the plutoniumbearing polystyrene or combustible material while it is being fired in the furnace. The weight of the plutonium-bearing material is recorded, and the boat transferred to Glovebox HC-21C through the HC-2 conveyer glovebox.

The boat and material are then placed in a muffle furnace (the second muffle furnace is used as an afterburner for the off gas), and the furnace door is closed. A rotameter is adjusted to provide a flow of inert purge gas into the furnace. The purpose of the inert gas is to reduce the oxygen available and, thus, reduce the risk of a fire. The off gas is removed through the second preheated furnace, where it is oxidized at $1000^{\circ} \mathrm{C}$, via a connecting pipe. The inert gas flow, in conjunction with the exhaust flow rates, will maintain the amount of organic material below a flammable concentration in the first furnace. Air is added to the second furnace to ensure the organics are destroyed. It was estimated that, at the maximum expected flow rate, the off gas from the first furnace would have a minimum residence time of 2 seconds in the second furnace. This time should be sufficient to allow complete destruction of all organics.

Once the rotameters are set, the furnace heating cycle is started. The operator ensures that the emergency stop button is in the up (pulled out) position and that the furnace door is closed. The operator then selects the correct cycle program on the controller for the feed material being processed and depresses the manual start switch.

Program 1, designed for sludge stabilization for the interim action, is most like the program that will be needed for polystyrene cubes and combustible material thermal treatment. A revised program 1 directs the controller to ramp the furnace up to $300^{\circ} \mathrm{C}$ for the polystyrene cubes or $175^{\circ} \mathrm{C}$ for the combustible material at a rate of $300^{\circ} \mathrm{C} / \mathrm{h}$ and hold it there for $11 / 2$ hours. This program, with slow ramp-up and hold time, allows organic material to be driven off slowly so as not to build up to potentially flammable concentrations. The furnace is then ramped up to $500^{\circ} \mathrm{C}$ at a ramp rate of $300^{\circ} \mathrm{C} / \mathrm{h}$. The inert gas is manually turned down late in the cycle to complete the oxidation of residual carbon. The controller then ramps the furnace up to $1000^{\circ} \mathrm{C}$ at the rates provided in Table 4.20 .

The furnace is held at $1000^{\circ} \mathrm{C}$ for 1 hour. The controller then shuts off power to the furnace and allows it to cool. It takes roughly $51 / 2$ hours for the furnace to cool to $200^{\circ} \mathrm{C}$. Total process time per batch is 13.6 hours. 


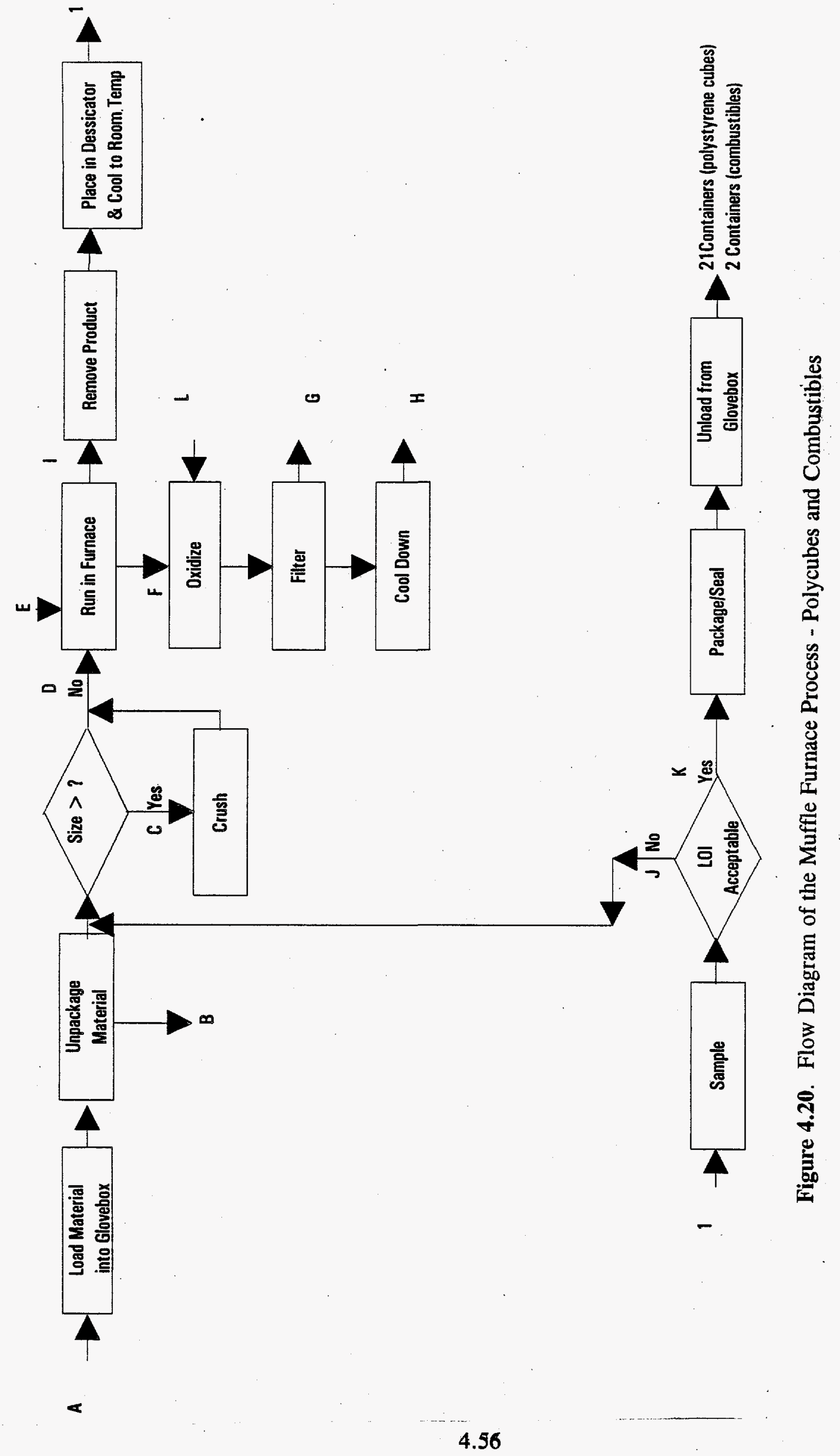


Table 4.20. Ramp-Up Rates for Polystyrene Thermal Treatment

\begin{tabular}{|c|c|}
\hline Rate $\left({ }^{\circ} \mathbf{C} / \mathbf{h}\right)$ & Temperature Range $\left({ }^{\circ} \mathbf{C}\right)$ \\
\hline \hline 300 & up to 500 \\
\hline 200 & 500 to 700 \\
\hline 125 & 700 to 900 \\
\hline 75 & 900 to 1000 \\
\hline
\end{tabular}

The actual program designed for the polystyrene may differ from the revised Program 1 described above. For example, ramp-up and hold-at-temperature times may be increased for the polystyrene to ensure complete polystyrene destruction without boilover. A lower bound for polystyrene treatment is probably $13.6 \mathrm{~h} / \mathrm{batch}$.

After the furnace has cooled to below $200^{\circ} \mathrm{C}$, the exhaust rotameter is shut off and the furnace door is opened. The boat is removed using a boat handling tool. The boat, along with the product, is placed in a desiccator located in Glovebox HC-21C to further cool. After the product has cooled to roughly room temperature (about 1 hour), the boat is removed from the desiccator and transferred to Glovebox HC-21A via the conveyor in Glovebox HC-2. In Glovebox HC-21A, the product is sieved in the sieve shaker if larger chunks of product exist. The product is collected in a separate container (slip lid can), which is stored in a separate desiccator located in Glovebox HC-21A, until the container is filled. A sample of the product is taken and an LOI analysis is performed. The product remains in the desiccator while awaiting LOI results. If the LOI is less than $1 \%$, the product is weighed, canned, packaged, and sent to the vaults for storage. Any material greater than $1 \%$ LOI is recycled through the furnaces.

\subsubsection{Equipment Description}

This section contains a brief description of the process equipment.

- Glovebox HC-21C - Glovebox HC-21C is located on the west side of room 230A in 234-5Z Building. The glovebox is about $3 \mathrm{~m}$ long. The inside of the working floor is $1.1 \mathrm{~m}$ wide, with a sloping face along its entire length. The glovebox is supported by a stand, and the floor of the glovebox is $1.4 \mathrm{~m}$ above the room floor. A conveyer runs along the north end of the glovebox and fits closely to the working floor. The glovebox will house two muffle furnaces, one Mettler balance and one desiccator.

- Glovebox HC-21A - Glovebox HC-21A is located in room 230B in the 234-5Z Building. The glovebox is similar in design to Glovebox HC-21C. The HC-2 conveyor also runs along the 
north end of the glovebox, and items are passed back and forth between Gloveboxes HC-21C and HC-21A. The glovebox will house a sieve shaker, one desiccator, and one Mettler balance.

- Muffle Furnace - The furnace is a Thermolyne Model FA1630. Its chamber dimensions are $14 \mathrm{~cm}$ wide by $13 \mathrm{~cm}$ high by $33 \mathrm{~cm}$ in depth. The operating temperature range is $150^{\circ}$ to $1093^{\circ} \mathrm{C}$. A door safety switch removes power to the heating elements when the door is opened. Four additional factory drilled holes have been located in the back plate of the furnace for the inert gas supply line, the exhaust line, and two thermocouples. The exhaust line would be routed from the first to the second muffle furnace.

- Boats - The boats are constructed of a 10-cm-diameter, Schedule 10 stainless steel pipe with a pipe cap welded to each end. The pipe is then cut lengthwise leaving it with a dimension roughly $23 \mathrm{~cm}$ long, which is equivalent to a little less than $1.5 \mathrm{~L}$. Stands and tubing are welded on the bottom for stability. The tubing allows the boat to be remotely handled with a specially designed boat handling tool which, resembles a tuning fork. Inconel 600 boats may be required because of the high operating temperatures.

- Vacuum Line - The 1.3-cm exhaust line from each furnace ties into the plant's 110-Torr vacuum system. The exhaust air passes through a ceramic filter, an air heat exchanger, and a rotameter. The rotameter is adjusted manually to throttle the flow rate. The ceramic filters have a $\mathrm{dP}$ gage to indicate if the filter becomes plugged (the $\mathrm{dP}$ is checked before starting a heating cycle). The exhaust line is made from Inconel 600 to withstand the high temperatures, because stainless steel becomes embrittled and suffers extensive scaling at temperatures over $800^{\circ} \mathrm{C}$.

- Heat Exchanger - The hot exhaust stream flows through a 1.3-cm-diameter Inconel tubing coil mounted inside a 15 -cm-diameter aluminum pipe that is open at both ends for convective cooling flow.

- Ceramic Filter - A stainless steel cartridge with ceramic filter media is installed in the exhaust line to filter out suspended particles in the off gas.

- Desiccator - Desiccator cabinets are constructed of stainless steel with tempered glass door and sides. The cabinet is fitted with a front opening, positive-latch door with a neoprene gasket. A manual relief valve allows for chamber pressure equalization. Outside dimensions are $32 \mathrm{~cm}$ long by $32 \mathrm{~cm}$ wide by $31 \mathrm{~cm}$ high.

The desiccant is silica gel contained in a small canister that can be recharged. Each canister has an indicating window that changes color when the desiccant needs recharging (drying). Each of the furnace controllers are programmed so that the canisters can be recharged. Recharging consists of heating the desiccant up to $175^{\circ} \mathrm{C}$ for $11 / 2 \mathrm{~h}$. 
- Inert Gas Supply System - The inert gas will be supplied by an inert gas station that will be located in room 230A. The station will consist of a cabinet that will house two $170-\mathrm{kg}$ inert gas bottles. A manifold will automatically switch to the second bottle when the first one empties.

- Mesh Sieve and Shaker - A fairly uniform particle size is required to ensure that samples taken for LOI are representative. If no large chunks of material are present after processing, sieving may not be required. If the particle size distribution is large, a four-mesh sieve and sieve shaker are used to screen the material after it has cooled. A mortar and pestle may also be used to break up larger chunks. The sieve is installed in an enclosed shaker in Glovebox HC-21A, and the sieve plates are purged with argon before sieving to displace moist glovebox air.

- Scale - The scale is an electric Mettler balance. A scale will be located in both Glovebox HC-21C, to weigh feed items prior to processing, and in Glovebox HC-21A, to weigh items prior to packaging.

\subsubsection{Criteria}

- Technical Feasibility - The equipment exists in the PFP, has been tested, and is planned for use in the interim action. However, modifications are needed.

- Effluents/By-products - The effluents/by-products consist of one container and the plastic for sealing in the container per container, filters and filtrate ( 1 to $3 \mathrm{~L}$ per campaign), and off gas. Overall effluent descriptions are listed in Tables 4.21 (combustibles) and 4.22 (polystyrene cubes).

- Energy Resources - Like other high-fired oxides, the product material will require processing to be used as an energy source.

- Weapons Potential - The resultant product is a high-fired oxide that will be difficult to digest with acids and would require processing to convert to a metal. The product is impure plutonium and contains plutonium isotopes not useful in weapons production.

- End Product Volume - Thermal treatment results in the minimum volume for the product. Assuming only plutonium oxide is left, the weight of the product from the polystyrene cubes is $81 \mathrm{~g} / \mathrm{batch}$ for a total of $31 \mathrm{~kg}$. The combustibles result in $100 \mathrm{~g} / \mathrm{batch}$ or $121 \mathrm{~kg}$. This amount will fill 21 containers (polystyrene cubes) or 2 containers (combustibles).

- End Product Stability - The product will be chemically inert and will have an LOI of less than $1 \%$ before it is packaged.

- Environmental Risk - Minimal; the risk of an explosion is about 6 E-07 (see worker risk). 
Table 4.21. Muffle Furnace - Combustibles Effluent Stream Descriptions (rounded to two significant digits)

\begin{tabular}{|c|c|c|c|c|c|c|c|c|c|c|c|c|c|}
\hline Stream & A & $B$ & D & $E$ & $F$ & G & $\mathrm{H}$ & 1 & $\mathrm{~J}$ & $K$ & $L$ & Not Shown & \\
\hline Description & $\begin{array}{c}\text { Combustible } \\
\text { Feed }\end{array}$ & Packaging & Batch & Inert Gas & $\begin{array}{l}\text { Gas from } \\
\text { Furnace } 1\end{array}$ & Filter Wash & $\begin{array}{c}\text { Gas to* } \\
\text { Ventilation }\end{array}$ & Product & Rework & $\begin{array}{c}\text { Acceptable } \\
\text { Product }\end{array}$ & $\begin{array}{c}\text { Air to 2'nd } \\
\text { Furnace }\end{array}$ & Air Input & $\begin{array}{c}\text { Filter Wash } \\
\text { Input }\end{array}$ \\
\hline Phase & Solid & Solid & Solid & Gas & Gas & Liquid & Gas & Solid & Solid & Solid & Gas & Gas & Liquid \\
\hline gms/container & 3,600 & $0.01 \mathrm{~m} 3 /$ day & & & & & & & & & & & \\
\hline gms/batch & & & $<500$ & 4,700 & 8,200 & 1.3 I/camp & 11,000 & 100 & 10 & 90 & 3,100 & 3,100 & 1.3 l/camp \\
\hline gms Pulbatch & & & 17 & & & & & 17 & 1.70 & 15 & & & \\
\hline & & & & & & & & & & & & & \\
\hline HNO3 (gms) & & & & & & 1.31/camp & & & & & & & $1.31 /$ camp \\
\hline 02 & & & & & 620 & & 1,200 & & & & 620 & 620 & \\
\hline Pu02 & & & & & & & & 19 & 1.90 & 17 & & & \\
\hline $\mathrm{N} 2$ & & & & 4,700 & 7,200 & & 9.700 & & & & 2,500 & 2,500 & \\
\hline Other & & & 480 & & 400 & & 400 & 81 & 8.10 & 73 & & & \\
\hline & & & & \multicolumn{3}{|c|}{ (from combustibles) } & m combustib & & & (ash) & & & \\
\hline & & & & & & & & & & & & & \\
\hline & & & & & & & & & & & & & \\
\hline & * The compo & in and quant & f combl & jes are un & known. Th & efore the rea & ions loffga & tity ane & posit & unkn & & & \\
\hline
\end{tabular}


Table 4.22. Muffle Furnace - Polycubes Effluent Stream Descriptions (rounded to two significant digits)

\begin{tabular}{|c|c|c|c|c|c|c|c|c|c|c|c|c|c|c|}
\hline Stream & A & B & C & D & $\mathbf{E}$ & $F$ & G & $\mathrm{H}$ & 1 & $\mathrm{~J}$ & K & $L$ & \begin{tabular}{|l|} 
Not Shown \\
\end{tabular} & \\
\hline Description & $\begin{array}{c}\text { Polycube } \\
\text { Feed }\end{array}$ & Packaging & $\begin{array}{l}\text { Oversized } \\
\text { Material }\end{array}$ & Batch & Inert Gas & $\begin{array}{l}\text { Gas From } \\
\text { Furnace } 1 \\
\end{array}$ & Filter Wash & $\begin{array}{c}\text { Gas to } \\
\text { Ventilation }\end{array}$ & Product & Rework & $\begin{array}{c}\text { Acceptable } \\
\text { Product } \\
\end{array}$ & $\begin{array}{l}\text { Added Air } \\
\text { Furnace } 2 \\
\end{array}$ & Air Input & $\begin{array}{c}\begin{array}{c}\text { Filter Wash } \\
\text { Input }\end{array} \\
\end{array}$ \\
\hline Phase & Solid & Solid & Solid & Solid & Gas & Gas & Liquid & Gas & Solid & Solid & Solid & Gas & Gas & Liquid \\
\hline gms/container & 840 & $0.01 \mathrm{~m} 3 / \mathrm{day}$ & 840 & & & & & & & & & & & \\
\hline gms/batch & & & & $<500$ & 4,700 & 8,100 & 1.3 /camp & 16,000 & 81 & 8.1 & 73 & 4,300 & 5,900 & 1-3//camp \\
\hline gms Pulbatch & & & & 71 & & & & & 71 & 7.1 & 64 & & & \\
\hline & & & & & & & & & & & & & & \\
\hline HNO3 (gms) & & & & & & & 1.3 I/camp & & & & & & & 1.3 //camp \\
\hline 02 & & & & & & 610 & & 700 & & & & 900 & 1,100 & \\
\hline Pu02 & & & & & & & & & 81 & 8 & 73 & & & \\
\hline $\mathrm{CO2}$ & & & & & & & & 1,500 & & & & & & \\
\hline $\mathrm{N} 2$ & & & & & 4,700 & 7,100 & & 13,100 & & & & 3,400 & 4,800 & \\
\hline \multirow[t]{2}{*}{ Other } & & & & 430 & & 430 & & 360 & & & & & & \\
\hline & & & \multicolumn{3}{|c|}{ (polystyrene) } & $H$ and oxide & & $(\mathrm{H} 2 \mathrm{O})$ & & & & & & \\
\hline
\end{tabular}


- Worker Risk: Explosion - Minimal risk. The first furnace will be inerted to reduce the risk of combustion of the organic off gas. Also, the furnace will be operated at slightly negative pressure compared to the glovebox. It is assumed the chance of an occurrence is similar to the chance of an explosion in the high-level waste (HLW) calciner, which is estimated to be $6 \mathrm{E}-07$.

Routine - Workers will be exposed during the mortar and pestle operation and the crushing operation.

- Costs - There are capital costs associated with this option, as the present configuration will require modification so that off gas will be routed through the second furnace. A condenser may also be required.

The systems operations cost is minimal: maximum crew of 2 people, around the clock, for 415 operational days (polystyrene cubes) or 122 operational days (combustibles). At $\$ 100 \mathrm{~K} /$ person/yr, the cost would be $\$ 1.0 \mathrm{M}$ (polystyrene cubes) or $\$ 300 \mathrm{~K}$ (combustibles). Costs would include electricity to run the muffle furnaces.

The D\&D costs should be minimal. The waste generated during D\&D would be the equipment in the gloveboxes and the gloveboxes themselves.

- Operation Duration - The operation would take 415 operational days (assuming $1 \mathrm{batch} / \mathrm{d}$ ), or 1.66 years (assuming 50-week years), for polystyrene cubes and 122 operational days, or 0.48 years, for combustibles.

- Public Acceptance - Public acceptance has been high for the interim action.

- Flexibility - The only restrictions on input would be criticality issues and, possibly, some level of volatility.

- Materials Covered - As presently configured, the muffle furnaces could handle the combustibles, oxides, sand slag and crucibles, and metals and alloys. The polycubes will require some modification, possibly as described in this section, for safety, and fluoride compounds could not be handled because fluoride is not destroyed by calcination.

\subsection{Muffle Furnace - Metals and Alloys, and Sand, Slag, and Crucibles (Residues)}

The process description, required equipment, and criteria for using muffle furnaces to treat metals and alloys, and residues are provided in this section. 


\subsubsection{Process Description}

A container of plutonium-bearing alloys, plutonium metal, or plutonium-bearing residues is sealed into Glovebox HC-21A (see Figure 4.21). The metal is cut or crushed if too large for the carrier. The metal or plutonium bearing material is placed into a tared "boat," which is weighed on an electronic scale located in the glovebox. The boat is a container for the metal, or plutonium bearing material, while it is being fired in the furnace. The material weight is recorded, and the boat is transferred to Glovebox HC-21C through the HC-2 conveyer glovebox.

The boat is then placed in one of two furnaces, and the furnace door is closed. A rotameter is adjusted to remove the off gas from the furnace at a rate of 3.4 to $3.5 \mathrm{~m}^{3} / \mathrm{h}$. The off gas is removed via the 111-Torr vacuum system.

Once the rotameter is set, the furnace heating cycle is started. The operator ensures that the emergency stop button is in the up (pulled out) position and that the furnace door is closed. The operator then selects the correct cycle program on the controller for the feed material being processed and depresses the manual start switch.

A modified program 2, designed for RMC Line Oxycarbonate (Oxalate) type items, is chosen to be most appropriate for metals, alloys, and residues, which have no potential to contain organics. The metals are expected to increase significantly in size as they are oxidized. The furnace will be slowly ramped to about $500^{\circ} \mathrm{C}$ and held at this temperature for 1 hour, or more, to allow the operators to cut energy to the furnace before a thermal reaction could get out of control. The furnace is then ramped directly up to $1000^{\circ} \mathrm{C}$ and is held for 1 hour. The controller then removes power to the furnace and allows it to cool. It takes roughly $51 / 2$ hours for the furnace to cool to $200^{\circ} \mathrm{C}$. Total process time per batch is at least 13.6 hours.

After the furnace has cooled to below $200^{\circ} \mathrm{C}$, the exhaust rotameter is shut off and the furnace door is opened. The boat is removed using a boat handling tool. The boat, along with the metal oxides, is placed in a desiccator located in Glovebox HC-21C to further cool. After the product has cooled to roughly room temperature (about 1 hour), the boat is removed from the desiccator and transferred to Glovebox HC-21A via the conveyor in Glovebox HC-2. In.Glovebox HC-21A, the product is sieved in the sieve shaker if larger chunks of product exist to ensure a representative sample can be taken. The product is collected in a separate container (slip lid can), which is stored in a separate desiccator located in Glovebox HC-21A, until the container is filled. A sample of the product is taken, and an LOI analysis is performed. The product remains in the desiccator while awaiting LOI results. If the LOI is less then $1 \%$, the product is weighed, canned, packaged, and sent to the vaults for storage. Any product greater than $1 \%$ LOI is recycled through the furnaces.

\subsubsection{Equipment Description}

This section contains a brief description of the process equipment. 

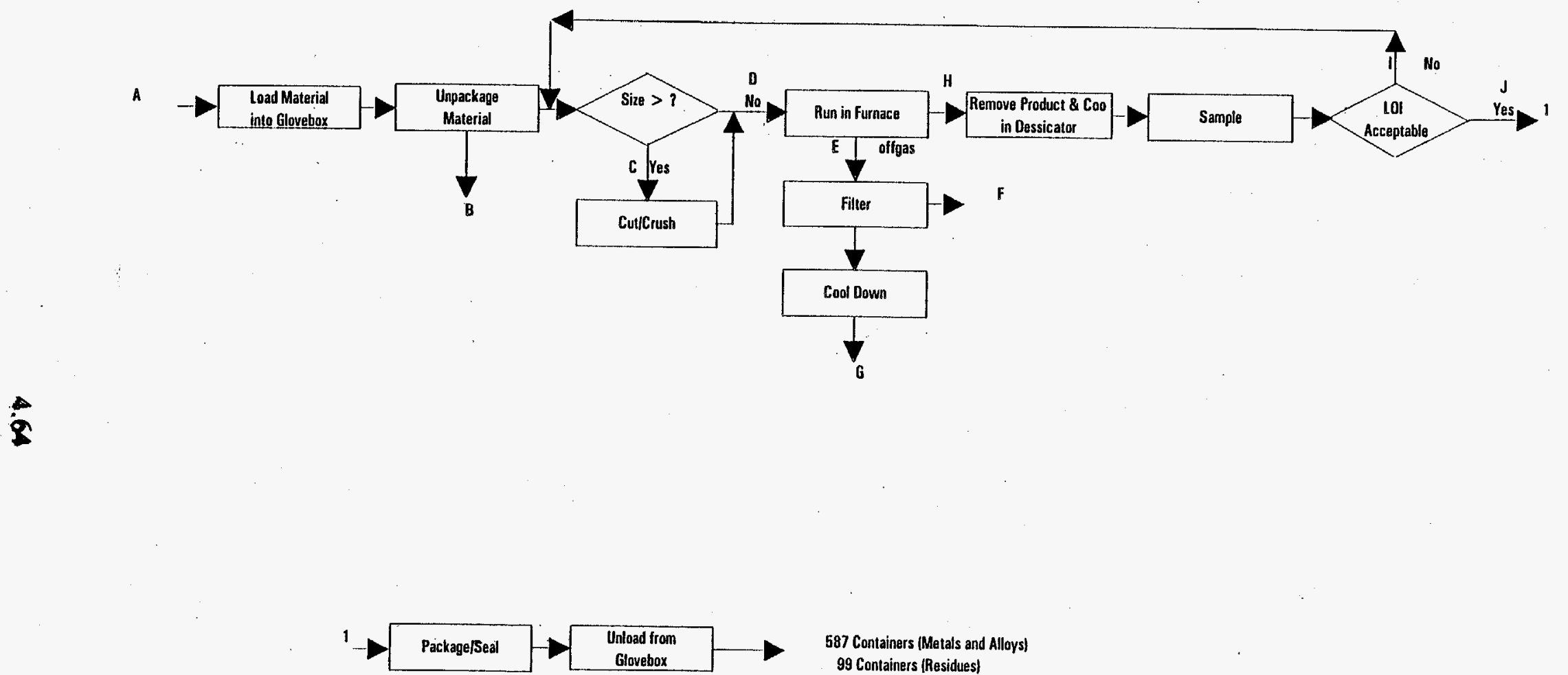

Figure 4.21. Flow Diagram for the Muffle Furnace Process - Metals and Alloys, and Sand, Slag and Crucibles (Residues) 
- Glovebox HC-21C - Glovebox HC-21C is located on the west side of room 230A in 234-5Z Building. The glovebox is about $3.0 \mathrm{~m}$ long. The inside of the working floor is $1.1 \mathrm{~m}$ wide, with a sloping face along its entire length. The glovebox is supported by a stand, and the floor of the glovebox is $1.4 \mathrm{~m}$ above the room floor. A conveyer runs along the north end of the glovebox and fits closely to the working floor. The glovebox will house two muffle furnaces, one Mettler balance and one desiccator.

- Glovebox HC-21A - Glovebox HC-21A is located in room 230B in the 234-5Z Building. The glovebox is similar in design to Glovebox HC-21C. The HC-2 conveyor also runs along the north end of the glovebox. Items are passed back and forth between Gloveboxes HC-21C and HC-21A. The glovebox will house the sieve shaker, one desiccator, and one Mettler balance.

- Muffle Furnace - The furnace is a Thermolyne Model FA1630 with chamber dimensions of $14 \mathrm{~cm}$ wide by $13 \mathrm{~cm}$ high by $33 \mathrm{~cm}$ in depth. The operating temperature range is $150^{\circ}$ to $1093^{\circ} \mathrm{C}$. A door safety switch removes power to the heating elements when the door is opened. Four additional factory-drilled holes have been located in the back plate of the furnace for the carbon dioxide supply line, the exhaust line, and two thermocouples.

- Boats - The boats are constructed of a 10-cm-diameter, Schedule 10 stainless steel pipe with a pipe cap welded to each end. The pipe is then cut lengthwise leaving it with a dimension roughly $23 \mathrm{~cm}$ long with a volume of a little less than $1.5 \mathrm{~L}$. Stands and tubing are welded on the bottom for stability. The tubing allows the boat to be remotely handled with a specially designed boat handling tool that resembles a tuning fork. Inconel 600 boats may be required because of the high operating temperatures.

- Vacuum Line - The 1.3-cm exhaust line from each furnace ties into the plant's 111-Torr vacuum system. The exhaust air passes through a ceramic filter followed by an air heat exchanger and a rotameter. The rotameter is adjusted manually to throttle the flow rate. The ceramic filters have a $\mathrm{dP}$ gage to indicate if the filter becomes plugged. The $\mathrm{dP}$ is checked prior to starting a heating cycle. The exhaust line is made from Inconel 600 to withstand the high temperatures. Stainless steel becomes embrittled and suffers extensive scaling at temperatures over $800^{\circ} \mathrm{C}$.

- Heat Exchanger - The hot exhaust stream flows through a 1.3-cm-diameter, Inconel tubing coil mounted inside a $15-\mathrm{cm}$-diameter, aluminum pipe that is open at both ends for convective cooling flow.

- Ceramic Filter - A stainless steel cartridge with ceramic filter media is installed in the exhaust line to filter out suspended particles in the off gas. 
- Desiccator - Desiccator cabinets are constructed of stainless steel with tempered glass door and sides. The cabinet is fitted with a front opening, positive-latch door with a neoprene gasket. A manual relief valve allows for chamber pressure equalization. Outside dimensions are $32 \mathrm{~cm}$ long by $32 \mathrm{~cm}$ wide by $31 \mathrm{~cm}$ high.

The desiccant is silica gel contained in a small canister that can be recharged. Each canister has an indicating window that changes color when the desiccant needs recharging (drying). Each of the furnace controllers are programmed so that the canisters can be recharged. Recharging consists of heating the desiccant up to $175^{\circ} \mathrm{C}$ for $11 / 2$ hours.

- Mesh Sieve and Shaker - A fairly uniform particle size is required to assure that samples taken for LOI are representative. If no large chunks of product are present after processing, sieving may not be required. If the particle size distribution is large, a four-mesh sieve and sieve shaker is used to screen the product after it has cooled. A mortar may also be used to break up larger chunks. The sieve is installed in an enclosed shaker in Glovebox HC-21A. The sieve plates are purged with argon prior to sieving to displace moist glovebox air.

- Scale - The scale is an electric Mettler balance. A scale will be located in both Glovebox HC-21C to weigh feed items prior to processing and in Glovebox HC-21A to weigh items prior to packaging.

\subsubsection{Criteria}

- Technical Feasibility - The equipment exists in the PFP, has been tested, and is planned for use in the interim action. However, some form of stirrer may be required and a final process defined for metals, alloys, and residues.

- Effluents/By-products - One container and the plastic for sealing in the container per container (assumed), filter wash and filtrate ( 1 to $3 \mathrm{~L}$ per campaign), and off gas (see Tables 4.23 and 4.24).

- Energy Resources - Same as for other high-fired oxides (see polycubes).

- Weapons Potential - The resultant product is high-fired oxides that would be difficult to digest with acids and would require processing to convert to a metal. The product may include impure plutonium with metals, metal oxides, and plutonium isotopes not useful in weapon production.

- End Product Volume - Thermal treatment results in an increased volume for the metals and alloys product. Plutonium metal volume increases significantly when oxidized. The impact of oxidizing the other metals is unknown. The weight of the product is estimated as $557.91 \mathrm{~g} / \mathrm{batch}$ for a total of $1160 \mathrm{~kg}$. Five-hundred and eighty-seven containers are estimated for the product (original containers numbered 499). 
Table 4.23. Muffle Furnace - Residue Effluent Stream Descriptions (rounded to two significant digits)

\begin{tabular}{|c|c|c|c|c|c|c|c|c|c|c|c|c|}
\hline Stream & A & B & C & D & $\mathbf{E}$ & $F$ & G & $H$ & I & d & Not Shawn & \\
\hline Description & $\begin{array}{c}\text { Residual } \\
\text { Feed }\end{array}$ & Packaging & $\begin{array}{c}\text { Oversized } \\
\text { Material }\end{array}$ & Batch & Off Gas & Filter Wash & $\begin{array}{c}\text { Gas to } \\
\text { Ventilation }\end{array}$ & Product & Rework & $\begin{array}{l}\text { Acceptable } \\
\text { Product }\end{array}$ & Air Input & $\begin{array}{c}\text { Filter Wash } \\
\text { Input }\end{array}$ \\
\hline Phase & Solid & Solid & Solid & Solid & Gas & Liquid & Gas & Solid & Solid & Solid & Gas & Liquid \\
\hline gms/container & 990.00 & $0.01 \mathrm{~m} 3 / \mathrm{day}$ & 99 & & & & & & & & & \\
\hline gms/batch & & & & $<500$ & 3,100 & 1.31/camp & 3,100 & 450 & 45 & 410 & 3,100 & 1.3 I/camp \\
\hline gms Pu/batch & & & & $<53$ & & & & 53 & 5 & 47 & & \\
\hline & & & & & & & & & & & & \\
\hline HNO3 & & & & & & $1.31 /$ camp & & & & & & 1.3 //camp \\
\hline 02 & & & & & 620 & & 620 & & & & 620 & \\
\hline Pu02 & & & & & & & & 60 & 6 & 54 & & \\
\hline $\mathrm{CO2}$ & & & & & & & & & & & & \\
\hline N2 & & & & & 2,500 & & 2,500 & & & & 2,500 & \\
\hline Dther & & & & 447 & $? ? ?$ & & ??? & 390 & 39 & 350 & & \\
\hline
\end{tabular}


Table 4.24. Muffle Furnace - Metals and Alloys Stream Descriptions (rounded to two significant digits)

\begin{tabular}{|c|c|c|c|c|c|c|c|c|c|c|c|c|}
\hline Stream & $A$ & B & C & D & $\mathbf{E}$ & $F$ & G & $\mathrm{H}$ & 1 & $J$ & Not Shown & \\
\hline Description & Metals Feed & Packaging & Too Big & Batch & Off Gas & Filter Wash & $\begin{array}{c}\text { Gas to } \\
\text { Ventilation }\end{array}$ & Product & Rework & $\begin{array}{c}\text { Acceptable } \\
\text { Product } \\
\end{array}$ & Air Input & $\begin{array}{c}\text { Filter Wash } \\
\text { Input }\end{array}$ \\
\hline Phase & Solid & Solid & Solid & Solid & Gas & Liquid & Gas & Solid & Solid & Solid & Gas & Liquid \\
\hline gms/container & 2,100 & $0.01 \mathrm{~m} 3 /$ day & 1,000 & & & & & & & & & \\
\hline gms/batch & & & & $<500$ & 3,100 & 1.3 I/camp & 3,100 & 560 & 56 & 500 & 3,100 & 1.3 l/camp \\
\hline gms Pulbatch & & & & $<370$ & & & & 370 & 37 & 330 & & \\
\hline & & & & 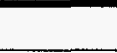 & & & & & & & & \\
\hline HNO3 & & & & & & 1.3 //camp & & & & & & 1.3 l/camp \\
\hline 02 & & & & & 580 & & 580 & & & & 620 & \\
\hline PuO2 & & & & 42 & & & & 420 & 42 & 380 & & \\
\hline Pu & & & & 330 & & & & & & & & \\
\hline N2 & & & & & 2,500 & & 2,500 & & & & 2,500 & \\
\hline Other & & & & 130 & & & & 140 & 14 & 120 & & \\
\hline & & & \multicolumn{3}{|c|}{ Metals/Oxides } & & \multicolumn{3}{|c|}{ Metals/Oxides } & \multicolumn{2}{|l|}{ Metals/Oxides } & \\
\hline
\end{tabular}


- End Product Stability - The product will be chemically inert and will have an LOI of less than $1 \%$ before it is packaged.

- Environmental Risk - Minimal (see worker risk).

- Worker Risk: Explosion - slight risk. Plutonium metal is pyrophoric. However, large pieces of plutonium metal are not pyrophoric. The temperature will be slowly ramped to $500^{\circ} \mathrm{C}$ to assure the metal will not ignite. Also, if required, the furnace can be operated under reduced oxygen to control the oxidation rate of the metal. Carbon dioxide, or another inert gas, could be used. The furnace will be operated at slightly negative pressure compared to the glovebox. It is assumed the chance of occurrence is no worse than the chance of an explosion in the HLW. calciner which is estimated as $6 \mathrm{E}-07$.

Routine - Workers will be exposed during the mortar and pestle operation.

- Costs - The system construction cost is minimal if a stirrer is required.

For metals and alloys, the systems operations cost is not minimal (max crew of 2 people, around the clock, for 1040 operational days). Personnel costs, at $\$ 100 \mathrm{~K} /$ person/yr, are estimated at $\$ 2.5 \mathrm{M}$. For residues, 1347 operational days at $\$ 3.2 \mathrm{M}$ would be required. Costs would include electricity to run the muffle furnaces.

D\&D costs should be minimal. The waste generated during $D \& D$ would be the equipment in the gloveboxes and the gloveboxes themselves.

- Operation Duration - Estimated for metals and alloys as 1040 operational days (assuming 2 batches/d), or 4.2 years (assuming 50-week years). For residues, 1347 operational days or 5.4 years would be needed.

- Public Acceptance - Public acceptance has been high for the interim action.

- Flexibility - The only restrictions on input are criticality issues, potential for overflowing the boat, and organics greater than 2 .

- Materials Covered - As presently configured, the muffle furnaces could handle the combustibles, oxides, sand slag and crucibles, and metals and alloys. For treating polycubes, the process will require some modification for safety, and it is not applicable for the fluoride compounds. 


\subsection{Molten Salt Oxidation}

The molten salt oxidation (MSO) process (Figure 4.22) was originally developed by Lawrence Livermore National Laboratory and Rockwell International (Rockwell 1993; Cooper et al. 1991) as an alternative to incineration for treating mixed wastes. The process is described below in detail.

\subsubsection{Process Description}

In the MSO process, wastes, and oxygen are introduce under the surface of a bed of molten salt. The salt is comprised of a suitable mixture of the carbonates, chlorides, or sulfates of sodium, potassium, lithium, or calcium. The salts provide heat transfer and reaction media and catalyze the reaction of the organic waste components with oxygen to produce carbon dioxide, nitrogen, and water (steam). Inorganic components (such as radioactive actinides and metallic impurities) in the form of "ash" are retained in the molten salt bed (melt) as a result of particle wetting, encapsulation, and chemical dissolution and solvation. Pyrolysis of halogenated hydrocarbons in the waste generates acid gases which are scrubbed by the alkaline carbonates, producing the corresponding salt. For example, the reactions of sodium carbonate with plutonium chloride and carbon tetrachloride solutions are as follows:

$$
\begin{gathered}
4 \mathrm{PuCl}_{3}+6 \mathrm{Na}_{2} \mathrm{CO}_{3}+\mathrm{O}_{2} \rightarrow 4 \mathrm{PuO}_{2}+12 \mathrm{NaCl}+6 \mathrm{CO}_{2} \\
\mathrm{CCl}_{4}+2 \mathrm{Na}_{2} \mathrm{CO}_{3} \rightarrow 4 \mathrm{NaCl}+3 \mathrm{CO}_{2}
\end{gathered}
$$

"Ash" builds up in the melt as either dissolved substances or as a slurry. Continuous removal of the "ash" at concentrations greater than $20 \mathrm{wt} \%$ preserves the fluidity of the melt for contacting of the waste with oxygen, wetting particulates, and transfer of the melt. The withdrawn melt/ash is dissolved in water. The oxides and salts of actinides, being insoluble in the alkaline solution, precipitate and are filtered out. This solid "ash" from filtering is collected and requires further processing (i.e., calcination) to meet stability requirements. The alkaline solution containing the dissolved salts is sent to the tank farms as low-level radioactive waste. Off gases from the MSO process are pre-filtered and then HEPA filtered before being vented.

The MSO process is operated at $800^{\circ}$ to $1000^{\circ} \mathrm{C}$ and at atmospheric pressure with a residence time in the molten salt unit on the order of hours. The unit is typically operated with $20 \%$ to $30 \%$ excess air. Equipment modifications to the feed system are required for the different material types processed to get the feed size down to 1/8 in. or less (Martin Marietta Energy Systems, Inc. et. al. 1993). The total heat of reaction for organics is often sufficient to maintain the operating temperature of the molten salt bed without the need for auxiliary heat. 


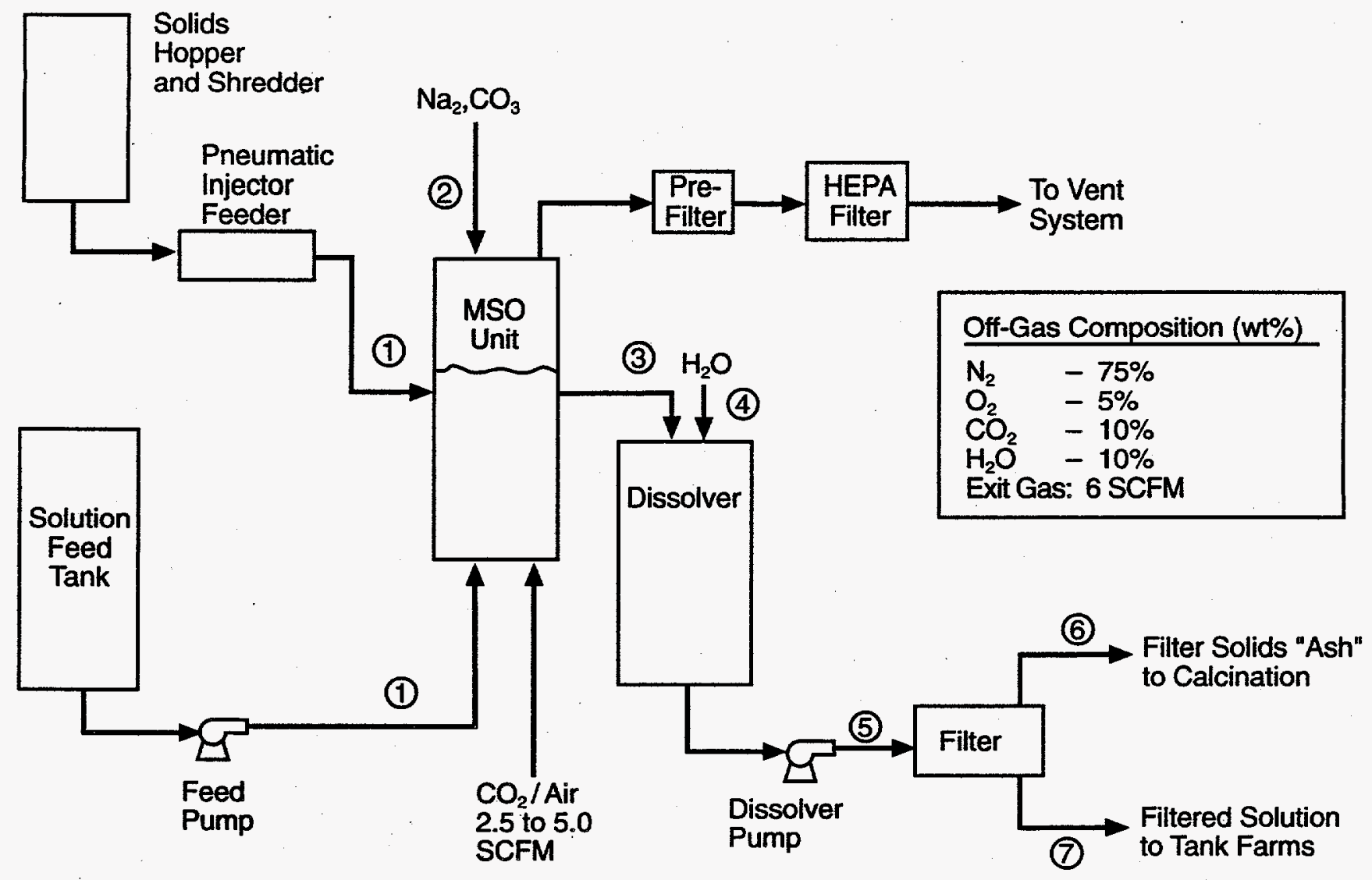

\begin{tabular}{||l|r|r|r|r|r|r|r|r||}
\hline \multicolumn{1}{|c|}{ Stream } & \multicolumn{1}{c|}{ Vent } \\
\hline \multicolumn{1}{|c|}{ Component } & \multicolumn{1}{|c|}{2} & 3 & 4 & 5 & 6 & 7 & \\
\hline Polycubes $(\mathrm{g} / \mathrm{h})$ & 97 & 0 & 0 & 0 & 0 & 0 & 0 & 0 \\
\hline $\mathrm{PuO}_{2}(\mathrm{~g} / \mathrm{h})$ & 260 & 0 & 260 & 0 & 260 & 260 & $<0.03$ & 0 \\
\hline Oxygen $(\mathrm{g} / \mathrm{h})$ & 0 & 0 & 0 & 0 & 0 & 0 & 0 & 150 \\
\hline Nitrogen $(\mathrm{g} / \mathrm{h})$ & 0 & 0 & 0 & 0 & 0 & 0 & 0 & 1500 \\
\hline Sodium Carbonate $(\mathrm{g} / \mathrm{h})$ & 0 & 1060 & 1060 & 0 & 1060 & 0 & 1060 & 0 \\
\hline Water (g/h) & 0 & 0 & 0 & 2650 & 2650 & 150 & 2500 & 34 \\
\hline Carbon Dioxide $(\mathrm{g} / \mathrm{h})$ & 0 & 0 & 0 & 0 & 0 & 0 & 0 & 330 \\
\hline
\end{tabular}

Figure 4.22. Molten Salt Oxidation Flow Diagram 


\subsubsection{Facilities and Equipment Required}

An MSO process will require new equipment to be installed in the PFP. The equipment required for an MSO process is depicted on the attached flowsheet. The molten salt unit is a 6-in.-in-diameter by 36 -in.-high alumina tube similar to the one used by Oak Ridge National Laboratory (Crosley et al. 1993).

The MSO process can be operated utilizing the PFP's existing utilities, materials, supplies, and personnel. Utilities needed are air, carbon dioxide, and water. Raw materials needed are sodium carbonate. Two operators per shift are expected to operate the MSO unit and supporting equipment.

The PFP will need space modifications to accommodate the MSO process. Roughly $1000 \mathrm{ft}^{2}$ of floor space and roughly $500 \mathrm{ft}^{3}$ of glovebox space are needed. A new glovebox will be needed to house all the MSO equipment as the existing PFP gloveboxes are not large enough.

\subsubsection{Schedule}

The MSO process has been successfully demonstrated to treat mixed wastes (Upadhye et al. 1993a) and high explosives and liquid propellants (Upadhye et al. 1993b). The MSO processes' applicability to the various PFP wastes has also been documented (Wojdac 1994). Therefore, little process development time is necessary for the MSO process.

The size of the tested MSO unit process design (15 $\mathrm{cm}$ in diameter by $91 \mathrm{~cm}$ high) is sufficient to process the PFP wastes without the need for scale-up design work. Time will be needed, however, for installation and checkout of the process. Operating procedures, safety analyses, SAR revisions, and operator training must be developed and completed.

The total operating time, based on a feed rate of $0.45 \mathrm{~kg}$ of waste per hour for all materials (solutions and solids), is provided in Table 4.25.

\subsubsection{End Product Description}

The products from MSO are concentrated actinide oxides and salts (ash) from the filtration step. This "ash" must be processed further (i.e., calcination) to meet the loss-on-ignition requirements for stability. The amount would be approximately $1500 \mathrm{kgs}$ as plutonium oxide plus the water weight.

\subsubsection{Effluents and By-Products}

The solid by-product from the MSO process is $\mathrm{NaCl}$ and $\mathrm{Na}_{2} \mathrm{CO}_{3}$ and trace actinides collected on the MSO unit pre-filter. This by-product is assumed to be sent to the tank farms as a caustic solution.

The gaseous effluents from the MSO process are carbon dioxide, nitrogen, water, and oxygen. This gaseous stream is pre-filtered then HEPA filtered before being vented. The existing PFP 
Table 4.25. MSO Operating Data

\begin{tabular}{|l|c|c|c||}
\hline \multicolumn{1}{|c|}{ Material } & Hours & Weeks $^{\text {(a) }}$ & PFP Inventory (kgs) \\
\hline \hline Nitrate Solutions & 7696 & 107 & 3498 \\
\hline Chloride Solutions & 484 & 7 & 220 \\
\hline Oils and Organics & 49 & 0.7 & 22 \\
\hline Other Aqueous Solutions & 2904 & 41 & 1320 \\
\hline Combustibles & 154 & 2.1 & 69.6 \\
\hline Polycubes & 415 & 6 & 188.6 \\
\hline Metals and Alloys & 2288 & 32 & 1040 \\
\hline Process Residues & 3023 & 42 & 1374 \\
\hline Fluoride Compounds & 33 & 0.5 & 14.7 \\
\hline (a) Assumed 24 h/d, 5 d/wk, at 60\% availability. \\
\hline
\end{tabular}

ventilation system is capable of handling this gaseous stream. It is assumed that the off-gas stream contains only trace amounts of $\mathrm{CO}, \mathrm{NO}, \mathrm{NO}_{\mathrm{x}}, \mathrm{HNO}_{3}, \mathrm{HCl}$, and any unburned hydrocarbons such that it meets air quality emission limitations without the need for off-gas condensation or oxidation.

The liquid effluent from the MSO process is the alkaline solution from filtering containing the dissolved salts. This liquid stream is assumed to contain $\mathrm{Pu} \leq 0.013 \mathrm{~g} / \mathrm{L}$ and is assumed to be sent to the tank farms without further processing.

\subsubsection{Risks}

No radioactive or hazardous components are exhausted to the ventilation system. Other than the waste, no additional chemicals are used in the process other than sodium carbonate. The oxides/salts and "ash" are stable and non-hazardous. Therefore, there are minimal exposure risks with the MSO process.

Operational risks of back-burn and steam explosions have been described in the literature (Upadhye et al. 1993b) and can be mitigated with proper equipment and operating conditions. Direct denitration of plutonium nitrate solutions must be such that the aqueous solutions are slowly added to the melt to avoid the rapid generation of steam which could blow the melt out of the reactor. Rockwell has successfully accomplished direct denitration by the slow addition of plutonium nitrate coupled with an inert gas sparge to keep the melt bed agitated (Wojdac 1994). 


\subsubsection{Costs}

New capital equipment costs of approximately $\$ 600,000( \pm 30 \%)$ are expected. In addition, costs will be incurred to develop the process for the PFP wastes, to modify the PFP for adequate space, and to install and checkout equipment. Also, administrative costs will be incurred for preparation and approval of documents (operating procedures, safety analyses, SAR revisions, maintenance, training, etc.). Operational costs of an MSO process are expected to be no greater than other competing processes due to the minimal number of steps involved and the simplicity of operations. Waste disposal costs are also expected to be comparable to other competing processes due to utilizing the existing PFP ventilation system and the existing tank farms.

It is estimated that the operating cost of an MSO process will be on the order of dollars $/ \mathrm{kg}$-waste (Cooper et al. 1991). It is also estimated that two operators per shift can operate the MSO unit and supporting equipment.

\subsubsection{Comments}

The process has been successfully demonstrated on mixed combustible wastes in bench and pilotscale studies, with actinide removal efficiencies exceeding 99.9999\% (Cooper et al. 1991; Rockwell International 1994). It has also been demonstrated for treating carbon tetrachloride, TBP, and plutonium nitrate solutions. An MSO process has been successfully operated using a $10-\mathrm{cm}-$ or 15-cm-diameter size unit at the following locations:

- Oak Ridge National Laboratory - 15-cm-diameter unit processing hazardous wastes

- Lawrence Livermore National Laboratory - 15-cm-diameter unit processing radioactive and mixed wastes

- Los Alamos National Laboratory - 10-cm-diameter unit processing radioactive combustible waste and rags using an in-line shredder and feeder.

The MSO process is favored by the DOE (EM-40) over other alternative technologies for treating mixed wastes (Taylor 1993). The MSO process also has several advantages over incineration:

- There is no open flame in MSO.

- The containment of actinides and heavy metals is accomplished by chemical means (wetting and dissolution).

- The operating temperature of MSO is much lower and without high exhaust velocities, thus lowering the volatilities of radioactive actinides.

- No acid gases are generated in MSO. 
- More complete destruction due to the catalytic effect of the salt, a longer residence time, and more intimate contact with the caustic molten salt.

The MSO process has future applications for processing a large quantity of all the wastes at the Hanford Site as well as radioactive and mixed wastes from other sites.

A two-stage MSO process (pyrolysis and oxidation) was not considered due to concerns with technical feasibility within 2 years. In addition, carbonate recycle was not considered because of the complexity of additional processing.

\subsubsection{Nitrate Solutions}

Stabilization of plutonium nitrate solutions can be accomplished by direct injection of the nitrate solutions into the molten salt bed. Conditions must be such that the aqueous solutions are slowly added to the melt to avoid the rapid generation of steam which could blow the melt out of the reactor. Rockwell experimenters have determined that direct denitration can be successfully accomplished by the slow addition of plutonium nitrate coupled with an inert gas sparge to keep the melt bed agitated.

\subsubsection{HEPA Filters}

Typically, spent HEPA filters are physically degraded and contaminated with radioactive dust. The primary contaminants are plutonium and americium. Utilizing molten salt technology, the HEPA filters would be crushed and compacted into cylinders. The cylinders would be introduced into the salt bed via an in-line shredder/feeder feed mechanism. Oxygen is introduced via a support gas injector to support the combustion of the wood filter frames and other combustible materials. The glass filter matrix forms beads in the salt bed. The beads will be almost neutrally buoyant in the molten salt bed as their specific gravity is 2.23 compared to 2.53 for sodium carbonate. The plutonium oxide will, thus, be retained in the "ash."

\subsubsection{Combustibles}

Molten salt technology, in this instance, demonstrates a unique feature in that it is a thermal process but does not fit the definition of incineration. The degradation process is a function of the temperature of the salt bed, which is fixed, and the oxygen content of the salt bed environment, which is variable. The rate of degradation can, therefore, be controlled by adjusting the oxygen sparge rate. The combustibles would be fed to the molten salt unit through and in-line shredder/feeder.

\subsubsection{Polycubes}

The molten salt feed system for polycubes would make use of the fact that the system runs at an elevated temperature. Full size polycubes would be introduced into a heated hopper where they would be heated to a temperature above their softening point. The flowable material would then be fed to the molten salt reactor using a pneumatic injector. The oxygen content of the salt bed would be regulated 
to control the rate of oxidation, and the plutonium oxide would be collected in the "ash." In this case, as with any application of molten salt technology, if it is found that the styrene or other reactive materials are not fully reacted during the residence time in the reactor, the off gas can be processed through a second molten salt reactor, thus utilizing a two-stage system. The dimensions of each reactor can be tailored to fit the unit operations requirements of velocity through the bed, transit time, and reaction temperature.

\subsubsection{Sludges}

Molten salt technology offers a unique solution in that it can easily operate in a pulse continuous mode. In a pulse continuous mode the sludges are packaged in a size sufficiently small to obviate events of any consequence regarding the rapid decomposition of nitrated tri-n-butyl phosphate. The packages, similar to toilet tissue rolls, would be fed to the hot reactor unit via a pneumatic or mechanical feed mechanism.

\subsubsection{Oils and Organics}

Chlorinated simple hydrocarbons react readily with molten sodium carbonate to produce sodium chloride and carbon dioxide.

$$
\mathrm{CCl}_{4}+\mathrm{Na}_{2} \mathrm{CO}_{3} \rightarrow 4 \mathrm{NaCl}+3 \mathrm{CO}_{2}
$$

In this case oxygen is required, ordinary oils undergo simple oxidation to carbon dioxide and water, with the non-combustible residues remaining in the salt bed.

\subsubsection{Graphite}

Graphite, especially ultrapure nuclear-grade graphite, is exceptionally difficult to oxidize by any means. For MSO, the sodium carbonate salt would be augmented with $10 \%$ sodium sulfate to catalyze the reaction if needed.

\subsubsection{Fluorine-Bearing Materials}

For MSO, fluorine can cause corrosion of refractory lining in the MSO vessel in the range of 25 weight\% NaF. When operating an MSO system with high fluorine wastes, the NaF concentration in the MSO vessel is conservatively maintained at $10 \%$ and is run in a constant salt overflow mode. The overflow salt, containing $10 \% \mathrm{NaF}$, is dissolved in water and mixed with calcium hydroxide to form insoluble $\mathrm{CaF}_{2}$. The remaining $\mathrm{Na}_{2} \mathrm{CO}_{3}$ is then recycled back to the MSO vessel after drying. In this manner, the saturation efficiency of $\mathrm{Na}_{2} \mathrm{CO}_{3}$ can be maintained at a high level of weight-percent. 


\subsection{Vertical Calciner}

The vertical calciner direct denitration method is described below.

\subsubsection{Direct Denitration Process}

Direct denitration is a process whereby plutonium nitrate solutions are converted directly to plutonium oxide in a calciner without formation of an intermediate plutonium compound. The plutonium nitrate solution is heated in an air atmosphere to evaporate the water and nitric acid, leaving a solid plutonium oxide particle. The addition of additives may be necessary to prevent the formation of a mastic stage and to prevent foaming. The testing to date has not covered all the material combination present at PFP and operating problems are likely without development testing. The overall calcination reaction is as follows:

$$
\mathrm{Pu}\left(\mathrm{NO}_{3}\right)_{4} \rightarrow \mathrm{PuO}_{2}+3.4 \mathrm{NO}_{2}+0.6 \mathrm{NO}+1.3 \mathrm{O}_{2}
$$

The product is a dry, impure plutonium oxide powder. The calciner off-gas stream consists of a mixture of air, water, nitric acid, and oxides of nitrogen. In addition, fine plutonium oxide powder is often entrained in the gas stream. The off-gas stream is filtered to remove the entrained oxide and cooled in a condenser to remove most of the water and nitric acid. The off gas is then sent to the plant ventilation system.

During thermal denitration of uranyl nitrate and plutonium nitrate, the solution is successively dehydrated and then denitrated, remaining fluid becomes increasingly viscous and pasty until conversion to the dry oxide state is essentially complete. The material will become mastic, tending to form hard deposits on equipment surfaces and on particulate material throughout the reaction zone, unless the transition to dry oxide is accomplished quickly.

The feed to the vertical calciner reactor is metered slowly into a heated stirred bed of previously generated product solids. The liquid feed is rapidly evaporated, then, more slowly, undergoes drying and denitration and final heat treatment to stable plutonium dioxide. The agitator blades classify the solid particles, with the larger particles moving upward and the fines settling to the bottom of the calciner. The plutonium oxide product is discharged through a slot in a pipe, down an overflow tube, and into a receiver. The height of the adjustable overflow tube determines the bed volume within the calciner. The vertical calciner is operated at $800^{\circ} \mathrm{C}$. Capacity of the vertical calciner is roughly 2 to $3 \mathrm{~L} / \mathrm{h}$ of solution for concentrated feeds and 3 to $4 \mathrm{~L} / \mathrm{h}$ for dilute feeds.

The calciner can process plutonium nitrate solutions and filtrate, plutonium-uranium nitrate solutions, and plutonium-thorium nitrate solutions. The nitrate-based solutions may contain organics and chlorides. In addition, nitric acid digestible materials, such as sludges and residues, are candidate feed materials for this process. Aqueous hydrochloric solutions may also be processed in a vertical calciner. 
The plutonium oxychloride will decompose releasing chloride to the off gas. Other chloride compounds such as $\mathrm{KCl}$ would remain in the oxide product.

The plutonium dioxide product may also contain some residual sulfate and/or phosphate impurities, but will be free of other volatile acid impurities. Organic impurities are largely consumed and only partly report to the off-gas condensate. Off-gas condensates are expected to be non-TRU; however, test data are not available.

\subsubsection{Facilities and Equipment Required}

The equipment required for a vertical calciner denitration process is depicted on the attached flowsheet. The equipment is sized to process 2 to $3 \mathrm{~L} / \mathrm{h}$ of solution for concentrated feeds and 3 to $4 \mathrm{~L} / \mathrm{h}$ for dilute feeds.

The existing PFP does not have a vertical calciner in place. However, the PFP does have the necessary utilities, operating materials, supplies, and manpower to operate a vertical calciner process and has operated other calcination process in the past. The PFP's floor space must be modified to accommodate the vertical calciner equipment. Roughly $50 \mathrm{~m}^{2}$ of floor space and roughly $15 \mathrm{~m}^{3}$ of glovebox space is needed. Glovebox HC-9B may be used for the vertical calciner, and Glovebox HA-46 may be used for treatment of the off-gases.

New capital equipment costs of approximately $\$ 50 \mathrm{~K}$ are expected for processing only nitrate solutions and $\$ 60 \mathrm{~K}$ for all solutions. Costs of supporting equipment for all the solutions are shown in Table 4.26. Additional costs will be incurred to modify the PFP for adequate space and to install and

Table 4.26. Equipment Description and Costs

\begin{tabular}{|c|c|c|c|}
\hline Description & Size/Capacity & $\begin{array}{l}\text { Material of } \\
\text { Construction }\end{array}$ & $\begin{array}{c}\text { Estimated } \\
\text { Cost }(\$)\end{array}$ \\
\hline Feed Tank & $\begin{array}{l}15 \mathrm{~cm} \text { dia. by } 150 \mathrm{~cm} \text { high; } \\
27.8 \mathrm{~L} \text { capacity }\end{array}$ & Stainless Steel or Glass & 2,000 \\
\hline Feed Metering Pump & $14 \mathrm{~min}$ & Stainless Steel & 3,000 \\
\hline Feed Line Water Jacket & $2.5 \mathrm{~cm}$ dia. by $30 \mathrm{~cm}$ long & Stainless Steel & 1,000 \\
\hline $\begin{array}{l}\text { Vertical Calciner with Off-Gas Filters, } \\
\text { Stirrer, Drive, and Drive Controller }\end{array}$ & $13 \mathrm{~cm}$ dia. by $46 \mathrm{~cm}$ high & Inconel or Hastelloy & 25,000 \\
\hline Pu Oxide Receiver Vessel & $15 \mathrm{~cm}$ dia. & Stainless Steel & 1,000 \\
\hline Calciner Heaters and Controller & $15 \mathrm{~cm}$ dia. muffle; $6 \mathrm{KW}$ & & 10,000 \\
\hline Off-Gas Condenser and/or Scrubber & $\begin{array}{l}\text { Shell \& Tube; } 30,000 \mathrm{BTU} / \mathrm{hr} \text {. } \\
\text { capacity } \\
15 \mathrm{~cm} \text { dia. by } 122 \mathrm{~cm} \text { long scrubber }\end{array}$ & Hastelloy C-22 & 10,000 \\
\hline Condensate Receiving Tank & $\begin{array}{l}15 \mathrm{~cm} \text { dia. by } 150 \mathrm{~cm} \text { high; } \\
27.8 \mathrm{~L} \text { capacity }\end{array}$ & Stainless Steel or Glass & 2,000 \\
\hline Condensate/Scrubber Pump & $1.4 \mathrm{~min}$ & Hastelloy & 5,000 \\
\hline
\end{tabular}


checkout equipment. Also, administrative costs will be incurred for preparation and approval of documents (operating procedures, safety analyses, SAR revisions, maintenance, training, etc.). Operational costs of a vertical calciner direct denitration process are expected to be less than other non-direct denitration processes due to the minimal number of steps involved and the simplicity of operations. Waste disposal costs are also expected to be less than other nondirect denitration processes due to a lower impact on the ventilation and water treatment operations.

The vertical calciner direct denitration method has been demonstrated on a laboratory scale to successfully convert plutonium nitrate solutions of varying concentrations and molarities into plutonium dioxide powder. Although there are no data regarding plutonium nitrate - thorium nitrate and plutonium nitrate - uranyl nitrate mixtures, it is assumed that they would behave similarly in a direct denitration process to produce powder oxide products. Also, there are no literature references regarding the direct conversion of nitrate sludges and residues to oxides although these materials are expected to behave in the same manner as the nitrate solutions if they can be easily digested in nitric acid and fed to the calciner. Therefore, little process development time is necessary for the vertical calciner direct denitration process.

The size of the tested vertical calciner direct denitration process design (12-cm-diameter by 25-cm-high reactor) is sufficient to process the PFP wastes without the need for scale-up design work. However, the process equipment must undergo a thorough checkout with operating conditions established. Operating procedures, safety analyses, SAR revisions, and operator training must be developed and completed.

The systems flows that correspond to Figure 4.23 for the plutonium-bearing materials is shown in Tables 4.27 to 4.30. Approximately 3800 hours (total duration around 1.4 yrs) of operating time are needed (Table 4.31), based on a feed rate of $1 \mathrm{~L} / \mathrm{h}$ into the vertical calciner reactor and processing all the nitrate solutions, sludges, and filtrates.

The product from direct denitration is a solid plutonium dioxide powder or, in the case of metal mixtures, mixed oxide powder. These materials are stable (less than $1 \%$ LOI) and are ready for final packaging. The estimate product weights are $3.7 \mathrm{~kg}$ of plutonium oxide from the chloride waste, $331 \mathrm{~kg}$ of plutonium oxide from the nitrate waste, and $74 \mathrm{~kg}$ of plutonium oxide from the other waste.

\subsubsection{Effluents Generated}

Gaseous effluent from the direct denitration process include air, water, and NOx. This stream is condensed, and then the non-condensed gases are passed through HEPA filters and discharged to the existing PFP ventilation system. A scrubber may be needed to protect plant ventilation equipment. The total quantity of $\mathrm{NO}_{\mathrm{x}}$ from the plant is not an emissions hazard. Liquid effluent are the condensed water and nitric acid with $\mathrm{Pu} \leq 1 \mathrm{mg} / \mathrm{L}$. This stream is neutralized with $\mathrm{NaOH}$ solution and sent to the tank farm. The solid effluent is the entrained oxide powder on the off-gas filters. The filters, when plugged, are blown back with compressed air. Thus, entrained fines are returned to the powder bed. 


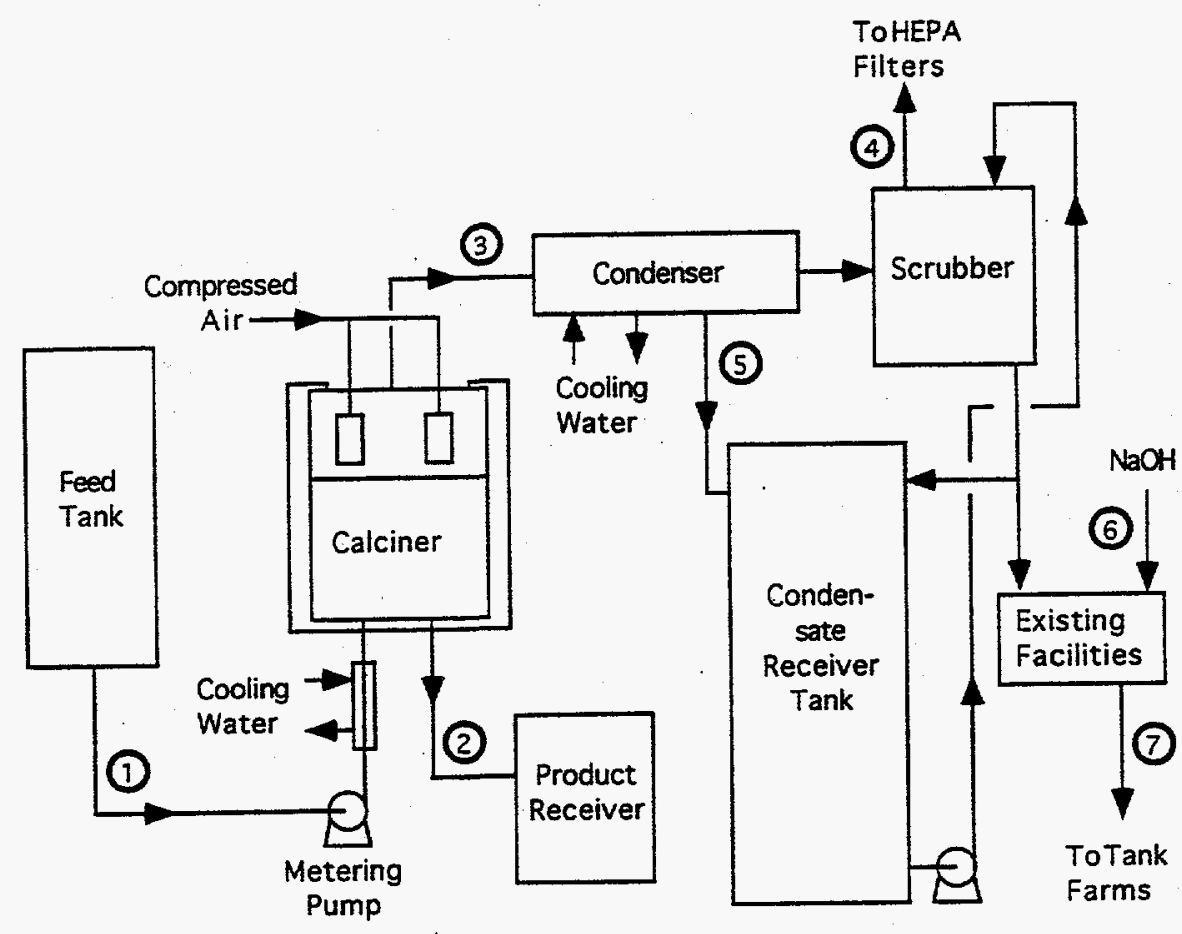

Figure 4.23. Vertical Calciner Flow Diagram

Table 4.27. Flows for Nitrate Solutions

\begin{tabular}{|c|c|c|c|c|c|c|c|}
\hline Stream Component & \multicolumn{7}{|c|}{ Nitrate Solutions } \\
\hline Description & 1 Feed & 2 Product & 3 Off Gas & $\begin{array}{c}4 \text { Off Gas } \\
\text { to Vent }\end{array}$ & 5 Condensate & $5 \stackrel{6}{\mathrm{M}} \stackrel{\mathrm{NaOH}}{\mathrm{NaO}}$ & $\begin{array}{l}7 \text { Neutralized } \\
\text { Liquid Waste }\end{array}$ \\
\hline Phase & Solution & Solid & Gas & Gas & Liquid & Liquid & Liquid \\
\hline Total Flow $(\mathrm{kg} / \mathrm{h})$ & 1.3 & 0.3 & 0.99 & 0.3 & 0.7 & 1.2 & 1.9 \\
\hline \multicolumn{8}{|l|}{ Chemical Components (g/h) } \\
\hline $\mathrm{Pu}\left(\mathrm{NO}_{3}\right)_{4}$ & 546 & & & & & & \\
\hline$\overline{\mathrm{H}_{2} \mathrm{O}}$ & 559 & & 559 & 46 & 513 & 1000 & 1500 \\
\hline $\mathrm{HNO}_{3}$ & 315 & & 315 & & 315 & & \\
\hline U/Th & 3 & 3 & & & & & \\
\hline Halides $(F+C L)$ & 1 & & 1 & & 1 & & 1 \\
\hline Metal Ions & 3 & 3 & & & & & \\
\hline Organics & 6 & & & & & & \\
\hline NO & & & 20 & 20 & & & \\
\hline $\mathrm{NO}_{2}$ & & & 174 & 174 & & & \\
\hline $\mathrm{O}_{2}$ & & & 46 & 46 & & & \\
\hline $\mathrm{PuO}_{2}$ & & 306 & & & & & \\
\hline $\mathrm{NaOH}$ & & & & & & 200 & \\
\hline $\mathrm{NaNO}_{3}$ & & & & & & & 514 \\
\hline
\end{tabular}


Table 4.28. Flows for Organic Solutions

\begin{tabular}{|c|c|c|c|c|c|c|c|}
\hline $\begin{array}{c}\text { Stream } \\
\text { Component }\end{array}$ & \multicolumn{7}{|c|}{ Organic Solutions } \\
\hline Description & 1 Feed & 2 Product & 3 Off Gas & $\begin{array}{l}4 \text { Off Gas } \\
\text { to Vent }\end{array}$ & $\begin{array}{c}5 \\
\text { Condensate }\end{array}$ & $\begin{array}{c}6 \\
5 \underline{\mathrm{MaOH}}\end{array}$ & $\begin{array}{l}7 \text { Neutralized } \\
\text { Liquid Waste }\end{array}$ \\
\hline Phase & Solution's & Solid & Gas & Gas & Liquid & Liquid & Liquid \\
\hline Total Flow $(\mathrm{kg} / \mathrm{h})$ & 1.3 & $<0.23$ & & & & & \\
\hline \multicolumn{8}{|c|}{ Chemical Components $(\mathrm{g} / \mathrm{h})$} \\
\hline Pu (all forms) & 204 & 204 & & & & & \\
\hline $\mathrm{PuO}_{2}$ & & 232 & & & & & \\
\hline $\mathrm{H}_{2} \mathrm{O}$ & & & $X^{(2)}$ & $\bar{X}$ & $\bar{X}$ & $\bar{X}$ & $\mathrm{X}$ \\
\hline $\mathrm{HNO}_{3}$ & & & & & $\bar{x}$ & & \\
\hline$\overline{\mathrm{U}}$ & & $\bar{X}$ & & & & & \\
\hline Halides & & $\mathrm{X}$ & $\bar{X}$ & & $\mathrm{X}$ & & \\
\hline $\mathrm{CO}_{2}$ & & & $\bar{X}$ & $\bar{X}$ & & & \\
\hline Organics & $\bar{X}$ & & $\bar{X}$ & $\bar{X}$ & & & \\
\hline $\mathrm{NO}_{\mathrm{x}}$ & & & $\bar{X}$ & $\overline{\mathbf{X}}$ & & & \\
\hline $\mathrm{O}_{2}$ & & & $\bar{X}$ & $\overline{\mathbf{X}}$ & & & \\
\hline $\mathrm{NaOH}$ & & & & & & $\bar{X}$ & \\
\hline $\mathrm{NaNO}_{3}$ & & & & & & & $\bar{X}$ \\
\hline Other & 1086 & & & & & & \\
\hline
\end{tabular}

Table 4.29. Flows for Filtrate Solutions

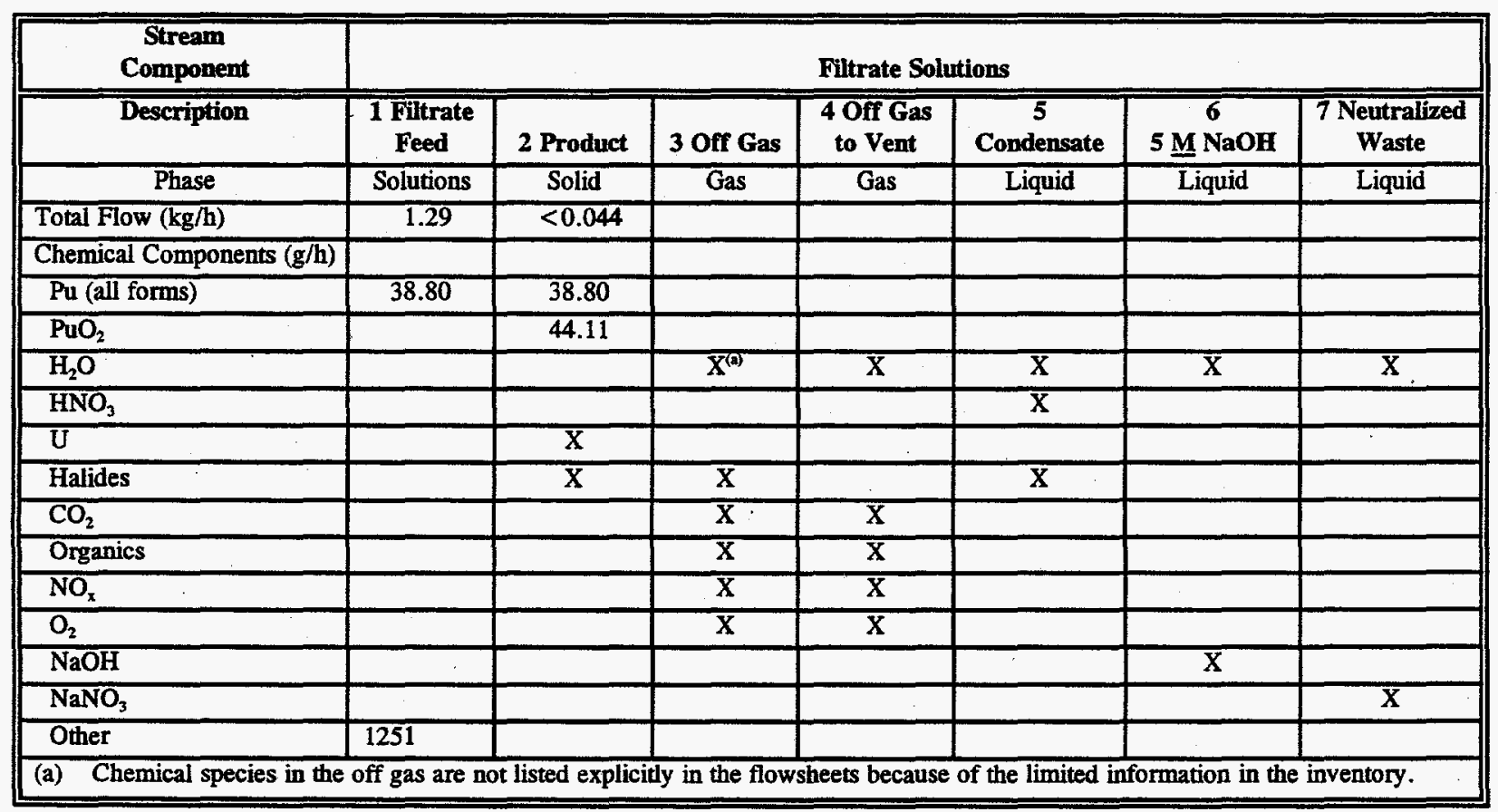


Table 4.30. Flows for Chloride Solutions

\begin{tabular}{|c|c|c|c|c|c|c|c|}
\hline $\begin{array}{c}\text { Stream } \\
\text { Description }\end{array}$ & 1 Feed & 2 Product & 3 Off Gas & $\begin{array}{c}4 \text { Off Gas to } \\
\text { Vent }\end{array}$ & $\begin{array}{c}5 \\
\text { Condensate }\end{array}$ & $\begin{array}{c}6 \\
5 \underline{\mathrm{M}} \mathrm{NaOH}\end{array}$ & $\begin{array}{c}7 \\
\text { Nentralized } \\
\text { Liquid } \\
\text { Waste }\end{array}$ \\
\hline Phase & Solution & Solid & Gas & Gas & Liquid & Liquid & Liquid \\
\hline Total Flow $(\mathrm{kg} / \mathrm{h})$ & 1.3 & 0.3 & 1.0 & 0.29 & 0.71 & 2.0 & 2.7 \\
\hline \multicolumn{8}{|c|}{ Chemical Components $(\mathrm{g} / \mathrm{h})$} \\
\hline $\mathrm{PuCl}_{3}$ & 273 & & & & & & \\
\hline$\overline{\mathrm{H}_{2} \mathrm{O}}$ & 559 & & 559 & 46 & 513 & 1919 & 2432 \\
\hline $\mathbf{H C l}$ & 97 & & 97 & & 97 & & \\
\hline $\mathrm{Pu}\left(\mathrm{NO}_{3}\right)_{4}$ & 273 & & & & & & \\
\hline $\mathrm{HNO}_{3}$ & 97 & & 97 & & 97 & & \\
\hline Metal Ions & 1 & $\overline{1}$ & & & & & \\
\hline No & & & 10 & 10 & & & \\
\hline $\mathrm{NO}_{2}$ & & & 87 & 87 & & & \\
\hline CL & & & 97 & 97 & & & \\
\hline$\overline{\mathrm{O}_{2}}$ & & & 46 & 46 & & & \\
\hline $\mathrm{PuO}_{2}$ & & 306 & & & & & \\
\hline $\mathrm{NaOH}$ & & & & & & 116 & \\
\hline $\mathrm{NaNO}_{3}$ & & & & & & & 148 \\
\hline $\mathrm{NaCl}$ & & & & & & & 148 \\
\hline
\end{tabular}

Table 4.31. Vertical Calciner Operating Durations

\begin{tabular}{|l|c|c|}
\hline \multicolumn{1}{|c|}{ Material } & Hours $^{(\mathrm{a})}$ & Inventory (kg) \\
\hline Nitrate Solutions & 6300 & 3498 \\
\hline Oil + Organic Solutions & 40 & 22 \\
\hline Filtrate Solutions & 5200 & 2904 \\
\hline Chloride Solutions & 400 & 220 \\
\hline (a) Assumed $24 \mathrm{~h} / \mathrm{d}, 5 \mathrm{~d} / \mathrm{wk}$, at $60 \%$ availability. \\
\hline
\end{tabular}

Some advantages and disadvantages of a vertical calciner direct denitration process are described below.

\subsubsection{Advantages}

1. No feed preparation (evaporation) is required.

2. No chemical additions are necessary for the process. 
3. The process is well suited for variable feeds (e.g., 5 to $500 \mathrm{~g} / \mathrm{L}$ concentrations and chloride, fluoride, and organic impurities).

4. The process requires only minimal and easy operator interface due to few pieces of equipment, resulting in less radiation exposure.

5. It produces a stable oxide product that meets LOI requirements.

6. The process does not form a mastic phase when processing nitric and acid solutions.

7. The ratio of heat transfer area to bed volume is $30 \%$ larger than horizontal screw calciner.

8. Relatively minor chemical hazards exist. No toxic liquids are involved other than plutonium nitrate. Further, toxic gases other than plutonium oxide dusting and $\mathrm{NO}_{\mathrm{x}}$ off gases result from the process.

9. Processing of liquid and gaseous effluent is comparatively low.

\subsubsection{Disadvantages}

1. Vertical calciner method has not been used to produce plutonium dioxide at $800^{\circ} \mathrm{C}$, only at $400^{\circ} \mathrm{C}$.

2. Vertical calciner has not yet been demonstrated in Glovebox 188-1 for testing with solutions.

3. Proposed vertical calciner design has not been operated since the mid $1960 \mathrm{~s}$.

4. Vertical calciner cannot process caustic solutions. Sodium or potassium impurities in the aqueous feed solutions will form a mastic stage.

5. Vertical calciner has a moderate throughput rate requiring extensive processing time, unless multiple units are installed.

6. Vertical calciner has not been used for impure metal nitrate mixtures. 


\subsection{Stability of End Products}

The end products of the PFP plutonium stabilization need to be storable for up to 50 years when stored in the appropriate containers, in an appropriate environment, and in the appropriate geometry to avoid criticality. The following is proposed criteria the end product must meet to be "storable for 50 years." The criteria listed were developed using the WIPP acceptance criteria for TRU and information from the Plutonium Storage Workshop of May 26 to 27, 1993. The criteria were developed primarily from a risk perspective and address only the end products of the stabilization process.

The term "stable" is used to denote a product that is suitable for interim-term $(<50$ years) storage. A product is stable if it

- is noncombustible

- is immobilized if the product is a dispersible

- has no free-liquid

- has had any pyrophoric material, other than uranium/plutonium rendered safe by mixing with chemically stable materials (e.g., glass or concrete) or processed to remove their hazardous properties

- has no explosives or compressed gases (exclusive of radiolytic gas buildup that may require venting)

- has had any corrosive material neutralized, rendered non-corrosive, or is to be packaged in a manner to ensure container adequacy for at least 50 years

- meets criticality prevention requirements

- has a loss on ignition of less than $1 \%$ at $450^{\circ} \mathrm{C}$ for 2 hours.

Also, to ensure long-term stability, the following is recommended for storing the products:

- contact with plastics or other organics should be prevented

- fully stabilized and LOI qualified oxides of sufficient size to minimize dispersibility should be stored in multiple containers with a hermetic seal to prevent the absorption of water vapor. Containers should be continuously monitored for pressure buildup and have the capability to vent at relatively low pressures without loss of contents to avoid pressure releases that would disperse material. 
- Metal should be sealed in hermetically sealed containers, metal gasket seals, or, at a minimum, double food pack canisters with additional air-tight seal.

Based on current storage practices and experiences across the country, oxide powders and plutonium metal are considered storable with the appropriate packaging and monitoring. Both forms have various advantages and disadvantages, such as compact size and reduced dose rate for metals and resistance to oxidation and swelling for oxides. The relative hazards associated with storage of these materials is shown in Table 5.1. The relative safeguards consequence values for metals, oxides, and other forms of plutonium-bearing material are shown in Table 5.2, which shows oxides with a slightly better value. For this study, the additional processing equipment, worker dose rate during processing, and secondary waste generation precludes attempting to make metals, but does not preclude storage of existing metal. The primary product from stabilization processes will be plutonium oxide powder with minimal quantities of fines. An additional step for all oxide production should be considered that would allow mild compaction and high temperature sintering to minimize dispersibles.

Table 5.1. Approximate Hazards from Release of Plutonium Metals and Oxides ${ }^{(a)}$

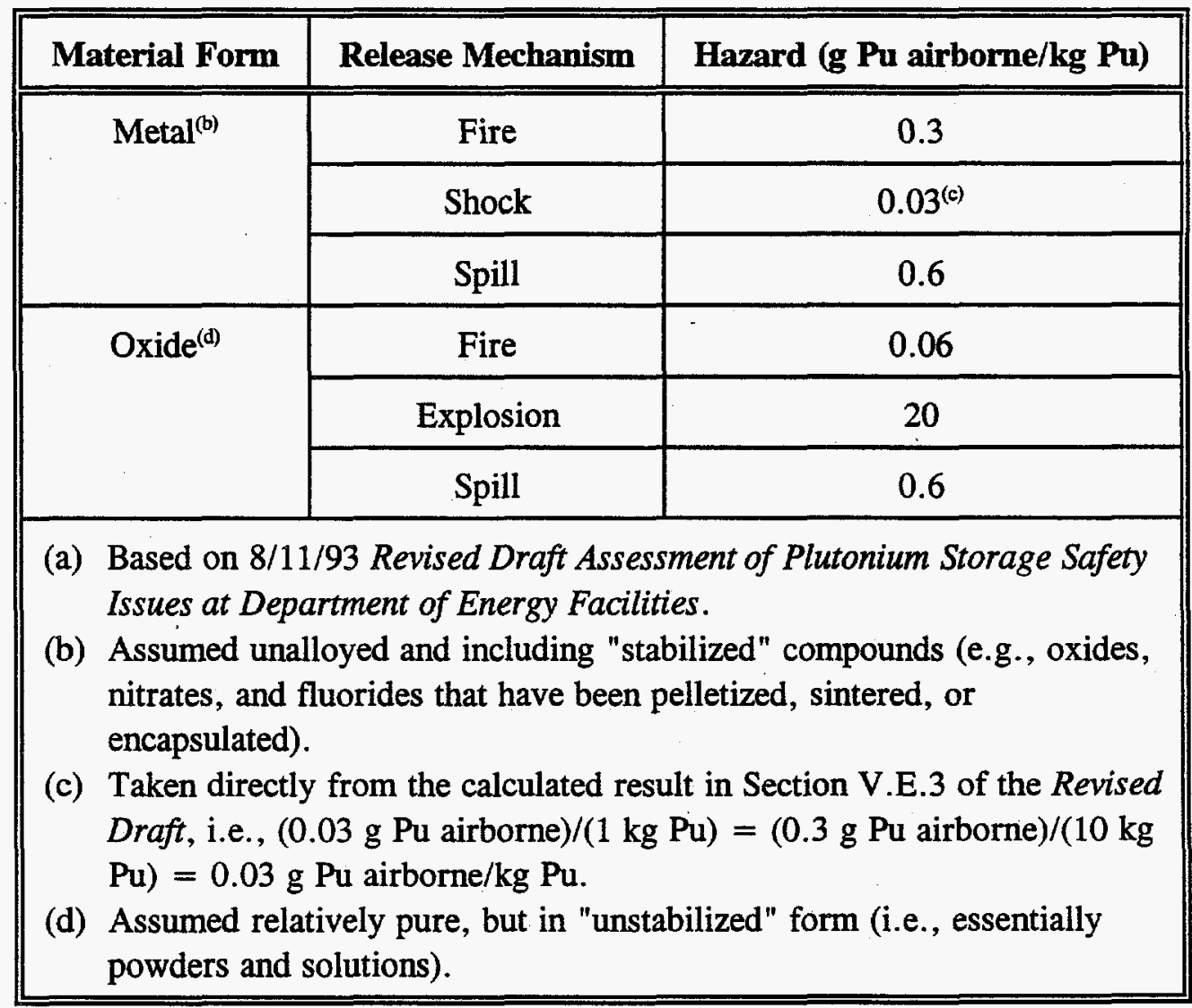


Table 5.2. Consequence Value Table for Theft/Diversion of SNM ${ }^{(a)}$

\begin{tabular}{|c|c|}
\hline Type of Nuclear Material & $\begin{array}{c}\text { Relative } \\
\text { Safeguards } \\
\text { Consequence Value }\end{array}$ \\
\hline Assembled weapons and test devices & 1.0 \\
\hline \multicolumn{2}{|l|}{ Category I Quantity - Pure Products } \\
\hline $\begin{array}{l}\text { Pits, major components, ingots, recaasatable metals } \\
\text { Directly convertible materials }{ }^{\left({ }^{)}\right)}\end{array}$ & $\begin{array}{l}0.7 \\
0.7\end{array}$ \\
\hline \multicolumn{2}{|l|}{ Category I Quantity - Simple Compounds } \\
\hline Oxides, carbides, etc. & 0.6 \\
\hline \multicolumn{2}{|l|}{ Category I Quantity - High-Grade Material } \\
\hline $\begin{array}{l}\text { Solutions, e.g, nitrates }(>25 \mathrm{~g} / \mathrm{L})^{(\mathrm{c})} \\
\text { Fuel elements and assemblies, alloys and mixtures } \\
\mathrm{UF}_{4} \text { or } \mathrm{UF}_{6}\left(>50 \%{ }^{235} \mathrm{U}\right)\end{array}$ & $\begin{array}{l}0.5 \\
0.5 \\
0.5 \\
\end{array}$ \\
\hline \multicolumn{2}{|l|}{ Category II Quantity } \\
\hline $\begin{array}{l}\text { Pure products } \\
\text { High-grade material } \\
\text { Low-grade material } \\
\text { Solutions, e.g., nitrates }(1-25 \mathrm{~g} / \mathrm{L})^{3} \\
\text { Recyclable materials } \\
\text { Process residues } \\
\text { Moderately radioactive materials }{ }^{(\mathrm{d})} \\
\text { Pu-238 } \\
\mathrm{UF}_{4} \text { or } \mathrm{UF}_{6}\left(>20 \%,<50 \%{ }^{235} \mathrm{U}\right)\end{array}$ & $\begin{array}{l}0.2 \\
0.2 \\
0.2\end{array}$ \\
\hline \multicolumn{2}{|c|}{$\begin{array}{l}\text { (a) Derived from Site Safeguard and Security Preparation Guide: Part I - SSSP } \\
\text { Program, Table 3-1. } \\
\text { (b) Directly convertible materials are any items or materials from which pure } \\
\text { product material can be obtained by simple separation of the pure product } \\
\text { from its matrix material. } \\
\text { (c) Concentration criteria are based on "Formula Kilogram," as defined in DOE } \\
\text { Order } 5633.3 \text {. } \\
\text { (d) Radioactive materials are characterized according to the radiation level } \\
\text { (unshielded): } \\
\text { For moderately radioactive materials, } 15 \text { to } 100 \mathrm{rem} / \mathrm{h} @ 1 \mathrm{~m} \text {. } \\
\text { For highly radioactive materials, }>100 \mathrm{rem} / \mathrm{h} @ 1 \mathrm{~m} \text {. }\end{array}$} \\
\hline
\end{tabular}


The hazards were derived from Section V.E of the Revised Draft as follows. ${ }^{(a)}$ For each material form and release mechanism, the hazard was calculated as the product of the "airborne release fraction" (ARF, with units of $\mathrm{g} \mathrm{Pu}$ airborne/g Pu) and "respirable fraction" (RF). For example, for oxide released through a fire (Section V.E.1), ARF $=0.006$ and $\mathrm{RF}=0.01$, yielding a hazard of $(0.006)(0.01)=0.00006 \mathrm{~g} \mathrm{Pu}$ airborne/g Pu; or, when scaled to one kilogram, $(0.00006 \mathrm{~g} \mathrm{Pu}$ airborne $/ \mathrm{g} \mathrm{Pu})(1000 \mathrm{~g} / \mathrm{kg})=0.06 \mathrm{~g} \mathrm{Pu}$ airborne $/ \mathrm{kg} \mathrm{Pu}$.

It must be assumed, based on present storage packaging experience, that various containers will require stabilization and repackaging after the initial processing period because of a failure of the container seal or unpredicted gas generation over the possible 50-year storage period. Therefore, facilities need to be in place to remove the material from the package, thermally treat the plutonium material, and repackage the material.

(a) Revised Draft Assessment of Plutonium Storage Safety Issues at DOE Facilities. August 11, 1993. 


\subsection{Technical Review of PFP Residue Waste Treatment Alternatives}

This section summarizes the results of the independent review team's assessment of proposed processes for treating residual plutonium-bearing materials currently in storage at Hanford's PFP. The selected treatment operation will be used to prepare these materials for interim ( $<50$ years) storage in a safe and cost-effective manner. These materials consist of plutonium-bearing solutions (including nitrate, chloride, organic and other miscellaneous solutions) and solids (including oxides, residues, metals, and alloys, polycubes, combustibles, and fluorides).

\subsection{Objective of Review}

The objective of this review was to provide an independent assessment of the technologies being considered for the treatment of the PFP plutonium-bearing wastes. This review was conducted during the course of the overall study to provide near in-process feedback. The independent team's review focused on

1. assessing the applicability of the proposed processes to complete the required treatment

2. providing an additional screening of the technologies to identify those most promising for completing the treatment mission

3. identifying and recommending additional technologies that have significant advantages in completing the treatment mission.

\subsection{Review Process}

The process for conducting the independent review involved the following activities:

- a presentation of specific technical information on each candidate process by the report authors to the independent review team

- an initial screening of the processes by the independent review team to establish those that are applicable

- a rating of the feasible alternatives against a predetermined set of criteria. These criteria consisted of technical feasibility, effluent and by-product disposition, worker safety, cost, and implementation and operation duration. 


\subsection{Bases and Assumptions}

The scope of this review was limited to the materials currently in storage at the PFP with the exception of the reactive sludges. The disposition of these sludges was to be considered in a separate interim action that was proposed to occur on an expedited schedule.

This review was conducted while the present engineering study was in progress. Consequently, only qualitative information on costs, schedules, environmental, and occupation impacts was used to complete the review in many instances. However, in the context of the review, this was acceptable because the purpose of this review was to provide preliminary guidance for completion of the study.

\subsection{Summary and Recommendations}

Based upon this review, the independent review team identified the preferred processes for each waste stream as summarized in Table 6.1. These technologies were, in general, preferred based on meeting the criteria of availability, flexibility, and technical maturity.

The following recommendations were also made by the independent review team:

1. The benefits of removing americium-241 from the stored plutonium material need to be further assessed. It is not clear if the reduction in occupational exposure will outweigh costs considering the additional waste processing required, process complexity, and future ingrowth of americium-241 during the 50-year storage period. Based on available information americium-241 removal should not be considered.

Table 6.1. Preferred Technologies for PFP Residue Treatment

\begin{tabular}{||l|l||}
\hline \multicolumn{1}{|c|}{ Waste Stream } & \multicolumn{1}{c|}{ Preferred Processes } \\
\hline \hline Solutions: & $\begin{array}{l}\text { Thermal treatment (calcination) } \\
\text { Ion exchange with thermal treatment }\end{array}$ \\
\hline Aqueous & $\begin{array}{l}\text { No reasonable technology identified; MSO } \\
\text { is most promising }\end{array}$ \\
\hline Organic & $\begin{array}{l}\text { Continuous calciner } \\
\text { Muffle furnace for special applications }\end{array}$ \\
\hline Solids: & $\begin{array}{l}\text { Repackage muffle furnace for special } \\
\text { applications, e.g., fines, turnings }\end{array}$ \\
\hline Oxides, Fluorides, Residues & $\begin{array}{l}\text { No reasonable technology identified; MSO } \\
\text { is most promising }\end{array}$ \\
\hline Metals, Alloys &
\end{tabular}


2. The development and finalization of the preferred processes are recommended on an expedited basis. In addition, the development of the MSO process followed by plutonium oxide recovery should be expedited. Molten salt oxidation was the only technology identified that had multipurpose applicability to this treatment problem.

3. There is an apparent lack of acceptable processes for treating the organic liquids, combustible solids, and polycubes. It is suggested that the MSO process be further reviewed for these waste streams.

4. The waste streams should be processed by a strategy that gives priority to major safety concerns. Thus, the aqueous liquids should be treated early followed by the organic solids and low-fired plutonium oxide. The second consideration is the quantity of material needing stabilization, which suggests early processing of the oxides. The priority for early treatment of organic solids is frustrated by the current lack of good, demonstrated technology.

5. The potential for direct repackaging of the metals and high-fired oxides should be examined. These waste streams represent approximately $40 \%$ of the mission need.

\subsection{Description of the PFP Treatment Scope}

The processes for producing a product that may be suitable for 50-year storage in Z-Plant vaults were evaluated based upon their application to the plutonium-bearing material now stored in the PFP. This material consists of aqueous solutions, a limited quantity of organic solutions, numerous solid compounds, and solid combustible material. PFP residue treatment needs are given in Table 6.2. Table 6.2 summarizes the type of material, gross weight, mass of plutonium number of items (packages), and percentage of plutonium in the material category.

The aqueous solutions consist of 318 containers of nitrate solutions, 28 containers of chloride solutions, 16 containers of caustic solutions, and 104 containers of concentrated filtrate from the oxalate precipitation process. About half of the nitrate solutions contain uranium or thorium in addition to the plutonium. About $14 \%$ of the total PFP inventory is contained in these solutions. The concern with the solutions is that many have already been in the containers longer than the container design life, so breaching of the containers is possible. Additionally, liquids are not considered to be a stable form suitable for 50 -year storage.

There are only two containers of organic solutions. These solutions are a mixture of TBP extractant and $\mathrm{CCl}_{4}$ diluent from the reclamation facility solvent extraction system and lard oil from the 234-5 $\mathrm{Z}$ machining processes. The concern with this material is that organic solutions are not considered to be stable for 50 -year storage.

The bulk of the solid compounds, 4817 items, consists of 1288 containers of high-fired oxide and 3524 containers of low-fired oxide. This material has been placed in crimp-sealed cans that were 
Table 6.2. PFP Residue Treatment Needs

\begin{tabular}{|c|c|c|c|c|}
\hline & Total Wt. (kg) & Mass Pu (kg) & No. of Items & Pu Mass (\%) \\
\hline \multicolumn{5}{|l|}{ Solutions: } \\
\hline Nitrate & 3498 & $289^{(a)}$ & 318 & 10.1 \\
\hline Chlorides & 220 & 3.3 & 28 & 1.3 \\
\hline Organics & 22 & 3.5 & 2 & 0.13 \\
\hline Other & 1320 & 62 & 120 & 2.4 \\
\hline \multicolumn{5}{|l|}{ Solids: } \\
\hline Plutonium Oxides & 6622 & $1224^{(a)}$ & 4817 & 48 \\
\hline $\begin{array}{l}\text { High-Fired } \\
\text { Low-Fired }\end{array}$ & $\begin{array}{l}1631 \\
4991\end{array}$ & $\begin{array}{l}301^{(b)} \\
923^{(b)}\end{array}$ & $\begin{array}{l}1288 \\
3524\end{array}$ & \\
\hline Metal/Alloy & 1040 & $770^{(\mathrm{a})}$ & 499 & 30 \\
\hline Combustibles & 62 & $*$ & 32 & \\
\hline Process Residue & 1374 & 154 & 1480 & 6.1 \\
\hline Polycubes & 187 & 31 & 224 & 1.2 \\
\hline Fluorides & 15 & 3 & 14 & 0.12 \\
\hline Total & & 2539.5 & 7281 & 99.35 \\
\hline
\end{tabular}

subsequently bagged out of the glovebox and placed (while still in the heat-sealed, plastic bags) in crimp-sealed or taped, slip-lid containers. The concern with this material is that the current packaging may fail and that concentrations of hydrogen and other gases could accumulate because of radiolytic decomposition of either the water vapor in contact with the oxide or the plastic packaging.

The solids category includes 375 containers of plutonium metal with various degrees of purity and 124 containers of plutonium alloys with various degrees of purity. Metals in the alloys include combinations of beryllium, uranium, and thorium. The concern is that the metals and alloys may not be stable for 50-year storage in their current packaging configuration. The solids category includes 1480 containers of assorted process residues such as sand, slag and crucible residue, and incinerator ash. There are also 14 containers of $\mathrm{PuF}_{4}$ and $\mathrm{PuF}_{3}$ in the solids category. The concern with these residues and fluorides is that they also are not stable for 50-year storage in their current packaging configuration. 
The solid combustible category includes 32 containers of assorted combustible material such as paper, rags, chemical wipes, wood, plastic, and graphite contaminated with both plutonium and uranium. It also includes 224 containers of polycubes. Polycubes are small blocks of plutonium oxide dispersed in polystyrene. These blocks were used in criticality experiments so the amount of plutonium oxide per block varies. The degree to which the plastic deviates from polystyrene also varies based on the $\mathbf{k}_{\text {eff }}$ that each block experienced during the criticality experiments. Blocks that were exposed to a high $\mathrm{k}_{\text {eff }}$ show a high degree of cross-linkage of the polystyrene matrix. The concern with the solid combustible materials is that they are not stable for 50 -year storage.

\subsection{Treatment Options Considered}

The engineering study team performed an initial screening on all potential technologies that might be used to stabilize or disposition the inventory of PFP plutonium-bearing materials. The team reviewed this list and agreed with the rejection of certain technologies from further consideration. The remaining technologies considered by the review team are summarized below.

1. Thermal stabilization options included

- vertical calciner

- MSO

- muffle furnace

- continuous calciner (added by review team).

2. Options to convert solids to solutions included

- CEPOD dissolution

- silver persulfate dissolution

- nitric acid - hydrofluoric acid dissolution (PRF facility)

- acid digestion.

3. Options to convert solutions to solids included

- oxalate precipitation

- hydroxide precipitation 
- peroxide precipitation

- direct denitration (thermal stabilization of nitrate solutions).

4. Options to remove americium and non-plutonium components included

- ion exchange

- solvent extraction

- peroxide precipitation.

Various combinations of the technologies were considered for each of the following categories of materials:

- aqueous solutions

- oxides, fluorides, and process residues

- organic solutions

- combustibles and polycubes

- metals.

\subsection{Treatment Process Rating}

The independent review team used two levels of screening before submitting the surviving candidate processes to numerical evaluation. The first level was a review of the initial screening done by PNL. Team members individually reviewed this initial screening and concurred with it. The second screening was based on independent review team judgment. Among the alternatives eliminated in this screening were the following:

- peroxide precipitation followed by thermal treatment of solutions on the basis of safety, process complexity, and inapplicability. Peroxide precipitation is a proven process for pure nitrate solutions and has been employed at the Rocky Flats Plant in Building 771 for many years. The safety concern is that the PFP solutions may contain impurities that are not compatible with the peroxide.

- CEPOD followed by thermal treatment of organics on the basis of inapplicability. CEPOD has been demonstrated for the dissolution of plutonium oxide and other plutonium-bearing solids, but not for the destruction of organics. 
- CEPOD followed by thermal treatment of oxides on the basis of clearly superior alternatives that do not require the dissolution of the oxides

- $\mathrm{HNO}_{3} / \mathrm{HF}$ dissolution of oxides and metals based upon efficiency and complexity

- silver persulfate leach followed by solvent extraction and direct denitration of oxides on the basis of clearly superior alternatives. Dissolution using the CEPOD technology will have less operator exposure, will have a higher processing capacity, and will not use the large quantities of silver.

- oxalate precipitation of aqueous streams based upon limited applicability

- MSO of metals on the basis of clearly superior alternatives. Metals are expected to be an acceptable final product form, so there is not a good reason to convert the plutonium to an oxide; simple repackaging is preferred.

- acid digestion of combustibles on the basis of cost/benefit considerations.

The independent review team introduced one additional technology, continuous calcination. The concept is to use the existing, or a new, screw calciner, in Hood 9B of the RMC Line for continuous treatment of oxides, residues, and fluoride-containing solids. The system would have to be modified to incorporate a solids load-in system and to provide for a withdrawal of the stabilized product from the calciner. The continuous calcination step could also be installed elsewhere.

Several iterations were required to produce an evaluation scheme that appropriately discriminated between the alternatives.

The process technology and material residue evaluations are matrixed in Table 6.3. For the purposes of this evaluation, the PFP residue streams were consolidated into five categories: aqueous

Table 6.3. Alternative Process Evaluations

\begin{tabular}{|c|c|c|c|c|c|c|c|}
\hline Waste Stream & $\begin{array}{c}\text { Thermal } \\
\text { Treatment } \\
\text { (Vertical Calciner) }\end{array}$ & \begin{tabular}{|c|} 
Hydroxide \\
Precipitation/ \\
Calcination \\
\end{tabular} & $\begin{array}{c}\text { CEPOD/ } \\
\text { Separation }{ }^{(a)} / \\
\text { Calcination }\end{array}$ & $\begin{array}{l}\text { Molten } \\
\text { Salt } \\
\text { Process }\end{array}$ & $\begin{array}{c}\text { Muffle } \\
\text { Furnace }\end{array}$ & $\begin{array}{c}\text { Continuous } \\
\text { Calciner }\end{array}$ & Repackage \\
\hline \multicolumn{8}{|l|}{ Solutions: } \\
\hline \multicolumn{8}{|l|}{ Aqueous } \\
\hline nitrate, chloride, other & $\overline{73}$ & 57 & 66 & 48 & & & \\
\hline Organic & 34 & & & 49 & & & \\
\hline \multicolumn{8}{|l|}{ Solids: } \\
\hline Oxides, Fluorides, Residues & & & 39 & $\overline{48}$ & 52 & 82 & \\
\hline Metals & & & & & 67 & & 95 \\
\hline Combustibles, Polycubes & & & & $\overline{48}$ & 54 & & \\
\hline
\end{tabular}


solutions, organic solutions, oxides and fluoride residue, alloys and metals, and combustibles and polycubes. This table also shows the eight technical alternatives considered for treatment of the residues. These process technologies are 1) thermal treatment (calcination); 2) ion exchange followed by calcination; 3) hydroxide precipitation followed by calcination; 4) CEPOD dissolution followed by separations and calcination; 5) MSO followed by salt dissolution, plutonium separation, and calcination; 6) thermal treatment by a muffle furnace; 7) thermal treatment by a continuous calciner; and 8 ) repackaging.

\subsubsection{Treatment Process Rating Criteria}

Part of the information provided to the PFP independent review team included suggested preliminary criteria for evaluating the proposed technologies to stabilize the materials stored at the PFP.

While considered important, more than half of these criteria do not appear as separate considerations in the final evaluation. In some cases, criteria were combined and others proved to be nondiscriminatory in that they either must be met or the technology cannot be used. The suggested preliminary criteria that do not appear as separate considerations in the final evaluation and the reasons for eliminating/ combining them are described in the following discussions.

\section{Effluents Covered/SAR}

The existing SAR document identifies processes and effluents that are within the constraints of the SAR. A technology that fits within this umbrella may be used without undertaking the time consuming process of revising the SAR. In practice, this criterion proved to be nondiscriminatory since virtually all of the proposed processes were felt to be within the constraints of the SAR.

\section{Energy Resource}

This criterion was initially suggested since it was believed that a final product form that could be easily converted to fuel for a power reactor would be beneficial to the nation. During the course of the evaluation, it became apparent that essentially all of the product forms would require about the same amount of additional processing to make a suitable power reactor fuel. Therefore, the criterion was considered to be nondiscriminatory.

\section{Weapons Potential}

This criterion was suggested in response to public reaction to earlier proposals to stabilize the PFP inventory. The concern was that the stabilization program was, in reality, a veiled attempt to make additional weapons material. This criterion would have given a low score to a final product form that could be easily converted to a weapon by DOE and a high score to a form that would be more difficult to convert. In fact, the closer one gets to a weapon component, the more exacting the process must be to produce suitable materials or components. Any of the final forms considered for the PFP material require only relatively simple processes to move closer to a usable weapons material. This characteristic of the product form essentially made this criterion nondiscriminatory. 


\section{End Product Volume}

The intent of the suggested criterion was to give preference to technologies that produced a final storage form that reduced the volume of the material requiring storage. Since final storage is to be in the PFP vaults, the volume cannot exceed what would fit in the available space. This restriction makes this a go/no-go parameter, but does not distinguish between technologies whose final forms fit in the available space. Additionally, most of the proposed final forms had similar volume characteristics, so the criterion was considered to be nondiscriminatory between the technologies.

\section{Environmental and Public Risk}

This very important criterion could not be used to distinguish between the competing technologies since it is a go/no-go parameter. Any technology that presents an unacceptable environmental or public risk must be dropped from consideration. The degrees of acceptability are not sufficiently defined to allow differences between the competing technologies to be used as a discriminator. In addition, the environmental impacts of a proposed technology are best judged through the National Environmental Policy Act process.

\section{Public Acceptance}

This criterion was suggested as a means of ensuring that the selected technologies would be acceptable to the general public. The independent review team, on the other hand, was selected for their technical expertise and experience with the technologies under consideration. It was not believed that team members possessed verifiable attributes for gauging public acceptance, so rankings against this criterion would be invalid.

\section{Materials Covered}

This criterion was suggested to give preference to technologies that could address multiple PFP material categories. It was combined with the technical feasibility considerations to eliminate overlap between the two criteria.

\section{Flexibility}

This criterion was suggested to ensure that the selected technologies would be capable of responding to variations in the characteristics of the feed material. This flexibility is important since the individual containers of solutions/solids in a particular category were generated by different sources and, thus, have varying characteristics. It was combined with the technical feasibility considerations to eliminate overlap between the two criteria. 


\section{Final Weighting Criteria}

Table 6.4 shows the criteria, weightings, and definitions used by the independent review team to quantitatively compare the processing alternatives. It should be cautioned that although the weightings are numerical, they are imperfect and only represent the best judgement of the independent review team based on the information available at the time. The weightings were derived to provide gross comparisons of alternatives for final screening to the few that offer the best chance of success for expeditiously completing the stabilization program.

\subsubsection{Results From Weighting Analyses}

Numerical ratings of the process technologies considered in this review were summarized above in Table 6.4. These results can be used in a qualitative way to indicate preference for one technology over another. The absolute values of the ranking, however, do not have significance. For instance, a continuous calciner is preferred for treatment of oxides, fluorides, and residues. However, based upon an overall assessment, there is little difference in preference for the CEPOD process, MSO process, and the muffle furnace.

Details of the numerical ratings for the technologies evaluated are summarized in Appendix B. Thermal treatment (vertical calciner) is preferred for aqueous solutions. Equipment for this has been designed and tested in the past, and a short development/testing period should show its application to these feedstocks. This step may be preceded by an ion exchange step for americium removal should worker dose become a major consideration during processing and subsequent storage.

No reasonable technology has been demonstrated for the two containers of organic material. Of those technologies examined, MSO appears to be most promising for this material.

The continuous calciner in Hood 9B, introduced by the independent review team, is favored for oxides, fluorides, and residues. This system requires little development work, can be available in a reasonably short time, and can operate at high rates to complete stabilization of this material in a short time. Muffle furnace capacity should be provided to handle special solid materials that may not be amenable to continuous calcination. Work with this equipment, to be used for sludge stabilization, should continue. This technology would have rated higher except for its very slow processing rate and very high worker risk due to exposure during the manual manipulation of the solid material.

The independent review team believes that the metals and alloys, except for small pieces, fines, turnings, and so forth, can be simply repackaged. The finer material can be stabilized to oxide in a muffle furnace.

The independent review team found no currently available, reasonable technology for the stabilization of combustibles and polycubes. MSO offers the most promise for future application. 
Table 6.4. Definitions for the PFP Stabilization Criteria

\begin{tabular}{|c|c|}
\hline Criteria & Preliminary Definition \\
\hline $\begin{array}{l}\text { Technical Feasibility }(50 \%) \\
\text { - maturity }(20 \%) \\
\text { - maintainability/reliability }(10 \%) \\
\text { - flexibility }(15 \%) \\
\text { - product stability }(5 \%)\end{array}$ & $\begin{array}{l}\text { The process should have been demonstrated at a pilot- or larger-scale } \\
\text { operation for actinide processing and can be made available for design } \\
\text { within } 2 \text { years. The process should be reliable, simple, straightforward, } \\
\text { and amenable to maintenance and operations. The process should be flex- } \\
\text { ible enough to process a variety of PFP materials. The process must fit in } \\
234-5 \mathrm{Z} \text { Building. The stability of the end product form is considered in } \\
\text { terms of handling and storage. The final form must be of higher integrity } \\
\text { than the original form. Criteria for 50-year storage have not been estab- } \\
\text { lished. Storage is to be in Z-Plant vaults. Storage as metal or oxide with a } \\
\text { low LOI is preferred. Containers are assumed to be hermetically sealed. } \\
\text { The presence of stabilized halides is assumed to be acceptable. It is } \\
\text { assumed that existing crimp-sealed cans do not meet this criteria. }\end{array}$ \\
\hline $\begin{array}{l}\text { Effluents/By-products }(5 \%) \\
\text { - minimize volume, hazard } \\
\text { - minimal volume and hazard of effluents }\end{array}$ & $\begin{array}{l}\text { Minimize the effluents and by-products (other than the end product). This } \\
\text { criterion considers the volume of effluent generated and the hazardous } \\
\text { nature. Liquid effluents must be amenable to tank farm disposition. Minor } \\
\text { quantities of } \mathrm{NO}_{x}, \mathrm{HCl}, \mathrm{HF} \text {, etc. may be mixed with plant ventilation } \\
\text { exhaust gases. }\end{array}$ \\
\hline $\begin{array}{l}\text { Worker Risk }(20 \%) \\
\text { - routine } \\
\text { - accident }\end{array}$ & $\begin{array}{l}\text { Radiation exposure is the dominant consideration in risk to workers. Alter- } \\
\text { natives are evaluated on the basis of postulated worker exposure. Processes } \\
\text { with higher potential for explosive chemical reactions were rejected from } \\
\text { consideration. }\end{array}$ \\
\hline $\begin{array}{l}\text { Cost }(5 \%) \\
\text { (development, construction, operations and D\&D) }\end{array}$ & $\begin{array}{l}\text { Life cycle costs includes those costs for developing, constructing, operat- } \\
\text { ing, and decommissioning/decontaminating of the process. }\end{array}$ \\
\hline $\begin{array}{l}\text { Implementation and Operating Duration }(20 \%) \\
\text { (total time: } 1 \text { to } 5 \text { years }(20 \%) \\
5 \text { to } 10 \text { years }(10 \%) \\
>10 \text { years }(0 \%)\end{array}$ & $\begin{array}{l}\text { Implementation time includes design, procurement, installation, training, } \\
\text { preparation and approval of safety documentation, cold testing, and startup. } \\
\text { Implementation time is estimated as follows: 1) existing equipment/existing } \\
\text { glovebox - } 1 \text { year; } 2 \text { ) new equipment/existing glovebox }-2 \text { years; } 3 \text { ) new } \\
\text { equipment/new glovebox - } 4 \text { years; and 4) a major installation/several } \\
\text { gloveboxes - } 6 \text { years. Operating time was estimated based on working off } \\
\text { the current inventory using } 3 \text { shifts/day, } 5 \text { days per week operation. The } \\
\text { allowable maximum time to process the PFP materials to a stable form has } \\
\text { not been established. The total time to implement and complete operations } \\
\text { will help determine the feasibility of the process. }\end{array}$ \\
\hline
\end{tabular}

The option of repackaging the PFP residues was considered for those material classes that in the authors' judgment could meet the 50-year storage requirement. These materials were the plutonium metal and alloys (excluding fines and turnings) and high-fired oxides. These materials represent approximately $42 \%$ of the plutonium suggested for stabilization and repackaging.

\subsection{Unresolved Issues}

Unresolved issues for selecting processes for stabilizing the plutonium residues are described in the following paragraphs. 


\subsubsection{Americium Removal}

The final selection of processes to be used to stabilize the various residues can be significantly impacted if it is determined that americium buildup from the decay of the plutonium-241 isotope must be removed. If the selected process does not discard the americium to waste, the resulting worker exposure during final product processing, handling, and packaging will be much higher. The higher exposure rates may require the addition of shielding, remote handling capabilities, exposure distribution to more operators, or a combination of these mitigating actions. Without the removal of the americium, the subsequent storage of stabilized plutonium forms will involve higher exposures during the routine operations of the vaults (e.g., monitoring, surveillance, and material control and accountability activities) compared to storage exposures with the americium removed.

Removal of the americium would occur only in those process options that include ion exchange, solvent extraction, or possibly precipitation. These unit operations complicate the stabilization process and normally increase wastes and costs, decrease the reliability (more steps subject to failure), and may increase worker exposure at the front end of the process prior to americium removal.

The review team did not rank americium removal very high because

- exposure dose rate data were not available for comparison

- front end exposure will not be changed and may even increase (see above)

- the impact on future storage operations could not be evaluated.

It is, therefore, recommended that more detailed exposure/shielding studies be conducted to evaluate the impact of americium removal on worker exposure for the various processes. If there is no significant benefit to removing americium, then there may be no justification for further review of the decontamination processes, e.g., ion exchange and solvent extraction.

\subsubsection{Uncertainties for 50-Year Storage Criteria}

The stated objective of the engineering study was to select processing alternatives to stabilize plutonium-bearing material for storage up to 50 years. This objective cannot be completely accomplished at this time since the DOE criteria for 50-year vault storage have not been finalized. Proposed criteria to date have included

- restricting stabilization forms to plutonium oxides, metals, and alloys

- minimum calcination temperature of $1000^{\circ} \mathrm{C}$

- maximum LOI at $1000^{\circ} \mathrm{C}, 0.5 \mathrm{wt} \%$ 
- handling final product in an ultra dry $\left(\leq 100 \mathrm{ppm}_{2} \mathrm{O}\right)$ and, possibly, inert atmosphere

- no plastics in storage package

- welded primary storage container.

These storage criteria are very conservative in that higher calcination temperatures and lower LOI are specified than has been previous PFP practice. The current storage containers include plastics and are not welded. Operating experience at the PFP has shown that plutonium oxide calcined at a lower temperature exhibits an acceptable LOI for storage. Some of the technologies being considered for stabilization of the PFP materials and near-term storage will not meet the temperature requirements or some of the other proposed storage criteria. The independent review team assumed that the stabilization options would be evaluated based on their ability to convert the plutonium-bearing materials to forms that are, based on best judgment, suitable for long-term storage using existing facilities with no more than moderate modifications. The evaluations did not consider that the technologies must meet all of the rather stringent criteria proposed for 50-year storage.

Based on the information provided to the independent review team, it does not appear that moderate modifications to the existing facilities will provide the capabilities required to satisfy the proposed 50-year storage criteria listed above. It is not reasonable to expend significant monies, time, or worker exposure on modifying facilities for final treatment and packaging until the storage criteria are defined.

The material to be stabilized and stored is already located in the PFP; thus, Department of Transportation regulations and acceptance criteria for other storage locations (e.g., WIPP) are not applicable. It is suggested that site-specific PFP storage criteria be written based on what is reasonable, given the PFP capabilities, configuration, services, vaults, operations, etc. These criteria do not need to consider other DOE sites or facilities. Restricting the scope of the criteria to the PFP should significantly reduce the time required to establish, approve, and implement the criteria, primarily because the approval level can be limited to the PFP stakeholders.

If and when the DOE promulgates final 50-year storage criteria, then those criteria will have to be compared to the site-specific criteria developed for the PFP. It is quite likely that significant differences will be identified and that a significant effort, with major capital expenditures, will be required to bring the PFP processes and facilities into compliance.

Thus, the suggested strategy is to pursue a near-term course whereby the most unstable material, solutions, and selected residues would be stabilized, packaged, and stored as expeditiously as feasible using readily implementable stabilization technologies and current package configurations. This plan converts the PFP plutonium inventory to a solid form that presents less risk than the current forms, but that probably will not meet final DOE 50-year storage criteria. In the long-term, a project would be initiated to bring the material, package configuration, and storage facilities into compliance with the DOE 50-year storage criteria when those criteria are established. 
As the first step in implementing this strategy, it is recommended that an aggressive program be undertaken to establish site-specific PFP storage criteria.

\subsubsection{Repackaging of Metals and Oxides}

Nearly $80 \%$ of the plutonium in the PFP residues is in the form of oxides, metals, or metal alloys, most of which is stored in a can/plastic bag/can configuration. The inner can, which is in direct contact with the plutonium material, is normally a crimp-sealed can (tuna can or tomato can). This can is removed from the glovebox by a bag out procedure whereby the can is placed in a plastic bag, a heat seal is made between the bag and the glovebox atmosphere, and the bag is cut along the seal such that both sides of the cut remain sealed. The plastic bagged inner can is then placed in a second can that is subsequently sealed with either a crimp lid or by taping a slip-on lid in place. Studies, evaluations, and incidents have shown that this package configuration is subject to failure and breaching. The component in this configuration that provides the hermetic seal is the heat-sealed plastic bag that, within the 50-year time period, will fail because of radiolytic and/or thermal degradation. The plastic is particularly vulnerable if it is in direct contact with the plutonium material.

Various concepts have been proposed for a package configuration that eliminates the plastic component. For contamination control purposes, the material must be placed in the inner container while both are in a glovebox. This container can then be hermetically sealed through the use of welding or metal-gasketed flanges. The problem becomes one of removing the sealed container from the glovebox while still providing contamination control. Proposed concepts have included double-lid technology (i.e., French cans), decontamination chambers, and welding/cutting of hollow bung (bagless transfer based on a British concept being developed at the Savannah River Site).

It is not reasonable to process or repackage the plutonium oxide, metals, and alloys until both the final storage criteria are established, and an acceptable package configuration is developed.

Conversely, incidents have occurred with the current package configuration where bags have failed, and metal has oxidized to an extent that the can was ruptured. Oxides that were not properly calcined, that were exposed to moist air prior to or during packaging, or whose package seals failed sufficiently to allow moisture in-leakage, can radiolytically decompose the moisture and cause pressurization or rupture of the package. The can seals, while normally adequate for a secondary seal, are occasionally found to be faulty because of poor operation or condition of the can sealer.

It is recommended that an aggressive program be undertaken to conceive, design, and implement a new package configuration so that the plutonium oxide, metals, and alloys can be repackaged to a 50 -year storage configuration.

\subsubsection{Worker Exposure}

Current DOE exposure criteria and as low as reasonably achievable (ALARA) requirements for new plutonium processing facilities are significantly lower than those in effect when the PFP was constructed. The independent review team has concern that the proposed stabilization operations can be 
conducted in full compliance with current regulations. Although most of the inventory information provided to the independent review team did not include isotopic data, 52 of the nitrate solution containers list a plutonium-240 concentration of up to $22 \%$. A basic premise of the stabilization concept is that simple, low cost processes will be employed since very limited quantities are involved, and long-term operation is not envisioned. For this type of operation, the proposed technologies are heavily dependent upon manual operations that inherently lead to greater operator exposure. It may not be possible to conduct the stabilization program without resorting to staff exposure management measures that spread the exposure over a greater number of workers, but that do not reduce the total exposure. This is an obvious departure from guidelines for new facility design where staff exposure management is not an acceptable design strategy. Staff exposure management is increasingly being employed at older government-owned, contractor-operated facilities to meet the ever-decreasing guidelines for operator exposure. It could be deemed acceptable for the stabilization program since the operations will be of reasonably short duration and new facilities are not involved. It would seem prudent, however, to evaluate the use of portable hot cells and manipulators for high exposure operations such as unpackaging, packaging, and repackaging of oxides and metals. 



\subsection{Conclusions and Recommendations}

This review assessed the technologies being considered for treatment of PFP wastes. Based upon this review, the technology review team identified the preferred technologies for each waste stream as summarized in Table 7.1. These technologies were, in general, preferred based on meeting the criteria of availability, flexibility, and technical maturity.

The following recommendations are also made:

1. The benefits of removing americium-241 from the stored plutonium material need to be further assessed. It is not clear if the reduction in occupational exposure will outweigh the costs considering the additional required waste processing, process complexity, and future ingrowth of americium-241 during the 50-year storage period.

2. The development and finalization of the preferred processes are recommended on an expedited basis. In addition, the development of the MSO process followed by plutonium oxide recovery should be expedited. This technology was the only technology identified that had multipurpose applicability to this treatment problem.

Table 7.1. Preferred Technologies for PFP Residue Treatment

\begin{tabular}{||l|l||}
\hline \multicolumn{1}{|c|}{ Waste Stream } & \multicolumn{1}{c|}{ Preferred Technologies } \\
\hline \hline Solutions: & $\begin{array}{l}\text { Thermal Treatment (Calcination). Ion Exchange with } \\
\text { Thermal Treatment }\end{array}$ \\
\hline Aqueous & $\begin{array}{l}\text { No reasonable technology identified; Molten Salt Oxidation is } \\
\text { most promising }\end{array}$ \\
\hline Organic & \\
\hline Solids: & $\begin{array}{l}\text { Continuous Calciner } \\
\text { Muffle Furnace for special applications. }\end{array}$ \\
\hline Oxides, Fluorides Residues & $\begin{array}{l}\text { Repackage } \\
\text { Muffle Furnace for special applications, e.g., fines, turnings. }\end{array}$ \\
\hline Metals, Alloys & $\begin{array}{l}\text { No reasonable technology identified; Molten Salt Oxidation is } \\
\text { most promising. }\end{array}$ \\
\hline Polycubes/Combustibles
\end{tabular}


3. There is an apparent lack of acceptable processes for treating the organic liquids, combustible solids, and polycubes. It is suggested that the MSO process further be reviewed for these waste streams.

4. The waste streams should be processed by a strategy that gives priority to major safety concerns first. Thus, the liquids should be treated early followed by the organic solids and low-fired plutonium oxide. The second consideration is the quantity of material needing stabilization, which would suggest early processing of the oxides. The priority for early treatment of organic solids is frustrated by the current lack of good, demonstrated technology.

5. The potential for direct repackaging of the metals and high-fired oxides should be examined. These waste streams represent approximately $40 \%$ of the mission need.

The personnel presenting the flowsheets did a cursory rating of the technologies using the initial screening criteria. The ranking was independent of the technical review team to get a different perspective. In general, the ranking were similar. A summary of the presenter's preferred processes is as follows:

- Aqueous solutions

- Vertical calciner

- Hydroxide precipitation/thermal treatment

- Organic solutions

- Vertical calciner

- Molten salt

- Combustibles/Fluoride Compounds

- Molten salt

- Muffle furnace

- Polycubes

- Modified muffle furnace

- Molten salt

- No action

- Oxides

- No action

- Muffle furnace (with faster temperature cycling)

- Process Residues

- Muffle furnace

- $\mathrm{HNO}_{3}$ dissolutions/solvent extraction/calcination 
- Metals and Alloys

- Muffle furnace

- $\mathrm{HNO}_{3}$ dissolutions/solvent extraction/calcination

A couple of differences are based on the concerns for 50-year storage and lack of clear definition, worker dose, and technology development. The presenters rank the oxides separate from the residues and recommended no action, while the review group recommended additional calcination based on recent workshops suggesting tighter requirements for storage. The presenters felt the current packaging for metals was not acceptable for 50 years and additional processing was needed, but not urgently. The review group ranked technologies requiring significant manual operation by workers other than packaging significantly lower than more remote processes. The presenters recommended technologies for the organic solutions and combustibles where the review group indicated all would require lengthy development. 


\subsection{References}

Allen, C. R., and P. C. Ely. 1980. Acid Digestion of Combustible Wastes. HEDL-TME-79-64, Hanford Engineering Development Laboratory, Richland, Washington.

Cecille, L., and R. Simon, eds. 1983. The Acid Digestion Process for Radioactive Waste. Harwood Academic Publishers, New York.

Cooper, J., W. A. Brummond, J. Celeste, J. Farmer, C. Hoenig, O. H. Krikorian, R. S. Upadhye, R. L. Gay, A. Stewart, and S. Yosim. 1991. Molten Salt Processing of Mixed Wastes with Off Gas Condensation. UCRL-JC-107288, Lawrence Livermore National Laboratory, Livermore, California.

Crosley, S. M., D. K. Lorenzo, J. E. Van Cleve, R. L. Gay, K. M. Barclay, J. C. Newcomb, and S. J. Yosim. 1993. "Treatment of Waste by the Molten Salt Oxidation Process at the Oak Ridge National Laboratory." In Proceedings of the Conference on Mixed Waste. Conf. 930906-3, Martin Marietta Energy Systems, Oak Ridge, Tennessee.

Crowe, R. D., and R. Szempruch. 1994. Technical Basis for Characterization of Plutonium for PFP Safety Analyses. WHC-SD-CP-TI-190, Rev 0, Westinghouse Hanford Company, Richland, Washington.

Eckerman and Jeffrey. 1993. External Exposure to Radionuclides in Air, Water, and Soil. EPA-402-4-93-081, Federal Guidance Report No. 12, Oak Ridge National Laboratory, Oak Ridge, Tennessee.

Marsh, S. F. 1989. Reillex ${ }^{T M} H P Q: A$ New, Macroporous Polyvinylpyridine Resin for Separating Plutonium Using Nitrate Anion Exchange. LA-UR-89-844, Los Alamos National Laboratory, Los Alamos, New Mexico.

Martin Marietta Energy Systems, Inc., U.S. Department of Energy, Oak Ridge National Laboratory and RUST Geotech, Inc. 1993. Mixed-Waste Treatment - What About the Residuals? A Comparative Analysis of MSO and Incineration. U.S. Department of Energy, Grand Junction, Colorado.

Navratil, J. D. 1979. Nuclear Technology 6:105.

Rockwell International. 1993. Molten Salt Oxidation of Radioactive Waste. Rocketdyne Division, Canoga Park, California.

Rockwell International. 1994. Technology Index - Molten Solids Processing - Molten Salt Process. Rockwell International, Canoga Park, California. 
Short. 1978. Technology, Safety, and Costs of Decommissioning Reference Non-Fuel-Cycle Nuclear Facilities. NUREG/CR-1754, Pacific Northwest Laboratory, Richland, Washington.

Taylor, L. H. 1993. Molten Salt Oxidation Technology - A Status Paper. U.S. Department of Energy, Germantown, Maryland.

Upadye R. S., J. G. Wilder, and C. E. Karlsen. 1993a. Molten Salt Destruction Process for Mixed Wastes. UCRL-JC-112666, Lawrence Livermore National Laboratory, Livermore, California.

Upadye R. S., W. A. Brummond, and C. O. Pruneda. 1993b. Destruction of Energetic Materials Using the Molten Salt Destruction Process. Lawrence Livermore National Laboratory, Livermore, California.

Vogt, E. C. 1983. Z-Plant Plutonium Handling Operations. RHO-CD-1244, Rockwell Hanford Operations, Richland, Washington.

Wojdac, L. F. 1994. 18 th Annual Actinide Separations Conference in Durango, Colorado - Molten Salt Technology Applications. Westinghouse Hanford Company, Richland, Washington.

\section{Bibliography}

U.S. Department of Energy (DOE). 1992. Molten Salt Oxidation Technology Progress Report. DOE/ID/12584-1 19, GJPO-112, Part 1, U.S. Department of Energy, Germantown, Maryland.

U.S. Department of Energy (DOE). 1993. Molten Salt Oxidation Technology Report. DOE/ID/12584-119, GJPO-112, Part 3, U.S. Department of Energy, Germantown, Maryland.

Lerch, R. E., C. R. Allen, A. G. Blasewitz, and E. Maestas. 1981.. "Acid Digestion of Combustible Nuclear Wastes." In Nuclear and Chemical Waste Management, Vol. 2:265-277.

Lerch, R. E., C. R. Allen, A. G. Blasewitz, and Maestas. 1981. Application of Acid Digestion to Reprocessing Wastes and Chemicals. TC-362, Hanford Engineering Development Laboratory, Richland, Washington.

Hoyt, R. C. 1993. Summary Report on Hanford Plutonium Disposition Workshop.

WHC-SD-CP-VEP-001, Rev. 0, Westinghouse Hanford Company, Richland, Washington.

Newcomb, J. C., and C. D. Newman. 1994. "Molten Salt Oxidation for the Destruction Of Mixed Wastes-A Ready Technology." In the Proceedings of the Mixed Waste Thermal Treatment Symposium. Rockwell International Corporation, Canoga Park, California. 
Appendix A

Description of Technologies 



\section{Contents}

$\mathrm{ACT}^{*} \mathrm{DE}^{*} \mathrm{CON}^{\mathrm{sm}}$ Soil and Sludge Washing Process (Bradtec, United Kingdom) $\ldots \ldots$ A.1

Ion Exchange $\ldots \ldots \ldots \ldots \ldots \ldots \ldots \ldots \ldots \ldots \ldots \ldots \ldots \ldots \ldots$

Direct Denitration via Vertical Calciner $\ldots \ldots \ldots \ldots \ldots \ldots \ldots \ldots \ldots \ldots \ldots$

Direct Denitration via Fluid Bed $\ldots \ldots \ldots \ldots \ldots \ldots \ldots \ldots \ldots \ldots$

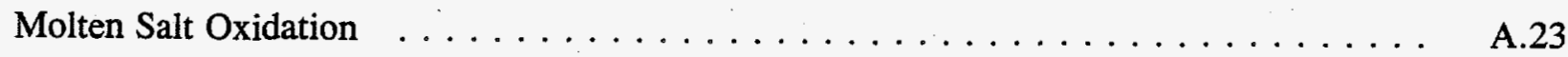

Direct Denitration via Horizontal Screw Calciner $\ldots \ldots \ldots \ldots \ldots \ldots \ldots$. . . . . .

Blend with High-level waste $\ldots \ldots \ldots \ldots \ldots \ldots \ldots \ldots \ldots \ldots \ldots \ldots$

Vitrification $\ldots \ldots \ldots \ldots \ldots \ldots \ldots \ldots \ldots \ldots \ldots \ldots \ldots \ldots$

Cold Glass Processing (Sol-Gel) $\ldots \ldots \ldots \ldots \ldots \ldots \ldots \ldots \ldots \ldots \ldots$

Seeded Magnetic Filtration (MAG'SEP, United Kingdom) $\ldots \ldots \ldots \ldots \ldots \ldots$. . . . . A.49

Existing MT-4 System $\ldots \ldots \ldots \ldots \ldots \ldots \ldots \ldots \ldots \ldots \ldots$

Microwave Drying $\ldots \ldots \ldots \ldots \ldots \ldots \ldots \ldots \ldots \ldots \ldots \ldots \ldots \ldots \ldots$

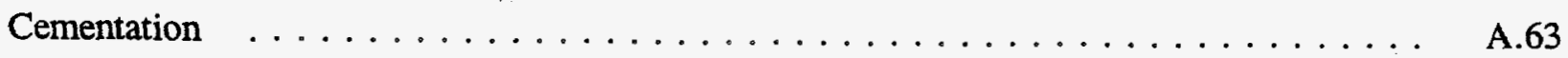

Sugar Denitration $\ldots \ldots \ldots \ldots \ldots \ldots \ldots \ldots \ldots \ldots \ldots \ldots \ldots \ldots \ldots \ldots$

Freeze Crystallization $\ldots \ldots \ldots \ldots \ldots \ldots \ldots \ldots \ldots \ldots \ldots$

Phase Separation (By Adduct Formation) $\ldots \ldots \ldots \ldots \ldots \ldots \ldots$ A.83

Absorption $\ldots \ldots \ldots \ldots \ldots \ldots \ldots \ldots \ldots \ldots \ldots \ldots \ldots \ldots \ldots \ldots$

Screening $\ldots \ldots \ldots \ldots \ldots \ldots \ldots \ldots \ldots \ldots \ldots \ldots \ldots \ldots \ldots \ldots \ldots$ A. . . . . . . .

Wet Oxidation $\ldots \ldots \ldots \ldots \ldots \ldots \ldots \ldots \ldots \ldots \ldots \ldots \ldots \ldots \ldots$

Direct Discard to Waste Isolation Pilot Plant $\ldots \ldots \ldots \ldots \ldots \ldots \ldots$. . . . . . . . .

Ozone Treatment $\quad \ldots \ldots \ldots \ldots \ldots \ldots \ldots \ldots \ldots \ldots \ldots \ldots$ A.99

Solvent Extraction $\ldots \ldots \ldots \ldots \ldots \ldots \ldots \ldots \ldots \ldots \ldots \ldots \ldots \ldots$ 


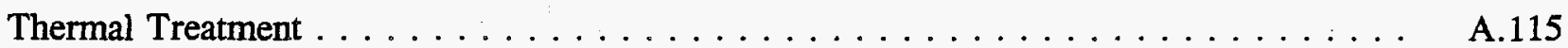

High Gradient Magnetic Separation $\ldots \ldots \ldots \ldots \ldots \ldots \ldots \ldots \ldots \ldots \ldots \ldots$ A.123

Silver Persulfate $\ldots \ldots \ldots \ldots \ldots \ldots \ldots \ldots \ldots \ldots \ldots \ldots \ldots \ldots \ldots$ A.127

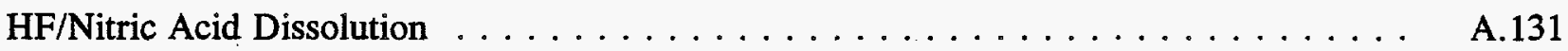

Zone Melting $\ldots \ldots \ldots \ldots \ldots \ldots \ldots \ldots \ldots \ldots \ldots \ldots \ldots \ldots \ldots \ldots \ldots \ldots$

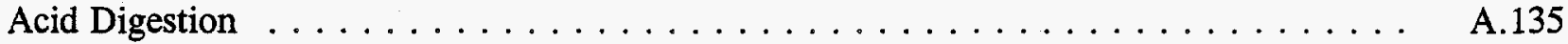

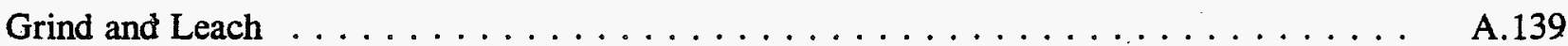

Muffle Furnace $\ldots \ldots \ldots \ldots \ldots \ldots \ldots \ldots \ldots \ldots \ldots \ldots \ldots \ldots \ldots$ A.141

Hydroxide Precipitation $\ldots \ldots \ldots \ldots \ldots \ldots \ldots \ldots \ldots \ldots \ldots \ldots \ldots$

Oxalate Precipitation $\ldots \ldots \ldots \ldots \ldots \ldots \ldots \ldots \ldots \ldots \ldots \ldots \ldots \ldots$ A.149

Peroxide Precipitation $\ldots \ldots \ldots \ldots \ldots \ldots \ldots \ldots \ldots \ldots \ldots \ldots \ldots \ldots \ldots$

Evaporation $\ldots \ldots \ldots \ldots \ldots \ldots \ldots \ldots \ldots \ldots \ldots \ldots \ldots \ldots \ldots \ldots \ldots$

Ammonia Precipitation $\ldots \ldots \ldots \ldots \ldots \ldots \ldots \ldots \ldots \ldots \ldots \ldots$

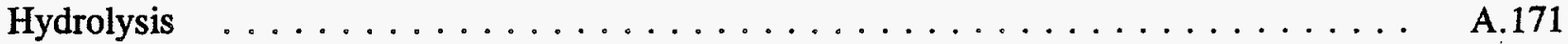

High Temperature Plasma $\ldots \ldots \ldots \ldots \ldots \ldots \ldots \ldots \ldots \ldots \ldots \ldots \ldots \ldots$

Membrane Separations $\ldots \ldots \ldots \ldots \ldots \ldots \ldots \ldots \ldots \ldots \ldots \ldots \ldots \ldots$ A.179

Precipitation of Silver Chloride $\ldots \ldots \ldots \ldots \ldots \ldots \ldots \ldots \ldots \ldots \ldots \ldots \ldots$

Catalyzed Electrochemical Plutonium Oxide Dissolution (CEPOD) Process $\ldots \ldots \ldots$. . . A.185 


\section{Appendix A}

\section{Description of Technologies}

\section{Accept: — Reject: $\underline{X}$ \\ Technology - ACT*DE*CON Soil and Sludge Washing Process (Bradtec, United Kingdom)}

\section{Waste Processed}

This technology can be used to process plutonium-contaminated sludge (G02), incinerator ash (G03), reduction residue non-chlorides (G05), plutonium-DU residue (G40), and plutonium-EU residue (G70).

\section{Process Description}

The ACT $* \mathrm{DE}^{*} \mathrm{CON}^{\mathrm{sm}}$ process is an alkaline-side dissolution technology that operates at ambient pressure and moderate temperatures. The $A C T * D E * C O N^{s m}$ process uses well established carbonate chemistry, a chelating agent ethylene-diaminetetraacetic acetate (EDTA), and an oxidant (hydrogen peroxide). The role of the oxidant is to adjust the oxidation states of the actinides (or certain fission products) to states in which they are more soluble at the operating $\mathrm{pH}$ or form soluble complexes with carbonate or EDTA. For example, if uranium were present in an oxidation state lower than +6 , it would be oxidized to uranium (VI) in the $A C T * \mathrm{DE}^{*} \mathrm{CON}^{\mathrm{sm}}$ process and would form the soluble carbonate complex $\left[\mathrm{UO}_{2}\left(\mathrm{CO}_{3}\right)_{3}\right]^{4}$.

The process has been tested on plutonium-contaminated soil from the U.S. Department of Energy (DOE) Mound Laboratory and uranium-contaminated soil from the DOE Fernald Site with some success. Decontamination factors (DF) of 13 for plutonium and as high as 82 for uranium have been reported. The process is being tested at the pilot-scale at the Idaho National Engineering Laboratory (INEL) Pit 9 that is contaminated with soil and sludge. To date the process has been most successful in treating low levels of plutonium and uranium in a soil matrix, where dissolution of metals is minimal. Testing of the process on Hanford Site sludge simulant resulted in the dissolution of 20 to $30 \mathrm{wt} \%$ of the bulk metals. However, there is no direct experience with plutonium contaminated sludges that exist in the Plutonium Finishing Plant (PFP). Technically, there are two major concerns regarding applying $A C T * D^{*}{ }^{*} \mathrm{CON}^{\mathrm{sm}}$ to PFP sludges. First, the plutonium concentration of the PFP sludges is orders of magnitude higher than that tested to date. Second, based on the testing of the Hanford Site sludge simulant, considerable ( 20 to $30 \mathrm{wt} \%$ ) dissolution of bulk metals is expected. 


\section{Facilities and Equipment}

No additional facilities are required. The process uses a mixer to mix the $\mathrm{ACT}^{*} \mathrm{DE}^{*} \mathrm{CON}^{\mathrm{sm}}$ solution in a tank with the sludge, a settler/filtration unit, and a collection system for recovery of cleaned sludge and the $\mathrm{ACT}^{*} \mathrm{DE} \mathrm{CON}^{\mathrm{sm}}$ leach liquor containing the radionuclides, which will be further concentrated and then converted to a suitable disposal form.

\section{Schedule}

The system could be set up very quickly after delivery of the equipment; however, bench-scale tests are recommended to assess the process applicability to the PFP wastes.

\section{Final Product Description}

Assuming the process works, the end product would be a cleaned sludge suitable for disposal as a low-level waste and a wash solution containing metal-carbonate complexes, metal-EDTA complexes, and metal ions in solution. Sodium is added to the ACT ${ }^{*} \mathrm{DE} * \mathrm{CON}$ sm solution in the form of $\mathrm{NaHCO}_{3}$, $\mathrm{Na}_{2} \mathrm{CO}_{3}$, and $\mathrm{Na}_{4} \mathrm{EDTA}$.

\section{Effluents Generated}

The $\mathrm{ACT}^{*} \mathrm{DE}^{*} \mathrm{CON}^{\mathrm{sm}}$ leach liquor contains plutonium and metal complexed with carbonate and EDTA. No speciation work has been performed; therefore, it is unknown if the plutonium is complexed with the carbonate, EDTA, or both. If the plutonium is complexed with the EDTA, recovery will be difficult; the simplest method of plutonium recovery would be evaporation and calcination. A typical volume of the $\mathrm{ACT}^{*} \mathrm{DE} * \mathrm{CON}^{\mathrm{sm}}$ leach liquor ranges from 3:1 to 25:1 volume of $\mathrm{ACT} * \mathrm{DE}^{*} \mathrm{CON}^{\mathrm{sm}}$ solution:volume of sludge treated.

\section{Risks}

This process is a chemical dissolution method with little risk of effluent release. It uses only carbonate, peroxide, and EDTA, chemicals of relatively low toxicity.

\section{Costs}

Because the process is simple, costs are expected to be low.

\section{Comments}

This process seems to be best suited for decontamination of soils where the plutonium and uranium concentrations are low, and metals concentration in the soil is also low. This process is not proven for the decontamination of sludges. 


\section{Justification for Further Study or Rejection}

The ACT*DE*CON ${ }^{\mathrm{sm}}$ process is not recommended because of the lack of experience with PFP residues and because significant bulk metals in the PFP sludges may also dissolve with the plutonium. In addition, recovery of the plutonium, by means other than evaporation and calcination, may be difficult because no speciation work has been performed on the $\mathrm{ACT}^{*} \mathrm{DE} \mathrm{CON}^{\mathrm{sm}}$ leach liquor. Finally, this process is not a proven technology for the decontamination of sludges.

\section{Bibliography}

Brown, K. A., R. R. Heinrich, D. O. Johnson, and D. E. Edgar. 1992. Preliminary Laboratory Study of Plutonium-238 Dissolution from Mound Soil by Means of the ACT*DE*CON ${ }^{* m}$ Process. ANL/ESD-15, Argonne National Laboratory, Argonne, Illinois.

Geeting, J. G. H. 1994. "The ACT*DE*CON"sm Process: Selective Leaching of Tank Sludges by the ACT ${ }^{*} \mathrm{DE}^{*} \mathrm{CON}^{\mathrm{sm}}$ Process." In Efficient Separations and Processing Integrated Program Technology Summary. DOE/EM-0126P, U.S. Department of Energy, Washington, D.C. 



\section{Description of Technologies}

Accept: $\underline{X}$ Reject:

\section{Technology - Ion Exchange}

\section{Waste Processed}

Nitrate, chloride, and other solutions may all be processed by ion exchange methods. Solutions which contain fluoride and sulfate or thorium ions may present problems, however. Fluoride ions measurably suppress sorption of plutonium, no matter how much aluminum is present (Marsh 1987). Verification of the ion exchange technology with solutions containing fluorides is required.

The plutonium sulfate solutions can start to affect resin capacity at concentrations $>0.5 \underline{\mathrm{M}}$. Thorium in solutions will compete with plutonium; however, lowering the acidity will remedy the situation. The presence of uranium does not affect the process unless extraordinary amounts are present that bind over the plutonium simply because of the binding possibility ratio. ${ }^{(a)}$ However, 100 times more uranium than plutonium would not significantly affect the process. Lastly, caustic solutions would require one additional step of adding acid to the caustic volume in a minimum 1:1 ratio.

\section{Process Description}

Ion exchange is generally used for purifying and concentrating plutonium. The process uses resins that are insoluble, high-molecular-weight polyelectrolytes which can reversibly exchange their mobile ions with those of equal charge from the surrounding solution. Generally there are four types of ion exchange: anion exchange in a weak or strong base, or cation exchange in a weak or strong acid.

Research suggests that the best process for purifying plutonium is anion exchange in nitric acid. In fact, the Los Alamos Plutonium Facility uses this process to recover and purify plutonium from impure scrap materials. Buchanan and Faris (1960) showed that this process is ideal because no metal ion is more strongly sorbed than plutonium (IV), while few other ions display even moderate sorption from nitric acid.

Nitrate anion exchange of plutonium (IV) is a well-established plutonium separation and purification process that has been in widespread use for about 30 years throughout the world for both processing and analytical applications. Nitric acid, anion exchange runs have shown that macroporous resins can be used in both primary and secondary columns at very high plutonium throughput rates at $25^{\circ} \mathrm{C}$.

Marsh (1989) demonstrates that a macroporous polyvinylpyridine resin, Reillex HPQ, is useful in that

(a) Personal communication between J. L. Ryan, (PNL), and K. Templeton, (PNL), June 24, 1994, in Richland, Washington. 
it offers high capacity and rapid sorption kinetics for plutonium (IV) from nitric acid. The resin also offers greater stability to chemical and radiolytic degradation.

For solutions with high concentrations of chloride, plutonium is separated by using a separate twocolumn facility fabricated from materials that resist corrosion of acid chloride (Ryan et al. 1988). Feed concentrations of 210 to $300 \mathrm{~g}$ molten salt extraction (MSE) salt/L of $6 \underline{\mathrm{M} \mathrm{HNO}} 3$ have been demonstrated. Resin loadings of about $80 \mathrm{~g} \mathrm{Pu} / \mathrm{L}$ have been demonstrated. The loaded resin is washed with $7 \underline{\mathrm{M} \mathrm{HNO}}{ }_{3}$, and the product is eluted with $0.35 \mathrm{M} \mathrm{HNO}_{3}$. Chloride contamination in the eluted plutonium product is about $40 \mathrm{ppm}$ solution, corresponding to a DF of about $10^{4}$ relative to plutonium for a 10-column-volume wash. The need to control the plutonium oxidation state and the measures required to achieve impurity decontamination make the chloride system much more complicated than the nitric acid system. Therefore, the mixed chloride-nitric acid system is more desirable unless a chloride product is required.

\section{Facilities and Equipment}

The maximum column diameter is $15 \mathrm{~cm}$, and the column height is 150 to $180 \mathrm{~cm}$ (which would hold $33.3 \mathrm{~L}$ ). This volume would allow for approximately $2 \mathrm{~kg}$ of solution to be processed every 36 hours. Currently, there is a design for an ion exchange unit on the south side of Glovebox MT-3 in room 41 of Building 236-Z (Vogt 1983). The unit would be placed in a double high glovebox. The manpower is unknown at this time.

\section{Schedule}

The process development is minimal since the technology has been used for the past 30 years. The processing rate will depend on the size of the column, the type of resin used, and the number of elution cycles that will be required. Assuming that the column is $180 \mathrm{~cm}$ by $15 \mathrm{~cm}$ inside diameter and the Reillex HPQ resin is used with a feed rate of $3 \mathrm{~L} / \mathrm{h}$, the processing time for each solution is as follows: nitrate solutions will take 24 weeks, chloride solutions will take 2.5 weeks, and other solutions will take 5.6 weeks. The durations are based on a $60 \%$ operational rate for $5 \mathrm{~d} / \mathrm{wk}, 24 \mathrm{~h} / \mathrm{d}$.

\section{Final Product Description}

The final product after vertical calcination would be plutonium oxide with no americium or other impurities present. The spent resin could be vacuumed extracted and treated the same as the plutonium bearing waste combustibles. In addition, the plutonium would be pure and have an high potential for fuel/weapons use. Lastly, the final plutonium product would be the most stable according to Cooper (1994).

\section{Effluents Generated}

The effluent stream will contain any americium or other elements that do not bind to the resin. The amount of plutonium left in the effluent stream will, in most cases, be below $0.013 \mathrm{~g} \mathrm{Pu} / \mathrm{L}$, which is 
the concentration limit for the high-level waste (HLW) tank farms. The effluent stream could be transferred to the HLW tank farms after neutralization if it is below the set concentration limit. The resin would require further treatment and disposal as a solid waste.

\section{Risks}

The main risk associated with the anion exchange is the possibility of a self-sustaining exothermic reaction. However, this danger can be avoided if the column is never left loaded, the column is not exposed to concentrated $\mathrm{HNO}_{3}$, the resin is changed on a 3-month interval, and the column is weakwalled and open (Cooper 1994). In addition to a possible exothermic reaction, the possibility of a criticality is a risk as well. This risk is simply avoided by selecting a column size that will not allow the critical limit of plutonium to gather.

\section{Costs}

The costs are unknown at this time.

\section{Comments}

Table A.1 provides a summary of the criteria evaluations for ion exchange. This process will probably not be accepted by the stakeholders because it purifies the final product for easier diversion to weapons. In addition, the process has had incidents of exploding and causing extreme risk to workers. Although steps can be taken to avoid such risk occurrence, the fear is still evident, especially if the safety steps are not known to a new process analyst.

\section{Justification for Further Study or Rejection}

Ion exchange has been used for the last 30 years as a common process to recover plutonium and is, therefore, accepted for further evaluation. However, because of the fear of developing weapons-grade material and the fear of resin rapid decomposition, the process needs to show a volume reduction in the final product and/or a significant decrease in risk to the workers and public from storing such a material.

\section{References}

Buchanan, R. F., and J. P. Faris. 1960. Applications of Anion-Exchange Spectrographic Procedures in Nitric Acid Medium. U.S. Atomic Energy Commission Report TID-7606, U.S. Atomic Energy Agency, Washington, D.C.

Cooper, T. D. 1994. "Plutonium Stabilization Chemistry at Hanford." In Proceedings of the 18th Annual Actinide Separation Conference. National Technical Information Services, Springfield, Virginia. 
Table A.1. Criteria Evaluations for Ion Exchange

\begin{tabular}{|c|c|}
\hline Criteria & Evaluation \\
\hline Technical Feasibility (technology maturity) & $\begin{array}{l}\text { Has been used for the last } 30 \text { years; } \\
\text { equipment exists, with some modifications } \\
\text { required }\end{array}$ \\
\hline $\begin{array}{l}\text { Effluents/By-Products } \\
\text { (minimize volumes, hazards) }\end{array}$ & Minimal - liquid effluent and resin \\
\hline Effluents Covered/Safety Analysis Report (SAR) & Resin not covered on SAR \\
\hline Energy Resource & Unknown \\
\hline Weapon Potential & $\begin{array}{l}\text { Pure plutonium dioxide product after } \\
\text { vertical calcination }\end{array}$ \\
\hline End Product Volume & Minimal \\
\hline End Product Stability & $\begin{array}{l}\text { Chemically, mechanically, and radiolytically } \\
\text { stable }\end{array}$ \\
\hline $\begin{array}{l}\text { Environmental and Public Risk } \\
\text { routine } \\
\text { accident }\end{array}$ & Minimal \\
\hline $\begin{array}{l}\text { Worker Risk } \\
\text { routine } \\
\text { accident }\end{array}$ & $\begin{array}{l}\text { Potential for accidents if not handled } \\
\text { appropriately }\end{array}$ \\
\hline $\begin{array}{l}\text { Cost } \\
\text { (construction, operations and } \\
\text { decontamination and decommissioning [D\&D]) }\end{array}$ & Unknown \\
\hline Operating Duration & $\begin{array}{l}\text { Nitrates- } 24 \text { weeks; chlorides }-2.5 \text { weeks; } \\
\text { others }-5.6 \text { weeks }\end{array}$ \\
\hline Public Acceptance & Unacceptable \\
\hline Flexibility & Solutions \\
\hline Materials Covered & Chloride, nitrate, and other solutions \\
\hline
\end{tabular}


Marsh, S. F. 1987. The Effect of Fluoride and Aluminum on the Anion Exchange of Plutonium From Nitric Acid. LA-10999, Los Alamos National Laboratory, Los Alamos, New Mexico.

Marsh, S. F. 1989. Evaluation of a New, Macroporous Polyvinylpyridine Resin for Processing Plutonium Using Nitrate Anion Exchange. LA-11490, Los Alamos National Laboratory, Los Alamos, New Mexico.

Ryan, J. L., L. Bray, and E. J. Wheelwright. 1988. Development and Demonstration Support For the Aqueous Process Flowsheet for Recovery of Plutonium from Special Isotope Separation Process Residues. PNL-6597, Pacific Northwest Laboratory, Richland, Washington.

Vogt, E. C. 1983. Z Plant Plutonium Handling Operations Safety Analysis Report. RHO-CD-1244, Rockwell Hanford Operations, Richland, Washington.

\section{Bibliography}

Moghissi, A., H. W. Godbee, and S. A. Hobart. 1986. Radioactive Waste Technology. The American Society of Mechanical Engineers, New York. pp. 240-242.

Muscatello, A. C., M. T. Saba, and J. D. Navratil. 1986. Recovery of Plutonium from Nitric Acid Waste. RFP-4009, Rocky Flats Plant, Golden, Colorado.

Navratil, J. D. 1979. Nuclear Technology 6:105.

Ryan, J. L., and E. J. Wheelwright. 1959. The Recovery, Purification, and Concentration of Plutonium by Anion Exchange in Nitric Acid. HW-55893, Hanford Atomic Products Operation, Richland, Washington. 
A. 10 


\section{Description of Technologies}

Accept: $\underline{X}$ Reject:

\section{Technology - Direct Denitration via Vertical Calciner}

\section{Waste Processed}

Plutonium nitrate solutions and filtrate, plutonium-uranium nitrate solutions, and plutonium thorium nitrate solutions all can be processed using this technology. The nitrate-based solutions may contain organics and chlorides. In addition, nitric acid digestible materials, such as sludges and residues, are candidate feed materials for this process. Hydrochloric acid solutions may also be processed in a vertical calciner.

\section{Process Description}

Direct denitration is a process whereby plutonium nitrate solutions are converted directly to plutonium oxide in a calciner without forming an intermediate plutonium compound. The plutonium nitrate solution is heated in an air atmosphere to evaporate the water and nitric acid, leaving a solid plutonium oxide particle. Additives may be necessary to prevent foaming and the formation of a mastic stage. The overall calcination reaction is as follows:

$$
\mathrm{Pu}\left(\mathrm{NO}_{3}\right)_{4} \rightarrow \mathrm{PuO}_{2}+3.4 \mathrm{NO}_{2}+0.6 \mathrm{NO}+1.3 \mathrm{O}_{2}
$$

The product is a dry, impure plutonium oxide powder. The calciner off-gas stream consists of a mixture of air, water, nitric acid, and oxides of nitrogen. In addition, fine plutonium oxide powder is often entrained in the gas stream. The off-gas stream is filtered to remove the entrained oxide and cooled in a condenser to remove most of the water and nitric acid. The off gas is then sent to the highefficiency particulate air filter (HEPA) via the ventilation system.

During thermal denitration of uranyl nitrate and plutonium nitrate, the solution is successively dehydrated and then denitrated, remaining molten and becoming increasingly viscous and pasty until its conversion to the dry oxide state is essentially complete. The material will become mastic, tending to form hard deposits on equipment surfaces and on particulate material throughout the reaction zone, unless the transition to dry oxide is accomplished quickly.

The feed to the vertical calciner reactor is metered slowly into a heated stirred bed of previously generated product solids. The liquid feed is rapidly evaporated. Then, more slowly, it undergoes drying, denitration, and a final heat treatment to form a stable plutonium dioxide product. The agitator blades separate the solid particles, with the larger particles moving upward and the fines settling to the bottom of the calciner. The plutonium oxide product is discharged through a slot in a pipe, down an overflow tube, and into a receiver. The height of the adjustable overflow tube determines the bed volume within 
the calciner. The vertical calciner is operated at $800^{\circ} \mathrm{C}$. The capacity of the vertical calciner is roughly $2 \mathrm{~L} / \mathrm{h}$ of solution for concentrated feeds and 3 to $4 \mathrm{~L} / \mathrm{h}$ for dilute feeds.

The plutonium dioxide product may contain some residual sulfate and/or phosphate impurities but will be substantially free of chloride, fluoride, and other volatile acid impurities. Organic impurities are largely consumed and only partly report to the off-gas condensate. Off-gas condensates are non-TRU.

A vertical calciner direct denitration process has been successfully demonstrated with plutonium nitrate solutions (Stiffler and Hopkins 1962).

\section{Facilities and Equipment Required}

The equipment required for a vertical calciner denitration process is depicted in Figure A.1. The existing PFP does not have the equipment necessary for a vertical calciner direct denitration process. However, the PFP does have the necessary utilities, operating materials, supplies, and manpower to operate an agitated pot direct denitration process. The PFP's floor space must be modified to accommodate the direct denitration equipment. Roughly $45 \mathrm{~m}^{2}$ of floor space and $14 \mathrm{~m}^{3}$ of glovebox space are needed. Glovebox HC-9B may be used for the vertical calciner, and Glovebox HA-46 may be used for treatment of the off gases.

\section{Schedule}

The vertical calciner direct denitration method has been demonstrated on a laboratory scale to successfully convert plutonium nitrate solutions of varying concentrations and molarities into plutonium dioxide powder. Although there are no data regarding plutonium nitrate/thorium nitrate and plutonium nitrate/uranyl nitrate mixtures, it is assumed that they would behave similarly in a direct denitration process to produce powder oxide products. And, although there are no literature references regarding the direct conversion of nitrate sludges and residues to oxides, these materials are expected to behave in the same manner as the nitrate solutions if they can be easily digested in nitric acid and fed to the calciner. Therefore, no process development time is thought to be necessary for the vertical calciner direct denitration process.

The size of the tested vertical calciner, direct denitration process design (13-cm-diameter by $25-\mathrm{cm}$ high reactor) is sufficient to process the PFP wastes without the need for scale-up design work. However, the process equipment must undergo a thorough checkout with operating conditions established. Operating procedures, safety analyses, safety analysis review (SAR) revisions, and operator training procedures must be developed and completed.

Approximately 3800 hours of operating time are needed, based on a feed rate of $1 \mathrm{~L} / \mathrm{h}$ into the vertical calciner reactor and processing of all the nitrate solutions, sludges, and filtrates. 


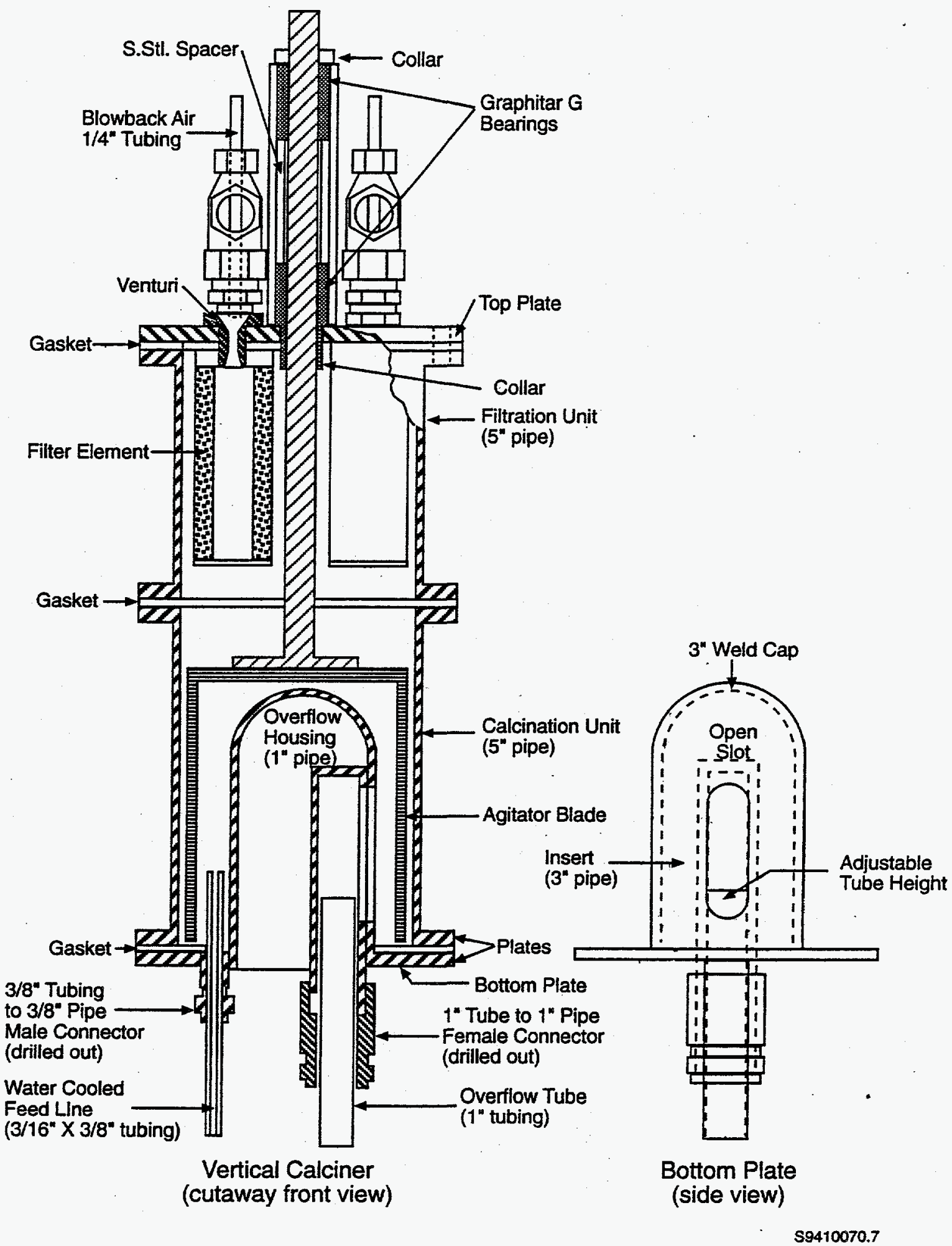

Figure A.1. Vertical Calciner Equipment 


\section{End Product Description}

The end product from direct denitration is a solid plutonium dioxide powder or, in the case of mixtures, a uranium trioxide/plutonium dioxide or thorium dioxide/plutonium dioxide powder. These materials are stable (less than $1 \%$ loss-on-ignition [LOI]) and are ready for final packaging.

\section{Effluent and By-Products}

Gaseous effluents from the direct denitration process include air, water, and oxides of nitrogen. This stream is condensed and then passed through HEPA filters and discharged to the existing PFP ventilation system. The liquid effluents consist of condensed water and nitric acid with plutonium $\leq 1 \mathrm{mg} / \mathrm{L}$. The level of $\mathrm{Pu}$ in the effluent has not been demonstrated with solutions being considered. This stream is neutralized with caustic solution and sent to the tank farm. The solid effluent is the entrained oxide powder on the off-gas filters. The filters, when plugged, are blown back with compressed air. Thus entrained fines are refumed to the powder bed.

\section{Risks}

The risks to the environment and public are minimal because the direct denitration process does not use any hazardous chemicals and generates only nitrogen oxide as a hazardous gaseous effluent. Worker risks are also minimal because of the small number of process steps involved. The feed materials are added slowly in small increments, which decompose "red oil" and any other organics safely without vigorous reactions.

\section{Costs}

New capital equipment costs of approximately $\$ 60,000( \pm 30 \%)$ are expected. In addition, costs will be incurred to modify the PFP for adequate space and to install and check out equipment. Also, administrative costs will be incurred for preparing and approving documents (operating procedures, safety analyses, SAR revisions, maintenance, training, etc.). Operational costs of a vertical calciner direct denitration process are expected to be less than other nondirect denitration processes because of the minimal number of steps involved and the simplicity of operations. Waste disposal costs are also expected to be less than other nondirect denitration processes because of a lower impact on the ventilation and water treatment operations.

\section{Comments}

A previous objection to installing a direct denitration process in the PFP was the loss of purification that was achieved by oxalate precipitation. Since purity requirements are not a major factor in converting plutonium nitrate solutions, sludges, or residues to a stable form, this objection is no longer valid.

A direct denitration process was recently evaluated as being equal to operating the existing Plutonium Recovery Facility (PRF) and remote mechanical (RMC) line processes (Hoyt 1993).

\section{A.14}


Some advantages and disadvantages of a vertical calciner direct denitration process follow.

\section{Advantages}

No feed preparation (evaporation) is required.

No additives are necessary for the process.

The process is well suited for variable feeds (e.g., 5 to $500 \mathrm{~g} / \mathrm{L}$ concentrations and chloride, fluoride, and organic impurities).

Minimal operator interface is required because of few pieces of equipment, resulting in safer radioactive exposure.

The process produces a stable oxide product that meets level of LOI requirements.

The process does not form a mastic stage.

The ratio of heat transfer area to bed volume is $30 \%$ larger than the horizontal screw calciner.

The process creates relatively minor chemical hazards. No toxic liquids are produced other than plutonium nitrate. In addition, no toxic gases other than plutonium oxide dusting and $\mathrm{NO}_{\mathrm{x}}$ off gases are produced.

Utilities requirements are comparatively low.

The processing of liquid and gaseous effluents is comparatively low.

\section{Disadvantages}

The vertical calciner method has not been used to produce plutonium dioxide at $800^{\circ} \mathrm{C}$ (only at $400^{\circ} \mathrm{C}$ ). The vertical calciner has not been tested at $800^{\circ} \mathrm{C}$.

The vertical calciner has not yet been installed in Glovebox 188-1 for testing of the argonne solutions received from Argonne National Laboratory (ANL) ${ }^{(a)}$.

The proposed vertical calciner design has not been operated since the mid 1960s.

The vertical calciner cannot process caustic solutions. Sodium or potassium impurities in the aqueous feed solutions will form a mastic stage.

The vertical calciner has a low throughput rate requiring extensive processing time, unless multiple units are installed.

(a) Internal WHC memo, Sutter, C. S. 1994. Test Proposal For Demonstrating Direct Denitration For Conversion Of Argonne Solutions To Stable, Storable Solids. Attachment 5 to Internal Memo 12120-94-010. 


\section{Justification for Further Study or Rejection}

The vertical calciner direct denitration process to stabilize the PFP nitrate solutions, sludges, and residues is recommended for further study. This recommendation is based on the process producing a stable product in one step with minimal off-gas processing.

\section{References}

Hoyt, R. C. 1993. Summary Report on Hanford Plutonium Disposition Workshop.

WHC-SD-CP-VES-001, Rev. 0, Westinghouse Hanford Company, Richland, Washington.

Stiffler, G. L., and H. H. Hopkins, Jr. 1962. A Vertical Calciner For Converting Plutonium Nitrate Solution To Plutonium Dioxide Powder. HW-73765, Hanford Atomic Products Operation, Richland, Washington.

\section{Bibliography}

Berglund, C. J. 1959. Direct Calcination of Plutonium Nitrate Solution. HW-61766, Hanford Atomic Products Operation, Richland, Washington.

Felt, R. E. 1965. Equipment for the Direct Calcination of Plutonium Nitrate. RL-SEP-674, Hanford Atomic Products Operation, Richland, Washington.

Lehmkuhl, G. D. 1977. Light Water Reactor Fuel Recycle Program Plutonium Nitrate-to-Oxide Conversion Project Progress Report. RFP-2590, Rocky Flats Plant, Golden, Colorado. 


\section{Description of Technologies}

Accept: _ Reject: $\underline{X}$

\section{Technology - Direct Denitration via Fluid Bed}

\section{Applicable Wastes Processed}

Plutonium nitrate solutions and filtrate, plutonium-uranium nitrate solutions, and plutonium-thorium nitrate solutions can be processed using direct denitration via fluid bid. The nitrate-based solutions may contain organics and chlorides. Sludges and residues are also candidate feed materials for this process.

\section{Process Description}

Direct denitration is a process whereby plutonium nitrate solutions are converted directly to plutonium oxide in a calciner without formation of an intermediate plutonium compound. The plutonium nitrate solution is heated in an air atmosphere to evaporate the water and nitric acid, leaving a solid plutonium oxide particle. Additives may be necessary to prevent foaming and the formation of a mastic stage.

The product is a dry, impure plutonium oxide powder. The calciner off-gas stream consists of a mixture of air, water, nitric acid, and oxides of nitrogen. In addition, fine plutonium powder is often entrained in the gas stream. The off-gas stream is filtered to remove the entrained oxide and cooled in a condenser to remove most of the water and nitric acid. The off gas is routed through the ventilation system to HEPA filters.

During thermal denitration of uranyl nitrate and plutonium nitrate, the solution is successively dehydrated and then denitrated, remaining molten and becoming increasingly viscous and pasty until conversion to the dry oxide state is essentially complete. The material will become mastic, tending to form hard deposits on equipment surfaces and on particulate material throughout the reaction zone, unless the transition to dry oxide is accomplished quickly.

The feed to the fluid bed reactor is concentrated in an evaporator. The concentrated plutonium nitrate solution is atomized with air and sprayed into the bed where the evaporation of water and nitric acid occurs. The plutonium nitrate calcines on the plutonium oxide particles to form plutonium oxide. The reaction typically takes place at $300^{\circ}$ to $400^{\circ} \mathrm{C}$. As the fluid bed increases in size, the plutonium oxide overflows to a product accumulator where it is collected for packaging.

A fluid bed direct denitration process has been successfully demonstrated with uranyl nitrate by the ANL (Vogler et al. 1972) and Mallinckrodt Chemical Works (Simecek and Trask 1963). Fluid bed denitration of highly-enriched uranyl nitrate was carried through pilot plant operation and into routine 
use at the Idaho Chemical Processing Plant (Souply and Neal 1977). In addition, the fluidized bed method has been demonstrated to convert a uranyl nitrate/plutonium nitrate mixture to uranium trioxide and plutonium dioxide powder (Vogler et al. 1972).

\section{Facilities and Equipment Required}

The equipment required for a fluid bed denitration process is depicted in Figure A.2. The equipment is sized for a $6.7 \mathrm{~kg} / \mathrm{h}$ input into the fluid bed reactor. All the equipment is stainless steel.

The existing PFP does not have the equipment necessary for a fluid bed direct denitration process. However, the PFP does have the necessary utilities, operating materials, supplies, and manpower to operate a fluid bed direct denitration process. The PFP's floor space must be modified to accommodate the direct denitration equipment. Roughly $280 \mathrm{~m}^{2}$ of floor space and $14 \mathrm{~m}^{3}$ of a glovebox space are needed.

\section{Schedule}

The fluid bed direct denitration method has been demonstrated on a laboratory-scale to successfully convert either plutonium nitrate or uranyl nitrate solutions of varying concentrations and molarities into plutonium dioxide or uranium trioxide powder. In addition, the fluidized bed method has been demonstrated to convert a uranyl nitrate/plutonium nitrate mixture to uranium trioxide and plutonium dioxide powder (Vogler et al. 1972). Although there are no data regarding plutonium nitrate/thorium nitrate mixtures, it is assumed that they would behave similarly in direct denitration processes to produce a powder oxide products. Also, there are no literature references regarding the direct conversion of nitrate sludges and residues to oxides, although these materials are expected to behave in the same manner as the nitrate solutions if they can be easily digested in nitric acid and fed to the calciner. Therefore, no process development time is necessary for the fluid bed direct denitration process.

The size of the tested fluid bed direct denitration process design (a reactor that is $10 \mathrm{~cm}$ in diameter by $91 \mathrm{~cm}$ in height) is sufficient to process the PFP wastes without the need for scale-up design work. However, the process equipment must undergo a thorough checkout with operating conditions established. Operating procedures, safety analyses, SAR revisions, and operator training must be developed and completed.

Approximately 735 hours of operating time are needed based on a feed rate into the fluid bed reactor of $6.7 \mathrm{~kg} / \mathrm{h}$ and on processing all the nitrate solutions, sludges, and filtrates.

\section{End Product Description}

The end product from direct denitration is a solid plutonium dioxide powder or, in the case of mixture, a uranium trioxide/plutonium dioxide or thorium dioxide/plutonium dioxide powder. These materials are low-fired oxides and must be re-fired at a temperature of at least $800^{\circ} \mathrm{C}$ to meet the stability recommendations. 


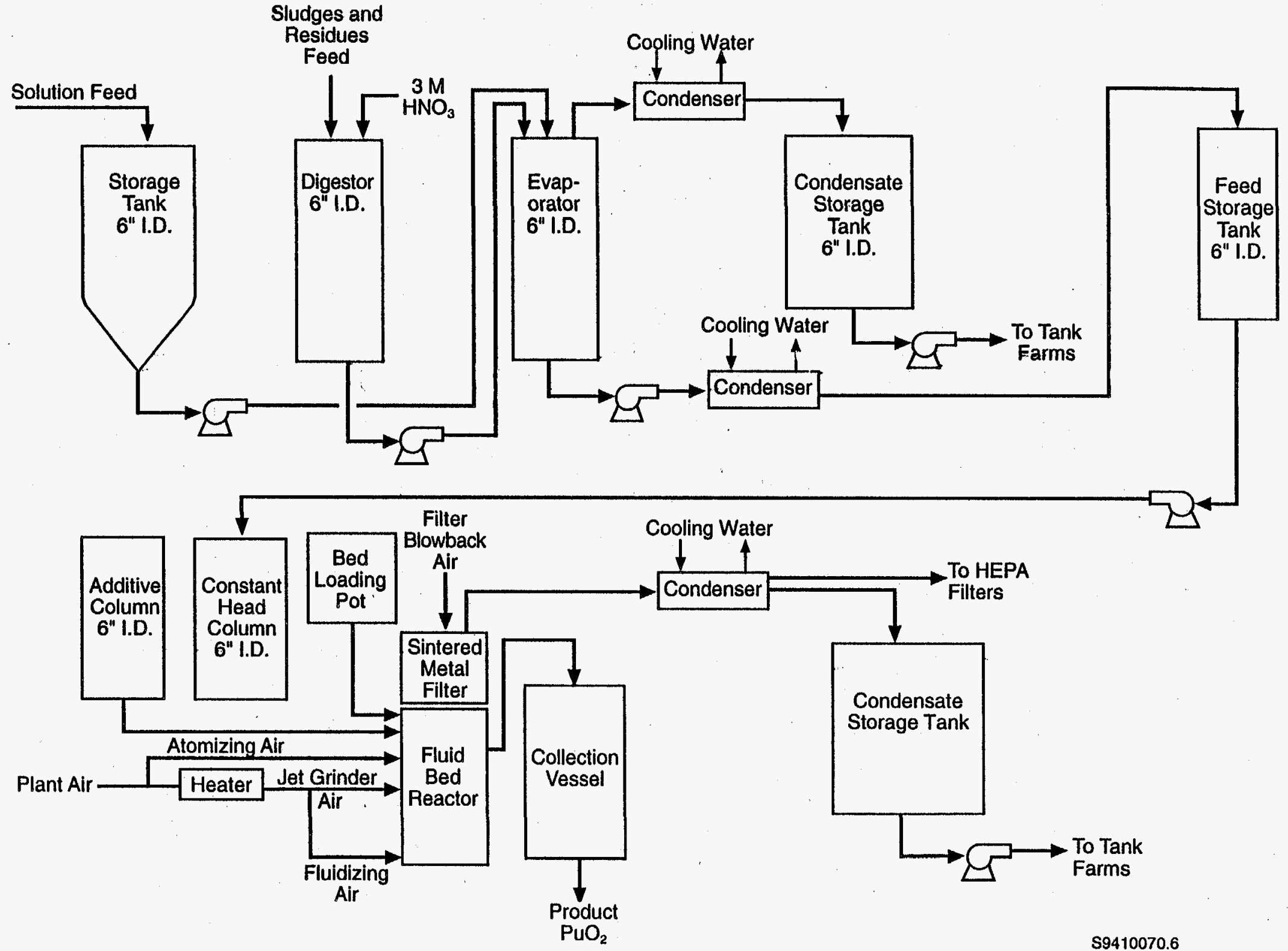

Figure A.2. Direct Denitration Fluid Bed Flowsheet 


\section{Effluents and By-Products}

Gaseous effluents from the direct denitration process include air, water, and oxides of nitrogen. This stream is passed through HEPA filters and discharged to the existing PFP ventilation system. Liquid effluents are the evaporated and condensed water and nitric acid, which contain $\leq 1 \mathrm{mg} / \mathrm{L}$ plutonium. These streams are processed at the waste water treatment facility. The solid effluent is the entrained oxide powder on the off-gas filter. The filter, when plugged, is cleaned (silver persulfate process) then disposed of as transuranic (TRU) waste.

\section{Risks}

The risks to the environment and public are minimal because the direct denitration process does not use any hazardous chemicals and generates only $\mathrm{NO}_{\mathrm{x}}$ as a hazardous gaseous effluent. Worker risks are also minimal because of the small number of process steps involved. The feed materials are added slowly in small increments, which decompose "red oil" and any other organics safely without vigorous reactions.

\section{Costs}

New capital equipment costs of approximately $\$ 50,000( \pm 30 \%)$ are expected. In addition, costs will be incurred to modify the PFP for adequate space and to install and check-out equipment. Also, administrative costs will be incurred for preparing and approving documents (operating procedures, safety analyses, SAR revisions, maintenance, training, etc.). The operational costs of a fluid bed direct denitration process are expected to be less than other nondirect denitration processes because of the minimal number of steps involved and the simplicity of operations. Waste disposal costs are also expected to be less than other nondirect denitration processes because of a lower impact on the ventilation and water treatment operations.

\section{Comments}

A previous objection to installing a direct denitration process in the PFP was the loss of purification that was achieved by oxalate precipitation. Since purity requirements are no longer a factor in converting plutonium nitrate solutions, sludges, or residues to a stable form, this objection is no longer valid.

The fluid bed direct denitration process was compared to the precipitation-calcination and sol-gel processes (Lehmkuhl 1977a) and the Coprecal and Peroxide Coprecipitation process (Sloat et al. 1978; Lehmkuhl 1977b). The fluid bed direct denitration process received a higher rating than the other processes. In addition, a direct denitration process was recently evaluated as being equal to operating the existing PRF and RMC line processes (Hoyt 1993).

The following list provides some advantages and disadvantages of a fluid bed direct denitration process (Souply and Neal 1977). 
Advantages

The process allows for excellent mass transfer between solid and gas effluents.

There is excellent heat transfer and ease of temperature control.

The process allows for a high degree of solids mobility, permitting simplicity of handling.

The process has a simplistic equipment design with an absence of moving parts.

A large capacity per unit volume of equipment can be attained.

The process can easily be adapted to remote operations.

The process requires minimum maintenance.

The process should not be hazardous to operate because no dangerous materials are involved other than the plutonium being processed.

No significant recycle streams are involved.

Compared with most other processes, fewer inventory problems exist. An excessive amount of plutonium will not be in the production stream at any one time.
Disadvantages

The fluid bed process produces large volumes of waste gases that have to be treated.

Engineers have limited experience using this process with plutonium and have no experience in remote operations. Therefore, the process will require extensive development to determine the operating parameters.

The process requires an evaporation step as part of feed preparation.

The process is relatively energy intensive. It is possible that a significant amount of power would be needed for proper operation.

\section{Justification for Further Study or Rejection}

The fluid bed direct denitration process is not recommended for further study to stabilize the RFP nitrate solutions, sludges, and residues. This recommendation is based on the fluidized bed method generating a large amount of waste gases, requiring new equipment with its associated costs, requiring evaporation for feed preparation, and not producing a stable final product. Although the fluidized bed process received high ratings in comparative studies, the objectives of those studies (make light water reactor [LWR] fuel) were different than this study (make a stable oxide). Hence, the fluidized bed direct denitration process is not as attractive as other direct denitration processes, such as the horizontal screw calciner or the vertical calciner. 


\section{References}

Hoyt, R. C. 1993. Summary Report on Hanford Plutonium Disposition Workshop. WHC-SD-CPVES-001, Rev. 0, Westinghouse Hanford Company, Richland, Washington.

Lehmkuhl, G. D. 1977a. Light Water Reactor Fuel Recycle Program Plutonium Nitrate-to-Oxide Conversion Project Progress Report, July-September 1976. RFP-2590, Rocky Flats Plant, Golden, Colorado.

Lehmkuhl, G. D. 1977b. Alternative Fuel Cycle Technologies Nitrate-To-Oxide Conversion Project Progress Report January-June 1977. RFP-2591, Rocky Flats Plant, Golden, Colorado.

Simecek, S., and W. T. Trask. 1963. The Integrated Fluid-Bed System. MCW-1478, Mallinckrodt Chemical Works, Uranium Division, Weldon Spring, Missouri.

Sloat, R. J., R. G. Barnes, R. B. Bendixsen, and G. P. Miller. 1978. Processing Alternatives for Uranium-Plutonium Coconversion. NEDG-21951, Oak Ridge National Laboratory, General Electric Company, San Jose, California.

Souply, K. R., and D. H. Neal. 1977. Fluid Bed Direct Denitration Process of Plutonium Nitrate to Oxide Conversion. RFP-2600, Rocky Flats Plant, Golden, Colorado.

Vogler, S., D. E. Grosvenor, N. M. Levitz, and F. G. Teats. 1972. Development Studies on a Fluidized-Bed Process for Conversion of U/Pu Nitrates to Oxides, Part 1. Laboratory-scale Denitration Studies. ANL-7917, Argonne National Laboratory, Argonne, Illinois. 


\section{Description of Technologies}

Accept: $\underline{X}$ Reject:

\section{Technology - Molten Salt Oxidation}

\section{Applicable Wastes Processed}

The molten salt oxidation (MSO) technology can process the following wastes: organic liquids, oils, combustible solids (cellulosic matter, rubber, plastics), aqueous solutions, slurries (process residues), noncombustibles, metals, alloys, and polycubes.

\section{Process Description}

The MSO process was originally developed by Lawrence Livermore National Laboratory (LLNL) and Rockwell International (Rockwell International 1994; Cooper et al. 1991) as an alterative to incineration for treating mixed wastes. In the MSO process, wastes and oxygen are introduced under the surface of a bed of molten salt. The salt is comprised of a suitable mixture of the carbonates, chlorides, or sulfates of sodium, potassium, lithium, or calcium. The salts provide heat transfer and reaction media and catalyze the reaction of the organic waste components with oxygen to produce carbon dioxide, nitrogen, and water (steam). Inorganic components (such as radioactive actinides and metallic impurities) in the form of "ash" are retained in the molten salt bed (melt) as a result of particle wetting, encapsulation, and chemical dissolution and solvation. The pyrolysis of halogenated hydrocarbons in the waste generates acid gases that are scrubbed by the alkaline carbonates, producing the corresponding salt. For example, the reactions of sodium carbonate with plutonium chloride and carbon tetrachloride solutions are

$$
\begin{gathered}
4 \mathrm{PuCl}_{3}+6 \mathrm{Na}_{2} \mathrm{CO}_{3}+\mathrm{O}_{2} \rightarrow 4 \mathrm{PuO}_{2}+12 \mathrm{NaCl}+6 \mathrm{CO}_{2} \\
\mathrm{CCl}_{4}+2 \mathrm{Na}_{2} \mathrm{CO}_{3} \rightarrow 4 \mathrm{NaCl}+3 \mathrm{CO}_{2}
\end{gathered}
$$

The MSO process is operated in two stages. In the first stage, pyrolysis of the organic waste occurs under oxygen deficient conditions, with partial oxidation of the pyrolysis products. The gaseous products of pyrolysis from the first stage are completely oxidized in the second stage, which is operated with excess oxygen. The second stage also acts as a "polishing" step for cleaning up residual amounts of acid gases and for retaining any entrained actinide products. By operating a two-stage MSO process, lower temperatures (around $700^{\circ} \mathrm{C}$ ) can be used, which minimize the volatility of salt constituents and increase the range of vessel materials and components compatible with the melt. A two-stage process also stabilizes the melt against possible polymerization in the presence of high concentrations of alumina and silica. A single-stage process will work but was not selected for evaluation for the reasons given above. 
"Ash" builds up in the melt as either dissolved substances or as a slurry. Removal of the "ash" (continuously or batch-wise) at concentrations greater than $20 \%$ preserves the melt's fluidity for contacting the waste with oxygen, wetting particulates, and transferring the melt. The withdrawn melt/ash is dissolved in water. The oxides and salts of actinides, being insoluble in the alkaline solution, precipitate and are filtered out. The dissolved salts are separated into carbonates and noncarbonates by crystallization and filtration. The carbonates are recycled back to the reactor, and the stable salts and oxides are disposed of as low-level waste (LLW). The solid "ash" from filtering is collected and requires further processing (i.e., calcination) to meet stability requirements. Once the carbonate has been consumed in the reactor via the acid gas reaction, the melt mixture is withdrawn and processed similarly to the melt/ ash mixture. Off gases from the MSO process are cooled, oxidized, and then passed through HEPA filters before being vented.

The MSO process is operated at atmospheric pressure with a residence time of plutonium in the molten salt unit on the order of hours. Equipment modifications to the feed system are required for the different material types processed. In addition, auxiliary energy is required to maintain the salt bed temperature, but in many cases the system produces excess energy during the processing of combustibles.

\section{Facilities and Equipment Required}

The molten salt unit is a $15-\mathrm{cm}$-internal diameter by $91-\mathrm{cm}$-high alumina tube similar to the one used by Oak Ridge National Laboratory (ORNL) (Crosley et al. 1993).

A MSO process will require molten salt reactors, a feed system, and salt recycling equipment to be installed in the PFP (see Figures A.3, A.4, and A.5). The MSO process can be operated using the PFP's existing utilities, materials, supplies, and personnel. The PFP will need space modifications to accommodate the MSO process. Roughly $90 \mathrm{~m}^{2}$ of floor space and $10 \mathrm{~m}^{3}$ of glovebox space are needed. Glovebox HC-9B may be used for the MSO equipment.

\section{Schedule}

The MSO process has been successfully demonstrated to treat mixed wastes (Upadhye et al. 1993) high explosives, and liquid propellants (Upadhye et al. 1994). The MSO process's applicability to the various PFP wastes has also been developed and documented (Wojdac 1994). Therefore, little process development time is necessary for the MSO process.

The size of the tested MSO unit process design (15 cm in diameter by $91 \mathrm{~cm} \mathrm{high}$ ) is sufficient to process the PFP wastes without the need for scale-up design work. Time will be needed, however, for installing and checking out the process. Operating procedures, safety analyses, SAR revisions, and operator training must be developed and completed. 


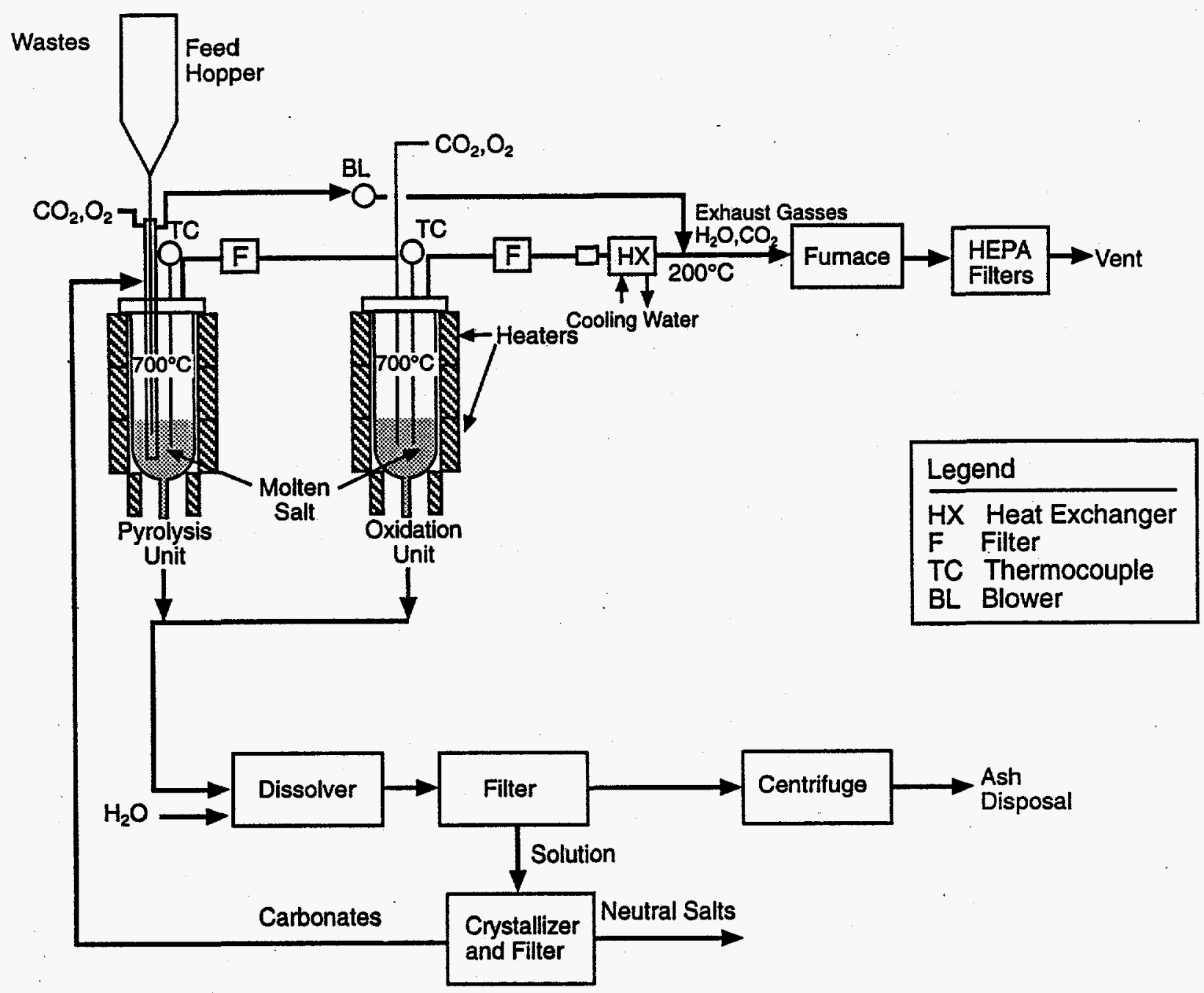

$\$ 9410070.4$

Figure A.3. Two-Stage Molten Salt Reactor System 


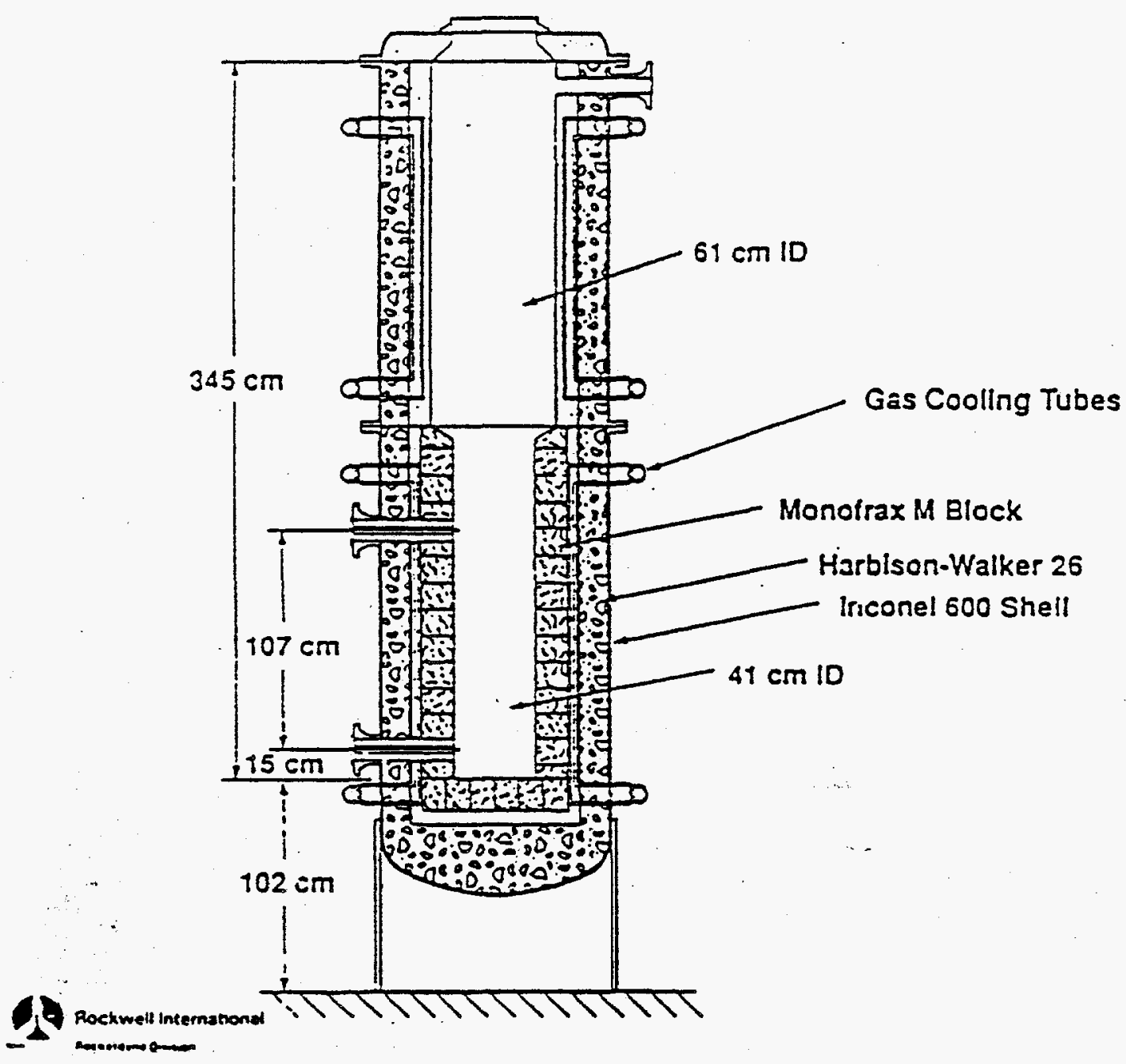

Figure A.4. The Molten Salt Unit Designed by Rockwell Reflects Experience in Waste Destruction as Well as Coal Gasification. (The wall below the liquid level is lined with a dense alpha-alumina. This unit is designed for single-stage engineering tests in pyrolysis or oxidation.) 


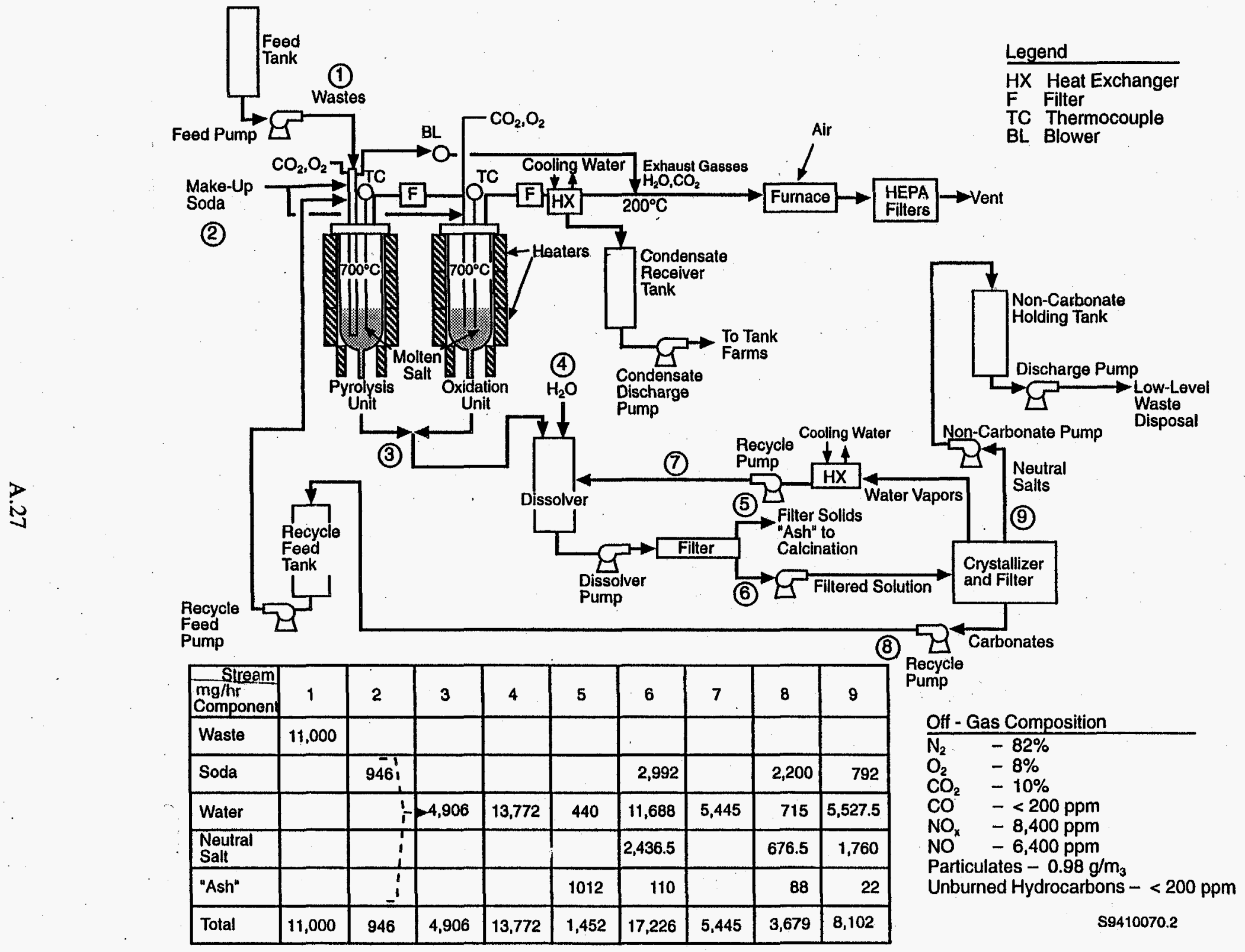

Figure A.5. Molten Salt Oxidation Flowsheet 
The total operating time would be approximately 3405 hours based on processing all solutions, slurries, combustibles, non-combustibles, metals, alloys, and polycubes. For this size of a unit, a $2.3-\mathrm{kg} / \mathrm{h}$ input rate (Crosley et al. 1993) is expected for solutions, and a $1.4-\mathrm{kg} / \mathrm{h}$ input rate is expected for solids.

\section{End Product Description}

The products from MSO are concentrated actinide oxides and salts (ash) from the filtration step. This "ash" must be processed further (i.e., calcination) to meet the LOI requirements for stability.

\section{Effluents and By-Products}

The solid by-product from the MSO process is the noncarbonate neutral salt that contains trace amounts of actinides. The stream can be disposed of as LLW without further processing. The gaseous effluents from the MSO process are carbon dioxide, nitrogen, water, and traces of $\mathrm{NO}_{\mathrm{x}}$. The $\mathrm{NO}_{\mathrm{x}}$ can be minimized by controlling the redox conditions in the reactor. This stream passes through a heat exchanger to capture entrained liquid droplets, then through a furnace to ensure complete oxidation of any trace contaminants, and then through HEPA filters before being vented. The existing PFP ventilation system is capable of handling this gaseous stream. The recycled carbonate solution would eventually, after extended usage, become a liquid effluent requiring processing in the water treatment facility. It is unknown if the water treatment facility can effectively process this waste stream. The condensate from the off-gas heat exchanger is also a liquid effluent requiring processing in the water treatment facility or it could be sent to the HLW tanks.

\section{Risks}

No radioactive or hazardous components are exhausted to the ventilation system. No hazardous chemicals are used in the process. The oxides/salts and "ash" are stable and nonhazardous. Therefore, there are minimal exposure risks with the MSO process.

Operational risks of back-burn and steam explosions have been described in the literature (Upadhye 1993a) and can be mitigated with proper equipment and operating conditions. Direct denitration of plutonium nitrate solutions must be such that the aqueous solutions are slowly added to the melt to avoid the rapid generation of steam, which could blow the melt out of the reactor. Rockwell has successfully accomplished direct denitration by the slow addition of plutonium nitrate coupled with an inert gas sparge to keep the melt bed agitated (Wojdac 1994).

\section{Costs}

New equipment costs of approximately $\$ 500,000( \pm 30 \%)$ are expected. In addition, costs will be incurred to develop the process for the PFP wastes, to modify the PFP for adequate space, and to install and check out equipment. Also, administrative costs will be incurred for preparing and approving documents (operating procedures, safety analyses, SAR revisions, maintenance, training, etc.). 
Operational costs of an MSO process are expected to be no greater than other competing processes because of the minimal number of steps involved and the simplicity of operations. Waste disposal costs are also expected to be comparable to other competing processes because of using the existing PFP ventilation system and, probably, the water treatment process.

It is estimated that the operating cost of an MSO process will be on the order of dollars $/ \mathrm{kg}$ waste (Cooper et al. 1991). The cost of salt recovery and recycle will be an order of magnitude lower (Cooper et al. 1991).

\section{Comments}

The MSO process has been successfully demonstrated on mixed combustible wastes in bench and pilotscale studies, with actinide removal efficiencies exceeding 99.9999\% (Cooper et al. 1991; Rockwell International 1994). It has also been demonstrated for treating carbon tetrachloride, TBP, and plutonium nitrate solutions.

The MSO process is favored by the U.S. Department of Energy (DOE) because of the following:

- There is no open flame in MSO.

- The containment of actinides and heavy metals is accomplished by chemical means (wetting and dissolution).

- The operating temperature of MSO is much lower and without high exhaust velocities, thus lowering the volatilities of radioactive actinides.

- No acid gases are generated in MSO.

- More complete destruction is accomplished because of the catalytic effect of the salt, longer residence time, and more intimate contact with the caustic molten salt.

The MSO process has future applications for processing a large quantity of all the wastes at the Hanford Site as well as radioactive and mixed wastes from other sites.

\section{Justification for Further Study or Rejection}

The MSO process is recommended for further study for stabilizing the PFP wastes. Material balances must be developed to know the volumes and compositions of products, by-products, and effluents. In addition, it must be known if the water treatment facility can adequately process the liquid effluents. Finally, development work will be required to determine the necessary equipment modifications and operating conditions for the different material types. 


\section{References}

Cooper, J., W. A. Brummond, J. Celesta, J. Farmer, C. Hoenig, O. H. Krikorian, R. S. Upadhye, R. L. Gay, A. Stewart, and S. Yosim. 1991. Molten Salt Processing of Mixed Wastes with Off-Gas Condensation. UCRL-JC-107288, Lawrence Livermore National Laboratory, Livermore, California.

Crosley, S. M., D. K. Lorenzo, J. E. Van Cleve, R. L. Gay, K. M. Barclay, J. C. Newcomb, and S. J. Yosim. 1993. "Treatment of Waste by the Molten Salt Oxidation Process at the Oak Ridge National Laboratory." In Proceedings of Conference on Mixed Waste. Conf. 930906-3, Martin Marietta Energy Systems, Oak Ridge, Tennessee.

Rockwell International. 1994. Technology Index - Molten Solids Processing - Molten Salt Process. Rockwell International, Canoga Park, California.

Upadhye, R. S., J. G. Wilder, and C. E. Karlsen. 1993. Molten Salt Destruction Process for Mixed Wastes. UCRL-112666, National Technical Information Services, Springfield, Virginia.

Upadhye, R. S., W. A. Brummond, and C. O. Pruneda. 1994. Destruction of Energetic Materials Using the Molten Salt Destruction Process. UCRL-JC-117252, Lawrence Livermore National Laboratory, Livermore, California.

Wojdac, L. F. 1994. "Molten Salt Technology Applications." In Proceedings of $18_{-}^{\text {th }}$ - Annual Actinide Separations Conference in Durango, Colorado. National Technical Information Services, Springfield, Virginia. 


\section{Description of Technologies}

Accept: — Reject: $\underline{X}$

\section{Technology - Direct Denitration via Horizontal Screw Calciner}

\section{Applicable Wastes Processed}

This technology can be used to process plutonium nitrate solutions and filtrate, and plutonium-thorium nitrate solutions. The nitrate-based solutions may contain organics and chlorides. Sludges and residues are also candidate feed materials for this process.

\section{Process Description}

Direct denitration is a process whereby plutonium nitrate solutions are converted directly to plutonium oxide in a calciner without forming an intermediate plutonium compound (Figure A.6). The plutonium nitrate solution is heated in an air atmosphere to evaporate the water and nitric acid, leaving a solid plutonium oxide particle. Additives may be necessary to prevent the formation of a mastic state and foaming. The overall calcination reaction is

$$
\mathrm{Pu}\left(\mathrm{NO}_{3}\right)_{4} \underset{4}{\Delta} \mathrm{PuO}_{2}+3.4 \mathrm{NO}_{2}+0.6 \mathrm{NO}+1.3 \mathrm{O}_{2}
$$

The product is a dry, impure plutonium oxide powder. The calciner off-gas stream consists of a mixture of air, water, nitric acid, and oxides of nitrogen. In addition, fine plutonium oxide powder is often entrained in the gas stream. The off-gas stream is filtered to remove the entrained oxide and cooled in a condenser to remove the water and nitric acid. The off gas is then routed through the ventilation system to HEPA filters.

During thermal denitration of uranyl nitrate and plutonium nitrate, the solution is successively dehydrated and then denitrated, remaining molten and becoming increasingly viscous and pasty until its conversion to the dry oxide state is essentially complete. The material will become mastic, tending to form hard deposits in equipment surfaces and on particulate material throughout the reaction zone, unless the transition to dry oxide is accomplished quickly.

The plutonium nitrate-nitric acid stream is continuously fed directly to a trough at the head end of the calciner and forced down the trough by the screw. Air is pulled counter-currently to the plutonium flow to aid in calcination and to entrain moisture, nitrogen oxide, and carbon dioxide. The feed end of the calciner is kept between $200^{\circ}$ to $300^{\circ} \mathrm{C}$, and the product end is kept at $400^{\circ}$ to $450^{\circ} \mathrm{C}$. The residence time of plutonium within the calciner is estimated to be 30 minutes. The oxide product leaving the calciner is then collected for packaging. 


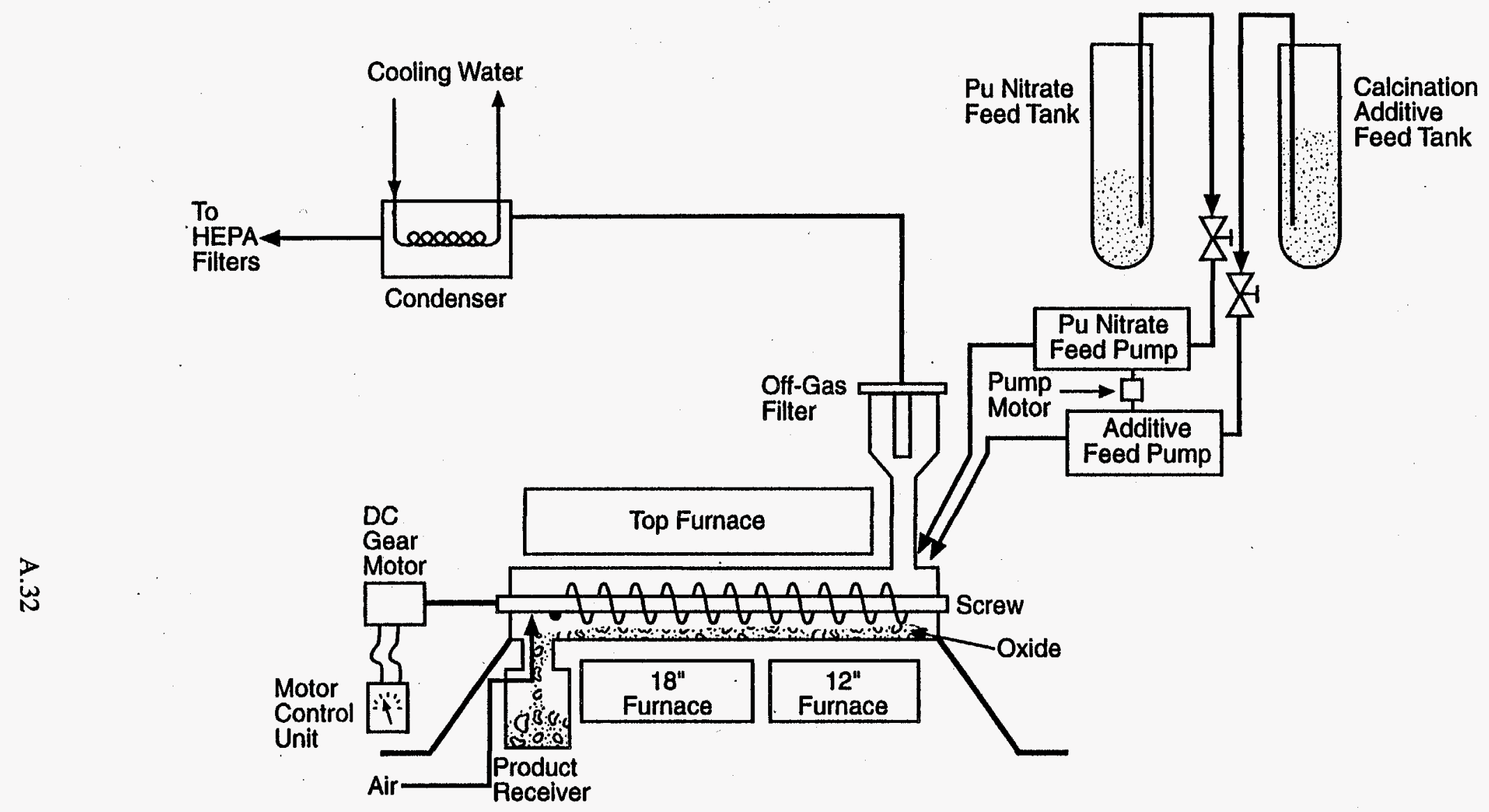

S9410070.1

Figure A.6. Direct Denitration Horizontal Screw Flowsheet 
A screw calciner direct denitration process has been successfully demonstrated with plutonium nitrate solutions at the Hanford Site (Felt 1965, 1978; Bryan et al. 1979).

\section{Facilities and Equipment Required}

The equipment required for a screw calciner denitration process is depicted in Figure A.6. The calciner is sized for a $1.8-\mathrm{L} / \mathrm{h}$ feed rate. The calciner is constructed of titanium, and the supporting equipment is made of glass or stainless steel.

The existing PFP has a screw calciner and supporting equipment suitable for a direct denitration process. The PFP also has the necessary utilities, operating materials, supplies, and manpower to operate a screw calciner direct denitration process. The floor space of the PFP will accommodate the direct denitration equipment.

\section{Schedule}

The screw calciner direct denitration method has been demonstrated on both a laboratory-scale and production-scale to successfully convert plutonium nitrate solutions of varying concentrations and molarities into plutonium dioxide powder. Although there are no data regarding plutonium nitratef thorium nitrate and plutonium nitrate/uranyl nitrate mixtures, it is assumed that they would behave similarly in a direct denitration process to produce a powder oxide product. Also, there are no literature references regarding the direct conversion of nitrate sludges and residues to oxides, although . these materials are expected to behave in the same manner as the nitrate solutions. Therefore, no process development time is necessary for the screw calciner direct denitration process.

The size of the tested screw calciner direct denitration process design $(5 \mathrm{~cm}$ in diameter by $7.6 \mathrm{~cm}$ deep by $99 \mathrm{~cm}$ long) is sufficient to process the PFP wastes with the need for scale-up design work. However, the process equipment must undergo a thorough checkout with operating conditions established. Operating procedures, safety analyses, SAR revisions, and operator training must be developed and completed.

Approximately 3000 hours of operating time are needed, based on using one screw calciner at a rate of $1.8 \mathrm{~L} / \mathrm{h}$ and processing all the nitrate solutions, sludges, and filtrates.

\section{End Product Description}

The end product from direct denitration is a solid plutonium powder or, in the case of mixtures, a uranium trioxide/plutonium dioxide or thorium dioxide/plutonium dioxide powder. These materials are low-fired oxides and must be re-fired at a temperature of at least $800^{\circ} \mathrm{C}$ to meet the stability requirements (less than a $1 \%$ LOI). 


\section{Effluents and By-Products}

Gaseous effluents from the direct denitration process include air, water, and oxides of nitrogen. This stream is passed through HEPA filters and discharged to the existing PFP ventilation system. Liquid effluents are the condensed water and nitric acid containing $\leq 1 \mathrm{mg} / \mathrm{L}$ of plutonium. The solid effluent is the entrained oxide powder on the off-gas filter. The filter, when plugged, is cleaned (silver persulfate process) and then disposed of as TRU waste.

\section{Risks}

The risks to the environment and public are minimal because the direct denitration process does not use any hazardous chemicals and generates only $\mathrm{NO}_{x}$ as a hazardous gaseous effluent. Worker risks are also minimal because of the small number of process steps involved. The feed materials are added slowly in small increments, which decompose "red oil" and any other organics safely without vigorous reactions.

\section{Costs}

New capital equipment costs are not expected as the existing PFP has a screw calciner and its support equipment. In addition, no costs will be incurred to modify the PFP for adequate space or to install equipment. However, costs will be incurred to check-out this existing equipment. Also, administrative costs will be incurred for preparing and approving documents (operating procedures, safety analyses, SAR revisions, maintenance, training, etc.). Operational costs of a screw calciner direct denitration process are expected to be less than other non-direct denitration processes because of the minimal number of steps involved and the simplicity of operations. Waste disposal costs are also expected to be less than other non-direct denitration processes because of a lower impact on the ventilation and water treatment processes.

\section{Comments}

A previous objection to installing a direct denitration process in the PFP was the loss of purification, which was achieved by oxalate precipitation. Since purity requirements are no longer a factor in converting plutonium nitrate solutions, sludges, or residues to a stable form, this objection is no longer valid.

The screw calciner direct denitration process was compared to precipitation-calcination and sol-gel processes (Lehmkuhl 1976) and the coprecal and peroxide coprecipitation processes (Sloat et al. 1978). The screw calciner direct denitration process received a higher rating than the other processes. In addition, a direct denitration process was recently evaluated as being equal to operating the existing PRF and RMC Line processes (Hoyt 1993). The screw calciner process cannot process uranium bearing solutions as the material will become mastic (Souply and Sperry 1977). In addition, the screw calciner process is not applicable to fluoride-bearing solutions. 
Some advantages and disadvantages of a horizontal screw calciner direct denitration process follow (Souply and Sperry 1977).

\section{Advantages}

No feed preparation is required.

The screw calciner is simple and reliable to operate because it has only two operating parameters: screw speed and temperature, which are both easy to control.

No hazardous chemicals are used in the process other than the nitric acid and the plutonium being processed.

Inventorying the plutonium would be simple.

The process has minimum maintenance requirements.

Pilot plant experience using plutonium has demonstrated the reliability of the equipment for a hands-on operation.

The process generates small volumes of liquid waste, and off gases consist mainly of the oxides of nitrogen.

\section{Disadvantages}

There could be considerable difficulty in detecting the controlling process upset conditions because of the lag time between the introduction of the feed and the emergence of the calcined oxide. If the oxide emerged not completely calcined, then the calciner would probably be full of the faulty product, which would present a recycle problem.

\section{Justification for Further Study or Rejection}

The screw calciner direct denitration process is not recommended for further study to stabilize the PFP nitrate solutions, sludges, and residues. This recommendation is based on the calciner not producing a stable final product and not being able to process uranium- and fluoride-bearing solutions. In addition, the existing screw calciner in the PFP has not been operated in many years, and its functionality is suspect. Although the screw calciner process received high ratings in comparative studies, the objectives of those studies (make a LWR fuel) were different than this study (make a stable oxide). Hence, the horizontal screw calciner direct denitration process is not as attractive as the vertical calciner process. 


\section{References}

Bryan, G. H., E. J. Wheelwright, and L. M. Browne. 1979. Direct Denitration of Plutonium Nitrate - Nitric Acid Solution in a Screw Calciner. PNL-SA-7829, Pacific Northwest Laboratory, Richland, Washington.

Felt, R. E. 1965. Equipment for the Direct Calcination of Plutonium Nitrate. RL-SEP-674, Hanford Atomic Products Operation, Richland, Washington.

Felt, R. E. 1978. Direct Denitration of Plutonium With a Screw Calciner - A Technical Review. RHO-CD-416, Rockwell Hanford Operations, Richland, Washington.

Hoyt, R. C. 1993. Summary Report on Hanford Plutonium Disposition Workshop.

WHC-SD-CP-VES-001, Rev. 0, Westinghouse Hanford Company, Richland, Washington.

Lehmkuhl, G. D. 1976. Light Water Reactor Fuel Recycle Program Plutonium Nitrate-to-Oxide Conversion Project Progress Report. RFP-2590, Rocky Flats Plant, Golden, Colorado.

Sloat, R. J., R. G. Barnes, R. B. Bendixsen, and G. P. Miller. 1978. Processing Alternatives for Uranium-Plutonium Co-Conversion. NEDG-21951, Oak Ridge National Laboratory, General Electric Company, San Jose, California.

Souply, K. R., and W. E. Sperry. 1977. Screw Calciner Mechanical Direct Denitration Process for Plutonium Nitrate to Oxide Conversion. RFP-2601, Rocky Flats Plant, Golden, Colorado.

\section{Bibliography}

Felt, R. E. 1965. Fluorination Reactivity of Plutonium Dioxide Prepared by Direct Calcination of Plutonium Nitrate in a Screw Calciner. RL-SEP-675, Hanford Atomic Products Operation, Richland, Washington.

Fisher, F. D. 1963. Reactivity of Plutonium Dioxide Prepared by Direct Calcination of Nitrate Solutions. HW-77846, Hanford Atomic Products Operation, Richland, Washington.

Fullam, H. T., and T. S. Soine. 1965. Chlorination Reactivity of Plutonium Oxide Prepared in a Screw Calciner. RL-SEP-673, Hanford Atomic Products Operation, Richland, Washington.

Lehmkuhl, G. D. 1977. Alternate Fuel Cycle Technologies Nitrate-to-Oxide Conversion Project Progress Report January-June 1977. RFP-2591, Rocky Flats Plant, Golden, Colorado.

Souply, K. R., and D. H. Neal. 1977. Fluid Bed Direct Denitration for Plutonium Nitrate to Oxide Conversion. RFP-2600, Rocky Flats Plant, Golden, Colorado. 


\section{Description of Technologies}

Accept: _ Reject: $\underline{X}$

\section{Technology - Blend with High-level Waste}

\section{Applicable Wastes Processed}

This technology is capable of processing all waste with significant amounts of dilution and added material.

\section{Process Description}

The process would involve transferring the material to the high-level waste (HLW) storage tanks at Hanford for interim storage and eventual stabilization in the high-level vitrification plant. The process would involve the pretreatment of the material to allow storage under the current storage guidelines described below.

The criticality requirements outlined in the latest draft of PFP final SAR (WHC 1991) and the latest draft of the Multi-Function Waste Tank Facility Preliminary Safety Analysis Report ${ }^{(a)}$ should be fulfilled. Both of these documents control how plutonium from PFP could be sent to the waste tanks. Criticality is controlled by limiting the concentration of plutonium in solution to less than $0.013 \mathrm{~g} \mathrm{Pu} / \mathrm{L}$ of waste. Also, the waste must contain at least $160 \mathrm{~g} \mathrm{Fe} / \mathrm{g} \mathrm{Pu}$. Both of these requirements must be met to ensure that criticality is not possible in the tank farm. In addition, the process of making the waste requires that the plutonium and iron be added to the waste in solution, as plutonium nitrate and iron nitrate. After the solution is well mixed, a caustic strike procedure is performed on the waste solution to co-precipitate the iron and plutonium as hydroxides.

\section{Facilities and Equipment Required}

The equipment would require mixing equipment and chemical addition equipment in PFP, but the biggest requirement is storage space in the HLW tanks. The plutonium inventory shows about $2500 \mathrm{~kg}$ that would require $190,000 \mathrm{~m}^{3}$ of storage space with the addition of 400,000 metric tons of iron. Therefore, this option is rejected from further study.

(a) Draft report. WHC-SD-W236A-PSAR-001, Rev. 0, Westinghouse Hanford Company. 


\section{References}

Westinghouse Hanford Company (WHC). 1991. Safety Analysis Report for the Plutonium Finishing Plant. WHC-SD-CP-021, Westinghouse Hanford Company, Richland, Washington. 


\section{Description of Technologies}

Accept: _ Reject: $\underline{X}$

\section{Technology - Vitrification}

\section{Waste Processed}

The vitrification technology can process nitrate solutions (FXX) and other solutions, compounds, and combustibles.

\section{Process Description}

Vitrification is a process of heating an appropriate mixture of materials to form a durable noncrystalline homogeneous mass of metal oxides. The process considered operates at temperatures of $1000^{\circ}$ to $1400^{\circ} \mathrm{C}$. The heating processes for this application include direct electrical (Joule heating) and indirect heat from induction coils or resistance heaters, and microwaves. The temperature used causes the destruction of combustibles, nitrates, carbonates, and other non-oxide material. The glass can incorporate into its matrix a variety of materials, including small percentages of chloride, sulfate, fluoride, and phosphates. Vitrification has been demonstrated on a variety of HLW materials that includes small amounts of plutonium. Russian investigators have vitrified plutonium-containing wastes into glasses containing $0.3 \mathrm{wt} \%$ plutonium (Kusknikov et al. 1991). German and American scientists have prepared glasses with $4 \%$ to $5 \%$ plutonium (Berkhout et al. 1992). Glass model systems predict that glasses containing as much as $9 \mathrm{wt} \%$ of plutonium can be satisfactorily prepared (Lyman 1993).

The Rocky Flats Plants (RFP) has been working on small Joule, microwave, and in-can vitrification systems (Roggenthen 1989). The process has been demonstrated for scrap contaminated with plutonium but not with all the materials in the PFP inventory. Previous HLW experience indicates little development would be needed to specify glasses containing mostly metal oxides, but streams with large quantities of chlorides and fluorides would require development because of potential secondary phase formation and corrosion concerns in the melter.

\section{Facilities and Equipment}

The facilities required for vitrification could include a batch furnace for the solid or wet material like the muffle furnaces being installed for interim sludge stabilization action. Solutions or high moisture material would require a continuous melter system with off-gas scrubbing capabilities for ease of handling feed, and to process the quantities in the existing inventory in a period of 5 years.

A system has been proposed for such a vitrification activity (McKibben et al. 1993). The melter would be a small, $40 \mathrm{~cm}^{2}$ melt cavity with an overall size that could be accommodated in a $9 \mathrm{~m}$ glovebox line. 
This system would include feed preparation, melter, and off-gas treatment. The power requirements would be approximately $10 \mathrm{~kW}$, and the raw materials would include 50 to 200 metric tons of glass formers consisting mainly of $\mathrm{SiO}_{2}$.

\section{Schedule}

The process development required would involve glass formulation for the materials to be vitrified. This effort could take 1 to 2 years depending on the type of material and how well the material is characterized. For example, the procurement, installation, and checkout of a melter system would depend on whether it is a Joule heated system or a batch processing system. A continuous Joule heated system would require about 9 months to buy or fabricate, 6 months to install, and another month to check out. A batch melter would probably only require 4 to 6 months to buy and 4 to 6 months to install with very limited check-out in a glovebox. The small $15-\mathrm{cm}$ continuous melter would process the entire inventory of solutions $(-3850 \mathrm{~L})$ in about 3 months operating $24 \mathrm{~h} / \mathrm{d}$ with $50 \%$ on-line efficiency. The batch system would probably require 2 to 5 years assuming 1-L batches of previously concentrated or precipitated solutions and similar operating times as above. If the solution were not concentrated, the processing time would exceed 5 years.

\section{Final Product Description}

The final product should be very stable because it was produced from molten material and would not leave any unoxidized or hydrated clinkers. The composition of the product would be primarily glassforming compounds with the largest percentage being silicon. The volume of the final product would be 10 to 50 times greater than calcined plutonium. The material would not fit in the current PFP storage area, which has a capacity of approximately 35,000 containers. The containers are not packed close together because of criticality safety rules. Diluting the plutonium with glass formers would not increase storage density unless extensive testing and support work were first completed. The current PFP monitoring system would not accept large product containers, and bulk stacking would not be allowed because there is still a criticality concern. Therefore, a glass product should not be considered for interim stabilization for the bulk material. Glass may be suitable for a few special items high in alkali or other glass-compatible impurities that could be processed in existing furnaces. Glass may also be suitable if the plutonium material is combined with the HLW and vitrified in the high-level vitrification plant. However, plutonium blending with HLW glass cannot be considered as an alternative for interim stabilization because the startup of the plant will not occur in the next few years; storage in the HLW tanks has been rejected in another description.

The final product could not be converted easily to a metal for weapons use without a significant amount of additional processing, although the processes would not be tremendously difficult. The conversion to an oxide for fuel would be more difficult than using a purified oxide directly, but only slightly more difficult than an oxide requiring additional purification. Alkali would be readily incorporated into the glass and would not require removal from the bulk plutonium as may be required for calcine storage. 
The stability for the glass would be good based on previous tests with glasses containing actinides (Walker and Riege 1979). The glass matrix with $1.3 \%$ plutonium retained $97 \%$ of the helium formed from alpha decay, and the leaching characteristics were not significantly changed (Kushnikov et al. 1991; Tsunetka et al. 1989). Other studies have found damage to the glass from alpha decay saturates at a $1 \%$ change in density, which does not seriously degrade glass integrity (Numark and Suzuki 1993). This saturation occurs well below levels that would be reached in HLW glass without plutonium, which means HLW glass stability data can be applied to plutonium glasses.

The glass product would require significant reprocessing for use as weapons or fuel material. The difference in reprocessing between glass and oxides would be the quantity of material to be handled and redissolved for purification. The dissolution is expected to be only slightly more difficult than highfired oxides.

\section{Effluents Generated}

The vitrification of plutonium-bearing material from nitrate solution would generate the same type and quantity of gases-as calcination, but the particulate composition and form would be different. The gas generated would contain excess air, $\mathrm{NO}_{\mathrm{x}}$, water vapor, and carbon dioxide. The particulate generated would be semi-volatile compounds and entrained glass particles. The gas stream would contain a slightly higher content of semi-volatiles in the gas stream than batch calcination because of the higher operating temperature $\left(1150^{\circ} \mathrm{C}\right)$. There would also be an increase in the quantity of entrained particles to the filter if the melter is fed continuously: The increase in volatilization and entrainment would be less than $1 \%$ total and the plutonium would be less than $0.1 \%$, which means the plutonium in the offgas scrubbing equipment would need to be recycled back to the melter or collected on an outlet filter. A close coupled outlet filter for a continuous melter has not been demonstrated, but it is expected that it could be developed and demonstrated in a couple of years. The recycled solids from a wet scrubbing system could be evaporated and returned to the melter.

\section{Risks}

The risk to the environment would be from the release of $\mathrm{NO}_{\mathrm{x}}$ or a untreated release of vitrification off gas because of a filter failure. The risk is minimal because the total quantity of $\mathrm{NO}_{\mathrm{x}}$ that could be generated would be less than $900 \mathrm{~kg}$ over the entire process. This assumes $5 \underline{\mathrm{M}}$ nitrate solutions with no destruction or off-gas scrubbing. Typical destruction in the melter and scrubbing equipment would easily reduce the $\mathrm{NO}_{\mathrm{x}}$ to several hundred kilograms.

The risk to the worker would be similar to other operations.

\section{Costs}

The construction cost of a small melter capable of processing 1 to $3 \mathrm{~L} / \mathrm{h}$ would be $\$ 300 \mathrm{~K}$, and an additional scrubber and condenser would cost an additional $\$ 100 \mathrm{~K}$. The operation of the melter could be performed by two people with additional support from feed transport to the melter, product packaging, 
and the analytical laboratory. The analytical support would be greater than calcination to ensure a proper feed/glass former ratio, but the support for the LOI test would be reduced.

Waste disposal would be similar to calcination with condensate from the melter being sent to the lowlevel waste treatment facility (LLWTF). Gases would be filtered and directed to the building vacuum system.

The decontamination and decommissioning (D\&D) of the melter and associated equipment would require the disposal of metals or ceramics contaminated with glass containing plutonium unless the process was performed in a batch mode. In a batch mode, the D\&D would be similar to the batch calcination, although additional furnaces may be required to handle the increased volume of material. The current furnaces could make glass products from dry or semi-dry material with no significant modifications.

\section{Comments}

The perception of external groups would be that the plutonium is being disposed of and would not be stored for use at another date. The form would be consistent with the disposal of HLW and LLW in the Hanford tank farms and should be appropriate for disposal.

Other comments are that the waste should be made into glass but should be preserved for future use as an oxide or for blending into the HLW glass with handling ease of granules. Table A.2 summarizes the criteria evaluations used in this review.

\section{Justification for Further Study or Rejection}

Overall, vitrification should not be considered for stabilization of the bulk material because of the increase in the product volume and potential difficulties in future long-term disposal considerations.

\section{References}

Berkhout, F., A. Diakov, H. Feiveson, H. Hunt, E. Lyman, M. Miller, and F. von Hippel. 1992. "Disposition of Separated Plutonium." Science \& Global Security 3:1-53.

Kushnikov, V. V., Y. I. Matyunin, and N. V. Krylova. 1991. "The Behavior of Alpha-Emitting Radionuclides in the Solidification of High-Activity Waste." Soviet Atomic Energy 70(4):299-303.

Lyman, E. S. 1993. The Solubility of Plutonium in Glass. Princeton University Center for Environmental and Engineering Studies Report No. 275, Princeton, New Jersey. 
Table A.2. Criteria Evaluations for Vitrification

\begin{tabular}{|c|c|}
\hline Criteria & Evaluation \\
\hline Technical Feasibility (technology maturity) & $\begin{array}{l}\text { Waste vitrification well developed for waste, glass } \\
\text { forms for plutonium need work at high plutonium } \\
\text { loadings }\end{array}$ \\
\hline $\begin{array}{l}\text { Effluents/By-Products } \\
\text { (minimize volumes, hazards) }\end{array}$ & $\begin{array}{l}\text { High temperature operation, off-gas treatment } \\
\text { required, and condensate waste stream }\end{array}$ \\
\hline Effluents Covered/SAR & Effluents should be covered in SAR \\
\hline Energy Resource & $\begin{array}{l}\text { Requires extensive material handling and processing } \\
\text { for use as energy resource or weapon. Difficulty: }\end{array}$ \\
\hline Weapon Potential & Medium \\
\hline End Product Volume & High \\
\hline End Product Stability & High \\
\hline $\begin{array}{l}\text { Environmental and Public Risk } \\
\text { routine } \\
\text { accident }\end{array}$ & $\begin{array}{l}\text { Medium, } \mathrm{NO}_{\mathrm{x}} \text { release with scrubbing equipment } \\
\text { Low }\end{array}$ \\
\hline $\begin{array}{l}\text { Worker Risk } \\
\text { routine } \\
\text { accident }\end{array}$ & $\begin{array}{l}\text { Medium, molten glass } \\
\text { Medium }\end{array}$ \\
\hline $\begin{array}{l}\text { Cost } \\
\text { (construction, operations and D\&D) }\end{array}$ & Medium \\
\hline Operating Duration & $<5$ years \\
\hline Public Acceptance & Excellent \\
\hline Flexibility & Good \\
\hline Materials Covered & All except metals \\
\hline
\end{tabular}


McKibben, J. M., R. W. Benjamin, D. F. Bickford, L. P. Fernandez, W. N. Jackson, W. R. McDonell, E. N. Moore, P. B. Parks, M. J. Plodinec, W. M. Rajczak, S. K. Skiles, and G. G. Wicks. 1993. Predecisional Draft Vitrification of Excess Plutonium. WSRC-RP-93-755, Westinghouse Savannah River Company, Savannah River, Georgia.

Numark, N. J., and T. Suzuki. 1993. "Comparison of Recycle and Disposal Options for Fissile Materials Arising from Disarmament Treaties." In Proceedings of the ASME 1993 International Conference. National Technical Information Services, Springfield, Virginia.

Roggenthen, D. K. 1989. Selection of Immobilization Technology for TRU Waste. RFP-4292, Rocky Flats Plant, Golden, Colorado.

Tsunetka, B., H. Kamizono, S. Nakayama, and S. Tashiro. 1989. Studies of Glass Waste Form Performance at the Japan Atomic Energy Research Institute. JAERI 89-110, Japan Atomic Energy Research Institute.

Walker, C. T., and U. Riege. 1979. "Compatibility of Actinides with HLW Borosilicate Glass: Solubility and Phase Formation." Ceramics in Nuclear Waste Management. CONF_790420, National Technical Information Service, Springfield, Virginia. 


\section{Description of Technologies}

Accept: _ Reject: $\underline{\mathrm{X}}$

\section{Technology - Cold Glass Processing (Sol-Gel)}

\section{Waste Processed}

The waste to be processed includes all inorganic solids and plutonium-bearing solutions. Most organic materials are not amenable to stabilization by the Sol-Gel process.

\section{Process Description}

There is no real experience with stabilizing material containing plutonium by Sol-Gel technology, but there is experience in fabricating vitreous forms from a variety of inorganic materials including those with high and low pH solutions. Overall, the process would require considerable development to demonstrate that the final form was stable and free of materials which would cause unacceptable gas generation from radiolysis or chemical reactions.

The process involves the addition of glass-forming material reacted with precursors so the product would be reactive at low temperatures when mixed with other materials (Brinker and Scherer 1990). The final product forms a vitreous material like high-temperature glasses, although the reaction has to be well controlled to ensure complete reaction. A typical example process is to mix alkoxides with water and the material to be stabilized. The reaction occurs in two steps, hydrolysis and condensation, to form a silicate glass mixed with water and/or methanol. The amount of water and methanol can be controlled by precise regulation of the initial quantity of reactants. It is doubtful the water could be reduced to an acceptable quantity for storage without further evaporation at higher temperatures.

\section{Facilities and Equipment}

The equipment required includes mixing vessels and a drying system that could be located in a moderately sized glovebox. The raw materials would be more expensive than those other options, but would not be high compared to the overall costs of operations. Operations and capital equipment cost would be low because the operation is not complex and only requires moderate temperatures.

\section{Schedule}

Process development is needed to develop a good system for plutonium, and the implementation time required would probably be in excess of 2 years. 


\section{Final Product Description}

The stability of the product without heat treatment may be acceptable, but it has not been demonstrated. When heat treated, the product stability should be similar to high temperature glass, but this has not been demonstrated with materials containing plutonium. Waste loading and potential for diversion should be similar to high temperature, vitrification process products.

\section{Effluents Generated}

The effluent would be a solution of water or methanol and non-glass-forming anions.

\section{Justification for Further Study or Rejection}

Table A.3 summarizes the criteria evaluations for the Sol-Gel technology. Process development is needed to develop a good system for plutonium, and the implementation time would probably be in excess of 2 years.

There is no real experience with stabilizing plutonium material using Sol-Gel technology, but there is experience in fabricating vitreous forms from a variety of inorganic materials, including those with high and low pH solutions. Overall, the process would require considerable development to demonstrate that the final form was stable and free of materials that would cause unacceptable generation of gas from radiolysis or chemical reactions. Therefore, the process should not be considered for further study.

\section{References}

Brinker, J. C., and G. W. Scherer. 1990. SOL-GEL Science. Academic Press, Boston. 
Table A.3. Criteria Evaluations for Sol-Gel

\begin{tabular}{|c|c|}
\hline Criteria & Evaluation \\
\hline Technical Feasibility (technology maturity) & $\begin{array}{l}\text { Industrial experience good, very little experience } \\
\text { with plutonium. Development }>2 \text { years technology } \\
\text { rejected }\end{array}$ \\
\hline $\begin{array}{l}\text { Effluents/By-Products } \\
\text { (minimize volumes, hazards) }\end{array}$ & Minimal \\
\hline Effluents Covered/SAR & For most precursor material \\
\hline Energy Resource & Low, same as vitrification \\
\hline Weapon Potential & Low, same as vitrification \\
\hline End Product Volume & High, same as vitrification \\
\hline End Product Stability & Unknown, good be similar to vitrification \\
\hline $\begin{array}{l}\text { Environmental and Public Risk } \\
\text { routine } \\
\text { accident }\end{array}$ & $\begin{array}{l}\text { Low } \\
\text { Low }\end{array}$ \\
\hline $\begin{array}{l}\text { Worker Risk } \\
\text { routine } \\
\text { accident }\end{array}$ & $\begin{array}{l}\text { Low } \\
\text { Low }\end{array}$ \\
\hline $\begin{array}{l}\text { Cost } \\
\text { (construction, operations and D\&D) }\end{array}$ & Low \\
\hline Operating Duration & Unknown \\
\hline Public Acceptance & Unknown \\
\hline Flexibility & Low \\
\hline Materials Covered & All but organics \\
\hline
\end{tabular}




\section{Description of Technologies}

Accept: _ Reject: $\underline{X}$

\section{Technology - Seeded Magnetic Filtration (MAG'SEP, United Kingdom)}

\section{Applicable Wastes Processed}

The wastes that can be processed using this technology include all dilute aqueous solutions containing TRUs, including plutonium. Acidic and alkaline solutions may require a $\mathrm{pH}$ adjustment (F01-F02, F04-F80).

\section{Process Description}

Bradtec, a U.K.-based company, has developed the MAG'SEP process, which is now in use at several DOE sites (Bibler et al. 1992). MAG'SEP makes possible the removal of specific ions from aqueous solutions by selectively binding them to magnetic seed materials. Magnetic particles with sorbed ions are then removed from the source stream by applying a magnetic force. A range of different sorbers is used for different radionuclides and heavy metals. Although direct experience with plutoniumcontaining solutions is limited, there appears to be no technical reason why MAG'SEP technology should not be applicable.

\section{Facilities and Equipment Required}

No additional facilities are required. The process uses a mixer to mix clean magnetic resin with the feed solution, a magnetic separator, and collection and elution units for contaminant removal and recycling of cleaned resin.

\section{Schedule}

The system can be set up very quickly after the delivery of the equipment and resin.

\section{End Product Description}

The end product is a solution containing high concentrations of specific actinides. 


\section{Effluents and By-Products}

A slurry effluent stream is generated, which is depleted in plutonium to a degree that depends on the feed, the strength of attachment of plutonium to the resin, and the flow rate. Under most conditions, it should be possible to produce an effluent containing less than $100 \mathrm{nCi} / \mathrm{g}$ of actinide elements. Eluted resin can be filtered and reused. After final use, it should be of sufficiently low activity that it can be directly disposed of as non-hazardous organic waste.

\section{Risks}

This process uses a physical separation method that has little risk of effluent release. The major technical risk is that some feed materials may have plutonium in sufficient concentrations that the eluate from the resin must be monitored to avoid potential criticality. A smaller (non-safety) risk is that the used resin may become contaminated to the point where it must be disposed as TRU waste.

\section{Costs}

No construction costs are incurred with this technique. Direct costs for plutonium removal are not available. However, for other ions, the cost was quoted as $\$ 0.5$ to $\$ 0.75 / 1000 \mathrm{~L}$ of solution. Total capital and operating costs for a unit capable of treating groundwater (3.8 billion L/yr for 10 years, plus 1.9 billion $\mathrm{L} / \mathrm{yr}$ for 3 years) were $\$ 900,000$ (capital) plus $\$ 1.4 \mathrm{M}$ to $\$ 1.89 \mathrm{M} / \mathrm{yr}$ ).

\section{Comments}

Although it is an innovative technique, Mag'Sep has been demonstrated at several DOE sites (Perera 1993; Tucker 1993).

\section{Justification for Further Study or Rejection}

Mag'Sep is not recommended for further study because relatively little experience exists using it with concentrated plutonium solutions. It is a simple method for concentrating plutonium from dilute aqueous solutions, which may effectively concentrate the plutonium to a degree where it can be economically converted to an acceptable disposal form without having to evaporate large volumes of water. However, it is not envisioned to be as simple as an ion exchange column with similar absorbent material. 
Table A.4. Criteria Evaluations for Mag'Sep (Seeded Magnetic Filtration)

\begin{tabular}{||l|l|}
\hline \multicolumn{1}{|c|}{ Criteria } & \multicolumn{1}{|c|}{ Evaluation } \\
\hline \hline Technical Feasibility (technology maturity) & Medium \\
$\begin{array}{l}\text { Effluents/By-Products } \\
\text { (minimize volumes, hazards) }\end{array}$ & $\begin{array}{l}\text { Product is plutonium-bearing sludge, effluent is } \\
\text { cleaned water }\end{array}$ \\
Effluents Covered/SAR & Unknown \\
Energy Resource & Low \\
Weapon Potential & None \\
End Product Volume & Decreased greatly \\
End Product Stability & Dry to a stable product \\
Environmental and Public Risk \\
routine \\
accident & None \\
Worker Risk & None \\
routine & \\
accident & Low \\
Cost & Low \\
(construction, operations and D\&D) & Low to medium \\
Operating Duration & Unknown \\
Public Acceptance & Should be high \\
Flexibility & Medium \\
Materials Covered & \\
\hline
\end{tabular}




\section{References}

Bibler, J. P., D. Bradbury, M. J. Dunn, and P. M. Tucker. 1992. "Removal of Heavy Metals and Radionuclides in Groundwater and Wastewater by Selective Magnetic Separation." In Proceedings, Spectrum '92. American Nuclear Society, La Grange Park, Hlinois.

Perera, J. 1993. "British Company to Help Clean U.S. Nuclear Sites." Nuclear Waste News $13(32): 316$

Tucker, P. M. 1993. "Demonstrating Novel Processes for Remediation in the Field." Nuclear Engineering International. pp. 30-31. 


\section{Description of Technologies}

Accept: — Reject: $\underline{X}$

\section{Technology - Existing MT-4 System}

\section{Waste Processed}

Polycubes, and potentially other items previously listed under thermal treatment (see thermal treatment), can be processed using the existing MT-4 system.

\section{Process Description}

The MT-4 system exists at PFP to thermally treat polycubes. The system was shut down in 1985 for safety reasons. The furnace operates at positive pressure. Nitrogen gas used for inerting purposes transported combustibles from the furnace to the air side of the glovebox.

\section{Purposes Transported}

The existing system needs to be upgraded to ensure safety and improve the process. The system is located in a glovebox and contains a pyrolyzing furnace, a condenser, a condensate receiver, a scrubber, and a vacuum pump. The furnace sits in an inerted portion of the glovebox. The inerted portion is $80 \mathrm{ft}^{3}$.

The procedure feed rate for the large $(5-\mathrm{cm})$ cubes is one cube every 2 hours (or $130 \mathrm{~cm}^{3} / \mathrm{h}$ ). The rate is slightly higher for smaller pieces. There is evidence that styrene and other pyrolytic products have escaped the furnace to the glovebox inerted area. ${ }^{\text {(a) }}$

The most recent review of the operation noted the need for the following:

- adding of a pressure controller to regulate furnace power to keep the furnace pressure negative to the glovebox

- rebuilding the furnace charging and discharging mechanism to minimize in-leakage

- adding a nitrogen purge for the inerted glovebox area and increased purge in the furnace to provide enough gas flow to move combustibles to the off-gas nozzle

(a) Internal WHC memo to J. W. Green from G. P. Miller, dated August 10, 1990; 15550-90-GPM-134. 
- moving the off-gas nozzle from the top to the bottom of the furnace and enlarging the off-gas line cross section

- relocating the condenser line to allow the off-gas line to turn downward

- installing a crusher

- redesigning the scrub material in the scrubber (now uses carbon tetrachloride)

- adding of a backflow damper.

Note that the recommendations in the literature are for upgrading the existing furnace. The furnace, as currently sized, would require 33 weeks to dispose of the polycubes, which is a small portion of the inventory. Consideration might be given to a larger furnace that could be used for thermal treatment of other materials. If other materials will be treated in this system, consideration also needs to be given to the scrubber material. A NaOH scrub may be more applicable.

Basically, the entire unit would have to be redesigned for thermally treating PFP waste. It does show the potential applicability of a furnace as the thermal treatment unit.

\section{Facilities and Equipment}

The current furnace is in an inerted, $2.3 \mathrm{~m}^{3}$ area of a glovebox. See the process description for details.

\section{Schedule}

If only the upgrades recommended in the references are implemented, the MT-4 system could be operational in the 2-year time frame and would be applicable to polycubes.

If the MT-4 system is replaced with a larger furnace and new off-gas system and the safety issues referred to in the references are considered in the design of the new system, the unit could still be operational within 2 years. The unit would only handle batch input and would not be-applicable to all the materials listed for thermal treatment.

\section{Final Product Description}

A description of the final product is not provided in the references, but since polystyrene would completely react, only an oxidized form of the metals put in the polystyrene would remain.

\section{Effluents Generated}

The generated effluents are not described in the references but are assumed to be an ash, off gas, and scrubber liquor (carbon tetrachloride). 


\section{Risks}

Another safety concern raised was the radiation dose rates operating personnel would be exposed to during handling and processing of the stored polycubes. A shielding analysis was performed using a standard 5 - by $5=\mathrm{cm}$ cube containing $230 \mathrm{~g}$ of plutonium containing $18.5 \%$ plutonium- 240 . The conclusions from this analysis recommended using some thickness of polystyrene shielding for neutron dose and a minimum of $0.7-\mathrm{cm}$ lead shielding for gamma ray dose..$^{(a)(b)(c)(d)}$

The buildup of americium- 241 has resulted in dose rates that range from 1 to $6 \mathrm{rem} / \mathrm{h}$ at contact with the polycube cans. ${ }^{(e)}$

\section{Costs}

Costs are not known.

\section{Justification for Further Study or Rejection}

The criteria evaluations are summarized in Table A.5. The MT-4 system would have to be rejected because of the safety issues involved with running the system. However, an improved system could be built to address the safety issues and be applicable to other forms of waste. Such a system would be relatively small (fit in a glovebox) and environmentally sound (low emissions).

This option was dropped from further study between the draft and formal draft reports because muffle furnaces exist in PFP that could pyrolyze the polycubes, and other materials, without such extensive modifications.

(a) Internal WHC memo to E. C. Vogt from F. F. Walters, dated June 7, 1989; 12720-89-FFW-90.

(b) Internal WHC letter to A. E. Schilling from J. J. Roemer, dated May 14, 1987; JJR-12723-87-127.

(c) Internal WHC memo to F. F. Walters from R. J. Morford, dated June 1, 1989; 1270-89-FFW-90.

(d) Draft WHC memo to T. E. Huber from G. P. Miller, no date; no identification.

(e) Internal WHC letter to A. E. Schilling from J. J. Roemer, dated May 14, 1987; JJR-12723-87-127. 
Table A.5. Criteria Evaluations for the Existing MT-4 System

\begin{tabular}{|c|c|}
\hline Criteria & Evaluation \\
\hline Technical Feasibility (technology maturity) & $\begin{array}{l}\text { The current system could be available in } 2 \text { years } \\
\text { with the recommended safety upgrades }\end{array}$ \\
\hline $\begin{array}{l}\text { Effluents/By-Products } \\
\text { (minimize volumes, hazards) }\end{array}$ & Minimal - scrubber liquor and off-gas \\
\hline Effluents Covered/SAR & Must be, this process done before for polycubes \\
\hline Energy Resource & Probably minimal \\
\hline Weapon Potential & Unknown \\
\hline End Product Volume & $\begin{array}{l}\text { Minimal - oxidized form of what was put in } \\
\text { polycubes }\end{array}$ \\
\hline End Product Stability & Unknown - very stable if high fired \\
\hline $\begin{array}{l}\text { Environmental and Public Risk } \\
\text { routine } \\
\text { accident }\end{array}$ & Unknown \\
\hline $\begin{array}{l}\text { Worker Risk } \\
\text { routine } \\
\text { accident }\end{array}$ & $\begin{array}{l}\text { Dose rates of }>1 \text { to } 6 \mathrm{rem} / \mathrm{h} \text { at the cans } \\
\text { Explosion potential unknown }\end{array}$ \\
\hline $\begin{array}{l}\text { Cost } \\
\text { (construction, operations and D\&D) }\end{array}$ & Minimal - upgrade of existing system \\
\hline Operating Duration & 33 weeks for polycubes only \\
\hline Public Acceptance & $\begin{array}{l}\text { Should be high - this is not a new process for } \\
\text { PFP, and if the safety issues are addressed, it } \\
\text { should be relatively safe. }\end{array}$ \\
\hline
\end{tabular}




\section{Description of Technologies}

Accept: _ Reject: $\underline{X}$

\section{Technology - Microwave Drying}

\section{Waste Processed}

The microwave drying technology can be used to process nitrates. The Japanese have used microwaves to denitrate directly from the nitrate solutions for 12 years (as of 1989). The material is calcined in another type of furnace. The Japanese have also denitrated nitrates that have been concentrated in a drum dryer first. Testing has been done in the United States on direct reduction of plutonium (III) fluoride with lithium metal to plutonium metal using microwaves.

\section{Process Description}

The Japanese use different systems, but their general rule appears to be this: use a different chamber (whether it be microwave or conventional furnaces) for each of the concentrating, denitrating, and calcining processes.

Oshima (1989) discusses the use of one microwave chamber to take unconcentrated nitrates and denitrate them. Two additional reports (Sato and Morisue 1983; Matsumura and Sato 1984) discuss the use of a rotary-kiln to concentrate the nitrates before denitration with microwaves. One description states that although the "... denitration product can be produced by using the microwave-heating apparatus described above, direct irradiation of the solution of starting material with microwaves leads to consumption of almost $80 \%$ of the energy merely for evaporation of nitric acid, water, etc., and not for heating the ... plutonium nitrate, which are the important constituents. Moreover, because the denitration time varies depending on the concentration of starting materials in the solution, it is extremely difficult to control the apparatus. Furthermore, since this system is based on the batch process, it is difficult to treat large quantities" (Sato and Morisue 1983). This description makes it sound like it is more economical to use a conventional thermal treatment to condense the nitrates.

Yet another Japanese system uses a microwave chamber to evaporate the nitrates and a second microwave chamber to denitrate the product. And another system undergoing testing uses three microwave chambers to concentrate, denitrate, and dry the product.

\section{Facilities and Equipment}

The direct denitration unit described in Koizumi et al. (1983a, 1983b) denitrated $3 \mathrm{~L}$ of uraniumnitrate in 45 minutes. The denitration unit is only 40 by $30 \mathrm{~cm}$. No height was given for the unit, but if the pictures are to scale, the unit would be about $40 \mathrm{~cm}$ high. This system would also require a scrapping apparatus, a calcination reduction furnace, and a ball mill within the contaminated area. 
The system described in Oshima and Tsuji (1984) is a continuous system using two chambers for evaporation and denitration in $2 \mathrm{~kg}$ batches. This microwave unit is $3.5 \mathrm{~m}$ by $0.73 \mathrm{~m}$ by $1.3 \mathrm{~m}$ (Kihara et al. 1992). The microwave generator is outside the contaminated area allowing for routine maintenance.

Off-gas treatment equipment would be needed as well as possibly a milling machine and an immobilization system. The number and types of chambers would also have to be determined.

Manpower should be low because this is a very easy process (assuming a continuous feed, all microwave system); in addition, microwaving uses no raw materials.

\section{Schedule}

As microwaves have not been widely used in the United States, a great deal of testing would be required. Required testing would probably extend the startup schedule beyond 2 years.

\section{Final Product Description}

If dried, the product is a concentrated slurry that could then be fed to a calciner. If denitrated, the product again has to be calcined. If calcined, the product has qualities of a conventionally calcined product, if the right power levels are used. In one uranyl test, the oxide formed hot spots $\left(\mathrm{U}_{3} \mathrm{O}_{8}\right.$ formed instead of $\mathrm{UO}_{3}$ ).

"... variations in the composition of the solution of starting materials have only a small influence on the quality of the product powder" (Sato and Morisue 1983).

\section{Effluents Generated}

This process generates off gases only, but no description is given in the literature. Depending on the off gases, scrubber liquors may be an effluent.

\section{Costs}

One document (Piper and Berreth 1978) gives initial costs as greater than a conventional calciner (fluidized bed or spray calciner). Other costs were not presented. Piper and Berreth (1978) also state that a microwave unit requires more energy than conventional calciners to produce the same quantity of product.

\section{Comments}

No documentation exists on public comments. However, because this is not a proven technology and there is no experience with it in the United States, it seems highly unlikely that microwave technology would be chosen over the more conventional thermal treatments. 
No use of microwaves in the United States was found for drying nitrates. The Japanese are much further along. Additionally, a U.S. report states conventional furnaces are more economical than microwaves for calcining. The same is probably true for drying. Further, a Japanese report used a rotary-kiln to preconcentrate the nitrates as the microwave technology would consume "...almost $80 \%$ of the energy merely for evaporation of nitric acid, water, etc."

\section{Justification for Further Study or Rejection}

Table A.6 summarizes the criteria evaluations for microwave technology. Microwave technology has not been used in the United States for drying or calcining nitrates, and much testing would be required for use of microwaves, extending a startup schedule beyond 2 years. Therefore, it is recommended that microwave technology be rejected.

The costs and benefits of microwaves versus conventional thermal treatments do not justify the use of microwave technology (Piper and Berreth 1978).

\section{References}

Kihara, Y., Y. Kato, Y. Takahashi, and J. Ohuchi. 1992. "Continuous Microwave Denitration of Uranium and Plutonium Nitrate Solution." From Proceedings of the Fourth International Symposium of Advanced Nuclear Energy Research - Roles and Direction of Material Science in Nuclear Technology. JAERI-M:92-207, Japanese Atomic Energy Research Institute, National Technical Information Service, Springfield, Virginia.

Koizumi, M., K. Ohtsuka, H. Oshima, H. Isagawa, H. Akiyama, A. Todokoro, and K. Naruki. 1983a. "Development of a Process for the Co-Conversion of Pu-U Nitrate Mixed Solutions to MixedOxide Powder Using Microwave Heating Methods." Nuclear Technology 61:55-70.

Koizumi, M., K. Ohtsuka, H. Isagawa, H. Akiyama, and A. Todokoro. 1983b. "Development of a Process for Co-Conversion of Pu-U Nitrate Mixed Solutions to Mixed Oxide Powder Using a Microwave Heating Method." Journal of Nuclear Science and Technology 20[7]:529-536.

Matsumura, K., and H. Sato. 1984. Microwave-Heated Continuous Denitrification Apparatus. RFP-TRANS-21, Rocky Flats Plant, Golden, Colorado.

Oshima, H. and N. Tsuji. 1984. Continuous Direct Denitration Process of Plutonium-Uranium Co-Conversion Using Microwave Heating Method. ORNL-TR-88/26, Oak Ridge National Laboratory, Oak Ridge, Tennessee.

Oshima, H. 1989. "Development of Microwave Heating Method for Co-Conversion of PlutoniumUranium Nitrate to MOX Powder." Journal of Nuclear Science and Technology 26[1]:161-166. 
Table A.6. Microwave Drying Evaluation

\begin{tabular}{|c|c|}
\hline Criteria & Evaluation \\
\hline Technical Feasibility (technology maturity) & Availability $>2$ years \\
\hline $\begin{array}{l}\text { Effluents/By-Products } \\
\text { (minimize volumes, hazards) }\end{array}$ & Unknown \\
\hline Effluents Covered/SAR & Unknown \\
\hline Energy Resource & Unknown \\
\hline Weapon Potential & Unknown \\
\hline End Product Volume & Unknown \\
\hline End Product Stability & Unknown \\
\hline $\begin{array}{l}\text { Environmental and Public Risk } \\
\text { routine } \\
\text { accident }\end{array}$ & Unknown \\
\hline $\begin{array}{l}\text { Worker Risk } \\
\text { routine } \\
\text { accident }\end{array}$ & Unknown \\
\hline $\begin{array}{l}\text { Cost } \\
\text { (construction, operations and D\&D) }\end{array}$ & Unknown \\
\hline Operating Duration & Unknown \\
\hline Public Acceptance & Unknown \\
\hline
\end{tabular}


Piper, T. C., and J. R. Berreth. 1978. The Potential Application of Microwave Energy in Solidifying High-Level Nuclear Wastes. ICP-1145, Idaho Chemical Corporation, Idaho Falls, Idaho.

Sato, H., and T. Morisue. 1983. Microwave-Heating Continuous-Denitration Apparatus. RFP-TRANS-374, Rocky Flats Plant, Golden, Colorado.

\section{Bibliography}

Davis, M. L. 1992. The Use of Microwave Energy in Powder Drying and Crucible Testing for Plutonium Metal Recovery. SRL-ATS-91-0261, Westinghouse Savannah River Company, Aiken, South Carolina.

Komatsu, F., A. Takusagawa, R. Wada, and K. Asahina. 1990. "Application of Microwave Treatment Technology for Radioactive Wastes." Waste Management 10[3]:211-215.

Krikorian, O. H., R. H. Condit, A. S. Fontes, Jr., W. R. Morris, J. W. Mogana, and R. W. Lougheed. 1993. Study of Plutonium Volatility Under Microwave Melting Conditions Used for Glass Encapsulation of Plutonium Sludge Wastes: Final Report. UCRL-ID-113718, Lawrence Livermore National Laboratory, Livermore, California.

Matsumura, K. 1983. Heating Apparatus for Denitration of Metal Nitrates. RFP-TRANS-355, Rocky Flats Plant, Golden, Colorado.

Petersen, R. D. 1990. "Microwave Vitrification of Rocky Flats TRU Sludge." In Spectrum 90: Proceedings of the International Topical Meeting on Nuclear and Hazardous Waste Management. American Nuclear Society, La Grange Park, Illinois.

Petersen, R. D., A. J. Johnson, S. D. Swanson, and R. L. Thomas, eds. 1987. Application of Microwave Energy for In-Drum Solidification of Simulated Precipitation Sludge. RFP-4148, Rocky Flats Plant, Golden, Colorado.

Priebe, S. J., T. C. Piper, and J. R. Berreth. 1979. Application of Microwave Energy to Post-Calcination Treatment of High-Level Nuclear Wastes. ICP-1183, Idaho Chemical Corporation, Idaho Falls, Idaho.

Roggenthen, D. K. 1989. Selection of Immobilization Technology for TRU Waste. RFP-4292, Rocky Flats Plant, Golden, Colorado.

White, T. L., R. D. Peterson, and A. J. Johnson. 1989. "Microwave Processing of Remote-Handled Transuranic Wastes at Oak Ridge National Laboratory." In Proceedings of the Symposium on Waste Management at Tucson, Arizona, February 26 - March 2, 1989. Vol-1, Arizona Board of Regents, Tucson, Arizona. 
White, T. L., E. L. Youngblood, J. B. Berry, and A. J. Mattus. 1990a. Status of Microwave Process Development for RH-TRU Wastes at Oak Ridge National Laboratory. CONF-900229-11, National Technical Information Service, Springfield, Virginia.

White, T. L., E. L. Youngblood, J. B. Berry, and A. J. Mattus. 1990b. First Results of In-Can Microwave Processing Experiments for Radioactive Liquid Wastes at the Oak Ridge National Laboratory. CONF-900466--54, National Technical Information Service, Springfield, Virginia. 


\section{Description of Technologies}

Accept: _ Reject: $\underline{X}$

\section{Technology - Cementation}

\section{Waste Processed}

Cementation can be used to process plutonium, ash, acids, plutonium liquid wastes with organics, borates, sulfates, nitrates, and/or chlorides (possibly all halides). However, they all will require some form of pretreatment.

\section{Process Description ${ }^{(a)(b)}$}

Cementation is primarily an immobilization technique. It does not change the waste itself (e.g., plutonium nitrate would still be present if treated with cementation) but isolates the material from the open air. However, cementation does not isolate the material from all air components. For example, oxygen and hydrogen are present in the concrete and are in contact with the waste. Waste products may also leach from concrete and then be released to the air. Besides isolating from the open air, concrete also reduces dispersibility in the event of a crushing-type accident.

At least one of the documents reviewed recommends concrete not be considered as an acceptable waste form because it "...may yield appreciable quantities of gas, mainly hydrogen, under alpha radiolytic conditions over long periods..." (Bida and Mackanzie 1983, p. 579). The same document goes on to recommend TRU combustibles be processed and the residues immobilized. If concrete is the immobilizing agent, then Bida and Mackanzie (1983) recommend methods such as formed under elevated temperatures and pressures (FUETAP) be used to reduce gas generation.

Cementation has been used a great deal for intermediate level waste immobilization in foreign countries, and Los Alamos National Laboratory (LANL) has used cementation for TRU and LLW, including organics. LANL cements particulates and liquids. LANL has had some problems: 1) because the waste is mixed waste, inspections of the waste forms are required daily; 2) the cemented wastes are no longer certified for Waste Isolation Pilot Plant (WIPP) acceptance - free standing water has been found in the containers as a result of gas buildup inside the concrete; and 3) gypsum cement with a plasticizer is breaking down after a few years and the concrete is softening. Furthermore, LANL's cemented waste forms are vented for gas buildup.

(a) Conversation between Sue Garrett (PNL) and Jeff Werne (PNL), 5/27/94.

(b) Conversation between Sue Garrett (PNL) and Jerry Veizey (LANL) 3/17/94. 
Accelerated curing methods are common industrial practice (for FUETAP). Cementation is a simple process, and the equipment is inexpensive with no innovations required.

The cementation process possibly takes pretreated particulate and liquid waste. The particulate is mixed with cement (Portland types are recommended) and potential additives. The liquid waste and additional water, if needed, are then added to the dry mixture. The concrete is mixed either in line and then put in a drum or mixed directly in a drum. The partially filled drum is set aside to cure for 28 days (concrete reaches about $90 \%$ of its total strength in 28 days). The properties of the final concrete waste form are highly sensitive to the waste makeup. This factor means that the slightest change in the wastes could alter the concrete properties (e.g., make it weaker or more porous) and that the proper concrete mix needs to be tailored to each variation in the feed stream (e.g., $10 \%$ more nitrates in the new waste may require a new mix).

If FUETAP is used, the only difference is in the curing process. After being placed in a drum, the concrete is cured at $0.1 \mathrm{MPa}$ and $100^{\circ} \mathrm{C}$ for 24 hours and then dewatered by heating to $250^{\circ} \mathrm{C}$ for another 24 hours.

\section{Facilities and Equipment}

Assuming pretreatment of all waste is completed before cementing and mixing is undertaken in the drum, the required equipment would be 1) feed/storage tanks/bins for the water, liquid waste, particulate waste, cement, and additives; 2) a drum; 3) a glovebox; 4) an agitator; 5) a scale for the drum; 6) pumps; 7) HEPAs; 8) hoists for moving the agitator and the drums; and 9) a drum sealer. All of this equipment is readily available and inexpensive.

If FUETAP is used, an oven for drying and a pressure unit (Dole et al. 1981) would also be required.

\section{Schedule}

No process development would be needed. However, each waste stream, and variation thereof, would require an analysis to determine the tailored concrete mixes.

Equipment installation and initial checkout should be minimal, but again, each variation in waste streams may require test sampling and testing.

The processing rate would depend upon the waste being cemented and the proper mix for that stream. However, the limiting factors would be the mixing time, the curing area size, and the sealing time. Curing time is usually given as 28 days, which means the curing area must be able to hold 28 days' worth of drums. Assuming that mixing and sealing times are on the order of 1 hour and that there is only one station of each, a maximum of 8 to 24 drums might be processed per day. The curing area would then have to be able to handle 160 to 480 drums in a 28-day period (assumes no mixing or sealing on weekends). 
The FUETAP process may also be limited by the size of the drying oven and the pressure unit. If the pressure unit can only handle one drum per day, and there is only one unit, then only one drum per day could be processed. If the pressure unit and the drying oven can each handle up to six drums per day, then six drums per day could be processed.

\section{Final Product Description}

The long-term stability of concrete under alpha radiation and neutron bombardment (americium-241) is unknown. However, LANL is seeing deterioration of their gypsum-based concrete.

The physical properties of the concrete are dependent upon the materials in the concrete and the exact mix of the materials. Neat concrete (pure concrete with the optimal ratio of water to cement) usually has a compression strength on the order of 10,000 psi, while concrete with $25 \%$ Savannah River Plant sludge loading has been measured at 4,588 psi. At $40 \%$ loading, the compression strength falls to 464 psi.

In general, the compression strength of the concrete waste form is good, and the retention of actinides is very good in concrete (because of the naturally high $\mathrm{pH}$ of the concrete). Furthermore, there is a constant rate of hydrogen buildup because of alpha radiolysis of free water in the concrete (but if water is driven off, the thermal conductivity of the concrete goes down). Finally, the thermal properties are good (but thermal pressurization would rupture a sealed standard $208 \mathrm{~L}$ drum), and the volume of the final product can often be double the initial waste volume (IAEA 1993). Note that "...concrete waste forms are generally inferior to glass forms regarding radionuclide leachability, thermal conductivity, maximum product temperatures, compressive and impact strengths, radiation effects (radiolysis of water in concrete), and required material outputs (canisters, total mass, off gas, etc.)" (Lokken 1978).

The quantity of waste per drum depends on the waste loading. As an example, assuming mixes similar to the Savannah River Plant's mix (Dole et al. 1981), $70 \mathrm{~kg}$ of particulate could be placed in each drum (this may be high since the quantity of plutonium and heat generation per package is limited). Cemented waste may be anywhere from 1.2 to 9 times larger than the original waste volume (Rusin et al. 1979), and the actual increase may be more if plutonium dioxide is cemented.

Note that one paper (Lokken 1978) which states that the number of concreted canisters of HLW would be 7 to 22 times the number of glass canisters for the same waste.

\section{Effluents Generated}

No effluents are generated using this technology. Water used to clean the concrete from the mixers would be reused in future drums. 


\section{Risks}

Grout dilutes the waste material and acts as a shield, thereby decreasing worker exposure. It also immobilizes the plutonium in a matrix. However, radiolytic pressure buildup is significant and, if heated, would rupture a standard 55-gallon drum.

\section{Costs}

The costs would be minimal. One document states two people could run the process.

\section{Comments}

Concrete is used for immobilization only and requires pretreatment for a lot of PFP waste. In addition, its properties are not as good as glass (especially hydrogen buildup). Table A.7 summarizes the criteria evaluations for concrete and grout.

\section{Justification for Further Study or Rejection}

The cementation process is rejected for further study. The advantages and disadvantages of this process are described below.

\section{Advantages}

Cementation has excellent properties for retaining actinides.

This process is suitable for liquids to dry solids.

It has excellent thermal properties.

Cementation is a simple, low temperature process.

Plutonium, regardless of oxidation state, is highly immobile in concrete, and americium leaches at the same rate as plutonium.

\section{Disadvantages}

Cementing only immobilizes plutonium, and its properties are not as good as glass.

The final waste volume can often be double the initial volume.

Trial formulations are required for each waste stream and variant thereof.

Much of the PFP waste cannot be immobilized without pretreatment.

Off gassing of hydrogen occurs at a constant rate.

A potential exists for a high gas release from a fire. 
Table A.7. Criteria Evaluations for Concrete/Grout

\begin{tabular}{|c|c|}
\hline Criteria & Evaluation \\
\hline Technical Feasibility (technology maturity) & $\begin{array}{l}\text { This technology could be developed in } 2 \text { years, but } \\
\text { the technology has not been used successfully on } \\
\text { TRU waste (LANL waste is not certified due to } \\
\text { standing liquids) }\end{array}$ \\
\hline $\begin{array}{l}\text { Effluents/By-Products } \\
\text { (minimize volumes, hazards) }\end{array}$ & None (pretreatment would cause waste) \\
\hline Effluents Covered/SAR & Unknown \\
\hline Energy Resource & Negligible for non-heated/pressurized case \\
\hline Weapon Potential & Would need refining \\
\hline End Product Volume & 1.2 - much more than original volume \\
\hline End Product Stability & $\begin{array}{l}\text { Stable except in fire } \\
\text { Water and gas generation }\end{array}$ \\
\hline $\begin{array}{l}\text { Environmental and Public Risk } \\
\text { routine } \\
\text { accident }\end{array}$ & $\begin{array}{l}\text { Reduces chance of dispersibles } \\
\text { Might explode in fire }\end{array}$ \\
\hline $\begin{array}{l}\text { Worker Risk } \\
\text { routine } \\
\text { accident }\end{array}$ & $\begin{array}{l}\text { Same as any other remote operation around the } \\
\text { original waste } \\
\text { Fire - explosion }\end{array}$ \\
\hline $\begin{array}{l}\text { Cost } \\
\text { (construction, operations and D\&D) }\end{array}$ & Minimal \\
\hline Operating Duration & Depends on waste loading \\
\hline Public Acceptance & Used at LANL/ORNL \\
\hline
\end{tabular}




\section{References}

Dole, R. L., J. G. Moore, G. A., G. C. Rogers, West, H. E. Devaney, M. T. Morgan, E. W. McDaniel, and J. H. Kessler. 1981. Cementitious Radioactive Waste Hosts Formed Under Elevated Temperatures and Pressures (FUETAP Concretes). CONF-811122-39, National Technical Information Services, Springfield, Virginia.

Bida, G., and B. R., Mackanzie. 1983. "An Evaluation of Alternatives Technologies." Scientific Basis for Nuclear Waste Management VI. Ed. D. G. Brookins. Elsevier Science Publishing Co., Inc., New York.

International Atomic Energy Agency.(IAEA). 1993. Treatment and Conditioning of Spent Ion Exchange Resins for Research Reactors, Precipitation Sludges and Other Radioactive Concentrates. IAEA-TECDOC-689, International Atomic Energy Agency, Vienna.

Lokken, R. O. 1978. A Review of Radioactive Waste Immobilization in Concrete. PNL-2654, Pacific Northwest Laboratory, Richland, Washington.

Rusin, J. M., J. W. Wald, and R. O. Lokken. 1979. Alternative Waste Forms -- A Comparative Study. PNL-SA-7782, Pacific Northwest Laboratory, Richland, Washington.

\section{Bibliography}

Angus, M. J., and F. P. Glasser. 1986. "The Chemical Environment in Cement Matrices." Scientific Basis for Nuclear Waste Management IX. Ed. L. O. Werne. Materials Research Society, Pittsburgh, Pennsylvania.

Atabek, R., P. Bouniol, E. Revertegat, J. Oliver, P. Gegout, and M. Jorda. 1990. "Nuclear Waste Immobilization in Cement-Based Materials." Scientific Basis for Nuclear Waste Management XIII. Eds. V. M. Oversby and P. W. Brown. Materials Research Society, Pittsburgh, Pennsylvania.

Atkins, M., J. Cowie, F. P. Glasser, T. Jappy, A. Kindness, and C. Pointer. 1990. "Assessment of the Performance of Cement-Based Composite Material for Radioactive Waste Immobilization." Scientific Basis for Nuclear Waste Management XIII. Eds. V. M. Oversby and P. W. Brown. Materials Research Society, Pittsburgh, Pennsylvania.

Atkins, M., F. P. Glasser, and L. P. Moroni. 1991. "The Long-Term Properties of Cement and Concretes." Scientific Basis for Nuclear Waste Management XIV. Eds. T. A. Abrajano Jr. and L. H. Johnson. Materials Research Society, Pittsburgh, Pennsylvania. 
Atkinson, A., D. J. Goult, and J. A. Hearne. 1986. "An Assessment of the Long-Term Durability of Concrete in Radioactive Waste Repositories." Scientific Basis for Nuclear Waste Management IX. Ed. L. O. Werne. Materials Research Society, Pittsburgh, Pennsylvania.

Bayliss, S., F. T. Ewart, R. M. Howse, J. L. Smith-Briggs, H. P. Thomason, and H. A. Willmott. 1987. "The Solubility and Sorption of Lead-210 and Carbon-14 in a Near-Field Environment." Scientific Basis for Nuclear Waste Management XI. Ed. M. J. Apted, R. E. Westerman. Materials Research Society, Pittsburgh, Pennsylvania.

Berner, U. R. 1987. "Modelling Porewater Chemistry in Hydrated Portland Cement." Scientific Basis for Nuclear Waste Management X. Ed. J. K. Bates, Waldemar B. Seefeldt. Materials Research Society, Pittsburgh, Pennsylvania.

Brodda, B., and X. Mingxia. 1989. "Leaching of Chlorine, Cesium, Strontium and Technetium from Cement-Fixed Intermediate Level Liquid Waste." Scientific Basis for Nuclear Waste Management XII. Ed. W. Lutze, R. C. Ewing. Materials Research Society, Pittsburgh, Pennsylvania.

Broderson, K. 1989. "Hygroscopic Water Uptake and Dry/Wet Cycling Compared with Normal Water Exposure of Cemented Waste Forms." Scientific Basis for Nuclear Waste Management XII. Eds. W. Lutze, R. C. Ewing. Materials Research Society, Pittsburgh, Pennsylvania.

Burnett, N. C., R. D. Hooton, R. B. Heimann, and M. Onofrei. 1986. "The Development of durable Cementitious Materials for use in a Nuclear Fuel Waste Disposal Facility." Scientific Basis for Nuclear Waste Management IX. Ed. L. O. Werne. Materials Research Society, Pittsburgh, Pennsylvania.

Cote, P., and M. Gilliam, eds. 1989. Environmental Aspects of Stabilization and Solidification of Hazardous and Radioactive Wastes. STP 1033, American Society for Testing and Materials, Philadelphia, Pennsylvania.

Crandell, J. L. 1980. "Developed of Solid Radionuclide Waste Forms in the United States." Scientific Basis for Nuclear Waste Management. Ed. C. J. M. Northrup, Jr. Vol. 2. Plenum Press, New York.

Crisler, L. R. 1980. "A Preliminary Assessment of Nine Waste-Form Products/Processes for Immobilizing Transuranic.Wastes." Immobilizing Transuranic Wastes. RFP-3131, Rocky Flats Plant, Golden, Colorado.

Fajun, W., M. W. Grutzeck, and D. M. Roy. 1985. "Leaching of Warm-Pressed CsZP-Cement Composite Waste Forms." Scientific Basis for Nuclear Waste Management VIII. Eds. C. M. Jantzen, J. A. Stone, and R. C. Ewing. Materials Research Society, Pittsburgh, Pennsylvania.

Feldman, R. F., J. J. Beaudoin, and K. E. Philipose. 1990. "Durable Concrete for a Waste Repository - Measurement of Ionic Ingress." Scientific Basis for Nuclear Waste Management XIII.

Eds. V. M. Oversby and P. W. Brown. Materials Research Society, Pittsburgh, Pennsylvania. 
Flambard, A. R., H. U. Fusban, C. Keling, and G. Marx. 1986. "Investigations into the Mobilization of Actinides for ILW Conditioned in Cement and Bitumen and Studies of their Sorptive and Migration Behaviour in both the Near- and Far-Fields for a Repository in a Deep Slat Environment." Scientific Basis for Nuclear Waste Management IX. Ed. L. O. Werne. Materials Research Society, Pittsburgh, Pennsylvania.

Glasser, F. P., M. J. Angus, C. E. McCulloch, D. MacPhee, and A. A. Rahman. 1985. "The Chemical Environment in Cements." Scientific Basis for Nuclear Waste Management VII. Eds. C. M. Jantzen, J. A. Stone, and R. C. Ewing. Materials Research Society, Pittsburgh, Pennsylvania.

Glasser, F. P., D. E. MacPhee, and E. E. Lachowski. 1987. "Solubility Modelling of Cements: Implications for Radioactive Waste Immobilization." Scientific Basis for Nuclear Waste Management X. Ed. J. K. Bates, and W. B. Seefeldt. Materials Research Society, Pittsburgh, Pennsylvania.

Glasser, F. P., D. E. MacPhee, and E. E. Lachowski. 1987. "Modeling Approach to the Prediction of Equilibrium Phase Distribution in Slag-Cement Blends and Their Solubility Properties." Scientific Basis for Nuclear Waste Management XI. Ed. M. J. Apted and R. E. Westerman. Materials Research Society, Pittsburgh, Pennsylvania.

Hoglund, S., L. Eliasson, B. Allard, K. Anderson, and B. Torstenfelt. 1986. "Sorption of Some Fission Products and Actinides in Concrete Systems." Scientific Basis for Nuclear Waste Management IX. Ed. L. O. Werne. Materials Research Society, Pittsburgh, Pennsylvania.

International Atomic Energy Agency (IAEA). 1992. Treatment and Conditioning of Radioactive Organic Liquids. IAEA-TECDOC-656, International Atomic Energy Agency, Vienna.

Jakubick, A. T., R. W. Gillham, I. Kahl, and M. Robin. 1987. "Attenuation of Pu, Am, Cs, and Sr Mobility in Concrete." Scientific Basis for Nuclear Waste Management X. Ed. J. K. Bates and W. B. Seefeldt. Materials Research Society, Pittsburgh, Pennsylvania.

Jiang, W:, X. Wu, and D. M. Roy. 1993. "Alkali-Activated Fly Ash-Slag Cement Based Nuclear Waste Forms." Scientific Basis for Nuclear Waste Management XVI. Eds. C. G. Interrante and R. T. Pabalan. Materials Research Society, Pittsburgh, Pennsylvania.

Kessler, J. H., G. C. Rogers, L. R. Dole, and M. T. Morgan. 1983. "Formulation and Durability of Tailored Cementitious Hosts Applied to TRU Waste Generated at the Rocky Flats Plant." Scientific Basis for Nuclear Waste Management VI. Ed. D. G. Brookins. Elsevier Science Publishing Co., Inc., New York.

Komarneni, S., D. M. Roy, A. Kumar. 1985. "Tuff-Cement or Concrete in the Repository Environment." Scientific Basis for Nuclear Waste Management VIII. Eds. G. M. Jantzen, J. A. Stone, and R. C. Ewing. Materials Research Society, Pittsburgh, Pennsylvania. 
Langton, C. A., M. D. Dukes, and R. V. Simmons. 1984. "Cement-Based Waste Forms for Disposal of Savannah River Plant Low-Level Radioactive Salt Waste." Scientific Basis for Nuclear Waste Management VII. Ed. G. L. McVay. Elsevier Science Publishing Co., Inc., New York.

Lewis, M. A., and D. W. Warren. 1990. "The Use of Additives for Reducing Hydrogen Yield in Mortar Containing Slag and Chloride Salts." Scientific Basis for Nuclear Waste Management XIII. Eds. V. M. Oversby and P. W. Brown. Materials Research Society, Pittsburgh, Pennsylvania.

Lokken, R. O., J. W. Shade, and P. F. C. Martin. 1990. "Effect of Curing Temperature on the Properties of Cementitious Waste Forms." Scientific Basis for Nuclear Waste Management XIII. Ed. V. M. Oversby and P. W. Brown. Materials Research Society, Pittsburgh, Pennsylvania.

McDaniel, E. W., O. K. Tallent, T. L. Sams, D. B. Delzer, and W. D. Bostick. 1989. "Basis for Selecting Cement-Based Waste Forms for Immobilizing Radioactive Waste." Scientific Basis for Nuclear Waste Management XII. Ed. W. Lutze and R. C. Ewing. Materials Research Society, Pittsburgh, Pennsylvania.

Momine, J. C., A. Billion, and G. Courtois. 1989. "Leaching Scale Effect for Cement-Based Forms." Scientific Basis for Nuclear Waste Management XII. Eds. W. Lutze and R. C. Ewing. Materials Research Society, Pittsburgh, Pennsylvania.

Muurinen, A., J. Rantanen, R. Ovaskainen, and O. J. Heinonen. 1983. "Diffusion Measurements in Concrete and Compacted Bentonite." Scientific Basis for Nuclear Waste Management VI. Ed. D. G. Brookins. Elsevier Science Publishing Co., Inc., New York.

Offermann, P. 1989. "Calculation of the Radiolytic Gas Production in Cemented Waste." Scientific Basis for Nuclear Waste Management XII. Eds. W. Lutze and R. C. Ewing. Materials Research Society, Pittsburgh, Pennsylvania.

Onofrei, M., M. N. Gray, D. Breton, and G. Ballivy. 1991. "The Effect of Leaching on the Pore Structure of Cement-Based Grouts for Use in Nuclear Fuel Waste Disposal." Scientific Basis for Nuclear Waste Management XIV. Eds. T. A. Abiajano, Jr. and L. H. Johnson. Materials Research Society, Pittsburgh, Pennsylvania.

Palmer, J. D., and G. A. Fairhall. 1993. "The Radiation Stability of Ground Granulated Blast Furnace Slag/Ordinary Portland Cement Grouts Containing Organic Admixtures." Scientific Basis for Nuclear Waste Management XVI. Eds. by C. G. Interrante and R. T. Pabalan. Materials Research Society, Pittsburgh, Pennsylvania.

Petersen, R. D. 1987. Organic and Sludge Immobilization System. RFP-4095, Rocky Flats Plant, Golden, Colorado. 
Roggenthen, D. K. 1989. Selection of Immobilization Technology for TRU Waste. RFP-4292, Rocky Flats Plant, Golden, Colorado.

Ross, W. A., C. O. Harvey, R. O. Lokken, R. P. May, F. P. Roberts, C. L. Timmerman, R. L. Treat, and J. H. Westsik, Jr. 1982. "A Comparative Assessment of TRU Waste Forms and Immobilization Processes." Scientific Basis for Nuclear Waste Management. Ed. S. V. Topp. Elsevier Science Publishing, Inc., New York.

Ross, W., J. Westsik, Jr., F. Roberts, C. Harvey. 1983. "Comparison of the Leachability of Three TRU Cement Waste Forms." Scientific Basis for Nuclear Waste Management VI. Ed. D. G. Brookins. Elsevier Science Publishing Co., Inc., New York.

Roy, D. M., B. E. Scheetz, L. D. Wakeley, and S. D. Atkinson. 1980. "Low Temperature Ceramic Waste Form: Characterization of Manazite Cement Compositions." Scientific Basis for Nuclear Waste Management. Vol. 2. Ed. C. J. M. Northrup Jr. Plenum Press, New York.

Rudolph, G., P. Vejmelka, and R. Koster. 1981. "Leach and Corrosion Test Under Normal and Accident Conditions on Cement Products from Simulated Intermediate Level Evaporator Concentrates." Scientific Basis for Nuclear Waste Management, Vol. 3. Ed. J. G. Moore. Plenum Press, New York.

Serne, R. J. 1990. "Grouted Waste Leach Tests: Pursuits of Mechanisms and Data for Long-Term Performance Assessment." Scientific Basis for Nuclear Waste Management XIII. Eds. V. M. Oversby and P. W. Brown. Materials Research Society, Pittsburgh, Pennsylvania.

Serne, R. J., L. L. Ames, P. F. C. Martin, V. L. LeGore, C. W. Lindenmeier, and S. J. Phillips. 1980. Leach Testing of In Situ Stabilization Grouts Containing Additives to Sequester Contaminants. PNL-8492, Pacific Northwest Laboratory, Richland, Washington.

Stone, J. A. 1979. "Studies of Concrete as Host for Savannah River Plant Radioactive Waste. "Scientific Basis for Nuclear Waste Management 1 . Ed. G. J. McCarthy. Plenum Press, New York.

Tallent, O. K., E. W. McDaniel, G. D. DelCul, K. E. Dodson, and D. R. Trotter. 1987. "Immobilization of Technetium and Nitrate in Cement-Based Materials." Scientific Basis for Nuclear Waste Management XI. Eds. M. J. Apted and R. E. Westerman. Materials Research Society, Pittsburgh, Pennsylvania.

White, E. L., B. E. Scheetz, D. M. Roy, K. G. Zimmerman, and M. W. Grutzeck. 1979. "Permeability Measurements on Cementitious Materials for Nuclear Waste Isolation." Scientific Basis for Nuclear Waste Management I. Ed. G. J. McCarthy. Plenum Press, New York. 
Wilding, C. R., D. C. Phillips, and C. E. Lyon. 1989. "The Effects of Radiation on Intermediate Level Waste Forms." Scientific Basis for Nuclear Waste Management XII. Eds. W. Lutze and R. C. Ewing. Materials Research Society, Pittsburgh, Pennsylvania. 


$$
\text { A. } 74
$$




\section{Description of Technologies}

Accept: _ Reject: $\underline{X}$

\section{Technology - Sugar Denitration}

\section{Waste Processed}

Sugar denitration can be used to process nitrate solutions only. This process is a pretreatment to thermal treatment or other processes.

\section{Process Description}

The following information was obtained from Bray (1963), Johnson and Arnold (1986), and Bray and Martin (1962).

Sugar denitration is a simple process. Sugar is added to the nitrate solutions in "large batch equipment" such as the PUREX tanks. The solution is then heated to a minimum of $85^{\circ} \mathrm{C}$. The references do not say how the solutions were heated. The reaction is less vigorous and exothermic than the formaldehyde reaction that had previously been used for PUREX denitration. The off-gas system consists of a down-draft condenser. Measurements taken during a process run indicated that $49 \%$ of the nitrates was destroyed in 10 minutes at $100^{\circ} \mathrm{C}$. Eighty percent was destroyed in 2.5 hours.

Staff members at PUREX were worried about residual carbon, which is not a concern if the process is followed by a thermal treatment. Nineteen moles of $\mathrm{HNO}_{3}$ were destroyed per mole of sugar. PFP nitrates could be denitrated with additional sucrose to guarantee nitrate destruction.

\section{Facilities and Equipment}

This process was performed in a tank at PUREX. It could be carried out in a standard furnace (e.g., the interim action furnaces) that could then be used directly for thermal treatment/calcination.

\section{Schedule}

This is a very simple process; it was used at PUREX. Therefore, it is likely the construction and testing required could probably be completed in a 2-year period.

\section{Final Product Description}

This process produces an interim product that would require additional processing. The product would be an aqueous solution with residual nitrates, contaminants, and, potentially, sugar. 


\section{Effluents Generated}

The only effluents are oxides of carbons and nitrates (gases). The nitrate could be collected as $\mathrm{HNO}_{3}$ using down-draft condensers.

\section{Risks}

The reactions rate could cause foaming in the container. The written references describe the reaction as easily controlled.

\section{Costs}

Costs would be minimal - the process could be performed (albeit slowly) in the furnaces available at PFP.

\section{Comments}

This process has been demonstrated for waste solutions, but undeveloped for improving oxidation process. The criteria evaluations are summarized in Table A.8.

\section{Justification for Further Study or Rejection}

The process is simple to use and appears to be safer than some other (formaldehyde) methods of denitration. Testing would be required as one source states only $8 \%$ denitration was accomplished using sucrose. However, the other references state that approximately $19 \underline{\mathrm{M}}$ of $\mathrm{HNO}_{3}$ were destroyed for each mole of sugar. The need for denitration before stabilization has not been demonstrated.

\section{References}

Bray, L. A. 1963. Denitration of PUREX Wastes with Sugar. HW-76973, Hanford Works Operation, Richland, Washington.

Bray, L. A., and E. C. Martin. 1962. Invention Report, Use of Sugar to Neutralize Nitric Acid Waste Liquors. HW-75565, Hanford Works Operation, Richland, Washington.

Johnson, A. J., and P. M. Arnold. 1986. Waste Generation Reduction - Nitrates Comprehensive Report of Denitration Technologies. RFP-3899, Rocky Flats Plant, Golden, Colorado. 
Table A.8. Criteria Evaluations for Sugar Denitration

\begin{tabular}{|c|c|}
\hline$\overline{\text { Criteria }}$ & Evaluation \\
\hline Technical Feasibility (technology maturity) & Feasible within 2 years \\
\hline $\begin{array}{l}\text { Effluents/By-Products } \\
\text { (minimize volumes, hazards) }\end{array}$ & Off gas only $-\mathrm{CO}_{2}$ and $\mathrm{NO}_{2 \mathrm{x}}$ \\
\hline Effluents Covered/SAR & Unknown \\
\hline Energy Resource & Minimal \\
\hline Weapon Potential & About same as original nitrate solution \\
\hline End Product Volume & A little less than the original nitrate solution \\
\hline End Product Stability & $\begin{array}{l}\text { A little better than original nitrate solution - some } \\
\text { nitrates may still be present }\end{array}$ \\
\hline $\begin{array}{l}\text { Environmental and Public Risk } \\
\text { routine } \\
\text { accident }\end{array}$ & Should be less than original solution \\
\hline $\begin{array}{l}\text { Worker Risk } \\
\text { routine } \\
\text { accident }\end{array}$ & Should be minimal \\
\hline $\begin{array}{l}\text { Cost } \\
\text { (construction, operations and D\&D) }\end{array}$ & Minimal, basically the cost of sugar \\
\hline Operating Duration & 2.5 hours to destroy $80 \%$ of the nitrates \\
\hline $\begin{array}{l}\text { Public Acceptance } \\
\text { Flexibility } \\
\text { Materials Covered }\end{array}$ & $\begin{array}{l}\text { Should be high } \\
\text { Very good } \\
\text { Nitrates only }\end{array}$ \\
\hline
\end{tabular}




\section{Description of Technologies}

Accept: X Reject:

\section{Technology - Freeze Crystallization}

\section{Waste Processed}

The freeze crystallization technology can be used to process nitrate solutions, chloride solutions, organic solutions, and other aqueous solutions.

\section{Process Description}

Freeze crystallization uses the process of forming ice from an aqueous solution so that the contaminants remain in solution while the ice is pure water. The ice can then be separated, remelted, and discharged as clean water. The contaminants have been concentrated in the remaining solution. Waste reductions of $90 \%$ have been achieved using freeze crystallization.

The freeze crystallization process is a low-temperature, low-pressure process "...that is intrinsically safe" (Backus et al. 1993).

Freeze crystallization is used to remove dissolved solids from low-viscosity aqueous liquids, slurries, and sludges. The process consists of heat exchanging, freezing, washing, melting, and refrigerant or energy recovering.

This technique can be used on liquid wastes containing potentially hazardous materials typically in the range of $1 \%$ to $10 \%$ total dissolved solids. Removal efficiencies of $99.9 \%$ have been achieved on aqueous waste with as little as $30 \mathrm{ppm}$ total dissolved solids.

There are two basic forms of freeze crystallization used by industry: vacuum flash/vapor compression and secondary refrigerant freezing. Vacuum flash/vapor compression evaporates some of the water as the ice is forming. The vapor is condensed and combined with the ice after the ice is freed from the contaminated liquor. The ice-liquor slurry is produced by direct contact using secondary refrigerant freezing. The waste heat from the refrigerant loop is used to remelt the water.

"At eutectic compositions, liquid mixtures behave as a single homogeneous entity and do not fractionate or separate into different components with a change in temperature. Therefore, freeze crystallization is not a viable technology to separate components from a mixture with a eutectic composition" (PNL 1993).

"Typical influent (dissolved) organic concentrations rage from $3 \%$ to $7 \%$ by weight. Dissolved inorganic and heavy metal concentrations may range from 1,000 to $10,000 \mathrm{mg} / \mathrm{L}$ by weight. All 
impurities are reduced in concentration in the melted ice effluent stream by a factor of 10,000 . About $90 \%$ recovery of the water can be achieved with multiple stages" (PNL 1993).

"Residence time in the crystallizer is between 60 and 80 hours" (PNL 1993).

"Electric consumption is estimated to be over $350 \mathrm{kWh} / 3800 \mathrm{~L}$ of melted water recovered" (PNL 1993).

\section{Facilities and Equipment}

Basic components include an ice crystallizer, refrigeration system, ice separator, and, possibly cooling towers.

\section{Schedule}

"Development work is needed to optimize salt wash columns to improve operational flexibility, decontamination efficiency, and inorganic salt purification" (PNL 1993).

It is not known whether the process could be constructed and tested within 2 years.

\section{Final Product Description}

The final product is an intermediary product. It is a concentrated solution containing the contaminants. This process could be used as a pretreatment process to some other process (e.g., thermal treatment).

\section{Effluents Generated}

The effluent generated is relatively clean water. The water should technically be clean, but testing done to date has had less than expected decontamination efficiencies.

\section{Risks}

The risks should be low associated with freeze crystallization, because the process runs at reduced temperature and pressure.

\section{Costs}

The costs are unknown, but the conference reference made a qualitative comparison of costs between membrane systems, evaporators, and freeze crystallization. 
"Freeze crystallization is more economical when treating concentrated waste streams, because the process is not sensitive to concentration changes and operates efficiently at low-and high-contaminant concentrations. The process is more efficient than evaporation processes because the heat of fusion of water is only $15 \%$ of the heat of vaporization" (PNL 1993).

"Capital costs are typically higher than for membrane systems but are on the same order of cost as an evaporation/crystallization system. Energy costs for freeze crystallization are estimated to be higher than for membrane systems but significantly lower than for comparable evaporation/crystallization systems" (PNL 1993).

"Electricity consumption is estimated to be over $350 \mathrm{kWh} / 3800 \mathrm{~L}$ of melted water recovered" (PNL 1993).

"Freeze crystallization techniques have been effectively used for concentrating food juices, but current use in wastewater treatment is limited, perhaps because of the high operating costs" (PNL 1993).

\section{Comments}

The criteria evaluations are summarized in Table A.9. The public should like this process because it is an inherently safe way to concentrate waste as part of an overall process. However, the technology has not been used on solutions with high concentrations of plutonium.

\section{Justification for Further Study or Rejection}

The process is less expensive in terms of capital and operating costs than evaporation and is inherently safer than evaporation because it operates at low temperatures and pressures. However, the technology has only been used on waste solutions, not on solutions with relatively high concentrations of plutonium.

\section{References}

Backus, P. M., J. B. Berry, G. J. Coyle, P. W. Lurk, and S. M. Wolf. 1993. "Development of Treatment Technologies for the Processing of U.S. Department of Energy Mixed Waste." In Proceedings of the AICHE Spring 1993 Meeting, March 28 - April 1, 1993. CONF-930364--1, National Technical Information Service, Springfield, Virginia.

Pacific Northwest Laboratory (PNL). 1993. Remedial Action Assessment System (RAAS). PNL-8751, Pacific Northwest Laboratory, Richland, Washington. 
Table A.9. Criteria Evaluations for Freeze Crystallization

\begin{tabular}{|c|c|}
\hline Criteria & Evaluation \\
\hline Technical Feasibility (technology maturity) & Unknown \\
\hline $\begin{array}{l}\text { Effluents/By-Products } \\
\text { (minimize volumes, hazards) }\end{array}$ & Effluent is "clean" water \\
\hline Effluents Covered/SAR & Yes \\
\hline Energy Resource & $15 \%$ of that of evaporation \\
\hline Weapon Potential & NA - pretreatment stage \\
\hline End Product Volume & Reduced from original volume \\
\hline End Product Stability & $\begin{array}{l}\text { May be worse than original waste as contaminants } \\
\text { are now concentrated }\end{array}$ \\
\hline $\begin{array}{l}\text { Environmental and Public Risk } \\
\text { routine } \\
\text { accident }\end{array}$ & Less than evaporation \\
\hline $\begin{array}{l}\text { Worker Risk } \\
\text { routine } \\
\text { accident }\end{array}$ & Unknown \\
\hline $\begin{array}{l}\text { Cost } \\
\text { (construction, operations and D\&D) }\end{array}$ & See note below \\
\hline Operating Duration & Unknown \\
\hline Public Acceptance & Should be high \\
\hline Flexibility & High \\
\hline Materials Covered & All solutions except "oils and organics" \\
\hline
\end{tabular}




\section{Description of Technologies}

Accept: _ Reject: $\underline{\mathrm{X}}$

\section{Technology - Phase Separation (By Adduct Formation)}

\section{Waste Processed}

Previous work has been conducted on TBP mixed into diluent, as a pretreatment. Applicable PFP waste consists of organic solutions.

\section{Process Description}

Concentrated phosphoric acid is mixed with TBP/diluent solutions at room temperature in conventional solvent extraction equipment, such as mixer-settlers or pulsed equipment. The TBP forms a TBP-acid polar adduct with almost all the radioactivity. The adduct can be split for recovery (of phosphoric acid) or pyrolyzed.

\section{Facilities and Equipment}

Conventional solvent extraction equipment (mixer settlers or pulsed equipment) is necessary for this process. Theoretically, PFP extraction equipment would work.

\section{Schedule}

Experience with this process and with miscellaneous waste processing is limited (IAEA 1992). Only TBP and diluent have been addressed. Therefore, this technology would probably take more than 2 years to become operational.

\section{Final Product Description}

This technology produces an intermediary stage product. The product is a TBP-acid polar adduct that contains the contamination.

\section{Justification for Further Study or Rejection}

The criteria evaluations for the phase separation technology are summarized in Table A.10. This technology would take more than 2 years to become operational. Experience exists only with a TBP/ diluent. Therefore, this technology was rejected. 
Table A.10. Criteria Evaluations for Phase Separation

\begin{tabular}{|c|c|}
\hline Criteria & Evaluation \\
\hline Technical Feasibility (technology maturity) & Limited experience, probably take years to develop \\
\hline $\begin{array}{l}\text { Effluents/By-Products } \\
\text { (minimize volumes, hazards) }\end{array}$ & Phosphoric acid, bicarbonate, or hydroxide \\
\hline Effluents Covered/SAR & Unknown \\
\hline Energy Resource & Minimal \\
\hline Weapon Potential & Unknown \\
\hline End Product Volume & $\begin{array}{l}\text { Combination of TBP and actinides unless pyrolyzed - } \\
\text { not minimal }\end{array}$ \\
\hline End Product Stability & Still has TBP \\
\hline $\begin{array}{l}\text { Environmental and Public Risk } \\
\text { routine } \\
\text { accident }\end{array}$ & Unknown \\
\hline $\begin{array}{l}\text { Worker Risk } \\
\text { routine } \\
\text { accident }\end{array}$ & Unknown \\
\hline $\begin{array}{l}\text { Cost } \\
\text { (construction, operations and D\&D) }\end{array}$ & $\begin{array}{l}\text { Assuming PFP equipment could be used, minimal } \\
\text { costs }\end{array}$ \\
\hline Operating Duration & Unknown \\
\hline Public Acceptance & Unknown \\
\hline Flexibility & Probably good \\
\hline Materials Covered & TBP-diluent solutions only \\
\hline
\end{tabular}




\section{References}

International Atomic Energy Agency (IAEA). 1992. Treatment and Conditioning of Radioactive Organic Liquids. IAEA-TECDOC-656, International Atomic Energy Agency, Vienna. 


\section{Description of Technologies}

Accept: _ Reject: $\underline{X}$

\section{Technology - Absorption}

\section{Waste Processed}

The absorption technology can be used to process organic solutions.

\section{Process Description}

Absorbents are used to convert organics from a liquid to a solid form. "The suitability of absorption alone for the solidification of organic liquid wastes is only moderate" (IAEA 1989, 1992). The process is adversely affected by the presence of water or other ionic contaminants. Waste viscosity also affects the quantity of liquid absorbed. "Finally, the waste form is readily dispersible in air or water if the product container is breached" (IAEA 1989, 1992).

\section{Final Product Description}

The final product varies from loose dry particles to jelly-like solid and has no compressive strength. The product can be dispersed readily in air or water if the product container is breached.

\section{Justification for Further Study or Rejection}

Organics are not destroyed. Absorption only turns organics waste into a solid. However, the suitability for solidification is only moderate, and the waste form is readily dispersible in air or water.

\section{References}

International Atomic Energy Agency (IAEA). 1989. Options for the Treatment and Solidification of Organic Radioactive Wastes. IAEA Technical Report Series No. L94, International Atomic Energy Agency, Vienna.

International Atomic Energy Agency (IAEA). 1992. Treatment and Conditioning of Radioactive Organic Liquids. IAEA-TECDOC-656, International Atomic Energy Agency, Vienna. 


\section{Description of Technologies}

Accept: $\underline{\mathrm{X}}$ Reject: _

\section{Technology - Screening}

\section{Waste Processed}

Materials requiring size separation can be processed using the screening technology.

\section{Processed Description}

Screening is the separation of a mixture of various sizes of grains into two or more portions by means of a screening surface. The screening surface acts as a multiple go and no-go gage, and the final portions consist of grains of more uniform size than those of the original mixture. The material that remains on a given screening surface is the oversize material, and the material passing through the screening surface is the intermediate material. The screen surface may consist of woven wire, silk, or plastic cloth; perforated or punched plate; grizzly bars; or wedge weir sections.

Screening machines may be divided into five main classes: grizzlies, revolving screens, shaking screens, vibrating screens, and oscillating screens. Grizzlies are used primarily for scalping at $5 \mathrm{~cm}$ or coarser, while revolving screens and shaking screens are generally used for separations above $1.3 \mathrm{~cm}$. Vibrating screens cover this range and also down into the fine meshes. Oscillating screens are confined, in general, to finer meshes below four mesh.

Screening is a volume reduction technology that concentrates contamination into a smaller volume. The concentration usually makes subsequent treatment more efficient and economical.

The concept of reducing the particle size is based on the findings that most organic and inorganic contaminants tend to bind, either physically or chemically, to smaller particle sizes. Separating the small particles from the larger particles can effectively separate and concentrate the contaminants into a smaller volume that can be further treated.

\section{Facilities and Equipment}

The primary screening equipment required could be an off-the-shelf device sold commercially. Screening devices come in many sizes. It is likely that one could be found that could be installed into the PFP facility that requires little facility modification to the facility. 


\section{Schedule}

This process is a simple one that uses off-the-shelf equipment. It is unlikely that additional testing would be required.

\section{Final Product Description}

The plutonium product generated by this process would consist of a finer or coarser grain material than the feed stocks.

\section{Costs}

The costs would be minimal - the equipment purchase would be small since this process is an off-theshelf process.

\section{Justification for Further Study or Rejection}

Screening should be given further consideration. It appears to be a process that could reduce the volume of contaminated material prior to further processing and segregate plutonium oxide fines for recycle or packaging. In addition, it is relatively inexpensive and a proven technology. However, it is not known which specific items or streams could be processed by screening.

\section{Bibliography}

Perry, R. H., and C. H. Chilton. 1973. Chemical Engineer's Handbook. 5th ed. McGraw-Hill, New York, New York.

Gregory, R. A., Technical Contact. 1992. ENVEST Environmental Cost Engineering Report Model. U.S. Air Force Environmental Restoration Program, Tyndall Air Force Base. 


\section{Description of Technologies}

Accept: — Reject: $\underline{X}$

\section{Technology - Wet Oxidation}

\section{Waste Processed}

The wet oxidation technology processes organic solutions.

\section{Process Description}

Wet oxidation is a technique for breaking down organics to carbon dioxide and water. Organic waste is leached with hydrogen peroxide in the presence of a catalyst at $100^{\circ} \mathrm{C}$ with excess water distilled or evaporated to leave a concentrated inorganic waste that contains the radioactivity. The process has been used in Japan on LLW.

"The benefits and/or disadvantages of this process versus incineration do not appear to have been established" (IAEA 1989).

"The process is efficient and can be operated as a closed, contained system." ${ }^{\text {(a) }}$

DETOX uses homogeneous metal catalysts in an acidic water solution. The DETOX process is highly tolerant of waste compositions, waste forms, water contents, and particle sizes.

\section{Facilities and Equipment}

This process involves careful control of chemical reactions at high temperatures and pressures; it requires sophisticated control systems and effluent treatment. The equipment needs include an oxidation vessel, condensers, and a filtration system. However, no off-gas system is needed (DETOX).

\section{Schedule}

"The wet oxidation technique is still very much in the experimental stage and is being studied by few researchers" (IAEA 1989).

(a) Dodge, P. M. DETOX Wet Oxidation Waste Treatment Process. PNL flyer. 


\section{Final Product Description}

The final product would be an aqueous waste that is easy to treat and chemically inert $(99.9999+\%$ oxidized).

\section{Costs}

Since DETOX uses no fuel, it costs less than incineration to operate. A 100-L reactor vessel can oxidize 5 to $23 \mathrm{~kg} / \mathrm{h}$ of hazardous material at capital cost of $\$ 100$ to $\$ 200 \mathrm{~K}$ and an operating cost of $\$ 1600 /$ metric ton of organic material.

\section{Justification for Further Study or Rejection}

This process is rejected for further study. A summary of its advantages and disadvantages is provided below.

Advantages

Most organic materials are destroyed.

The waste is chemically inert.

Waste oxidation is a low temperature operation.

A combined use for other wastes is provided.

There has been some plant-scale experience worldwide.

This process is much simpler than incineration.
Reactive chemical storage is required.

The residue requires immobilization.

Wet oxidation is in the experimental stage.

\section{Disadvantages}


Table A.11. Criteria Evaluations for Wet Oxidation

\begin{tabular}{|c|c|}
\hline Criteria & Evaluation \\
\hline Technical Feasibility (technology maturity) & $\begin{array}{l}\text { In experimental stage, development time }>2 \text { years } \\
\text { likely }\end{array}$ \\
\hline $\begin{array}{l}\text { Effluents/By-Products } \\
\text { (minimize volumes, hazards) }\end{array}$ & $\begin{array}{l}\text { No discharge - there would be aqueous waste at the } \\
\text { end }\end{array}$ \\
\hline Effluents Covered/SAR & Inert waste \\
\hline Energy Resource & Unknown \\
\hline Weapon Potential & Unknown \\
\hline End Product Volume & Minimal \\
\hline End Product Stability & Very stable \\
\hline $\begin{array}{l}\text { Environmental and Public Risk } \\
\text { routine } \\
\text { accident }\end{array}$ & Unknown \\
\hline $\begin{array}{l}\text { Worker Risk } \\
\text { routine } \\
\text { accident }\end{array}$ & Unknown \\
\hline $\begin{array}{l}\text { Cost } \\
\text { (construction, operations and D\&D) }\end{array}$ & $\begin{array}{l}5 \text { to } 23 \mathrm{~kg} / \mathrm{h} \text { - construction of } \$ 100 \text { to } 200 \mathrm{~K} \text {, } \\
\text { operations - } \$ 1600 / \text { metric ton }\end{array}$ \\
\hline Operating Duration & Unknown \\
\hline Public Acceptance & $\begin{array}{l}\text { Probably better than for thermal treatment } \\
\text { Highly tolerant }\end{array}$ \\
\hline Flexibility & Unknown \\
\hline Materials Covered & Organics \\
\hline
\end{tabular}




\section{References}

Dodge, P. M. DETOX Wet Oxidation Waste Treatment Process. PNL flyer, Pacific Northwest Laboratory, Richland, Washington.

International Atomic Energy Agency (IAEA). 1989. Options for the Treatment and Solidification of Organic Radioactive Wastes. IAEA Technical Report Series No. 294, International Atomic Energy Agency, Vienna.

\section{Bibliography}

International Atomic Energy Agency (IAEA). 1992. Treatment and Conditioning of Radioactive Organic Liquids. IAEA-TECDOC-656, International Atomic Energy Agency, Vienna. 


\section{Description of Technologies}

Accept: _ Reject: $\underline{X}$

\section{Technology - Direct Discard to Waste Isolation Pilot Plant}

\section{Applicable Waste Processed}

Most PFP waste would not qualify for shipment to Waste Isolation Pilot Plant (WIPP) or the

Transuranic Storage and Assay Facility (TRUSAF) facility onsite without some type of pretreatment.

WIPP Waste Form Requirements (Westinghouse 1989a, 1989b)

Criterion: Immobilization

Powders, ashes, and similar particulate waste material shall be immobilized if more than 1 wt $\%$ of the waste matrix in each package is in the form of particles below 10 microns in diameter, or if more than $15 \mathrm{wt} \%$ is in the form of particles below 200 microns in diameter.

Criterion: Liquid Wastes

TRU waste cannot be in a free-liquid form. Minor liquid residues remaining in well-drained bottles, cans, and other containers are acceptable.

Criterion: Pyrophoric Materials

Pyrophoric materials, other than radionuclides, shall be rendered safe by mixing with chemically stable materials (e.g., concrete, glass) or processed to remove their hazardous properties. No more than $1 \mathrm{wt} \%$ of the waste in each package may be pyrophoric forms of radionuclides, and these shall be generally dispersed in the waste.

Criterion: Explosives and Compressed Gases

Contact-handled TRU waste shall contain neither explosives nor compressed gases as defined by 49 CFR 173, Subparts C and G.

Criterion: Radioactive Mixed Waste

TRU waste shall contain no hazardous wastes unless they exist as co-contaminants with TRUs. Waste packages containing hazardous materials shall be identified with the appropriate U.S. Department of Transportation label. TRU-contaminated corrosive materials shall be neutralized, rendered noncorrosive, or packaged in a manner to ensure container adequacy through the design lifetime. 
Criterion: Specific Activity of Waste

For purposes of TRU waste certification, the $100 \mathrm{nCi} / \mathrm{g}$ TRU waste limit shall be interpreted as $100 \mathrm{nCi} / \mathrm{g}$ of waste matrix. The weight of added external shielding and the containers (including any rigid liners) should be subtracted before performing the $\mathrm{nCi} / \mathrm{g}$ calculation.

\section{Criterion: Nuclear Criticality}

Contact-Handled (CH) Waste

The fissile or fissionable radionuclide content for CH TRU waste containers shall be no greater than the following values, in plutonium-239 fissile gram equivalents:

$200 \mathrm{~g} / 55$-gal $\left(0.21 \mathrm{~m}^{3}\right)$ drum

$100 \mathrm{~g} / 30$-gal $\left(0.11 \mathrm{~m}^{3}\right)$ drum

$178 \mathrm{~g} / \mathrm{m}^{3}\left(5 \mathrm{~g} / \mathrm{ft}^{3}\right)$ in boxes, up to a $350 \mathrm{~g}$ maximum.

For materials other than plutonium-239, uranium-235, and uranium-233 that shall be treated as equivalent, fissile equivalents shall be obtained using ANSI/ANS-8.15-1981 (R1987).

\section{Justification for Further Study or Rejection}

Direct discard to WIPP is rejected as a process. The advantages and disadvantages of this alternative are provided below.

\section{Advantages}

This process provides a simple alternative.

\section{Disadvantages}

Without pretreatment, most of the PFP waste would not meet the acceptance requirements for shipment to WIPP or an interim storage facility.

Critically limits mean there would be a very large volume of waste. 


\section{References}

American National Standards Institute/American Nuclear Society (ANSI/ANS). 1981 (R1987).

Nuclear Criticality Control of Special Actinide Elements. American National Standards Institute, New York.

Westinghouse Electric Corporation. 1989a. TRU Waste Certification Compliance Requirements For Acceptance of Contact-Handled Wastes Retrieved from Storage to be Shipped to the Waste Isolation Pilot Plant. WIPP/DOE-II, Westinghouse Electric Corporation, Waste Isolation Pilot Plant, Carlsbad, New Mexico.

Westinghouse Electric Corporation. 1989b. TRU Waste Acceptance Criteria for the Waste Isolation Pilot Plant. WIPP-DOE-069, Rev.3, Westinghouse Electric Corporation, Waste Isolation Pilot Plant, Carlsbad, New Mexico. 



\section{Description of Technologies}

Accept: _ Reject: $\underline{X}$

\section{Technology - Ozone Treatment}

\section{Applicable Wastes Processed}

The ozone treatment process can be applied to aqueous solutions containing organic materials and oils.

\section{Process Description}

Ozone treatment removes organic contaminants from aqueous solutions. In the ozone treatment reactor, the organic compounds are oxidized to various intermediate- and end-products and/or volatilized during mixing or ozonation. The overall organic removal process, therefore, depends on the rate of volatilization as well as the chemical oxidation kinetics.

Ozone oxidation of dissolved organics occurs through direct oxidation of the organic, or indirectly through conversion of ozone into ozonide ion $\left(\mathrm{O}_{3}\right)$ and subsequent hydroxyl radicals $(\mathrm{OH})$ which, in turn, attack the organics directly. As hydroxyl radicals are strong oxidants it is expected that simple ozonation by direct ozone-organic reactions will produce reactant degradation, but not complete oxidation to carbon dioxide. Alternately, the use of either ultraviolet light or hydrogen peroxide will enhance the conversion of ozone along hydroxyl radical routes and lead to chemical oxidation. Hence, ozone in combination with ultraviolet light or hydrogen peroxide results in continued attack of partial oxidation products and of a greater range of organic compounds.

Ozone treatment can occur at room or elevated temperatures. Heating the solution during ozonation can significantly reduce the reaction time (Hancher et al. 1990).

\section{Facilities and Equipment Required}

Ozone treatment has been demonstrated to safely remove organic contaminants from cooling water (Stopka 1989) and recycled nitric acid (Hancher et al. 1990). The equipment for an ozone system is shown in Figure A.7. An ozone system consists of 1) air preparation package to deliver the required quantity of dry air at $-50^{\circ}$ to $-60^{\circ} \mathrm{F}$ dew point, 2) ozone generator, and 3) in-line contactor complete with ozone resistant check valve. A bubble-type, gas-liquid contractor is normally used, as it exhibits significant removals by both oxidation and volatilization mechanisms (Musterman 1991).

The PFP does not have the equipment necessary for an ozone treatment system. However, the PFP does have the necessary utilities, operating materials, supplies, and manpower to operate an ozone treatment process. The PFP's floor space must be modified to accommodate the ozone treatment process. Roughly $230 \mathrm{~m}^{2}$ of floor space and roughly $6 \mathrm{~m}^{3}$ of glovebox space are needed. 


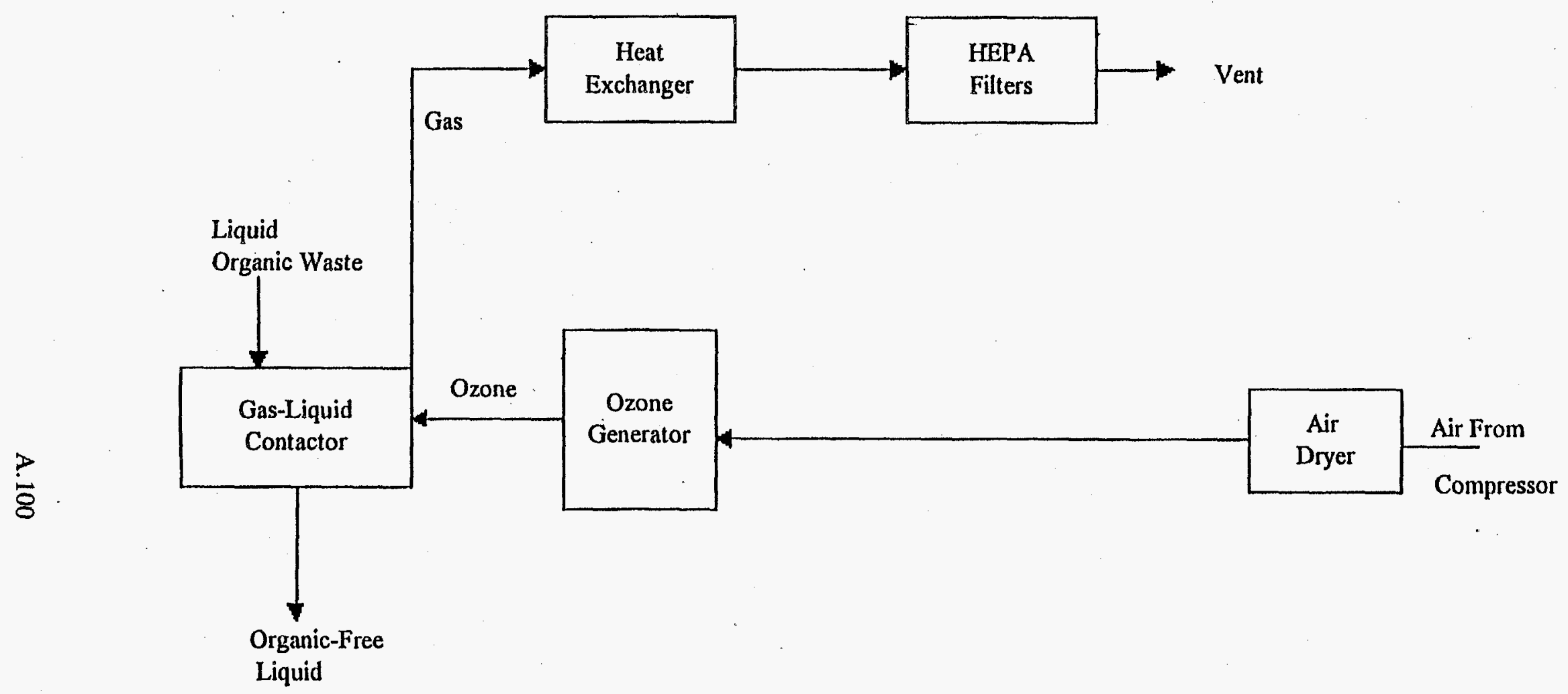

Figure A.7. Ozone Treatment Flowsheet 


\section{Schedule}

Process development time would be needed for the ozone treatment process because it has not been tested with actinide solutions. However, the process has been tested on carbon tetrachloride solutions and shown to be effective (Ollis 1991). Time also would be needed for scale-up design work on an ozone treatment process applicable to the PFP wastes. The process equipment must undergo a thorough checkout with operating conditions established. Finally, operating procedures, safety analyses, SAR revisions, and operator training must be developed and completed.

It is unknown how long it would take ozone treatment to process the PFP waste materials, as no operating parameters have been established.

\section{End Product Description}

The end product from an ozone treatment process would be an organic-free solution. This solution would require further processing for final stabilization.

\section{Effluents and By-Products}

The gaseous effluent stream from ozone treatment consists of carbon dioxide, air, and water. This stream is cooled and passed through HEPA-filters before being vented to the existing PFP ventilation system.

\section{Risks}

The risks are unknown for an ozone treatment process handling actinide solutions because no experience exists with these materials. The risks associated with ozone are well documented and can be minimized with properly designed equipment and operating parameters.

\section{Costs}

New equipment costs would be expected, and the ozone cost would be high (Musterman 1991). Ozone in combination with ultraviolet light or hydrogen peroxide would require half the capital of an ozone system (Musterman 1991). In addition, costs would be incurred to modify the PFP for adequate space and to install and check out equipment. Furthermore, administrative costs would be incurred for preparing and approving documents (e.g., operating procedures, safety analyses, SAR revisions, maintenance records, training records). Waste disposal costs are unknown because of the unknown material balances and process flow conditions. 


\section{Comments}

The ozone treatment process has not been demonstrated on actinide solutions. Material balances and, hence, the volumes and compositions of products and effluents are unknown. Development work will be required to determine which PFP wastes can be processed.

Carbon tetrachloride results (Musterman 1991) show that organic removal was primarily accomplished by the volatilization mechanism since the ozone oxidation rate was too slow to exert a significant removal effect. Increasing the reactor ozone concentration and hydraulic retention time did not significantly improve the removal efficiency. Enhanced removal must be achieved by either the addition of a catalyst or by off-gas capture and recycle.

Ozone in combination with ultraviolet light or hydrogen peroxide is $\mathrm{pH}$ sensitive and requires better mixing in the contractor (Ollis 1991). It also requires destruction of any ozone in the gas phase exhaust via the use of a catalyst. In addition, with ultraviolet light, ozone mass transfer limits are encountered.

\section{Justification}

The ozone treatment process is not recommended for further study. Other competing processes, such as hydrolysis, are developed and proven to handle actinide-organic solutions. Other reasons for rejecting this process are described above.

\section{References}

Hancher, C. W., M. E. Johnson, and G. E. Harris. 1990. Ozone Treatment of Recycled Nitric Acid. Oak Ridge Y-12 Development Division, Oak Ridge, Tennessee.

Musterman, J. 1991. "Ozonation of Volatile and Semi-Volatile Compounds for Groundwater Remediation." In Chemical Oxidation--Technologies for the Nineties: Proceedings of the First International Symposium. Technomic, Lancaster, Pennsylvania.

Ollis, D. F. 1991. Comparative Aspects of Advanced Oxidation Processes. Department of Chemical Engineering, North Carolina State University, Raleigh, North Carolina.

Stopka, K. 1989. "Close the Loop - Apply Ozone in Cooling Water Treatment." Water Conditioning \& Purification 31(4):38. 


\section{Description of Technologies}

Accept: $\underline{X}$ Reject:

\section{Technology - Solvent Extraction}

\section{Waste Processed}

The solvent extraction process can be used on nitrate solutions (F00, F01, F40, F50, F70, F80).

\section{Process Description}

Solvent extraction processes have been extensively used in both the U.S. and foreign nuclear industry. Typical applications include purifying aqueous uranium feedstocks in uranium refineries, recovering uranium and plutonium from metallurgical scrap, reprocessing all kinds of irradiated nuclear reactor fuels (the PUREX process), and separating TRU elements from aqueous nitric acid solutions (the Trans Uranic Extraction (TRUEX) process). Of the potential solvent extraction systems, the TRUEX process is the most thoroughly investigated for the pretreatment of tank wastes.

Overall, the operation of the basic TRUEX flowsheet is as follows. The TRU waste is fed into the contactor bank, where the TRU elements are extracted by the TRUEX solvent. The aqueous waste raffinate containing the bulk waste exits as a nonTRU waste. The loaded solvent is scrubbed to effect a cleaner separation; the solvent is then stripped with dilute acid to recover the TRU elements that are +3 cations (e.g., americium, cesium, as well as the rare-earth fission products and technetium). In a second strip, the plutonium is recovered by adding a small amount of complexant or reductant in the aqueous feed to this strip (e.g., HF of hydroxylammonium nitrate). Any uranium in the feed would be removed from the solvent in the solvent cleanup step.

\section{Facilities and Equipment}

This proven technology, which has evolved considerably over the last 45 years, initially used packed columns, which were soon replaced by pulsed columns because of their greater efficiency. This greater efficiency allowed shorter columns, which reduced the required facility height. Pulsed columns are still in use today; however, because of facility cost benefits, mixer-settler units have also been developed. Later, centrifugal mixer settlers (mixers with centrifugal settling zones, commonly called "centrifugal contactors") were developed at Savannah River Laboratory (SRL). The centrifugal contactor has the advantage of compact size coupled with high throughput and extraction efficiency. The SRL contactor has been in use at the SRL Plant since 1967. An impressive advantage of the centrifugal contactor, compared with other solvent extraction equipment, is its ability to operate at very high and 
very low organic-to-aqueous (O/A) flow ratios. If the normally high extraction efficiency of the centrifugal contactor is still high at these extreme O/A flow ratios, then the contactor can be used to concentrate (by factors of 10 to 1000 or more) those metal ions that have a high distribution ratio (D value) during extraction and/or a low D value during stripping (Leonard 1987).

Thus, solvent extraction could use columns, pulsed columns, mixer settlers or centrifugal contactors. The existing PFP does have pulsed columns, which could be used for this process if their size and condition warranted. If these pieces of equipment are unsatisfactory, a centrifugal contactor may be preferred for the reasons mentioned above. The compact contactor stages give low liquid holdup, fast startup and shutdown, greater safety with respect to nuclear criticality by virtue of their small size and high mass transfer efficiency. The PFP does have the necessary utilities and manpower to operate a solvent extraction process.

Raw materials include nitric acid to acidify the waste. Dilute nitric acid $(<0.5 \underline{\mathrm{M}})$ and $\mathrm{HF}(<0.1 \underline{\mathrm{M}})$ are necessary for the strip and scrub influents and the solvent acid wash influent. Sodium carbonate $\sim 0.25 \underline{\mathrm{M}}$ is also used as part of the solvent clean up process. Octyl(phenyl)-N, N-diisobutylcarbamoylmethylphosphine oxide (CMPO), tributyl phosphate (TBP), and normal paraffinic hydrocarbon (NPH) are required for the solvent that is recycled.

\section{Choice of Diluent}

Due to toxicity and volatility of $\mathrm{CCl}_{4}$, studies have been conducted to find a suitable replacement. Trichloroethylene (TCG) has a higher boiling point than $\mathrm{CCl}_{4}\left(121^{\circ} \mathrm{C}\right.$ versus $77^{\circ} \mathrm{C}$ for $\left.\mathrm{CCl}_{4}\right)$ and, thus, a lower vapor pressure. It is also less toxic and less expensive than $\mathrm{CCl}_{4}$. Comparisons of americium distribution coefficients for TRUEX process solvent utilizing $\mathrm{CCl}_{4}$ and TCE diluents show that there is no significant difference in the values for $\mathrm{D}_{\mathrm{Am}}$ (Leonard et al. 1987). Thus TCE can be substituted for $\mathrm{CCl}_{4}$ as the diluent in the TRUEX process solvent without a significant change in the concentration of americium in the various flowsheet effluents. Although one cannot conclude with absolute certainty that the behavior found for americium can be extended to plutonium and all nonTRU constituents, it is very unlikely that any significant difference in metal distribution coefficients would be found between the two diluents.

No direct comparisons were found between either NPH and either TCE or $\mathrm{CCl}_{4}$. However, most recent research involves using TCE or NPH as the diluent. Chamberlain et al. (1990) state the TRUEX diluent can be either NPH such as Conoco $\mathrm{C}_{12}-\mathrm{C}_{14}$ or, when there is a concern about fire or explosion prevention, a chlorocarbon, such as TCE.

\section{Schedule}

The solvent extraction process is well established. Calculations based on the design could be started immediately and the whole process configured by the time the installation was certified. The processing rate of centrifugal contactors can be made to order. Flow rates on the order of $20 \mathrm{ml} / \mathrm{min}$ (for 2 -cm contactors) to gal/min (for 6-in. contactors) can be achieved. 


\section{Final Product Description}

The final product from the solvent extraction system is an acidic aqueous waste steam with the actinides and lanthanides. The actinides and lanthanides could be concentrated by a factor of 10 or more from the feed stream. Greater than $99 \%$ of the bulk metal components would be removed. Based on estimates from the Generic TRUEX Model (which models solvent extraction by means of centrifugal contactors), the estimated molar concentration of the product is $0.1 \underline{\mathrm{M}} \mathrm{HNO}, 0.1 \underline{\mathrm{M}} \mathrm{HF}, 0.1 \underline{\mathrm{M}}$ ascorbic acid.

This liquid could then be treated in a series of steps: 1) the liquid (nitric acid solution) is evaporated,

2) the nitrates of the waste compounds are calcined to oxides, and 3) the resulting waste oxides are treated and stored as appropriate.

\section{Effluents Generated}

The extraction feed is the waste steam undergoing treatment. The scrub and strip influents are required to extract the TRU from the loaded solvent, which is composed of $0.2 \mathrm{M}$ CMPO and 1.4 $\underline{\mathrm{M}}$ tributylphosphate (TBP) in an NPH (e.g., kerosene) diluent. The solvent is recycled. The effluent streams are the nonTRU raffinate, which contain the bulk of the $0.74 \underline{\mathrm{M}} \mathrm{HNO} 3$ and $\sim 100 \%$ of the metal salts. The americium product contains $0.14 \underline{\mathrm{M}}$ HNO3 and the majority of the americium. The plutonium product contains $0.004 \underline{\mathrm{M}} \mathrm{HNO} 3$ and the majority of the plutonium. The alkaline wash and acid rinse are required to remove solvent degradation products from hydrolysis and radiolysis. Although these streams are shown as being recycled, eventually they would require treatment and disposal.

\section{Risks}

Because solvent extraction is a well studied, well tested process, the environmental risks are low. Certain precautionary procedures must be observed in order to avoid a "red oil" explosion such as the occurrence at Tomsk-7. Most studies on the stability of red oil and related organic nitrates have assumed that the probability of fires or explosions can be significantly reduced by maintaining the temperatures below $135^{\circ} \mathrm{C}$.

Risks to workers in the form of radiation is minimized because the separation of americium from plutonium is possible.

\section{Costs}

The costs would be in the medium range. 


\section{Comments}

There is concern regarding the use of $\mathrm{CCl} 4$ as a diluent in solvent extraction. Recent TRUEX process studies have used NPH or TCE as a suitable substitute.

\section{Justification for Further Study or Rejection}

Solvent extraction merits further consideration as a process to purify plutonium waste steams from bulk metals and to separate plutonium from americium because it is a well established process with a successful track record.

\section{References}

Chamberlain, D. B., R. A. Leonard, J. C. Hoh, E. C. Gay, D. G. Kalina, and G. F. Vandegrijt. 1990. TRUEX Hot Demonstration Final Report. ANL-89/37, Argonne National Laboratory, Argonne, Illinois.

Leonard, R. A. 1987. "Recent Advances in Centrifugal Contactor Design." Separation Science and Technology 23(12, 13):1473-1487.

Leonard, R. A., G. F. Vandegrijt, E. C. Gay, D. R. Fredrickson, C. S. Sabau, D. J. Chaiko, L. Burris, E. Horwitz, R. Chiarizia, H. Diamond, R. C. Gatrone, G. A. Clark, and K. A. Martin. 1987. The TRUEX Process for Recovery of Plutonium and Americium from Nitric Acid Waste Solutions - Continuing Development Studies, FY 1986. ANL-87-3, Argonne National Laboratory, Argonne, Illinois. 


\section{Description of Technologies}

Accept: _ Reject:

\section{Technology - Plutonium Reclamation Facility}

\section{Waste Processed}

The Plutonium Reclamation Facility (PRF) can be used to process solid material and solutions.

\section{Process Description}

The SAR (WHC 1991) was used as the basis for the PRF analysis. The PRF converts various plutonium-bearing materials and aqueous feeds to a plutonium nitrate solution for conversion to plutonium oxide. This process consists of three primary steps: 1) feed preparation via hydrolysis and dissolution, 2) solvent extraction, and 3) thermal treatment. The preparation step yields the feed stream by removing organic material. The plutonium-bearing material in $\mathrm{HNO}_{2}-\mathrm{HF}$ solution is separated from the solids using a centrifuge in the location where the solution is sent to the $\mathrm{HNO}_{3}-\mathrm{HF}$ extraction process. The extraction process concentrates the plutonium aqueous phase using stripping columns. The organic extract used in the extraction process is then reprocessed and recycled. The plutonium-rich aqueous phase comes later and uses an oxalate precipitation to precipitate the plutonium into a solid form. Figure A.8 shows the flow schematic for the PRF.

\section{Hydrolysis}

The material that will be stored prior to dissolution is stabilized by heating it in air, burning off any organic or cellulose material and decomposing nitric acid. There are two furnace locations used for thermal stabilization: Glovebox $\mathrm{HA}-40 \mathrm{~F}$ furnaces operate at $500^{\circ} \mathrm{C}$ and are used if there is less than $1 \%$ organic material; and Glovebox MT-4 furnaces operate at $750^{\circ} \mathrm{C}$ and are used if there is more than $1 \%$ organic material. Rocky Flats incinerator ash is reburned in Glovebox HA-40F. Plastic encapsulated plutonium is decarbonized in Glovebox MT-4 in two steps: a low temperature step where the organic material is distilled off in an inert (nitrogen) atmosphere, and a step where the residual is burned off. 


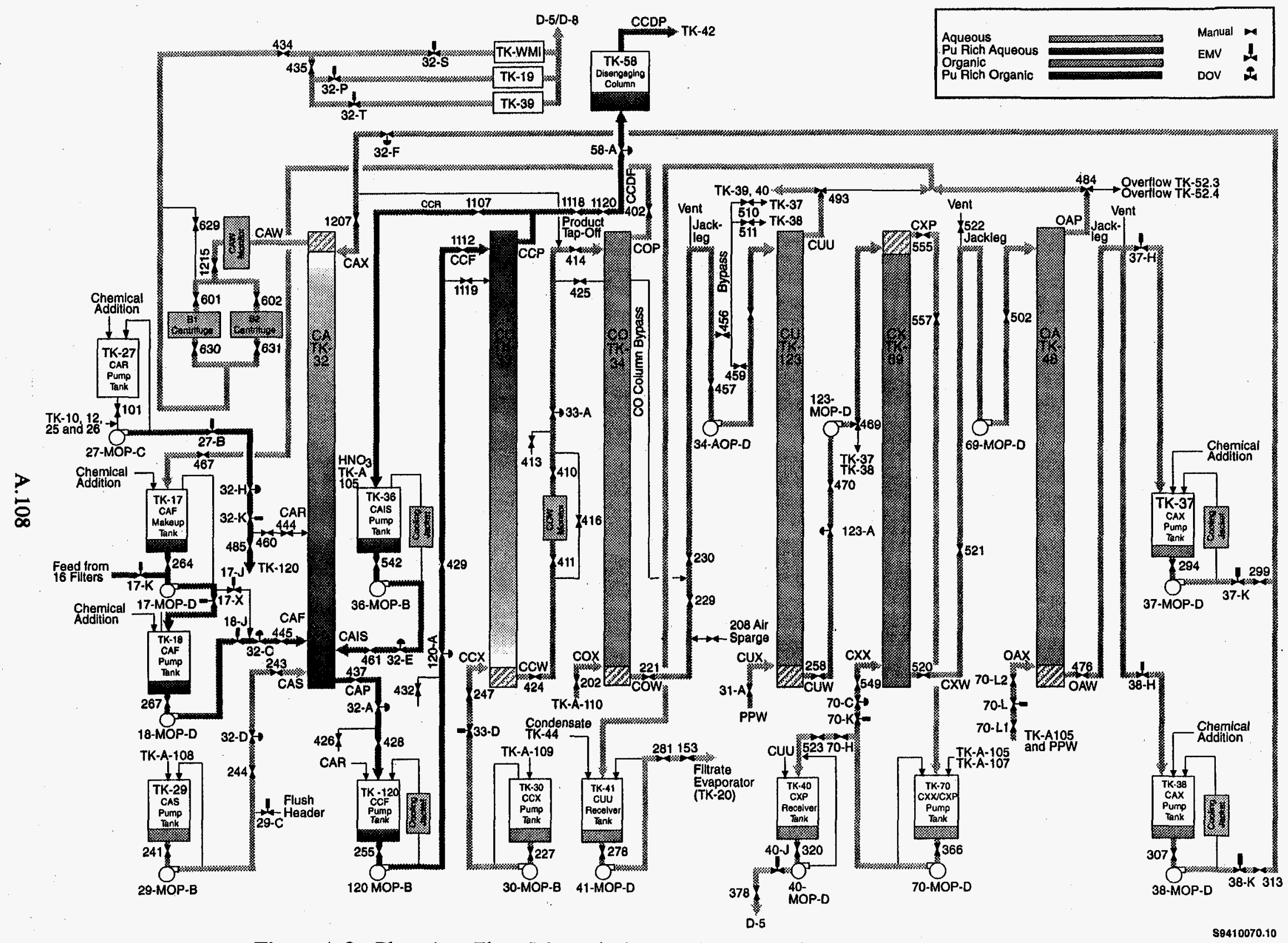

Figure A.8. Plutonium Flow Schematic for the plutonium Nitrate Reclmation Facility 
Glovebox MT-4 can be used to heat treat miscellaneous solids such as sludge, grease, and polystyrene cubes from critical mass studies. The glovebox is $4.9 \mathrm{~m}$ long, $0.91 \mathrm{~m}$ wide, and $2.4 \mathrm{~m}$ high. It contains two furnaces. One furnace operates at $425^{\circ} \mathrm{C}$ while purged with nitrogen to stabilize hydrolyzed plutonium scrap and drive all organics from contaminated plastics and grease that have not been nitrated. This furnace is a fused silica " $D$ " tube, $10 \mathrm{~cm}$ in diameter and $88 \mathrm{~cm}$ long. The solid feed is pushed through the furnace in metal (TBV) boats. The glovebox atmosphere is alarmed for high $(>3 \%)$ oxygen. The off gases are cooled and scrubbed before discharge to the ventilation system. The second furnace has a 10-cm-diameter, 132-cm-long "D" tube. The off gases are cooled and scrubbed before discharge. The product from this furnace normally meets the thermal stability specifications (LOI, DTA) for shipping and storage of solid waste.

\section{Dissolution}

Plutonium is recovered by dissolving the solid material in nitric acid, hydrofluoric acid, aluminum nitrate, and sodium fluoride. The most common dissolution is a mixture of "B" acid (12 $\underline{\mathrm{M}} \mathrm{HNO}_{3}$ and $0.35 \mathrm{M} \mathrm{HF}$ ) and ANN (aluminum nitrate nonahydrate). The aluminum is added to complex the fluoride and minimize the evaporation and condensation of HF in the glovebox and ventilation system. The dissolver in Glovebox HC-46F is used to dissolve difficult material with relatively high silicon concentrations, such as high-fired ash or residuals from the slag and crucible dissolver. These materials require additional fluoride. The fluoride converts the silica to volatile $\mathrm{SiF}_{4}$ that subsequently deposits on the reflux condenser tube walls as $\mathrm{SiO}_{2}$ and has to be periodically rodded out to prevent plugging and pressurization of the dissolvers. The loosened $\mathrm{SiO}_{2}$ is not returned to the dissolver or it will exhaust the fluoride ions in solution and rapidly regenerate the $\mathrm{SiF}_{4}$. The Glovebox $\mathrm{HC}-46 \mathrm{~F}$ dissolver has a Rasching-ring-packed scrubber that uses a $1 \mathrm{M}$ sodium hydroxide solution for removing fluoride and $\mathrm{SiF}_{4}$ from the off gas before releasing material to the ventilation system. Glovebox MT-5, primarily used to dissolve solids from the centrifuge or filters, typically uses a lower fluoride concentration and relies on reflux condensers. On occasion it is necessary to add NaF to the dissolver pots; $\mathrm{NaF}$ is reactive and hazardous.

Dissolution takes place in Glovebox MT-5. Glovebox MT-5 is $4.9 \mathrm{~m}$ long, $0.91 \mathrm{~m}$ wide, $0.93 \mathrm{~m}$ wide, $1.7 \mathrm{~m}$ high, and stands approximately $0.41 \mathrm{~m}$ above the floor. It is divided into six sections: five dissolver sections and one for chemical additions. The dissolver equipment is equipped with a nitrogen sparge ring to agitate material during dissolution. The dissolver pots each have an individual temperature controller, programmed to control the heating and cooling cycle. The gases and vapors that are generated during the boiling process rise through flex hoses connecting the pot dissolvers to the reflux condensers. The vapors from the boiling acid are condensed and flow back into the dissolver pot in a continuous cycle called refluxing. After a period of time, the dissolver liquid product is cooled and vacuum transferred through filter media to receiver tanks in Glovebox MT-6. The residual solids are left for two dissolutions cycles and rinsed with ANN. The residual solids are transferred by polybottle to Glovebox MT-6 for final packaging.

The MT-5 Glovebox has 5 dissolvers that can process $3 \mathrm{~L} /$ batch. The dissolution time required is estimated to be less than $2 \mathrm{~h} / \mathrm{batch}$ at a temperature of less than $105^{\circ} \mathrm{C}$. The plutonium concentration is 
less than or equal to $800 \mathrm{~g}-\mathrm{Pu} / \mathrm{batch}$, and the organic concentration should be less than $100 \mathrm{~g} / \mathrm{batch}$. The solution is then transferred to Tanks C2 and C3 located in Glovebox MT-6.

\section{Centrifuge}

Equipment in Glovebox MT-6 includes two 13.6-L receiver tanks, the Robuschi vacuum system used to transfer solutions from the dissolver pots in Glovebox MT-5 to the receiver tanks in Glovebox MT-6, three bowl-types centrifuges, a pump for pumping CA column waste, and a neutron monitor. Two of the centrifuges (B-1 and B-2), located in this glovebox, process the extraction waste (CAW) solutions from the solvent extraction process. The third centrifuge, $\mathrm{C}$, processes solutions collected from the two 13.6-L receiver tanks at a process rate of $0.5 \mathrm{~L} / \mathrm{min}$, prior to the transfer of these solutions to the solvent extraction feed preparation tanks (25 and 26) located in the canyon. The solids are periodically removed and put into containers with quick drying cement in preparation for waste disposal. The cement is non-combustible and absorbs any free liquid and neutralizes the acid. Calcined solids do not require cementing. Vacuum from the facilities 110 torr vacuum system is adequate to transfer solutions between gloveboxes if the miscellaneous treatment vacuum pump fails.

\section{Plutonium Extraction}

The solvent extraction and stripping equipment design in the PRF used 10-cm diameter, 16-m tall pulse columns. This design concept relies on column cartridges of stamped-out plates to break up the dispersed phase into small droplets, maximizing surface area and mixing to promote mass transfer efficiency. The columns have enlarged disengaging columns at both ends. Four columns are used for organic cleanup. Three of the columns are located in the Process Cell; the CO column is $6.1 \mathrm{~m} \mathrm{high}$, the CU is $7 \mathrm{~m}$ high, the CX is $4 \mathrm{~m}$ high. The OA column is located in an access hood; it is $1.4 \mathrm{~m} \mathrm{ft}$ long. These columns are all 5 to 6 in. in diameter. The columns are made from stainless steel, pyrex glass, and/or teflon pipe. The CA column contains stainless steel perforated plates with $11 \%$ free area spaced at $10-\mathrm{cm}$ intervals. The CC column contains stainless steel perforated plates with $23 \%$ free area spaced at 5-cm intervals. Three remaining columns contain plastic Rasching ring or Intalox saddle packing. The solvent extraction, stripping, and uranium scrub columns have air pulsers for improving mixing and movement of the aqueous and organic phases through the column. The pulse frequency is varied between 30 to $100 \mathrm{cycles} / \mathrm{min}$ at air pressures of 0.14 to $0.03 \mathrm{~m}$ pascals to produce the desired pulse height and maintain efficient aqueous-organic emulsion type operation.

Solvent extraction is a liquid-liquid separation process that uses differences in density, surface tension, and solubility of plutonium in nitric acid and an organic solvent composed of tributyl phosphate in $80 \%$ carbontetrachloride $\left(\mathrm{CCl}_{4}\right)$. In the CA column, dense organic liquid flows downward as a continuous phase. The CA column can process up to $120 \mathrm{~L} / \mathrm{h}$ of feed material. Counter to this flows an aqueous solution as tiny droplets; - eontaining plutonium plus impurities. As the aqueous solution passes upwards, the plutonium passes into the organic phase (is extracted) while the impurities remain in the aqueous. The organic solution, with the plutonium, is then transferred to a second column (CC column) containing another aqueous solution as a continuous phase. The $\mathrm{CC}$ column can process up to $60 \mathrm{~L} / \mathrm{h}$ of the organic stream from the CA column. The organic flows downward as tiny droplets while 
the plutonium is stripped as a purified material using nitric-acid hydroxylamine solution. The organic from the plutonium stripping column flows continuously through four columns to the $\mathrm{CO}$ column with a process rate of $60 \mathrm{~L} / \mathrm{h}$. Organic cleanup is required to remove trace plutonium and impurities before recycling back to the plutonium extraction $(\mathrm{CA})$ column.

\section{Product Evaporator and Concentrator}

The concentrator used to concentrate the plutonium product from solvent extraction is a jacketed, falling-film type, steam heated evaporator. It is made of welded titanium and contains titanium Rasching ring packing. Steam at $0.24 \mathrm{~m}$ pascal gage pressure is introduced to the 15 - $\mathrm{cm}$ diameter by 2.3-m outer pipe, heats the inner $5 \mathrm{~cm}$-diameter pipe and $2.5-\mathrm{cm}$ by $1.6-\mathrm{mm}$ packing. Plutonium nitrate flows down through the heated pipe and over the packing. The concentrate gravity flows into a stainless steel receiver tank. Any acid required to dilute product is added from the common feed tank, A-105. Live steam is introduced at the bottom to strip soluble organic from the solution. The vapor exits the concentrator via a de-entrainment section and enters the condenser (TK-44). Two 15-cm-long tantalum mist eliminators de-entrain mist from the vapor that is condensed by a shell and tube condenser (tank 44). The shell is $1.1 \mathrm{~m}$ long and $15 \mathrm{~cm}$ in diameter with a volume of $20 \mathrm{~L}$. There are nine $76 \mathrm{~cm}$ tubes inside the shell each $2.7 \mathrm{~cm}$ in diameter, for a total heat transfer area of $0.58 \mathrm{~m}^{2}$. The condenser was sized for a $5.9-\mathrm{kW}$ design duty. The vapor enters the shell side of the stainless steel horizontal condenser and is collected and condensed by water flowing through the coiled tubes. The condensate is collected and routed to solvent extraction for rework. The product evaporator has a process rate of approximately $10.7 \mathrm{~L} / \mathrm{h}$ of solution entering the evaporator.

The concentrated product is clarified using a centrifuge and stored in tanks 45,46 , and 128 . The product is pumped to tanks BT-1, 2, or 3, then loaded out into PR cans.

\section{Schedule}

The PRF process would be ready for startup after approval of administrative documentation (e.g., EIS, Operational Readiness Review.).

\section{Final Product Description}

The final product from the PRF would be a purified plutonium-nitrate solution that could be processed into plutonium oxide using precipitation processes, calcination, or denitration.

\section{Effluents Generated}

1. Material Dissolution

a. off gas $-\mathrm{NO}_{\mathrm{x}}$

b. waste solution (would be reprocessed) 


\section{Solvent Extraction}
a. organic solvent
b. aqueous stream to waste tanks

\section{Thermal Treatment}

a. off gas - $\mathrm{NO}_{\mathrm{x}}$

\section{Costs}

The cost to operate the PRF should include an upgrade of the existing control systems, equipment checkout, updating operation procedures, and personnel training.

\section{Comments}

Comments from the public that were received in response to a citizen bulletin indicate that most responses were strongly opposed to starting up the PFP because of the perception of making weapons and the use of $\mathrm{CCl}_{4}$ as a solvent used in the process.

\section{Justification for Further Study or Rejection}

Table A.12 summarizes the criteria evaluations for this technology. The primary justification for further study is that sections of the PRF may be used individually rather than the PRF as a whole. Sections such as the dissolution process or the Glovebox MT-4 muffle furnace may be used independently from other processes within the facility.

In addition, americium-241 needs to be removed from the wastes, and the PRF has the capability using solvent extraction.

\section{References}

Westinghouse Hanford Company (WHC). 1991. Safety Analysis Report for the Plutonium Finishing Plant. WHC-SD-CP-021, Rev. 0, Westinghouse Hanford Company, Richland, Washington. 
Table A.12. Criteria Evaluations for Plutonium Reclamation Facility

\begin{tabular}{|c|c|}
\hline Criteria & Evaluation \\
\hline Technical Feasibility (technology maturity) & High, existing facility \\
\hline $\begin{array}{l}\text { Effluents/By-Products } \\
\text { (minimize volumes, hazards) }\end{array}$ & $\begin{array}{l}\mathrm{CCl}_{4}, \mathrm{NO}_{x}, \text { plutonium in an aqueous } \\
\text { stream }\end{array}$ \\
\hline Effluents Covered/SAR & $\begin{array}{l}\text { High, most effluents are covered in } \\
\text { SAR }\end{array}$ \\
\hline Energy Resource & $\begin{array}{l}\text { High, but would require further } \\
\text { processing }\end{array}$ \\
\hline Weapon Potential & $\begin{array}{l}\text { Low volume, but with further } \\
\text { processing }\end{array}$ \\
\hline End Product Volume & $\begin{array}{l}\text { High stability, but with further } \\
\text { processing }\end{array}$ \\
\hline End Product Stability & Low \\
\hline $\begin{array}{l}\text { Worker Risk } \\
\text { routine } \\
\text { accident }\end{array}$ & Medium \\
\hline $\begin{array}{l}\text { Cost } \\
\text { (construction, operations and D\&D) }\end{array}$ & Low-medium \\
\hline Operation Duration & $\begin{array}{l}\text { Medium, need to upgrade existing } \\
\text { equipment, then D\&D facility } \\
23 \mathrm{~L} / \mathrm{h} \text { using dissolver }\end{array}$ \\
\hline Public Acceptance & Low \\
\hline Flexibility & $\begin{array}{l}\text { High, can process most items using } \\
\text { hydrolysis and dissolution process }\end{array}$ \\
\hline Materials Covered & $\begin{array}{l}\text { Most items can be processed using } \\
\text { hydrolysis and dissolution process }\end{array}$ \\
\hline
\end{tabular}




\section{A. 114}




\section{Description of Technologies}

Accept: $\underline{X}$ Reject:

\section{Technology - Thermal Treatment}

\section{Waste Processed}

- In the past, the following wastes have been treated by thermal treatment: plutonium nitrates (direct denitration - not covered in this review); TRU waste; LLW; plutonium wastes; organics; solids; liquids; sludges; plutonium-contaminated, plastic containing waste; and plutonium-organic waste.

Most of the waste from PFP could/might be thermally treated. Exceptions include the high-fired oxides ( $1654 \mathrm{~kg}$ of the $4598 \mathrm{~kg}$ of oxides being considered in this study) and the nonconforming solutions and residues (which may be highly reactive).

\section{Process Description}

Candidate thermal treatment systems include the following:

high temperature slagging

cyclone incinerator

rotary kiln

liquid injection incinerator

fluidized bed pyrolysis

infrared incinerator

horizontal tube furnace

controlled air incinerator

existing MT-4 distillation process (polycube processing).

The general process involves 1) feed preparation, such as shredding of solids and evaporation of liquids; 2) a primary chamber for pyrolysis or incineration of combustibles and organics and, in some cases, oxidation of the products (including plutonium oxide); 3) a secondary chamber for destruction of the organic off gases and/or oxidation of the products; 4) product collection and packaging; 5) off-gas treatment; and 6) potentially, an immobilization process. Immobilization is not addressed in this review but may be necessary after thermal treatment is applied because most of the systems reviewed produce an ash product that may contain dispersible material.

\section{Facilities and Equipment}

The processes reviewed were mainly full-scale systems. The equipment of any one of the systems would require at least the space equivalent to one tractor trailer. One of the mobile units required three tractor trailers, including one for the off-gas treatment. 
PFP has a pyrolyzing furnace, a condenser, a condensate receiver, a scrubber, and a vacuum pump in Glovebox 4 that was used for the disposal of polycubes until 1985. The system, as currently configured, would be insufficient and unsafe for thermal treatment of PFP waste. The unit was shutdown in 1985 because of safety reasons. Nitrogen, used to inert the furnace, also inerted the glovebox. The flow from the furnace to the glovebox allowed combustibles to enter the air side of the glovebox, causing a potential safety problem. Also, polystyrene overflowed the boats in the past, and the system would take 33 weeks to dispose of the polystyrene cubes alone.

For full-scale systems, 2000 to $8000 \mathrm{~m}^{2}$ acres of space would be required. But it is doubtful any of the full-scale systems could meet criticality requirements. One system reviewed, the fluidized bed process, described a 3-in.-diameter system developed at Hanford and was excessed in the mid-1980s. The system had a feed rate of $130 \mathrm{~g} / \mathrm{min}(7.8 \mathrm{~kg} / \mathrm{h})$ or $1.5 \mathrm{~kg} / \mathrm{h}$ of nitrate. The system was used for plutonium recovery and fit into a large hot cell (from the picture in the report, the size is estimated as $3 \mathrm{~m}$ high by about $1.2 \mathrm{~m}$ ). The fluidized bed was the only one of the processes reviewed that did not require a scrubber system as part of the off-gas treatment.

Besides the metals and potentially reactive non-conforming compounds, other wastes may not be compatible for thermal treatment. Some processes restrict plastics, salts, heavy metals, rubber, fluorides, and/or explosives. For example, the fluidized bed restricts high sodium or high heavy metal content in the feed stream as well as low-melting-point constituents.

\section{Schedule}

It is unknown if any non-full-scale processes that have been used on plutonium waste exist. If a smallscale system were to be built, it may require a great deal of testing for verification. But even if a small-scale system exists (such as the fluidized bed at Hanford), the system would still have to be tested with each type of waste to ensure compatibility. The system would take about 1 to 2 years for licensing and construction, but it may take over 2 years to complete testing the system. Furnaces are commercially available and may be applied to PFP waste for thermal treatment.

Based on the small-scale fluidized bed and assuming all waste but metals, high-fired oxides and potentially reactive non-conforming compounds could be treated at a rate of 1.5 to $7.8 \mathrm{~kg} / \mathrm{h}$, and the system runs $8 \mathrm{~h} / \mathrm{d}, 5 \mathrm{~d} / \mathrm{wk}$, then the entire treatable inventory could be treated in 40 weeks to a little over 4 years with the one unit. One of the full-scale units could treat the same waste in less than 1 day (the full-scale model costs $\$ 2.5 \mathrm{M})$.

Another low cost option that would not handle as much of the waste stream may be the use of the muffle furnace or the polystyrene furnace that are already installed in the PFP. Both of these options would require testing to ensure compatibility and may require modifications, such as a second furnace or a scrubber for off-gas treatment, for some of the waste streams. However, both options may be installed and approved for operation when treatment is to start. 


\section{Final Product Description}

The final product depends on the process to be used. If only combustibles and organics (including polystyrene) are treated, the product would be a chemically inert, non-flammable, relatively homogeneous ash. The ash may have high carbon content (pyrolysis), or low to no carbon content (incineration).

If non-combustibles are also to be treated (as with high temperature slag incinerators), the final product is an insoluble slag.

Finally, if treated in a fluidized bed, the ash product is a salt, catalyst, ash mixture that may be difficult to immobilize without further treatment.

Several of the reviewed documents state thermal treatment has the greatest volume reduction of any treatment for organics and combustibles (up to 100\%). Non-combustible/combustible mixtures treated with high temperature systems show volume reduction factors of 3 to 20 .

The product is more acid-leach resistant and forms larger sized particles with higher temperature oxidation. With temperatures below $700^{\circ}$ to $800^{\circ} \mathrm{C}$, plutonium can be recovered from the ash products using acid leach.

\section{Effluents Generated}

The effluents may include off gases and scrubber liquor. Only one of the systems reviewed did not produce both a scrubber liquor and off gas. The fluidized bed requires no scrubber systems because acid off gas is neutralized in situ. Therefore, only filtration is required.

Filtration, required by all the thermal treatment processes, would generate contaminated HEPAs. Contaminated bag filters may also be generated depending on the off-gas treatment process chosen.

\section{Risks}

Unless the heat is finely controlled, the chemical reactions may get out of control and result in an explosion. Pyrolysis, the burning of material in a low- or non-oxygen environment, is a possible means for controlling the burning. A secondary chamber would be required for the oxidation process.

\section{Costs}

Costs provided in the reviewed documents were for full-scale systems requiring anywhere from 2000 to $8000 \mathrm{~m}^{2}$. Capital costs estimates were for such systems. These system are much bigger than needed or would be considered acceptable for high concentrations of plutonium.

Operational costs should be minimal. Two people are required to operate many of the full-scale systems and should be sufficient for a PFP system. 
Waste disposal should also be minimal. The fluidized bed will generate no waste, while the other systems will all produce scrubber liquor. The neutralized scrubber liquor may contain some particulate matter and radioactivity. The liquor may be sent to tank farms where it would be evaporated before being put in a tank.

\section{Comments}

Public opinion is unknown. It may be positive, as it has been for the interim stabilization using a muffle furnace, or it may be very negative, as it generally is when the word "incineration" is used. Thermal treatment may be more acceptable if the hazardous constituents are destroyed during pretreatment so that high temperature calcining is the primary function of the thermal treatment.

\section{Justification for Further Study or Rejection}

Table A.13 summarizes the criteria evaluations for the thermal stabilization process. Thermal treatment has the highest reduction factor for combustibles and organics; has the maximum destruction of organics; results in a non-flammable, chemically inert product with the plutonium oxidized; and produces a relatively homogeneous product with minimal secondary waste. Much of the PFP waste may be stabilized using thermal treatment processes.

Thermal treatment development started in the early 1950 s and has been commercially available since the mid-1970s. Many of the thermal treatment methods reviewed have been used successfully on either TRU or plutonium waste.

Even the Hoyt report (1993) rates a system of direct denitration and thermal stabilization as the number one choice for stabilizing PFP waste, "...direct denitration and an enhanced thermal stabilization system... is more flexible and could handle all of the reactive residues (in PFP); however, it is not a nearterm solution to the stabilization of reactive materials." It is not understood why Hoyt says such a system is not a near-term solution because all of the equipment for such a system is commercially available (although it would take time to install and approve operating procedures).

\section{References}

Hoyt, R. C. 1993. Summary Report on Hanford Plutonium Disposition Workshop. WHC-S-D-CP-VES-001, Westinghouse Hanford Company, Richland, Washington. 
Table A.13. Criteria Evaluations for Thermal Stabilization

\begin{tabular}{||l|l|}
\hline \multicolumn{1}{|c|}{ Criteria } & \multicolumn{1}{|c|}{ Reasons for Disqualification } \\
\hline \hline $\begin{array}{l}\text { Technical Feasibility (technology maturity) } \\
\text { (minimize volumes, hazards) }\end{array}$ & Could be available within 2 years \\
Effluents Covered/SAR & Minimal - scrubber liquor and off gas \\
Energy Resource & Unknown \\
Weapon Potential & Unknown \\
End Product Volume & High-fired, acid leach resistant \\
End Product Stability & Minimal \\
Environmental and Public Risk \\
routine & Stabile, non-flammable and chemically inert \\
& \\
accident & Since the makeup of wastes is unknown, some of \\
& them may be explosive \\
Worker Risk & Construction and operations should be minimal \\
routine & cost. Exhaust system renovations may be \\
accident & required, however. \\
Cost & Less than 1 year to 3.5 years \\
(construction, operations and D\&D) & Unknown \\
Operating Duration & Unknown \\
Public Acceptance & Unknown \\
\hline
\end{tabular}




\section{Bibliography}

Ball, L. J. 1989. PREPP Operating Experience and Status. EGG-M-89442. Idaho National Engineering Laboratory, Idaho Falls, Idaho.

Bamber, D. C., L. A. McDonald, W. G. Roberts, P. W. Sutcliffe, and J. D. Wilkins. 1984. An Experimental Study of Factors in the Recovery of Plutonium from Combustible Wastes Treated by Incineration, Pyrolysis and Other Processes. EUR 9302, Commission of the European Communities, Luxembourg.

Campbell, B. F. 1959. Comparative Evaluation of the Agitated Trough and Fluidized Bed Denitration Processes for Application to the Hanford NPF Program. HW-61594, General Electric, Richland Washington.

Caramelle, D., J. Lannaud, B. Martinez, and A. Meyere. 1988. Alpha Waste Incineration Prototype Incinerator and Industrial Project. CEA-CONF--9571, France.

Charlesworth, D., and M. Hill. 1984. Electrically Fired Incineration of Combustible Radioactive Waste. DP-MS-84-141, Savannah River Site, Aiken, South Carolina.

Charlesworth, D. L., and R. B. McCampbell. 1984. Design of a Pu-238 Waste Incineration Process. DP-MS-84-109, Savannah River Site, Aiken, South Carolina.

Cowan, R. G., R. J. Cash, T. J. Owen, and G. E. Shook. 1987. Nitrate Destruction in an Elutriated Fluid-Bed Calciner. WHC-EP-0062, Westinghouse Hanford Company, Richland, Washington.

Ford, L. H., and M. J. Jenkins. 1984. Nuclear Science and Technology, Incineration of Simulated Plutonium-Contaminated Waste. EUR 9219, Commission of the European Communities, Luxembourg.

Glynn, W., C. Baker, A. LoRe, and A. Quaglieri. 1987. Mobile Waste Processing Systems and Treatment Technologies. Noyes Data Corporation, Parkridge, New Jersey.

Holmes, H., and D. L. Charlesworth. 1986. Operational Testing of an Electrically Fired Pu-238 Waste Incineration Process. DP-MS-86-150, Savannah River Site, Aiken, South Carolina.

International Atomic Energy Agency (IAEA). 1982. Treatment and Conditioning of Radioactive Organic Liquids. IAEA-TECDOC-656, Brussels.

Johnson, A. J., and P. M. Arnold. 1986. Waste Generation Reduction - Nitrates, Comprehensive Report of Denitration Technologies. RFP-3899, Rocky Flats Plant, Golden, Colorado. 
Klingler, L. M. 1979. Defense Waste Cyclone Incinerator Demonstration Program, April - September 1979, Mound Facility, Miamisburg, Ohio.

Klingler, L. M. 1980. Defense Waste Cyclone Incinerator Demonstration Program, October 1979 March 1980. Mound Facility, Miamisburg, Ohio.

Kohout, R. 1986. "Radioactive Waste Technology." Incineration. Eds. A. A. Moghissi, H. Godbee, S. A. Hobart. Association of Mechanical Engineers.

Notes from the ODP Workshop. May 26-27, 1993. Albuquerque, New Mexico.

Sheely, W. F. 1986. Fluidized Bed Calciner. HEDL-SA-3609-VT, Hanford Engineering Development Laboratory, Richland, Washington.

Souply, K. R., and D. H. Neal. 1977. Fluid Bed Direct Denitration Process for Plutonium Nitrate to Oxide Conversion. RFP-2600, Rocky Flats Plant, Golden, Colorado.

Van De Vorde, N., D. Hennart, J. Gijbels, and L. Mergan. 1984. "High Temperature Slagging Incinerator for TRU-Waste Treatment." In Fuel Reprocessing and Waste Management. Vol. 1. American Nuclear Society, LaGrange, Illinois.

Van De Vorde, N., A. Taeymans, D. Hennart, R. Vanbrabant, W. Balleux, G. Geenen, and J. Gijbels. 1986. Nuclear Science and Technology, High-Temperature Incineration of Radioactive Waste. EUR 10411, Commission of the European Communities, Luxembourg.

Vincent, J. J., T. Longuet, R. Cartier, and L. Chaudon. 1992. "Incineration Process for Plutonium Contaminated Waste." CEA-CONF-11075, National Technical Information Services, Springfield, Virginia.

Vogler, S., D. E Grosvenor, N. M. Levitz, and F. G. Teats. 1972. Development Studies on a Fluidized-Bed Process for Conversion of U/Pu Nitrates to Oxides, Part 1. ANL-7917, Argonne National Laboratory, Argonne, Illinois. 
A. 122 


\section{Description of Technologies}

Accept: _ Reject: $\underline{X}$

\section{Technology - High Gradient Magnetic Separation}

\section{Applicable Wastes Processed}

The high gradient magnetic separation (HGMS) technology can be used to process nonconforming process residues, including plutonium-bearing sludges (CO0, G00, G02); incinerator ash (G03); reduction residue (G05); all plutonium compounds except encapsulated compounds (C01-C11 + C40-C80); all noncombustibles (in powder form)(E00-E70); and duct and PRF floor holdup.

\section{Process Description}

HGMS is used to separate magnetic fractions from gases and liquids. Most commonly, the feed is slurried with water and passed through a magnetized volume (Worl 1993). Magnetic field gradients are produced in the magnetized volume by a porous ferromagnetic matrix material such as steel wool, steel balls, or nickel foam. Ferro- and para-magnetic particles are extracted from the slurry while the diamagnetic fraction passes through. The magnetic fraction can be stripped from the matrix by subsequent washing after the magnetic field is reduced to zero. Insoluble particles containing plutonium, uranium, americium, neptunium, and their salts are paramagnetic and can be concentrated by this method.

\section{Facilities and Equipment Required}

A superconducting magnet $(20,000$ to 80,000 gauss) with 2 - to 5 -cm bore; a slurry feed preparation tank with stirrer, glass column packed with steel wool; and an eluate collection tank are all required for the HGMS process.

\section{Schedule}

The system can be set up in 1 to 2 days after delivery of the superconducting magnet. Alternatively, a 20,000 gauss conventional magnet can be used.

\section{End Product Description}

The end product is a concentrated slurry containing plutonium and, possibly, other actinides. 


\section{Effluents and By-Products}

An aqueous slurry effluent stream is generated, which is depleted in plutonium to a degree that depends on the feed, the strength of attachment of plutonium to the waste matrix, and the flow rate. Under most conditions, it should be possible to produce an effluent stream containing $<100 \mathrm{nCi} / \mathrm{g}$ of actinide elements.

A final by-product comprised of contaminated steel wool would be generated; most of this by-product could be dissolved in acid and subjected to a final plutonium removal step by the same method, on a small scale.

\section{Risks}

This is a physical separation method with little risk of effluent release. The major technical risk is that some feed materials may have plutonium sufficiently embedded in the overall matrix such that magnetic separation is ineffective.

\section{Costs}

No construction costs are incurred with this technique. The major cost is for the magnet. Operational costs should be more than balanced by plutonium concentration and disposal waste volume reduction.

\section{Comments}

Table A.14 provides a summary of the criteria evaluations for this technology. Although innovative in its use with TRU waste streams, HGMS has been used for over 60 years in the removal of ferromagnetic (colored) particles from kaolinite clay for use in making white paper. Thus, it is a well-understood technology. However, it concentrates plutonium rather than stabilizes it and, therefore, is a waste volume-reduction technology.

\section{Justification for Further Study or Rejection}

Because volume reduction is not considered desirable per se, HGMS is not recommended for further study even though it offers a relatively simple, clean, and low-risk method for concentrating plutonium from inorganic matrices (such as crucibles) and may help convert the plutonium to an acceptable disposal form. Little experience exists with concentrate plutonium streams. In principle, the HGMS method is also applicable for removing plutonium from mixed wastes, provided that the wastes can be converted to a powder form of particle size 70 to 0.1 microns. 
Table A.14. Criteria Evaluations for High Gradient Magnetic Separation

\begin{tabular}{|c|c|}
\hline Criteria & Evaluation \\
\hline Technical Feasibility (technology maturity) & Medium \\
\hline $\begin{array}{l}\text { Effluents/By-Products } \\
\text { (minimize volumes, hazards) }\end{array}$ & $\begin{array}{l}\text { Product is plutonium-enriched sludge, effluent is } \\
\text { plutonium-depleted slurry }\end{array}$ \\
\hline Effluents Covered/SAR & Unknown \\
\hline Energy Resource & Low to medium \\
\hline Weapon Potential & Medium \\
\hline End Product Volume & Decreased \\
\hline End Product Stability & Further processing required \\
\hline $\begin{array}{l}\text { Environmental and Public Risk } \\
\text { routine } \\
\text { accident }\end{array}$ & $\begin{array}{l}\text { None } \\
\text { None }\end{array}$ \\
\hline $\begin{array}{l}\text { Worker Risk } \\
\text { routine } \\
\text { accident }\end{array}$ & $\begin{array}{l}\text { Low } \\
\text { Low }\end{array}$ \\
\hline $\begin{array}{l}\text { Cost } \\
\text { (construction, operations and D\&D) }\end{array}$ & Low to medium \\
\hline Operating Duration & Unknown \\
\hline Public Acceptance & Probably high \\
\hline Flexibility & Medium \\
\hline Materials Covered & $\begin{array}{l}\text { Solids with plutonium or plutonium oxide or } \\
\text { chlorides }\end{array}$ \\
\hline
\end{tabular}




\section{References}

Worl, L. A., L. R. Avens, K. J. de Aguero, F. C. Prenger, W. F. Stewart, and D. D. Hill. 1993. "Chloride Recovery. Opportunities for Magnetic Separation Applications in Complex 21."

Los Alamos National Laboratory Nuclear Materials Division Annual Review, 69-73. Los Alamos National Laboratory, Los Alamos, New Mexico.

\section{Bibliography}

Worl, L. A., L. R. Avens, K. J. de Aguero, F. C. Prenger, W. F. Stewart, and D. D. Hill. 1993.

"Remediation of Hanford Tank Waste Using Magnetic Separation." In Proceedings, of the Waste Management'93 Symposium. Arizona Board of Regents, Tucson, Arizona. 


\section{Description of Technologies}

Accept: $\underline{X}$ Reject:

\section{Technology - Silver Persulfate}

\section{Waste Processed}

The silver persulfate process can be used on solids containing plutonium ions or an other ionic form of plutonium. Any chlorine ion in the waste must be removed before processing to avoid formation of insoluble silver chloride. Organic material present in the waste would be oxidized.

\section{Process Description}

The silver persulfate process is a batch process that solubilizes plutonium compounds such as oxides and fluorides from solid materials by oxidation using $\mathrm{Ag}(\mathrm{II}){ }^{(\mathrm{a})}$ Insoluble plutonium oxide is converted to soluble $\mathrm{PuO}_{2}{ }^{+2}$, which allows for separation of the plutonium from the bulk solids. The persulfate ion $\left(\mathrm{S}_{2} \mathrm{O}_{8}^{-2}\right)$ is used to oxidize the silver from $\mathrm{Ag}(\mathrm{I})$ to $\mathrm{Ag}(\mathrm{II})$. The chemical reactions are as follows:

$$
\begin{aligned}
& 2 \mathrm{Ag}^{+}+\mathrm{S}_{2} \mathrm{O}_{8}^{-2} \rightarrow 2 \mathrm{Ag}^{+2}+2 \mathrm{SO}_{4}^{-2} \\
& 2 \mathrm{Ag}^{+2}+\mathrm{PuO}_{2} \rightarrow 2 \mathrm{Ag}^{+}+\mathrm{PuO}_{2}^{-2}
\end{aligned}
$$

Net reaction:

$$
\mathrm{PuO}_{2}+\mathrm{S}_{2} \mathrm{O}_{8}^{-2} \rightarrow \mathrm{PuO}_{2}^{+2}+2 \mathrm{SO}_{4}^{-2}
$$

$\mathrm{K}_{2} \mathrm{~S}_{2} \mathrm{O}_{8}$ is used as a source of persulfate. The plutonium-bearing material is added to a saturated $\mathrm{K}_{2} \mathrm{~S}_{2} \mathrm{O}_{8}$ solution. The reactions generally run for 1 or 2 hours before all of the persulfate is consumed. As the silver oxidizes other materials, such as organics and water, there are other sources that consume the persulfate.

The process has been used on a variety of objects, including HEPA and string filters. Although most tested materials show a $95 \%$ or better plutonium removal in 1 hour, the HEPA filters contained approximately $12 \%$ residual plutonium after treatment. The process does not work on materials containing plutonium metals.

(a) Thurman Cooper, WHC, personal communication, 1994. 


\section{Facilities and Equipment}

Minimal equipment is required for this process. A reaction vessel and a solids filtration/washing system, using less than $0.3 \mathrm{~m}^{3}$, could be used. The process would not need constant monitoring or control.

\section{Schedule}

Essentially no further development is required for this process.

\section{Final Product Description}

The product from this process would be an aqueous stream with the dissolved plutonium and other soluble compounds. Additional processing would be required to produce a stable storage form.

\section{Effluents Generated}

The process would yield a solids stream that has been leached of essentially all plutonium. Since $\mathrm{Ag}(\mathrm{II})$ can oxidize water, there is the potential for a small amount of oxygen gas generation. Small quantities of light organics present in the waste would be oxidized to carbon dioxide.

\section{Risks}

There are no major risks. The reaction is not vigorous.

\section{Justification for Further Study or Rejection}

Table A.15 summarizes the criteria evaluations for the silver persulfate process. The silver persulfate process is a simple method of leaching plutonium oxide from solids. It is far better than any dissolution method currently used, and requires minimal equipment, unlike the similar CEPOD process. 
Table A.15. Criteria Evaluations for Silver Persulfate

\begin{tabular}{|c|c|}
\hline Criteria & Evaluation \\
\hline Technical Feasibility (technology maturity) & Medium \\
\hline $\begin{array}{l}\text { Effluents/By-Products } \\
\text { (minimize volumes, hazards) }\end{array}$ & Plutonium-bearing solution, leached solids \\
\hline Effluents Covered/SAR & Unknown \\
\hline Energy Resource & None \\
\hline Weapon Potential & None \\
\hline End Product Volume & Increased \\
\hline End Product Stability & Further processing required \\
\hline $\begin{array}{l}\text { Environmental and Public Risk } \\
\text { routine } \\
\text { accident }\end{array}$ & $\begin{array}{l}\text { None } \\
\text { None }\end{array}$ \\
\hline $\begin{array}{l}\text { Worker Risk } \\
\text { routine } \\
\text { accident }\end{array}$ & $\begin{array}{l}\text { None } \\
\text { Low }\end{array}$ \\
\hline $\begin{array}{l}\text { Cost } \\
\text { (construction, operations and D\&D) }\end{array}$ & Minimal \\
\hline Operating Duration & Unknown \\
\hline Public Acceptance & Unknown \\
\hline Flexibility & Medium \\
\hline Materials Covered & $\begin{array}{l}\text { Solids such as plutonium oxide and plutonium } \\
\text { fluorides. }\end{array}$ \\
\hline
\end{tabular}




\section{Description of Technologies}

Accept: $\underline{X}$ Reject:

\section{Technology - HF/Nitric Acid Dissolution}

\section{Waste Processed}

Plutonium metal, low-fired oxides, and miscellaneous sludge all can be processed using the HF/nitric acid dissolution process.

\section{Process Description}

This technology is a pretreatment process for dissolving plutonium-bearing materials for additional purification. The process consists of adding a mixture of $\mathrm{HNO}_{3}$ and $\mathrm{HF}$ to the plutonium-bearing material to create a plutonium nitrate solution. Aluminum nitrate is also added to complex the fluorides to minimize corrosion problems and prevent problems with purification systems such as solvent extraction. The process is limited to materials that can dissolve the plutonium.

\section{Schedule}

Only minor demonstration would be required on certain materials. The process could be run at almost any suitable location and in existing equipment. A minimum amount of space would be required.

\section{Final Product Description}

The final product would be an acid solution containing plutonium. Further treatment would be required to produce a stable, long-term storage form.

\section{Effluents Generated}

The effluent would be $\mathrm{NO}_{\mathrm{x}}$, and solids with a low plutonium content.

\section{Risks}

There is little risk. The reaction is not vigorous with most materials. 


\section{Justification for Further Study or Rejection}

The experience using this technology with certain materials is extensive and should be studied further. However, high-fired materials will need a more aggressive dissolution procedure, so the HF/nitric acid dissolution process is rejected for that material. 


\section{Description of Technologies}

Accept: - Reject: $\underline{\mathrm{X}}$

\section{Technology - Zone Melting}

\section{Process Description}

Zone melting is a process whereby impurities are removed from a material by means of a thermal gradient. Because of differences in solubility at different temperatures, or because of phase separations, the impurities in a material can be forced from one region of the material to another. The result is a material that has a region of higher purity and a region of lower purity, relative to the starting material (Ogawa and Iwai 1991).

Zone melting has been used extensively to produce silicon crystals of very high purity. There is also some information in the literature (Ogawa and Iwai 1991) concerning the separation of uranium/zirconium alloys. However, there is no information on the use of zone melting to purify plutonium or to remove plutonium from other materials. Even if there was such a process in use, it would be very unlikely that it could find application for any of the PFP materials.

\section{References}

Ogawa, T., and T. Iwai. 1991. "Demixing of U-Zr Alloys Under a Thermal Gradient." Journal of the Less-Common Metals 175:59 to 69. 
A. 134 


\section{Description of Technologies}

Accept: _ Reject: $\underline{X}$

\section{Technology - Acid Digestion}

\section{Waste Processed}

Solid combustible waste can be processed using the acid digestion technology.

\section{Process Description}

Acid digestion is a chemical oxidation process for converting organic wastes to gaseous effluents and stable solid residues. Typical waste materials such as polyvinylchloride, polyethylene, paper and other cellulosic materials, ion exchange resins, and all types of rubber (neoprene, latex, hypalon) are digested in a $\mathrm{H}_{2} \mathrm{SO}_{4}-\mathrm{HNO}_{3}$ solution heated to $\sim 250^{\circ} \mathrm{C}$. Sulfuric acid carbonizes and partially oxidizes the waste, but the primary oxidant is nitric acid that is added continuously to the digester at a rate proportional to the waste addition. Because acid digestion is a combustion process, it has the same basic requirements as other combustion or incineration processes regarding the preparation of feed materials, containment, off-gas cleanup, and process control. The primary difference between acid digestion and other incinerator processes is that acid digestion takes place in an aqueous media, which results in somewhat different process control requirements and, for a nuclear system, different criticality control requirements.

A radioactive acid digestion test unit (RADTU) was completed in 1977 and operated at the Hanford Site on potentially contaminated non-glovebox waste from a plutonium facility for 6 months. During that time, $2100 \mathrm{~kg}$ of mostly cellulosic materials were processed at an average rate of $2.7 \mathrm{~kg} / \mathrm{h}$. The RADTU design was capable of processing wastes containing as much as $3.6 \mathrm{~kg}$ of plutonium without exceeding critical mass operating limits. The RADTU system was later upgraded to treat $10 \mathrm{~kg} / \mathrm{h}$ of waste.

A wide variety of waste materials and chemicals potentially associated with fuel reprocessing operations were treated using acid digestion. The materials were divided into three categories: organic solvents, cleaning solutions, and decontamination reagents and miscellaneous process chemicals. In addition, separate studies were performed to determine the behavior of iodine and ruthenium in the acid digester. Studies also were performed to determine the fate of plutonium, americium, and uranium in the acid digestion system.

All combustibles examined were decomposed, with the exception of carbon tetrachloride $\left(\mathrm{CCl}_{4}\right)$ and $\mathrm{NPH}$ that distilled from the digester. While an engineering solution to overcome the volatilization of these solvents should be possible, none was tried because at that time incineration was favorably viewed. 
Dry, solid potassium permanganate reacted very violently in the acid digester, probably because of the formation of manganese heptoxide, which is explosive at high temperatures. Potassium permanganate should not be added in a dry solid state.

Plutonium and americium form semi-soluble sulfates during acid digestion and will remain with the process residue. Both are readily leachable in dilute nitric acid. Solubilities of plutonium and americium were estimated to be $0.1 \mathrm{~g} / \mathrm{L}$ and $0.0015 \mathrm{~g} / \mathrm{L}$, respectively. Uranium, on the other hand, is soluble in acid digestion solutions to greater than $100 \mathrm{~g} / \mathrm{L}$. As expected, ruthenium and iodine volatilized during acid digestion.

\section{Facilities and Equipment}

In the late $1970 \mathrm{~s}$, a pilot plant that could treat $10 \mathrm{~kg} / \mathrm{h}$ was installed at Z-plant in five gloveboxes, the largest of which measured approximately $3.7 \mathrm{~m}$ wide by $0.91 \mathrm{~m}$ in diameter by $3.7 \mathrm{~m}$ high. The equipment has since been disassembled. If similar gloveboxes are available, the system could be built again using many off-the-shelf items. The system is composed of a feed preparation system, a digester, a solids recovery system, off-gas treatment system, and an acid fractionator. A separate glovebox would house each of these systems. The system would use electric power and would primarily consume nitric and sulfuric acids. A large fraction of the sulfuric acid could be recycled in the acid fractionator.

A minimum of two personnel would be required to run the acid digestion treatment system.

\section{Schedule}

The system is well developed. In addition to the RADTU tested at Hanford, an acid digestion plant was installed in Mol, Belgium, and ran for approximately 1 year. The plant was used to oxidize plutonium contaminated solid combustibles and recover the plutonium. Approximately $7 \mathrm{~kg}$ of plutonium were recovered. Thus, if acid digestion were favored, a plant could be built in relatively short order based upon the RADTU design or the Mol, Belgium, plant design.

Based on the RADTU processing rate of $2.5 \mathrm{~kg} / \mathrm{h}$ and $256 \mathrm{~kg}$ of combustibles, approximately 100 hours would be required for treatment.

\section{Final Product Description}

The acid digestion residue of combustible waste materials primarily consists of sulfates and oxides of the inert "filler" materials in the wastes themselves. The residue accumulates in the digester acid and must be separated from the acid by filtrating or distilling the sulfuric acid. The resulting dried residue is similar in volume to that resulting from direct incineration of combustible wastes. Differential thermal analysis of the residue has shown it to be inert with no self-sustaining reactions occurring when the residue was heated to $800^{\circ} \mathrm{C}$ in the presence of air. 
The volume reduction is dependent on the waste treated. Volume reductions of 5:1 to 100:1 have been measured for different wastes.

Laboratory tests with plutonium indicate that it readily converts to slightly soluble plutonium sulfate in the digester and predominately remains as a precipitate with the process residue. Plutonium in the original waste material becomes part of the residue by converting to either plutonium (III) or (IV) sulfate in the presence of sulfuric acid. Both compounds are insoluble in the presence of high concentration of sulfate ion and semi-soluble in the presence of nitric acid and sulfuric acid. The plutonium is readily leached from the process residue using dilute nitric acid. Following recovery, the plutonium may be stabilized as appropriate.

\section{Effluents Generated}

The following effluents are based upon treating $100 \mathrm{~kg} / \mathrm{d}$ of solid combustibles (Allen and Ely 1980).

Solids Residue: $15 \mathrm{~kg} / \mathrm{d} \mathrm{CaSO}{ }_{4}, \mathrm{SiO}_{2}, \mathrm{ZnSO}_{4}, \mathrm{Fe}_{2}\left(\mathrm{SO}_{4}\right)_{3}, \mathrm{Ti}\left(\mathrm{SO}_{4}\right)_{2}$

Scrubber Off Gas: $1075 \mathrm{~kg} / \mathrm{d} \mathrm{CO}_{2}=17.3 \%, \mathrm{~N}_{2}=70.3 \%, \mathrm{O}_{2}=8.3 \%, \mathrm{NO}=1.1 \%, \mathrm{H}_{2} \mathrm{O}=1.7 \%$, $\mathrm{Ar}=1.1 \%$

Acid Fractionator Off Gas: $873 \mathrm{~kg} / \mathrm{d} \mathrm{HNO}_{3}=12.3 \%, \mathrm{HCl}=0.2 \%, \mathrm{H}_{2} \mathrm{O}=87.5 \%$

\section{Risks}

The safety aspects of the acid digestion process have been investigated in depth because of the possible formation of explosive nitro-organic compounds (red oil explosions). The particular condition of high temperatures and high sulfuric-to-nitric acid ratios used in the acid digestion process are not conductive to nitration reactions. The absence of nitro-organic compounds was confirmed by spectral analysis of digester solutions taken during various stages of acid digestion.

\section{Costs}

The costs for using this technology to process the plutonium would be in the medium range.

\section{Comments}

The acid digestion system, as tested, was only suitable for solid combustible wastes. Extending the technology to incorporate treatments of volatile solvents such as NPH will require an engineering solution and prototype testing. 


\section{Justification for Further Study or Rejection}

Because waste residue after acid digestion will require further treatment to stabilize the plutonium and additional development is needed for some organic solutions, this technology is not recommended.

\section{References}

Allen, C. R., and P. C. Ely. 1980. Acid Digestion of Combustible Wastes. HEDL-TME-79-64, Hanford Engineering Development Laboratory, Richland, Washington.

\section{Bibliography}

Lerch, R. E., C. R. Allen, A. G. Blasewitz, and E. Maestas. 1981. "Acid Digestion of Combustible Nuclear Wastes." Nuclear and Chemical Waste Management. Vol. 2, pp. 265-277.

Lerch, R. E. 1975. Application of Acid Digestion to Reprocessing Wastes and Chemicals. TC-362, Hanford Engineering Development Laboratory, Richland, Washington. 


\section{Description of Technologies}

Accept: — Reject: $\underline{\mathrm{X}}$

\section{Technology - Grind and Leach}

\section{Waste Processed}

Polycubes can be processed using the grind and leach technology.

\section{Process Description}

The process consists of grinding the polycubes into small pieces or slicing them into thin pieces. This process also could include cooling the polycubes in liquid nitrogen to cause the material to be brittle and shatter more easily. This method is common for size reducing some materials, but there is little experience with polycubes. Westinghouse Hanford Company personnel have tried this process in the laboratory with polycubes not containing plutonium or any substitute oxide. The process did not work well with a press. A milling machine or drill would work better, but the oxide powder might cause excessive wear on the equipment. The efficiency of leaching the plutonium from the polystyrene has not been demonstrated and may not reduce the plutonium levels sufficiently to dispose of the polystyrene as LLW. In the past some polycubes that had received a high neutron dose were found to be very brittle and could be cracked quite easily. It is not known whether the current cubes would be brittle. It is suspected they would be, but the leaching characteristics have not been determined by testing.

\section{Schedule}

Only minor development would be required. The process could be run at almost any suitable location. A minimum amount of space would be required.

\section{Final Product Description}

The final product would be an acid solution containing plutonium. Further treatment such as a calcination would be required to produce a stable, long-term storage form.

\section{Effluents Generated}

The effluent would be a slurry of wash solution and polystyrene fines that would require additional treatment. 


\section{Risks}

None. The reaction is not vigorous and does not form dangerous by-products.

\section{Justification for Further Study or Rejection}

The experience is limited and does ensure the polystyrene fines would not be TRU waste. This process will not be studied further. 


\section{Description of Technologies}

Accept: $\underline{X}$ Reject:

\section{Technology - Muffle Furnace}

\section{Waste Processed}

The muffle furnace technology can process plutonium oxide, plutonium $\left(\mathrm{C}_{2} \mathrm{O}_{4}\right)_{2}$, plutonium hydroxide, plutonium metal, and $\mathrm{PuF}_{4}$ (all material in the inventory designated as planned or being considered).

\section{Process Description}

The muffle furnace or thermal scrap stabilization process is a proposed action to operate two laboratory size muffle furnaces in Glovebox $\mathrm{HC}-21 \mathrm{C}$ at PFP. The furnaces would be used to stabilize reactive sludges by heating to approximately $500^{\circ}$ to $1000^{\circ} \mathrm{C}$. The furnace is set up to control oxidizing conditions and temperature to ensure controlled reactions. The plutonium-bearing material is oxidized with air at elevated temperatures to produce stable oxide granules. The powder is mostly plutonium oxide with impurities that would be screened and packaged. Unacceptable material would ground and recycled through the stabilization process. The batch process is limited to $500 \mathrm{~g} / \mathrm{batch}$ and the estimated throughput is 2 batches/d.

\section{Schedule}

Only minor demonstration is required, and it is currently being performed in the PFP support laboratory. The process would be run in Glovebox HC-21C, and/or additional furnaces could be added in any suitable glovebox location. A minimum amount of space is required. It would take many years to process all items, assuming additional stabilization is needed. Additional furnaces could be added, or many items that are currently considered stable would not need be processed unless monitoring information indicated problems.

\section{Final Product Description}

The final product would be a plutonium oxide powder, except for fluoride feeds. The fluorides would be dried at $300^{\circ} \mathrm{C}$ to remove moisture to prevent gas generation by radiolysis during storage. The oxides would sinter at a temperature high enough to minimize the quantity of fines. No additional treatment would be needed. 


\section{Effluents Generated}

The effluent generated would be $\mathrm{NO}_{x}$, carbon dioxide, and water vapor. If the feed contained volatile organics, they would be emitted from the furnace without destruction. It is possible the very fine divided powders would be entrained in the gas leaving the furnace. The furnace is equipped with a filter to minimize the release of particulates to the building ventilation system.

\section{Risks}

An uncontrolled reaction of plutonium metal or reactive material that was not indicated in material characterization could pressurize the furnace and release material into the glovebox and, in very severe cases, the room. The reactions are controlled by monitoring material put in the furnace, ensuring slow temperature ramps and maintaining temperature control.

\section{Justification for Further Study or Rejection}

Extensive experience exists with this process in the laboratory, and the process is very simple. This process should be considered for processing additional waste beyond that considered in the "Sludge Stabilization at the PFP" environmental assessment. ${ }^{(a)}$

(a) Preliminary draft of the Environmental Assessment - Sludge Stabilization At the Plutonium Finishing Plant, April 1994, U.S. Department of Energy, Richland, Washington. 


\section{Description of Technologies}

Accept: $\underline{X}$ Reject:

\section{Technology - Hydroxide Precipitation}

\section{Waste Processed}

Hydroxide precipitation can be used to process nitric, other, and chloride solutions containing plutonium (FXX).

\section{Process Description}

The precipitation of metal-laden aqueous solutions involves adding chemicals to alter the physical state of the dissolved or suspended metals and to facilitate their removal through sedimentation.

Hydroxide precipitation is accomplished by adjusting the $\mathrm{pH}$ of the aqueous solution to alkaline, which causes the soluble metal ions to form metal hydroxides (Martella et al. 1994). To remove plutonium from a solution, a base is added to adjust the $\mathrm{pH}$ to the point where the plutonium to be removed has the lowest solubility (usually ranging from 7 to 12 ). This treatment results in a metal sludge and a treatment effluent that has an elevated $\mathrm{pH}$. The precipitate is then filtered and can be processed using heat treatment technologies to form a stable plutonium oxide residue.

Many metal ions can be precipitated to form insoluble compounds, a number of which exhibit an affinity for sorption of other ions:

$$
\mathrm{M}^{\mathrm{n}+}+\mathrm{nOH}^{--}>\mathrm{m}(\mathrm{OH})_{\mathrm{n}}
$$

where $\mathrm{M}^{\mathrm{n}+}$ is plutonium and $\mathrm{n}$ can be calcium, $\mathrm{NH}^{4}$, sodium, potassium, or magnesium.

\section{Advantages}

A supernate containing a low plutonium concentration can be attained.

The system is simplistic.

The process does not require large capital investment.

The process is proven.

\section{Disadvantages}

The process may form a gelatinous precipitate that is difficult to filter.

The process results in poor purification (may be considered an advantage). 


\section{Historical Information}

Hydroxide precipitation using sodium hydroxide has been demonstrated at the Rocky Flats facility and at LANL to precipitate plutonium. The demonstration was on a laboratory scale. At the Rocky Flats facility, sodium hydroxide pellets were added to a 4-L bottle of plutonium waste solution. The supernate was decanted from the tops of the vessel after the precipitate settled. The precipitate was then filtered to dryness, requiring an extensive period of time. Before the advent of ion exchange, early production procedures at LANL used successive hydroxide precipitation for recovery of plutonium (III) or (IV).

Currently, LANL has been experimenting using magnesium hydroxide to precipitate plutonium from chloride and nitric solution with promising results.

The International Atomic Energy Agency (IAEA) $(1988,1992)$ has cited several instances where the common practice of radioactive waste management used ferric hydroxide precipitation, partly because ferric ions may already be present in some waste stream because of plant corrosion. In general, ferric hydroxide floc particles are larger and settle more easily than those of aluminum hydroxide. Ferric floc processes essentially involve the precipitation of ferric hydroxide either alone or in conjunction with other precipitate. Since some plant waste streams already contain iron at levels of 10 to $200 \mathrm{mg} / \mathrm{L}$, ferric hydroxide can be readily precipitated by the addition of alkali (e.g., $\mathrm{NaOH}, \mathrm{Ca}(\mathrm{OH})_{2}$, $\mathrm{Mg}(\mathrm{OH})_{2}$, or $\mathrm{NH}_{4} \mathrm{OH}$ ). Ferric hydroxide is stable over a wide $\mathrm{pH}$ range (5 to 15 ), but removes actinides most effectively at higher $\mathrm{pH}$ values. Ferric hydroxide forms a voluminous, gelatinous precipitate that may be difficult to handle. Conventional filtration is not very effective, so gravity settling is usually favored for the initial separation. Ferric floc treatment can be affected by the presence in waste streams of other components such as carbonate ions or some complexants (e.g., EDTA).

The same general procedure is used for other chemicals such as ammonium hydroxide, a combination of tannic acid and trisodium phosphate, a combination of iron and calcium phosphate, and those used for hydroxide precipitation.

\section{Facilities and Equipment}

The hydroxide precipitation process uses relatively inexpensive, off-the-shelf equipment. The process could be carried out in a glovebox on a bench scale in a batch mode, or a small continuous process could be built. For example, a $6 \mathrm{~m}^{3} / \mathrm{h}$ process to treat low to intermediate waste using sodium hydroxide requires a process tank of $1 \mathrm{~m}^{3}$ capacity, a floater $\left(3.9 \mathrm{~m}^{3}\right)$, and a settling vessel $\left(31 \mathrm{~m}^{3}\right)$ (IAEA 1992). The supernatant is processed through a filter to separate the precipitate and liquids. This process would generally require 2 to 3 operators (to monitor the process), a supervisor, and 2 to 3 technicians (to collect the precipitate from the filter and prepare it for the next process).

The RMC line located in the PFP currently has an oxalate precipitation in standby mode (WHC 1991). The precipitation takes place in a 6-in. stainless steel reactor vessel with a working volume of $2.7 \mathrm{~L}$ located in the RMC line. The process rate for this reactor is approximately $13.3 \mathrm{~L} / \mathrm{h}$. This process is 
Table A.16. Criteria Evaluations for Hydroxide Precipitation

\begin{tabular}{|c|c|}
\hline Criteria & Evaluation \\
\hline Technical Feasibility (technology maturity) & High \\
\hline $\begin{array}{l}\text { Effluents/By-Products } \\
\text { (minimize volumes, hazards) }\end{array}$ & $\begin{array}{l}\text { Metal hydroxides (e.g., plutonium hydroxide), } \\
\text { unreacted hydroxides }\end{array}$ \\
\hline Effluents Covered/SAR & High \\
\hline Energy Resource & $\begin{array}{l}\text { None, further processing required (e.g., thermal } \\
\text { treatment) }\end{array}$ \\
\hline Weapon Potential & Low volume, but further processing required \\
\hline End Product Volume & High, but further processing required \\
\hline End Product Stability & Unknown \\
\hline $\begin{array}{l}\text { Environmental and Public Risk } \\
\text { routine } \\
\text { accident }\end{array}$ & Unknown \\
\hline $\begin{array}{l}\text { Worker Risk } \\
\text { routine } \\
\text { accident }\end{array}$ & Low to medium \\
\hline $\begin{array}{l}\text { Cost } \\
\text { (construction, operations and D\&D) }\end{array}$ & Estimated at $10 \mathrm{~L} / \mathrm{h}$ \\
\hline Operation Duration & Unknown \\
\hline Public Acceptance & High \\
\hline Flexibility & Unknown \\
\hline Materials Covered & Most solution including nitric and chloride solutions \\
\hline
\end{tabular}


currently connected to a filter and calcining unit that may be used to process the precipitate to a plutonium oxide. A detailed evaluation of this process would be required to determine if this process could be modified to perform hydroxide precipitation.

\section{Schedule}

The process development would be minimal. The processing rate would depend on the size and type of process (batch or continuous). Assuming that the hydroxide precipitation process had a process rate of 3 items per day (approximately $24 \mathrm{~L} / \mathrm{d}$ ), a period of 150 work days would be required to process the FXX-solutions.

\section{Final Product Description}

The precipitation process is an intermediate process that prepares the plutonium-bearing waste for longterm stabilization. The primary product generated by this process is a precipitate (plutonium hydroxide) that can be readily treated to form a stable oxide using other processes, such as calcination. The volume of the precipitate is determined by the chemicals used; for example, $\mathrm{Mg}(\mathrm{OH})_{2}$ generates less volume than $\mathrm{CaOH}$. However, excess magnesium in the product increases the dose rate for the product. The process achieves low plutonium concentrations in the effluent but provides poor purification in the precipitate.

\section{Effluents Generated}

The primary effluent generated by this process is the aqueous liquids from the filter process. The aqueous liquids generally would have very low concentrations of plutonium at a neutral $\mathrm{pH}$ level. The liquids could be processed further to recover the low residuals using ion exchange units, or could be directed to storage in the waste tanks located in the tank farm.

\section{Costs}

The operational costs would include two to three operators to monitor the process, a supervisor, and two to three technicians to recover the precipitate from the filtration process. In addition, some chemical costs would be incurred.

The primary waste generated from this process is the filtrate from the filtration process. The filtrate could be either reprocessed to recover the low residuals or be sent to the waste tanks.

\section{Comments}

Table A.16 provides a summary of the criteria evaluations for hydroxide precipitation. Hydroxide precipitation using sodium hydroxide has been proven to be an extremely effective and cost-efficient 
process. Personnel at the PFP facility have had experience with this process. Based on the IAEA $(1988,1992)$ documentation, hydroxide precipitation is one of most effective ways to treat radioactive aqueous waste.

Many of the items on the inventory list may be processed in the dissolution phase using nitric acid to recover the plutonium in solution. It is possible that the solution can be processed using hydroxide precipitation.

\section{Justification for Further Study or Rejection}

Hydroxide precipitation has been studied and used successfully to recover plutonium for the last 45 years. This process has been well characterized and documented; therefore, this process has been accepted for further study.

\section{References}

International Atomic Energy Agency (IAEA). 1988. Treatment of Alpha-Bearing Wastes. Technical Report Series No. 287, International Atomic Energy Agency, Vienna, Austria.

International Atomic Energy Agency (IAEA). 1992. Chemical Precipitation Processes for the Treatment of Aqueous Radioactive Waste. Technical Report Series No. 337, International Atomic Energy Agency, Vienna, Austria.

Martella, L. L., M. T. Saba, and G. K. Campbell. 1984. Laboratory-Scale Evaluations of Alternative Plutonium Precipitation Methods. DOE/TIC-4500, Rev. 72, Rockwell International, Golden, Colorado.

Westinghouse Hanford Company (WHC). 1991. Safety Analysis Report for the Plutonium Finishing Plant. WHC-SD-CP-SAR-021, Westinghouse Hanford Company, Richland, Washington.

\section{Bibliography}

American Society of Mechanical Engineers (ASME). 1986. Radioactive Waste Technology. American Society of Mechanical Engineers and the American Nuclear Society, United Engineering Center, New York.

Commission of the European Communities (CEN). 1981. Radioactive Waste: Advanced Management Methods for Medium Active Liquid Waste. Commission of the European Communities, Brussels.

Glynn, W. C., A. Baker, A. Lore, A. Quaglieri. 1987. Mobile Waste Processing Systems and Treatment Technologies, Noyes Data Corporation, Park Ridge, New Jersey. 
International Atomic Energy Agency (IAEA). 1994. Treatment of Low and Intermediate-Level Radioactive Wastes, Technical Report Series No. 236, International Atomic Energy Agency, Vienna, Austria.

Pacific Northwest Laboratory (PNL). 1993. Remedial Action Assessment System (RAAS). PNL-8751, Pacific Northwest Laboratory, Richland, Washington. 


\section{Description of Technologies}

Accept: $\underline{X}$ Reject:

\section{Technology - Oxalate Precipitation}

\section{Waste Processed}

Oxalate precipitation can be used to process nitric solutions containing plutonium (F01, and maybe some F00).

\section{Process Description}

The precipitation of metal-laden aqueous solutions involves the addition of chemicals to alter the physical state of the dissolved or suspended metals and to facilitate their removal through sedimentation.

Oxalic acid is added to plutonium nitrate feed (direct strike), plutonium nitrate is added to oxalate acid (reverse strike), or both streams are added simultaneously (continuous process) (Martella et al. 1994). The direct strike method produces larger particles and is, therefore, most desirable as a conversion method. The plutonium (IV) oxalate precipitation equation may be written as

$$
6 \mathrm{H}_{2} \mathrm{O}+\mathrm{Pu}\left(\mathrm{NO}_{3}\right)_{4}+2 \mathrm{H}_{2} \mathrm{C}_{2} \mathrm{O}_{4}->\mathrm{Pu}\left(\mathrm{C}_{2} \mathrm{O}_{4}\right)_{2} * 6 \mathrm{H}_{2} \mathrm{O}_{\mathrm{ppt}}+4 \mathrm{HNO}_{3}
$$

The plutonium (III) oxalate precipitation equation may be written as

$$
10 \mathrm{H}_{2} \mathrm{O}+2 \mathrm{Pu}\left(\mathrm{NO}_{3}\right)_{3}+3 \mathrm{H}_{2} \mathrm{C}_{2} \mathrm{O}_{4} \rightarrow>\mathrm{Pu}_{2}\left(\mathrm{C}_{2} \mathrm{O}_{4}\right)_{3} * 10 \mathrm{H}_{2} \mathrm{O}_{\mathrm{ppt}}+6 \mathrm{HNO}_{3}
$$

Nitrate feeds prior to precipitation can range from 1 to $300 \mathrm{~g} / \mathrm{L}$ plutonium. The plutonium nitrate feed must contain enough acid to make the final slurry 1.5 to $4.5 \underline{\mathrm{M}} \mathrm{HNO}^{3}$. Acidities below $1.5 \underline{\mathrm{M}}$ produce fine particles too small to filter and increase co-precipitation of impurities. Acidities higher than $4.5 \underline{\mathrm{M}}$ increase plutonium solubility and form a precipitate that is thixotropic. Valence adjustment of plutonium (IV) using hydrogen peroxide is necessary if plutonium (III) or (VI) is present. Oxalate acid is added at a temperature of $50^{\circ} \mathrm{C}$ for plutonium (IV) and at room temperature for plutonium (III).

After filtration, the precipitate can be washed with low concentrations of oxalate acid and/or $\mathrm{HNO}_{3}$ to remove impurities. The plutonium oxalate cake can then be calcined to produce plutonium oxide. 
Advantages

\begin{tabular}{|c|}
\hline Plutonium (IV) Oxalate \\
\hline $\begin{array}{l}\text { Solids and solutions are more } \\
\text { stable than peroxide } \\
\text { precipitation. }\end{array}$ \\
\hline $\begin{array}{l}\text { Solutions containing high } \\
\text { concentrations of metal } \\
\text { impurities do not decompose } \\
\text { as does peroxide. }\end{array}$ \\
\hline $\begin{array}{l}\text { This process results in a high } \\
\text { decontamination of } \\
\text { impurities. }\end{array}$ \\
\hline
\end{tabular}

It is the most widely used of all conversion methods.

Fast filtration is possible.

This technology is capable of producing particles up to $40 \mu \mathrm{m}$.
Disadvantages

\begin{tabular}{lll}
\hline \multicolumn{1}{c}{ Plutonium (IV) Oxalate } & & Plutonium (III) Oxalate \\
\hline $\begin{array}{l}\mathrm{H}_{2} \mathrm{O}_{2} \text { used for valence } \\
\text { adjustments can be reacted } \\
\text { rapidly. }\end{array}$ & $\begin{array}{l}\text { The process does not decon- } \\
\text { taminate from cationic } \\
\text { impurities. }\end{array}$
\end{tabular}

Ions of iron, chromium, nic-

$\mathrm{kel}$, and uranium are

decontaminated.

Less process control is required than other methods.

Precipitate settles and filters rapidly.

The process does not decontaminate americium to acceptable limits.

The carbon content may exceed limits for oxide if calcination and fluorination are incomplete.

Two reagents are needed for valence adjustments.

More oxalic acid is necessary compared to oxalate (IV), thus increasing process volume.

\section{Historical Information}

Elevated temperatures $\left(50^{\circ} \mathrm{C}\right)$ are required for success.

The PFP has used an oxalate precipitation system in the RMC line to precipitate plutonium (IV) from plutonium nitrate solutions from various sources, such as PUREX, that are contained in cans (WHC 1991). This process has been used successfully as a intermediate step in producing plutonium buttons. This process worked successfully but produced large volumes of filtrates and large filtrate losses for rework or discard. This process is not feasible with evaporated filtrates having high manganese content because manganese catalyzes the decomposition of hydrogen peroxide.

Oxalate precipitation has been examined by the IAEA on intermediate level waste at the Joint Research Centre, Ispra, and the Joint Research Centre, Karlsruhe (IAEA 1992). The OXAL process developed at Ispra uses cesium as a carrier and provides DFs of about 200 for plutonium and of about 1700 for americium at $\mathrm{pH}=0$ to 1 . Decontamination factors as high as 5000 for americium were obtained by using calcium, but the maximum DFs for plutonium were in the range of 50 to 80 . Calcium gave the highest DFs for both plutonium and americium used at a carrier to an actinide ratio of 500:1. With the separation of actinides from some fission products, the DFs obtained were generally lower than those achieved by ferric floc and related processes; oxalate precipitations have not been investigated for the removal of low-level activity in waste streams. Finally, the chemicals used are not particularly attractive because they are relatively expensive and could create a toxicity hazard in the effluent. 


\section{Facilities and Equipment}

The RMC line located in the PFP currently has an oxalate precipitation in standby mode. The reactor where the precipitation takes place is in a 6-in. stainless steel vessel with a working volume of $2.7 \mathrm{~L}$ located in the RMC line. The process rate for this reactor is approximately $13.3 \mathrm{~L} / \mathrm{h}$. This process is currently connected to a filter and calcining unit that may be used to further process the precipitate to a plutonium oxide.

\section{Schedule}

To restart the RMC line oxalate precipitation process, a readiness review would be required, and instruments and controls would need to be refurbished.

\section{Final Product Description}

The primary product would be a plutonium oxalate precipitate that would be ready to undergo a thermal treatment, such as calcination, for conversion to a plutonium oxide.

\section{Effluents Generated}

The primary effluent generated would contain OXAL acid and residual plutonium that most likely would require a rework step.

\section{Costs}

The existing oxalate precipitation may be started up again, which would probably require a readiness review and some instrument and control upgrades.

The operational cost would require two to three operators to monitor the process, a supervisor, and two to three technicians to recover the precipitate from the filtration process. In addition, some chemical costs would be incurred. The effluent would have to be reworked and might require additional operators.

\section{Comments}

Table A.17 summarizes the criteria evaluations for this technology. The general impression gleaned from the literature (IAEA 1988, 1992, 1994) and discussions with personnel at the PFP is that oxalate precipitation is a process for plutonium production, but is not particularly well suited to treat waste material because of high plutonium losses to the filtrate. 
Table A.17. Criteria Evaluations for Oxalate Precipitation

\begin{tabular}{|c|c|}
\hline Criteria & Evaluation \\
\hline Technical Feasibility (technology maturity) & High \\
\hline $\begin{array}{l}\text { Effluents/By-Products } \\
\text { (minimize volumes, hazards) }\end{array}$ & $\begin{array}{l}\text { Nitric acid and plutonium oxalate, } \\
\text { unreacted plutonium nitrate }\end{array}$ \\
\hline Effluents Covered/SAR & High \\
\hline Energy Resource & Further processing required \\
\hline Weapon Potential & $\begin{array}{l}\text { Low volume, but with further } \\
\text { processing (e.g., thermal treatment) }\end{array}$ \\
\hline End Product Volume & High, but further processing required \\
\hline End Product Stability & Unknown \\
\hline $\begin{array}{l}\text { Environmental and Public Risk } \\
\text { routine } \\
\text { accident }\end{array}$ & Unknown \\
\hline $\begin{array}{l}\text { Worker risk } \\
\text { routine } \\
\text { accident }\end{array}$ & Low, use existing system \\
\hline $\begin{array}{l}\text { Cost } \\
\text { (construction, operations and D\&D) }\end{array}$ & Estimate $13 \mathrm{~L} / \mathrm{h}$ \\
\hline Operation Duration & Medium \\
\hline Public Acceptance & Most nitric solutions \\
\hline Flexibility & Unknown \\
\hline Materials Covered & Unknown \\
\hline
\end{tabular}




\section{Justification for Further Study or Rejection}

Currently, there is an oxalate precipitation process that exists in the RMC line. This process includes a filtration process and a calcination unit. One of the primary issues with this process is that there are significant plutonium losses in the filtrate. The original process was designed for plutonium production rather than for stabilization. The filtrate would have to be reworked using a hydroxide precipitation process.

\section{References}

International Atomic Energy Agency (IAEA). 1988. Treatment of Alpha Bearing Wastes. Technical Report Series No. 287, International Atomic Energy Agency, Vienna, Austria.

International Atomic Energy Agency (IAEA). 1992. Chemical Precipitation Processes for the Treatment of Aqueous Radioactive Waste. Technical Report Series No. 337, International Atomic Energy Agency, Vienna, Austria.

International Atomic Energy Agency (IAEA). 1994. Treatment of Low and Intermediate-Level Radioactive Wastes. Technical Report Series No. 236, International Atomic Energy Agency, Vienna, Austria.

Martella, L. L., M. T. Saba, and G. K. Campbell. 1984. Laboratory-Scale Evaluations of Alternative Plutonium Precipitation Methods. DOE/TIC-4500, Rev. 72, Rockwell International, Golden, Colorado.

Westinghouse Hanford Company (WHC). 1991. Safety Analysis Report for the Plutonium Finishing Plant. WHC-SD-CP-SAR-021, Westinghouse Hanford Company, Richland, Washington.

\section{Bibliography}

American Society of Mechanical Engineers (ASME). 1986. Radioactive Waste Technology. American Society of Mechanical Engineers and the American Nuclear Society, United Engineering Center, New York.

Collins, P. E. 1952. Production Test 234-5 Supplement A Plant Process Evaluation Precipitation of Plutonium (IV) Oxalate. HW-24898, Hanford Works, Richland, Washington.

Commission of the European Communities (CEN). 1981. Radioactive Waste: Advanced Management Methods for Medium Active Liquid Waste. Commission of the European Communities, Brussels, Belgium. 
Hill, O. F., and F. J. Leitz. 1951. Progress Report for December, 1950 Chemical Research Section. HW-20053, Hanford Works, Richland, Washington.

Pacific Northwest Laboratory (PNL). 1993. Remedial Action Assessment System (RAAS). PNL-8751, Pacific Northwest Laboratory, Richland, Washington. 


\section{Description of Technologies}

Accept: _ Reject: $\underline{X}$

\section{Technology - Peroxide Precipitation}

\section{Waste Processed}

Wastes to be processed include these nitric solutions containing plutonium (F01) and, possibly, other solutions that do not contain organics or substances that will react with hydrogen peroxide. Hydrogen peroxide is a powerful oxidant and a somewhat less powerful reductant. Hydrogen peroxide will oxidize many organic substances, particularly when there are unsaturated carbon bonds where attack can take place. Hydrogen peroxide can be used to oxidize most sulphur-containing compounds, nitrites, and hydrazine and has the advantage of not adding to the dissolved solid concentration.

\section{Process Description}

The precipitation of metal-laden aqueous solutions involves the addition of chemicals to alter the physical state of the dissolved or suspended metals and to facilitate their removal through sedimentation.

Plutonium nitrate feed solution ( 20 to $100 \mathrm{~g} \mathrm{Pu} / \mathrm{L}$ ) is adjusted to approximately $4 \underline{\mathrm{M}} \mathrm{HNO}_{3}$ because at acidities of less than $2 \underline{\mathrm{M}}$, an undesirable colloidal face-centered, cubic-phase precipitate is formed that is more dense and difficult to filter (Martella et al. 1984). Plutonium peroxide is soluble at acidities greater than $5 \underline{\mathrm{M}}$. Precipitate formation is also dependent upon peroxide addition and mixing. A slow and uniform initial peroxide addition $(3 \mathrm{~L} / \mathrm{h})$, along with slow mixing, forms a more stable, easily filtered precipitate. Sulfate $(0.05 \underline{\mathrm{M}})$ is sometimes added to the feed to add in coagulating the colloids present, which improves filterability. Although this improvement affects the efficiency of the fluorination cycle, it is not a consideration because the fluorination cycle is associated with the production process. During precipitation, the temperature of the solution is cooled to less than $15^{\circ} \mathrm{C}$ to prevent catalytic decomposition of peroxide caused by metallic impurities. The precipitate cake remaining after filtration is then washed with $0.35 \underline{\mathrm{M}} \mathrm{HNO}_{3}$ and is ready to be treated thermally using a process, such as calcination, to produce a plutonium oxide. The filtrate is then boiled to destroy the remaining peroxide. 
Using this process, americium has been decontaminated below appreciable limits at Rocky Flats.

This process achieves the highest decontamination rate from most cation impurities of all precipitation processes.

$\mathrm{H}_{2} \mathrm{O}_{2}$ does not add other impurities to the stream.

$\mathrm{H}_{2} \mathrm{O}_{2}$ is readily destroyed by boiling.

Optimal particle size formation for successive fluorination.
Disadvantages

$\mathrm{H}_{2} \mathrm{O}_{2}$ can decompose violently in the presence of certain metal impurities (iron, copper, manganese, etc.), requiring refrigeration during precipitation.

Precipitate is not stable and decomposes.

Filtrate losses are sometimes higher than other processes.

A high calcination temperature $\left(950^{\circ} \mathrm{C}\right)$ is required to volatize sulfate, if it is present.

Halogens and nitrates are carried in the crystal lattice.

\section{Historical Information}

The Rocky Flats facility has used the peroxide precipitation process. For completeness of precipitation, a several-fold excess peroxide-to-plutonium ratio beyond stoichiometric is required (Martella et al. 1984). Rocky Flats production adds at least an excess of $10 \underline{\mathrm{M} \mathrm{H}} \mathrm{H}_{2} / \underline{\mathrm{M}} \mathrm{Pu}$ using a $35 \%$ solution of $\mathrm{H}_{2} \mathrm{O}_{2}$ at $10 \mathrm{~L} / \mathrm{h}$.

Experiments have been conducted at the Hanford Site to examine the characteristics of peroxide precipitation. Using solutions that did not contain excess acid, the addition of $30 \% \mathrm{H}_{2} \mathrm{O}_{2}$ resulted in almost an immediate precipitation of plutonium peroxide with low losses. Using solutions with high acid (5.5 $\underline{\mathrm{M}}$ ) or partially neutralized (from $5.5 \underline{\mathrm{M}}$ to $2 \underline{\mathrm{M}} \mathrm{HNO}_{3}$ ) provided poor results when the $\mathrm{H}_{2} \mathrm{O}_{2}$ was added. Precipitation was very slow, the $\mathrm{H}_{2} \mathrm{O}_{2}$ decomposition was extensive, and losses were relatively higher.

\section{Final Product Description}

The primary product would be a plutonium peroxide precipitate that would be ready to undergo a thermal treatment, such as calcination, for conversion to plutonium oxide.

\section{Effluents Generated}

The primary effluent generated would be at or near a neutral $\mathrm{pH}$ level and may contain residual plutonium that may require a rework step. 


\section{Comments}

Peroxide precipitation appears to be a process for plutonium production using a relatively pure plutonium nitrate solution and is not particularly well-suited to treat waste material because of plutonium lost with the filtrate. Contaminants in the nitrate solution may oxidize violently with the peroxide. The filtrate will most likely be reworked using hydroxide precipitation to recover the residual plutonium. Finally, the IAEA $(1988,1992,1994)$ documentation that reviewed the treatments for aqueous organic waste did not cite instances where the aqueous wastes used peroxide precipitation.

\section{Justification for Further Study or Rejection}

This process should be rejected because of high plutonium losses to the filtrate. Also, hazards associated with handling hydrogen peroxide are another reason to reject the hydroxide peroxide precipitation process.

\section{References}

International Atomic Energy Agency (IAEA). 1988. Treatment of Alpha Bearing Wastes. Technical Report Series No. 287, International Atomic Energy Agency, Vienna, Austria.

International Atomic Energy Agency (IAEA). 1992. Chemical Precipitation Processes for the Treatment of Aqueous Radioactive Waste. Technical Report Series No. 337, International Atomic Energy Agency, Vienna, Austria.

International Atomic Energy Agency (IAEA). 1994. Treatment of Low- and Intermediate-Level Radioactive Wastes. Technical Report Series No. 236, International Atomic Energy Agency, Vienna, Austria.

Martella, L. L., M. T. Saba, and G. K. Campbell. 1984. Laboratory-Scale Evaluations of Alternative Plutonium Precipitation Methods. DOE/TIC-4500, Rev. 72, Rockwell International, Golden, Colorado.

\section{Bibliography}

American Society of Mechanical Engineers (ASME). 1986. Radioactive Waste Technology. American Society of Mechanical Engineers and the American Nuclear Society, United Engineering Center, New York. 
Commission of the European Communities (CEN). 1981. Radioactive Waste: Advanced Management Methods for Medium Active Liquid Waste. Commission of the European Communities, Brussels, Belgium.

Hill, O. F., and F. J. Leitz. 1951. Progress Report for December, 1950 Chemical Research Section. HW-20053, Hanford Works, Richland, Washington.

Pacific Northwest Laboratory (PNL). 1993. Remedial Action Assessment System (RAAS). PNL-8751, Pacific Northwest' Laboratory, Richland, Washington. 


\section{Description of Technologies}

Accept: _ Reject: $\underline{X}$

\section{Technology - Evaporation}

\section{Process Description}

Evaporation concentrates contaminants into a small volume of residual aqueous solution. Evaporation usually makes subsequent treatment more efficient and economical. Because the solute is generally non-volatile, the vapor/condensate is normally free of contamination, which distinguishes this technology from distillation (PNL 1993).

Evaporation is a proven method for the treatment of liquid radioactive wastes that provides good DFs and concentration factors. It is widely applied in nuclear facilities, and the advantages and limitations are well defined and clearly understood. Evaporation is probably the best technique for wastes having relatively high salt content (i.e., those wastes having a high electrical conductivity, a relatively low volume, and needing high $\mathrm{DFs}$ ).

The evaporation of liquid radioactive wastes with lower salt content $(1 \mathrm{to} 5 \mathrm{~g} / \mathrm{L}$ ) is normally carried out in two stages. Decontamination is performed in the first stage, and concentration is carried out in the second stage. In this manner, the conditions for decontamination concentration can be optimized independently. In the case of liquid radioactive wastes with high salt content, the process is usually carried out in one stage.

Details for the specific features of evaporators and a list of operational nuclear evaporators are provided by the IAEA $(1984,1988)$.

\section{Advantages}

Evaporation is a relatively simple operation.

The process has been used in the chemical industry for many years.

This process is a good intermediate step for reducing liquid volume and increasing the plutonium concentration that increases the DFs.
Disadvantages

There is a relatively high operating cost.

Erosion problems due to high temperatures and high liquid and vapor velocities exist.

There also are foaming problems.

Scaling problems exist: hard scaling caused by sulfate salts and silicates, soft scaling caused by carbonate salts and hydroxide salts. 


\section{Historical Information}

A typical alpha waste evaporator is operated at Belloprocess, Belgium (formally the Eurochemic Plant). It is a vertical-forced-circulation evaporator with a throughput of $1.5 \mathrm{~m}^{3} / \mathrm{h}$ concentrating liquid waste with activities exceeding $0.37 \mathrm{GBq} / \mathrm{m}^{3}$ beta/gamma and/or $3.7 \mathrm{MBq} / \mathrm{m}^{3}$ alpha (IAEA 1988). The concentration is controlled either by upper activity $\left(111 \mathrm{GBq} / \mathrm{m}^{3}\right.$ alpha or $37 \mathrm{TBq} / \mathrm{m}^{3}$ beta/gamma) or by salt concentration limits $\left(250 \mathrm{~kg} / \mathrm{m}^{3}\right)$.

At the KfK, Germany, intermediate-level liquid wastes arising from the Center's research activities and the WAK prototype reprocessing facility are evaporated in a natural convection evaporator with a throughput of $1 \mathrm{~m}^{3} / \mathrm{h}$ (IAEA 1988). The salt content of the raw waste amounts to about $3 \mathrm{~g} / \mathrm{L}$, its beta/ gamma activity amounts to $2.96 \mathrm{MBq} / \mathrm{mL}$, and the alpha activity amounts to $44 \mathrm{kBq} / \mathrm{mL}$. DFs of $10^{3}$ are achieved. The salt content of the evaporator is limited to $250 \mathrm{~g} / \mathrm{L}$.

Evaporation is also used at the Rocky Flats facility to concentrate plutonium waste streams (IAEA 1988). The process liquor is first decontaminated by chemicals, and the sludges are then fed to a multiple effect evaporator, which comprises four units in series. This is a forced-circulation, externally heated, vertical evaporator. The distillate is recycled, and the concentrate is spray dried. The capacity is about $15 \mathrm{~m}^{3} / \mathrm{h}$ and, according to the precipitation performance, the evaporator input concentrations are on the order of $10^{-8} \mathrm{~g} \mathrm{Pu} / \mathrm{L}$ and $10^{-11} \mathrm{~g} \mathrm{Am} / \mathrm{L}$.

Two types of steam evaporators are used in the PRF: one for concentrating product and one for concentrating aqueous waste (WHC 1991). The product concentrator is designed to increase the plutonium content in the aqueous product from a nominal value of $50 \mathrm{~g} \mathrm{Pu} / \mathrm{L}$ to about $250 \mathrm{~g} \mathrm{Pu} / \mathrm{L}$. The product concentrator is a steam jacketed, "falling film" type evaporator. Internal "steam stripping" inside the concentrator heats the product solution. Any organic contained in the solution atomizes into an organic vapor as it contacts the hot surface of the rasching rings. The concentrator steam jacket heats the vessels, which helps evaporate water. Nitric acid is added to adjust the acidity and prevent the formation of plutonium hydroxide polymer. The product can then be centrifuged to remove any suspended solids.

The aqueous waste concentrator evaporated waste solutions collected from solvent extraction (the CU and OA columns), the RMC oxalate filtrate "kill" tank, various gloveboxes, catch tanks, tank drains, and solutions picked up from hood and canyon floors (WHC 1991). The waste concentrator increases the plutonium content in the concentrate stream from a nominal value of $<0.5 \mathrm{~g} \mathrm{Pu} / \mathrm{L}$ up to $8 \mathrm{~g} \mathrm{Pu} / \mathrm{L}$. These solutions were filtered before being pumped to the evaporator feed tank. Nitric acid is added to adjust the acidity and prevent the formation of plutonium hydroxide polymer. Antifoaming agents are used when heating the oxalate filtrate for the RMC line; carbon dioxide is produced when destroying oxalate by heating. The feed waste solution is then pumped to the steam heated evaporator, where the solution is boiled to reduce it volume. The concentrated waste can then be treated using other technologies. 


\section{Facilities and Equipment}

The PRF currently has these processes, which are operated semi-remotely, in standby mode. To restart the evaporation process, a readiness review would be required and instruments and controls would need to be refurbished.

Another approach to evaporation is to use beakers placed on a heating plate in the MT-5 Glovebox. ${ }^{\text {(a) }}$ The concern about red oil production would be reduced significantly because the evaporation temperature would be $100^{\circ} \mathrm{C}$ at atmospheric conditions. The MT- 5 Glovebox currently contains a condenser that could be used as the reflux device to condense the vapors into another container. The processing rates would be very slow.

\section{Final Product}

The final product would be a concentrated liquid (with a plutonium concentration up to $350 \mathrm{~g} \mathrm{Pu} / \mathrm{L}$ ) that could be further treated to stabilize the plutonium.

\section{Effluents Generated}

The primary effluent generated would be the condensate from the evaporation units. The condensate may contain extremely low concentrations of plutonium $(<=0.0132 \mathrm{~g} \mathrm{Pu} / \mathrm{L})$ that may be transferred to the waste tanks.

\section{Comments}

Table A. 18 summarizes the criteria evaluations for the evaporation process. One concern pertaining to using evaporators is red oil formation. An explosive nitration product of TBP and its degradation products, red oil, can be produces during heating. When the temperature of TBP-Pu( $\left(\mathrm{NO}_{3}\right)-\mathrm{HNO}_{3}$ moisture reaches a level high enough to decompose plutonium nitrate, the $\mathrm{NO}_{2}$ produces nitrates in the organic. Three conditions are necessary for red oil formation during the concentration of plutonium nitrate solutions: (1) temperature above $150^{\circ} \mathrm{C}$, (2) a minimum $\mathrm{TBP} / \mathrm{plutonium}$ ration of 0.15 , and (3) conditions of incipient calcination with violent $\mathrm{NO}$ and $\mathrm{NO}_{2}$ release. To prevent the formation of red oil, live steam is used to strip TBP in the product concentrator. Steam pressures limited to $0.2 \mathrm{~m}$ pascal, which limits the temperature to $135^{\circ} \mathrm{C}$, in both the filtrate and product concentrations.

(a) 1994 personal communication between Antonio Villegas (PNL) and George Miller (WHC). 
Table A.18. Criteria Evaluations for Evaporation

\begin{tabular}{|c|c|}
\hline Criteria & Evaluation \\
\hline Technical Feasibility (technology maturity) & High \\
\hline $\begin{array}{l}\text { Effluents/By-Products } \\
\text { (minimize volumes, hazards) }\end{array}$ & $\begin{array}{l}\text { Depending on solution being evaporated, water, } \\
\mathrm{HNO}_{3} \text {, and } \mathrm{HCL} \text { solutions containing only small } \\
\text { amounts of plutonium }\end{array}$ \\
\hline Effluents Covered/SAR & High, most are covered in SAR \\
\hline Energy Resource & Unknown \\
\hline Weapon Potential & Unknown \\
\hline End Product Volume & Lower volume \\
\hline End Product Stability & Unknown \\
\hline $\begin{array}{l}\text { Environmental and Public Risk } \\
\text { routine } \\
\text { accident }\end{array}$ & Unknown \\
\hline $\begin{array}{l}\text { Worker Risk } \\
\text { routine } \\
\text { accident }\end{array}$ & Unknown \\
\hline $\begin{array}{l}\text { Cost } \\
\text { (construction, operations and D\&D) }\end{array}$ & Low \\
\hline Operation Duration & Unknown \\
\hline Public Acceptance & Unknown \\
\hline Flexibility & Applicable to all solutions that require concentration \\
\hline Materials Covered & Applicable to all solutions that require concentration \\
\hline
\end{tabular}




\section{References}

International Atomic Energy Agency (IAEA). 1988. Treatment of Alpha Bearing Wastes. Technical Report Series No. 287, International Atomic Energy Agency, Vienna, Austria.

International Atomic Energy Agency (IAEA). 1984. Treatment of Low- and Intermediate-Level Radioactive Wastes. Technical Report Series No. 236, International Atomic Energy Agency, Vienna, Austria.

Pacific Northwest Laboratory (PNL). 1993. Remedial Action Assessment System (RAAS). PNL-8751, Pacific Northwest Laboratory, Richland, Washington.

Westinghouse Hanford Company (WHC). 1991. Safety Analysis Report for the Plutonium Finishing Plant. WHC-SD-DP-SAR-021, Westinghouse Hanford Company, Richland, Washington.

\section{Bibliography}

American Society of Mechanical Engineers (ASME). 1986. Radioactive Waste Technology. American Society of Mechanical Engineers and the American Nuclear Society, United Engineering Center, New York. 
A. 164 


\section{Description of Technologies}

Accept: _ Reject: $\underline{X}$

\section{Technology - Ammonia Precipitation}

\section{Waste Processed}

This precipitation process has been demonstrated as one that can separate plutonium and uranium from nitric acid solutions. Items from the inventory list that would most likely be processed could include all nitric acid solutions (FO1), solutions containing plutonium and uranium (F40, F50, F70), and possibly some nonconforming solutions (F00).

\section{Process Description}

The precipitation of metal-laden aqueous solutions involves the addition of chemicals to alter the physical state of the dissolved or suspended metals and to facilitate their removal through sedimentation.

Precipitation using ammonia is accomplished by adjusting the $\mathrm{pH}$ of the aqueous solution to alkaline, which causes the soluble metal ions to form metal hydroxides (IAEA 1988, 1992). This process has been used to coprecipitate uranium diuranate and plutonium hydroxide. To remove plutonium and uranium from solution, ammonia is added to adjust the $\mathrm{pH}$ to the point where the plutonium to be removed has the lowest solubility (usually ranging from 7 to 12 ). This treatment results in a metal sludge and a treatment effluent that has an elevated $\mathrm{pH}$. The primary product is a precipitate that can be filtered and processed using heat treatment technologies to form a stable plutonium-uranium oxide residue.

$$
\begin{gathered}
\mathrm{Pu}\left(\mathrm{NO}_{3}\right)_{4}+4 \mathrm{NH}_{4}+4 \mathrm{H}_{2} \mathrm{O}->\mathrm{Pu}(\mathrm{OH})_{4}+4 \mathrm{NH}_{4} \mathrm{NO}_{3} \\
2 \mathrm{UO}_{2}\left(\mathrm{NO}_{3}\right)_{2}+5 \mathrm{NH}_{3}+5 \mathrm{H}_{2} \mathrm{O}->2 \mathrm{UO}_{3} \mathrm{NH}_{3} 3 \mathrm{H} 2 \mathrm{O}+4 \mathrm{NH}_{4} \mathrm{NO}_{3} \\
\mathrm{HNO}_{3}+\mathrm{NH}_{3}->\mathrm{NH}_{4} \mathrm{NO}_{3}
\end{gathered}
$$

The precipitate is then separated from the solution. The precipitate formed is a gelatinous "slimy" precipitate. In general, experience has shown that the precipitate is difficult to handle and filter because of its gelatinous nature. After separating the precipitate from the solution, the precipitate undergoes further stabilization through heat treatment to form uranium oxide and plutonium oxide.

There have been efforts to reduce the number of processing steps to overcome the problem of gelatinous filtrate. One such process is called the Copercal process (Breisch et al. 1979). This process is basically a two-step process that eliminates the filtering process. The first step is the coprecipitation 
step using ammonia. The solution and precipitate is then calcined together to produce uranium oxide and plutonium oxide. One of the primary drawbacks with the Copercal process is that a mastic material is formed during calcining that significantly reduces its efficiency and reliability. The advantages and disadvantages of this process are listed below.

Advantages

Ammonia precipitation can attain a supernate containing a low plutonium concentration.

The process offers a simplistic system.

It does not require large capital investment.
Disadvantages

The process forms a gelatinous precipitate that is difficult to filter and calcine.

It is primarily used for coprecipitation of plutonium and uranium during production campaigns.

Ammonia precipitation is a proven precipitation process.

\section{Facilities and Equipment}

The ammonium precipitation process can use relatively inexpensive, off-the-shelf equipment. The process could be carried out in a glovebox on a bench scale in a batch mode, or a small continuous process could be built. The design would be such that it would be critically safe. The supernatant is processed through a filter to separate the precipitate and liquids. This process would generally require two to three operators to monitor the process, a supervisor, and two to three technicians to collect the precipitate from the filter and prepare it for the next process.

The equipment could be similar in size and design to the oxalate precipitation process used in the RMC line (WHC 1991). The reactor that the precipitation takes place is a $15-\mathrm{cm}$ stainless steel vessel with a working volume of $2.7 \mathrm{~L}$. The process rate for this reactor is approximately $13.3 \mathrm{~L} / \mathrm{h}$. The cost for similar equipment is not known, but because of the nature of its size and capacity, minimal equipment purchases would be required.

\section{Schedule}

The process development would be minimal. The processing rate would depend on the size and type of process (batch or continuous). Assuming that the hydroxide precipitation process had a process rate of three items a day, (approximately $24 \mathrm{~L} / \mathrm{d}$ ), a period of 150 workdays would be required to process the FXX-solutions. This schedule assumes a daily startup period to calibrate the equipment, sampling, and daily shutdown period. 


\section{Final Product Description}

The precipitation process is an intermediate process that prepares the plutonium-bearing waste for longterm stabilization. The primary product generated by this process is a precipitate (plutonium hydroxide) that can be readily treated to form a stable oxide using other processes, such as calcination. The process can achieve low plutonium concentrations in the effluent but provides poor purification in the precipitate.

\section{Effluents Generated}

The primary effluents generated by this process are the aqueous liquids from the filter process. The aqueous liquids generally would have very low concentrations of plutonium at a neutral $\mathrm{pH}$ level. The liquids could be processed further to recover the low residuals using ion exchange units or could be directed to storage in the waste tanks located in the tank farm.

\section{Cost}

The operational cost would include two to three operators (who would be required to monitor the process), a supervisor, and two to three technicians to recover the precipitate from the filtration process. In addition, some chemical costs would be incurred.

The primary waste generated from this process is the filtrate from the filtration process. The filtrate could be either reprocessed to recover the low residuals or be sent to the waste tanks.

\section{Justification for Further Study or Rejection}

Table A.19 provides the criteria evaluations for ammonia precipitation. Ammonia precipitation has been studied and evaluated as a possible process since the 1970 s as a means of coprecipitation to recover plutonium and uranium. One of the major drawbacks is the formation of a gelatinous precipitate that makes filtering difficult. In addition, a mastic stage is formed during calcination that can significantly reduce the efficiency of the calciner. ${ }^{(a)}$

(a) 1994 personal communication between Antonio Villegas (PNL) and George Miller (WHC). 
Table A.19. Criteria Evaluations for Ammonia Precipitation

\begin{tabular}{|c|c|}
\hline Criteria & Evaluation \\
\hline Technical Feasibility (technology maturity) & Medium to high \\
\hline $\begin{array}{l}\text { Effluents/By-Products } \\
\text { (minimize volumes, hazards) }\end{array}$ & $\begin{array}{l}\text { Ammonia, ammonia nitrate, uranium compounds, } \\
\text { unreacted plutonium nitrate, gelatinous precipitate }\end{array}$ \\
\hline Effluents Covered/SAR & Most likely \\
\hline Energy Resource & Unknown \\
\hline Weapon Potential & None, further processing required \\
\hline End Product Volume & Further processing required \\
\hline End Product Stability & Further processing required \\
\hline $\begin{array}{l}\text { Environmental and Public Risk } \\
\text { routine } \\
\text { accident }\end{array}$ & Unknown \\
\hline $\begin{array}{l}\text { Worker Risk } \\
\text { routine } \\
\text { accident }\end{array}$ & Unknown \\
\hline $\begin{array}{l}\text { Cost } \\
\text { (construction, operations, and D\&D) }\end{array}$ & Low to medium \\
\hline Operation Duration & Estimate $10 \mathrm{~L} / \mathrm{h}$ \\
\hline Public Acceptance & Unknown \\
\hline Flexibility & Medium to high \\
\hline Materials Covered & Nitric solutions \\
\hline
\end{tabular}
..... 


\section{References}

Breisch, R. C., W. A. Graff, and G. P. Miller. 1979. Technical Data Summary for Copercal Conversion in a Light Water Reactor Fuel Reprocessing - Refabrication Plant Complex. NEDC-21746, General Electric, San Jose, California.

International Atomic Energy Agency (IAEA). 1988. Treatment of Alpha Bearing Wastes. Technical Report Series No. 287, International Atomic Energy Agency, Vienna, Austria.

International Atomic Energy Agency (IAEA). 1992. Chemical Precipitation Processes for the Treatment of Aqueous Radioactive Waste. Technical Report Series No. 337, International Atomic Energy Agency, Vienna, Austria.

Westinghouse Hanford Company (WHC). 1991. Safety Analysis Report for the Plutonium Finishing Plant. WHC-SD-CP-SAR-021, Westinghouse Hanford Company, Richland, Washington.

\section{Bibliography}

Commission of the European Communities (CEN). 1981. Radioactive Waste: Advanced Management Methods for Medium Active Liquid Waste. Commission of the European Communities, Brussels, Belgium.

International Atomic Energy Agency (IAEA). 1994. Treatment of Low and Intermediate-Level Radioactive Wastes. Technical Report Series No. 236, International Atomic Energy Agency, Vienna, Austria.

Pacific Northwest Laboratory (PNL). 1993. Remedial Action Assessment System (RAAS). PNL-8751, Pacific Northwest Laboratory, Richland, Washington.

Thomas, L. L. 1980. "Mixed Oxide Conversion Facility Alternative Conceptual Designs." In Proceedings of the National Topical Meeting on Fuel Cycles for the 80's. CONF-800943, AlliedGeneral Nuclear Services, Barnwell, South Carolina. 
A. 170 


\section{Description of Technologies}

Accept: $\underline{X}$ Reject:

\section{Technology - Hydrolysis}

\section{Applicable Wastes Processed}

Organic and oil solutions containing more than $20 \mathrm{wt} \%$ organic material and nitric acid can be processed using hydrolysis.

\section{Process Description}

Organic material in the presence of concentrated nitric acid and plutonium can create explosive compounds or mixtures (WHC .1991). Hydrolysis is a process whereby organic materials (solvents, sludges) are stabilized to prevent the formation of these nitrated organic compounds during subsequent processing (i.e., dissolution and drying). Hydrolysis not necessary when the materials contain less than $20 \mathrm{wt} \%$ organic materials.

Plutonium-contaminated materials containing greater than $20 \mathrm{wt} \%$ organic material are primarily TBP, dibutylphosphate (DBP), and monobutylphosphate (MBP). The organic material is heated in a vessel containing sodium hydroxide. The butyl-phosphate bonds are broken to form butyl alcohol and water soluble mono-, di-, and tribasic sodium phosphate salts. Nitric acid reacts with sodium hydroxide to form soluble sodium nitrate. These solids, which contain complex mixtures of metal hydroxides including plutonium hydroxide, are subsequently processed in miscellaneous treatment (dissolution and drying). The butyl is volatilized.

\section{Facilities and Equipment Required}

Glovebox HC-60 in the PFP is used for hydrolysis (WHC 1991). It does not need modifications to process the inventory of PFP organic materials. Glovebox HC-60 operations are already approved and documented in the SAR, operating procedures, etc. (Figure A.9). Existing utilities, personnel, and raw materials can be used.

\section{Scheduled}

The hydrolysis process in Glovebox HC-60 is a proven process requiring no development or equipment installation and checkout. Based on a 650 gram net batch charge weight, the inventory of PFP organic material should be processed in approximately 339 batches. If an overall batch processing time of 4 hours is assumed, the total processing time would be 1356 hours.

\section{A. 171}




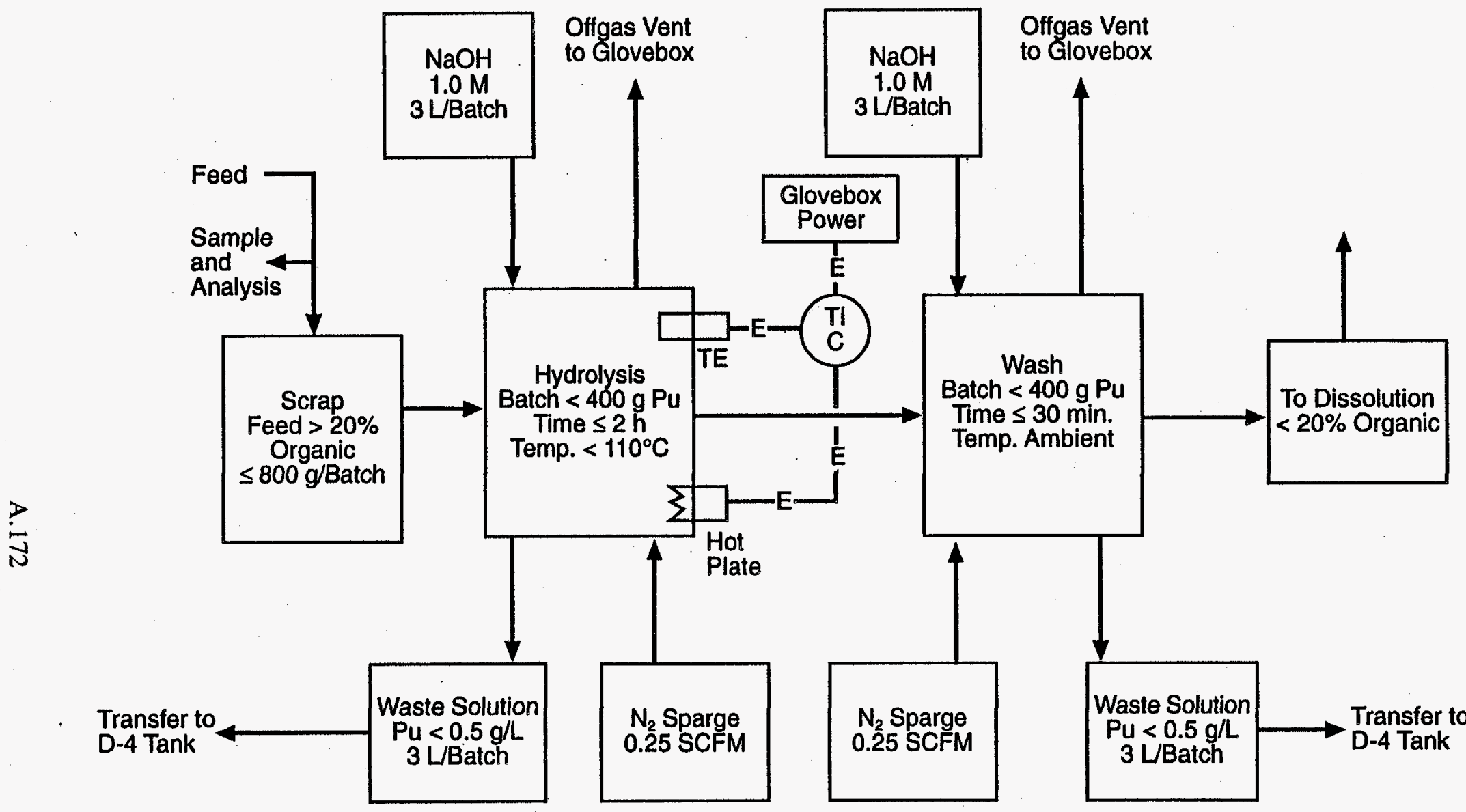

$\$ 9410070.8$

Figure A.9. Glovebox 60 Flowsheet 


\section{End Product Description}

The products from hydroxide hydrolysis are mono-, di-, and tribasic sodium phosphate salts, sodium nitrate, plutonium hydroxide, and other metal hydroxides. These soluble solids require further processing for final stabilization.

\section{Effluents and By-Products}

The liquid effluent from the hydrolysis process is the waste sodium hydroxide solution containing trace amounts of plutonium. This waste stream can be processed in the existing PFP waste water treatment facility. The gaseous effluent from the hydrolysis process is the butyl alcohol. This stream can be vented to the existing glovebox ventilation system.

\section{Risks}

The main concern of the hydrolysis process is to ensure that no rapid organic/nitric acid reactions occur, which is accomplished by controlling the temperature of the reaction vessel to less than $110^{\circ} \mathrm{C}$. Glovebox HC-60 relies on a hot plate control system to limit the solution temperature. The solution temperature is measured, and the power to the hot plate is shut off on high temperature or low deviation on the heat-up rate. Risks to the worker, to the environment, and to the public are minimized.

\section{Costs}

No new equipment costs are expected for operating the Glovebox HC-60 hydrolysis process. Operational costs are expected to be minimal due to previous operating experience. Administrative costs are also expected to be minimal because the necessary documents (SAR, operating procedures, maintenance, training, etc.) are already in place. Waste disposal costs are also minimal because the PFP's existing ventilation and waste water treatment processes can be used.

\section{Comments}

No installed process alternative to hydrolysis exists at PFP for preparing organic-bearing materials for final stabilization.

\section{Justification for Further Study or Rejection}

The hydrolysis process using the Glovebox HC-60 system in the PFP is recommended for further study. This process is proven, and the equipment has been successful in preparing organic-bearing materials for further processing and eventual stabilization. 


\section{References}

Westinghouse Hanford Company (WHC). 1991. Safety Analysis Report for the Plutonium Finishing

Facility. WHC-SD-CP-SAR-021, Rev. 0, Westinghouse Hanford Company, Richland, Washington. 


\section{Description of Technologies}

Accept: — Reject: $\underline{X}$

\section{Technology - High Temperature Plasma}

\section{Waste Processed}

Candidate wastes include all solid and/or liquid waste streams, depending on configuration. The process would be used for destroying organic materials and nitrates, evaporation and calcination, and/or vitrification of the waste.

\section{Process Description}

In this technology, a DC plasma arc is generated between two high-voltage electrodes. The thermal energy (Joule heating) from the arc is used, directly or indirectly, to heat the waste. The energy from the arc is enough to completely oxidize organic materials and melt inorganics. There are two different modes of operation: one where the arc is transferred directly to the waste or an electrode in contact with the waste (transferred mode), and another where a gas is passed through the arc and the gas then transfers the energy to the waste (non-transferred mode) (SAIC 1992; ECRC 1989). The gas used in non-transferred arcs is generally an inert gas, most often argon (SAIC 1992).

In the transferred mode, the waste material is held in a crucible or other thermally insulated container. The waste is heated by the arc because of Joule heating. Alternatively, the waste can be heated by directing the hot gas from a non-transferred plasma arc at the waste. Another method for treating waste using a non-transferred plasma arc is to feed the material directly into the stream of hot gas. The material will be carried along with the gas and can then be caught in a crucible.

The heat generated by the arc drives off water from the waste, oxidizes organic materials to water and carbon dioxide, destroys nitrates, and converts metals to oxides. Most organics are consumed completely in a few milliseconds. $\mathrm{NO}_{\mathrm{x}}$ may be formed in relatively high concentrations from the destruction of nitrates. The heat is sufficient to melt most oxides, resulting in a molten slag that, when cooled, could be a suitable interim storage form.

Because of the high temperatures, significant quantities of volatile metals could be carried into the offgas system. The process has also been known for producing significant particulate matter.

The transferred mode is a more efficient method of heating the waste, compared to non-transferred arcs, and has been used successfully on many different types of dry wastes, destroying essentially all of the organic components (Backus et al. 1993). However, there are disadvantages to this method. One

\section{A. 175}


is that, if there is a significant amount of water in the waste, hydrogen gas may be produced in significant quantities, and increases the risk of a deflagration or explosion in the reactor.

Feeding the waste into the hot gas stream produced by the discharge avoids the problem of hydrogen generation. Aqueous wastes can be handled better than by transferred arcs (Backus et al. 1993;

McLaughlin et al. 1993; Goheen 1994). This method is most effective on streams with dissolved solids or slurries with relatively small particles. There are instances where the short time the waste spends in the hot gas stream is insufficient to completely react all materials.

A substantial amount of work has been done on waste remediation using plasma technologies (Backus et al. 1993; McLaughlin et al. 1993). Less work has been done on non-transferred arc methods compared to transferred arc methods. However, plasma arc technology in waste remediation still requires some development before it is mature.

\section{Facilities and Equipment}

The plasma torch and crucible would require approximately $0.42 \mathrm{~m}^{3}$ of space because of the height of the equipment. All heat-generating components must be insulated. There would have to be a high voltage supply and cooling water for the torch. For a non-transferred apparatus, there would also have to be a supply of inert gas, such as argon. For a transferred arc, the existing off-gas system should suffice. It is not known whether the existing off-gas system could handle the effluent gas flow from a non-transferred apparatus.

\section{Final Product Description}

The final product is a glassy slag or, under certain conditions or configurations, an ash. The final product contains no organic material, water, or volatile components, as these are driven off or consumed by the plasma. A glass would be a suitable long-term storage form, while ash may require further processing.

\section{Effluents Generated}

The plasma torch produces an off-gas containing water, carbon monoxide and dioxide, and nitrogen compounds. The off gas may contain relatively large amounts of $\mathrm{NO}_{\mathrm{x}}$. No appreciable amount of complex organic molecules would be present in the off gas. However, there may be other volatile components, as well as significant particulate concentrations, in the off gas.

There is a greater flow of gas from the reactor in the case of a non-transferred arc, since there must be a continuous flow of gas through the torch to transfer energy. 


\section{Risks}

There is the potential for a deflagration or explosion in the equipment because of the generation of flammable gases, especially for transferred arc systems. The equipment can be designed to make this risk negligible. There are also risks associated with high temperatures and high voltages.

\section{Justification for Further Study or Rejection}

Table A.20 provides a summary of the criteria evaluations of this process. Although plasma arcs offer an efficient technology for destruction of organic compounds, the technology still requires some development. There are other, better developed technologies that can be used.

\section{References}

Backus, P. M., J. B. Berry, G. J. Coyle, P. W. Lurk, and S. M. Wolf. 1993. Development of Treatment Technologies for the Processing of U.S. Department of Energy Mixed Wastes.

DE-AC05-84OR21400, Oak Ridge National Laboratory, Oak Ridge, Tennessee.

Goheen, R. S. 1994. Calcination Kinetics Test Plan. TWRSPP-94-033, Pacific Northwest Laboratory, Richland, Washington.

McLaughlin, D. F., W. R. Gass, S. V. Dighe, J. D. McCormack, C. A. Delegard, and S. A. Colby. 1993. Plasma Calcination of Simulated High-Level Nuclear Waste. Westinghouse STC, Pittsburgh, Pennsylvania.

Science Applications International Corporation (SAIC). 1992. Technology Evaluation Report of Retech's Plasma Centrifugal Furnace, Volume 1. EPA/540/5-91/007a, U.S. Environmental Protection Agency, Cincinnati, Ohio.

The Electricity Council Research Centre (ECRC). 1989. Plasma Heated Glass Making. PB90-211772, Capenhurst, Chester, England.

\section{Bibliography}

Surma, J. E., C. J. Freeman, T. D. Powell, D. R. Cohn, R. A. Hamilton, D. L. Smatlak, P. Thomas, C. H. Titus, J. K. Whittle, and P. P. Woskov. 1993. Evaluation of the Graphite Electrode DC Arc Furnace for the Treatment of INEL Buried Wastes. PNL-8525, Pacific Northwest Laboratory; Richland, Washington. 
Table A.20. Criteria Evaluations for Plasma Arc

\begin{tabular}{|c|c|}
\hline Criteria & Evaluation \\
\hline Technical Feasibility (technology maturity) & Low to Medium \\
\hline $\begin{array}{l}\text { Effluents/By-Products } \\
\text { (minimize volumes, hazards) }\end{array}$ & Effluent is calcined/vitrified waste, off gas \\
\hline Effluents Covered/SAR & Yes \\
\hline Energy Resource & High \\
\hline Weapon Potential & None \\
\hline End Product Volume & Reduced \\
\hline End Product Stability & Medium to high \\
\hline $\begin{array}{l}\text { Environmental and Public Risk } \\
\text { routine } \\
\text { accident }\end{array}$ & $\begin{array}{l}\text { Low } \\
\text { Low }\end{array}$ \\
\hline $\begin{array}{l}\text { Worker Risk } \\
\text { routine } \\
\text { accident }\end{array}$ & $\begin{array}{l}\text { Low } \\
\text { Low }\end{array}$ \\
\hline $\begin{array}{l}\text { Cost } \\
\text { (construction, operations and D\&D) }\end{array}$ & Medium \\
\hline Operating Duration & Unknown \\
\hline Public Acceptance & Unknown \\
\hline Flexibility & High \\
\hline Materials Covered & Varies \\
\hline
\end{tabular}




\section{Description of Technologies}

Accept: _ Reject: $\underline{X}$

\section{Technology - Membrane Separations}

\section{Waste Processed}

The wastes processed are solutions containing radionuclides, nonradioactive salts, and suspended solids.

\section{Process Description}

Membrane separation techniques are used to separate suspended solids, colloids, and ions from process streams (Plock and Travis 1981; Baker et al. 1990). The process results in a purified stream and a concentrated stream containing impurities. In many instances, membrane filtration has replaced other concentration techniques, especially evaporation.

There are four categories of membrane separations in widespread industrial and laboratory use: microfiltration, ultrafiltration, reverse osmosis, and electrodialysis (Baker et al. 1990). The primary difference in microfiltration, ultrafiltration, and reverse osmosis is the size of the particles separated by the membrane. Microfiltration membranes have pore sizes in the range of 0.1 to $10 \mu \mathrm{m}$. Ultrafiltration membranes have pore sizes in the range of 20 to $1000 \AA$. Reverse osmosis membranes have the smallest pore sizes, from 5 to $20 \AA$.

For filtration and osmosis, the feed solution is passed through a pressurized cell containing the membrane. The membrane selectively allows portions of the solution to pass through, while retaining other components (solids, ions, etc.) in the feed. Electrodialysis uses a charged membrane to separate ions from a solution. In this case, an electrical potential, rather than a pressure gradient, is the driving force.

There have been some applications of membranes to solutions containing radioactive components (Plock and Travis 1980; Panicker et al. 1990). However, only dilute streams have been studied. It is probable that, to use a membrane on a stream containing high concentrations of plutonium, new technology development would be required.

\section{Justification for Further Study or Rejection}

Table A.21 summarizes the criteria evaluations for the membrane separation process. Membrane stability is a significant problem in membrane-based technologies. Stability would be even greater in a 
Table A.21. Criteria Evaluations for Membrane Separations

\begin{tabular}{|c|c|}
\hline Criteria & Evaluation \\
\hline Technical Feasibility (technology maturity) & Low to Medium \\
\hline $\begin{array}{l}\text { Effluents/By-Products } \\
\text { (minimize volumes, hazards) }\end{array}$ & $\begin{array}{l}\text { Effluent is concentrated waste stream, product is } \\
\text { clean water. }\end{array}$ \\
\hline Effluents Covered/SAR & Yes \\
\hline Energy Resource & Low \\
\hline Weapon Potential & None \\
\hline End Product Volume & Same as starting material \\
\hline End Product Stability & Additional processing required \\
\hline $\begin{array}{l}\text { Environmental and Public Risk } \\
\text { routine } \\
\text { accident }\end{array}$ & $\begin{array}{l}\text { None } \\
\text { None }\end{array}$ \\
\hline $\begin{array}{l}\text { Worker Risk } \\
\text { routine } \\
\text { accident }\end{array}$ & $\begin{array}{l}\text { None } \\
\text { Low }\end{array}$ \\
\hline $\begin{array}{l}\text { Cost } \\
\text { (construction, operations and D\&D) }\end{array}$ & Medium to high \\
\hline Operating Duration & Unknown \\
\hline Public Acceptance & High \\
\hline Flexibility & Low \\
\hline Materials Covered & Weak solutions with some particulates \\
\hline
\end{tabular}


high radiation environment, especially for organic membranes. Inorganic membranes could improve stability in high radiation environments; however, a lack of research in this area precludes any conclusions on stability. Significant technology development would be required.

\section{References}

Baker, R. W., E. L. Cussler, W. Eykamp, W. J. Coros, R. L. Riley, and H. Strathmann. 1990. Membrane Separation Systems--A Research and Development Needs Assessment. Volume 1. Department of Energy Membrane Separation Systems Research Needs Assessment Group, Washington, D.C.

Panicker, S. T., S. Prabhakar, B. M. Misra, and M.P.S. Ramani. 1990. Radioactive Liquid Effluent Management--State of Art and the Role of Membrane Processes. Government of India Atomic Energy Commission, Bombay, India.

Plock, C. E., and T. N. Travis. 1980. Plutonium Decontamination Studies Using Reverse Osmosis. Rockwell International Corporation, Canoga Park, California.

Plock, C. E., and T. N. Travis. 1981. Purification and Decontamination of a Caustic Water by Reverse Osmosis. Atomics International Div., Rocky Flats Plant, Golden, Colorado. 
A. 182 


\section{Description of Technologies}

Accept: $\underline{X}$ Reject:

\section{Technology - Precipitation of Silver Chloride}

\section{Waste Processed}

- Solutions containing chloride ions can be processed using this process.

\section{Process Description}

Silver chloride is one of the most insoluble chloride salts. Precipitation of silver chloride is a simple process for removing chloride ions from solutions. There is no information on plant-scale application of such a process to plutonium-bearing wastes.

\section{Schedule}

Only minor development would be required. The process could be run at almost any suitable location. A minimum amount of space would be required.

\section{Final Product Description}

The final product would be a solution free of chloride ions. Further treatment would be required to produce a stable, long-term storage form.

\section{Effluents Generated}

The effluent would be a solid silver chloride that can be easily filtered. A small amount of trapped impurities may be present in the precipitate.

\section{Risks}

There are no risks. The reaction is not vigorous and does not form dangerous by-products.

\section{Justification for Further Study or Rejection}

Table A.22 provides a summary of the criteria evaluation for this process. There are few methods by which chloride ions can be removed from solution. Precipitation of silver chloride is a simple and straightforward method of removing chloride ions to allow further processing. 
Table A.22. Criteria Evaluations for Silver Precipitation of Chlorides

\begin{tabular}{||l|l||}
\hline \multicolumn{1}{|c|}{ Criteria } & \multicolumn{1}{|c|}{ Evaluation } \\
\hline \hline Technical Feasibility (technology maturity) & Unknown \\
$\begin{array}{l}\text { Effluents/By-Products } \\
\text { (minimize volumes, hazards) }\end{array}$ & $\begin{array}{l}\text { Product is a chloride free solution, effluent is solid } \\
\text { silver chloride }\end{array}$ \\
Effluents Covered/SAR & Yes \\
Energy Resource & None \\
Weapon Potential & None \\
End Product Volume & Same as starting material \\
End Product Stability & Further treatment required \\
Environmental and Public Risk & \\
routine \\
accident \\
Worker Risk \\
routine \\
accident \\
Cost \\
(construction, operations and D\&D) \\
Operating Duration & None \\
Public Acceptance & None \\
Flexibility & Unknown \\
Materials Covered & Unknown \\
\hline
\end{tabular}

\section{A. 184}




\section{Description of Technologies}

Accept: $\underline{X}$ Reject: _

\section{Technology - Catalyzed Electrochemical Plutonium Oxide Dissolution (CEPOD) Process}

\section{Waste Processed}

This technology can process solid wastes containing plutonium oxide.

\section{Process Description}

CEPOD is a batch process that extracts plutonium from solid wastes by $\mathrm{Ag}$ (II) oxidation of plutonium to soluble $\mathrm{PuO}_{2}{ }^{+2}$ (Kurath et al. 1990; Surma et al. 1994; Wheelwright et al. 1990, 1991; Bourges et al. 1986; Madic et al. 1990). ${ }^{\text {(a) }}$ The process uses an electrochemical cell to produce highly reactive $\mathrm{Ag}(\mathrm{II})$ ions, which rapidly oxidizes plutonium oxide.

The CEPOD electrochemical cell consists of an anode and a cathode compartment, which are separated by a porous divider. The two compartments contain different solutions: silver nitrate in the anode compartment and nitric acid in the cathode compartment. The porous divider allows for the passage of some ions. The plutonium-containing solids are added to the anode compartment.

The reactions occurring in the cell are as follows:

Overall cell reaction:

$$
\mathrm{PuO}_{2}+2 \mathrm{NO}_{3}^{-}+4 \mathrm{H}^{+} \rightarrow \mathrm{PuO}_{2}^{+2}+2 \mathrm{NO}_{2}+2 \mathrm{H}_{2} \mathrm{O}
$$

Anode compartment:

$$
\begin{aligned}
& \mathrm{PuO}_{2}+\mathrm{Ag}^{+2} \rightarrow \mathrm{PuO}_{2}^{+1}+\mathrm{Ag}^{+1} \\
& \mathrm{PuO}_{2}^{+1}+\mathrm{Ag}^{+2} \rightarrow \mathrm{PuO}_{2}^{+2}+\mathrm{Ag}^{+1} \\
& 2 \mathrm{Ag}^{+2}+\mathrm{H}_{2} \mathrm{O} \rightarrow 2 \mathrm{Ag}^{+}+2 \mathrm{H}^{+}+\mathrm{O}_{2}
\end{aligned}
$$

(a) Ryan, J. L. Internal PNL Memo, dated August 14, 1994. 
Anode surface:

$$
\begin{aligned}
& \mathrm{Ag}^{+1} \rightarrow \mathrm{e}^{-}+\mathrm{Ag}^{+2} \\
& 2 \mathrm{H}_{2} \mathrm{O} \rightarrow \mathrm{O}_{2}+4 \mathrm{H}^{+}+4 \mathrm{e}^{-}
\end{aligned}
$$

Cathode surface:

$$
\begin{aligned}
& 2 \mathrm{H}^{+}+\mathrm{NO}_{3}^{-}+\mathrm{e}^{-} \rightarrow \mathrm{NO}_{2}+\mathrm{H}_{2} \mathrm{O} \\
& 4 \mathrm{H}^{+}+\mathrm{NO}_{3}^{-}+3 \mathrm{e}^{-} \rightarrow \mathrm{NO}+\mathrm{H}_{2} \mathrm{O}
\end{aligned}
$$

After the process is complete, the solids are filtered and washed to remove any residual solution. The plutonium-bearing solution would require further processing to produce a suitable form for storage. The polarity in the electrochemical cell can be reversed to cause the reduction of the $\mathrm{PuO}_{2}{ }^{+2}$ to solid plutonium oxide. The solids could then be calcined to produce a stable form with a low LOI. However, it is more efficient to send the liquids directly to a separate processing step, such as calculation.

Because $\mathrm{Ag}(\mathrm{II})$ is a vigorous oxidant, other materials in the waste will also be attacked. Any small quantities of light organics will be converted to water and carbon dioxide. Any americium in the waste will also be extracted.

As silver reacts with chloride ions to form a very insoluble compound, any chloride ions would have to be washed from the solids. The solid PFP wastes that would be treated by CEPOD should not contain any significant amount of chloride ion. A simple water wash would be sufficient to remove any residual chloride, if present. CEPOD and similar techniques have been demonstrated using elements other than silver, such as cerium. Cerium would not react with chloride and could be used if there were a significant amount of chloride present on the solids. However, the kinetics of electrochemical dissolvers using cerium are significantly slower than those using silver and must be maintained at an elevated temperature.

The CEPOD cell can be used to convert chloride ions in solution to chlorine gas, thereby removing chloride from the aqueous phase. If the cell is run with an acidic $\left(\mathrm{HNO}_{3}\right)$ solution and no silver, chlorine gas will be generated. The chlorine would have to be scrubbed from the off gas. This process could be done as a preliminary step, before adding silver, to remove chlorine from the system and avoid silver chloride formation. Initial tests using CEPOD to remove chlorine from a slurry showed CEPOD to be an inefficient method. One hour of treatment resulted in a maximum of $72 \%$ removal, and the solids still had to be separated and washed before being leached. 


\section{Facilities and Equipment}

There is an existing CEPOD dissolver unit in storage at the PFP plant. This equipment is available for use at PFP. The dissolver unit could be operated in $1.1 \mathrm{~m}^{3}$ of glovebox space, with controlling electronics located outside the glovebox. Existing off-gas equipment could be used to handle gases generated by the process.

\section{Schedule}

The process-scale equipment has processed batches containing on the order of $1 \mathrm{~kg}$ of plutonium in less than 8 hours. This process rate should be sufficient to handle PFP wastes without scale-up of the technology.

\section{Final Product Description}

The plutonium leaving the CEPOD dissolver is in the form of a $\mathrm{PuO}_{2}^{+2}$ solution, which may contain other soluble components. Additional processing of the solution would be required to produce a form suitable for long-term storage. Any process that can handle nitrate solutions could be used to treat the CEPOD effluent.

The polarity in the electrochemical cell can be reversed to cause the reduction of the $\mathrm{PuO}_{2}{ }^{+2}$ to solid plutonium oxide. However, this method although demonstrated is relatively untested and is not efficient.

\section{Effluents Generated}

CEPOD produces a liquid effluent containing $\mathrm{PuO}_{2}{ }^{+2}$ and other soluble components, and a solid effluent that contains almost no residual plutonium. $\mathrm{NO}_{\mathrm{x}}$ is produced at the cathode, which can be scrubbed and recycled back to $\mathrm{HNO}_{3}$. If the $\mathrm{HNO}_{3}$ concentration in the cathode compartment drops below $2 \underline{\mathrm{M}}$, hydrogen generation can occur.

\section{Risks}

Potentially explosive $\mathrm{H}_{2}$ gases can be generated at the cathode if the $\mathrm{HNO}_{3}$ concentration drops below $2 \mathrm{M}$. Therefore, the concentration of $\mathrm{HNO}_{3}$ must be monitored for safety. The present CEPOD design includes monitoring equipment for this purpose. A potential explosion would pose a risk to workers and, perhaps, the public.

\section{Costs}

An existing CEPOD dissolver is located in storage at the $236-\mathrm{Z}$ plant and is available for use in treatment of PFP wastes. 


\section{References}

Bourges, J., C. Madic., G. Koehly, and M. Lecomte. 1986. Journal of the Less-Common Metals. $122: 303$ to 311 .

Kurath, D. E., L. A. Bray, G. L. Bryan, J. L. Ryan, J. M. Seay, R. W. Stromatt, J. E. Surma, and E. J. Wheelwright. 1990. Engineering of the CEPOD II Dissolver System. PNL-7275, Pacific Northwest Laboratory, Richland, Washington.

Madic, C., J. L. Saulze, J. Bourges, M. Lecomte, and G. Koehly. 1990. "ASHES 90. Technical Seminar on Treatment and Conditioning of Radioactive Incinerator." CEA-CONF 10389, National Technical Information Services, Springfield, Virginia.

Surma, J. E., J. G. H. Geeting, M. G. Hyatt, D. L. Alexander, G. H. Bryan, and R. S. Holeman. 1994. Catalyzed Electrochemical Oxidation (CEO) of Rocky Flats Contaminated Combustible Materials. PNL-9974, Pacific Northwest Laboratory, Richland, Washington.

Wheelwright, E. J., J. L. Ryan, L. A. Bray, G. H. Bryan, and J. E. Surma. 1991. The Use of Catalyzed Electrolytic Plutonium Oxide Dissolution (CEPOD) For Waste Treatment. PNL-SA-19729, Pacific Northwest Laboratory, Richland, Washington.

Wheelwright, E. J., L. A. Bray, G. L. Bryan, D. E. Kurath, J. L. Ryan, and J. E. Surma. 1990. Kilogram-Scale Demonstration of Plutonium Recover from Plant Residues Using a CEPOD II Dissolver, Anion Exchange, Oxalate Precipitation, and Calcination to Oxide. PNL-7653, Pacific Northwest Laboratory, Richland, Washington. 
Appendix B

Basis for the Numerical Rating of PFP Residue Processing Alternatives 



\section{Contents}

Material Category: Solutions (Nitrates, Chlorides, Caustics, Filtrates) . . . . . . . . . B.1

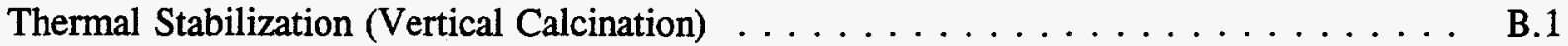

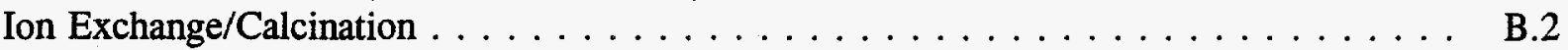

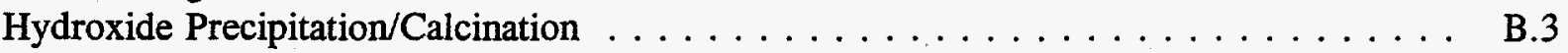

Molten Salt Oxidation/Dissolution/Thermal Treatment $\ldots \ldots \ldots \ldots \ldots \ldots \ldots$

Material Category: Organic Solutions (Tributyl phosphate, Carbon Tetrachloride, Lard Oil) . B.5

Thermal Stabilization (Vertical Calcination) $\ldots \ldots \ldots \ldots \ldots \ldots \ldots$

Molten Salt Oxidation/Dissolution/Thermal Treatment $\ldots \ldots \ldots \ldots \ldots \ldots$

Material Category: Solids (Oxides, Fluorides, Sand Slag \& Crucible, Incinerator Ash) _ . . B.7

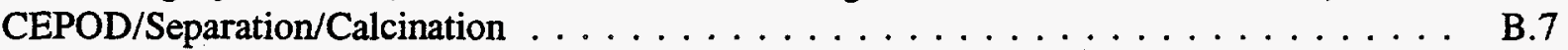

Molten Salt Oxidation/Dissolution/Thermal Treatment $\ldots \ldots \ldots \ldots \ldots \ldots$

Thermal Stabilization in Muffle Furnace $\ldots \ldots \ldots \ldots \ldots \ldots \ldots$

Thermal Stabilization in Continuous Calciner $\ldots \ldots \ldots \ldots \ldots \ldots \ldots \ldots$

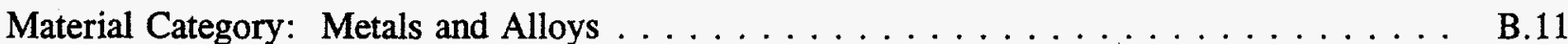

Thermal Stabilization in Muffle Furnace $\ldots \ldots \ldots \ldots \ldots \ldots \ldots \ldots \ldots$

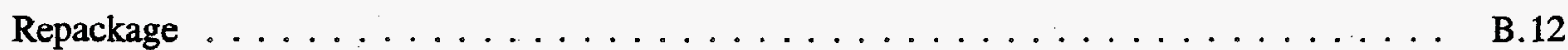

Material Category: Combustibles/Polycubes . . . . . . . . . . . . . . B.13

Molten Salt Oxidation/Dissolution/Thermal Treatment $\ldots \ldots \ldots \ldots \ldots \ldots \ldots$

Thermal Stabilization in Muffle Furnace $\ldots \ldots \ldots \ldots \ldots \ldots \ldots \ldots \ldots$ 


\section{Appendix B}

\section{Basis for the Numerical Rating of PFP Residue Processing Alternatives}

\section{Mạterial Category: Solutions (Nitrates, Chlorides, Caustics, Filtrates)}

\section{Proposed Process: Thermal Stabilization (Vertical Calcination)}

Total Score: 73

\begin{tabular}{|c|c|c|}
\hline Criteria & Rating & Reason \\
\hline \multicolumn{3}{|l|}{ Tech. Feasibility } \\
\hline Maturity (20) & 15 & State of development is good for nitrates; less so for other solutions. \\
\hline Maintenance (10) & 5 & $\begin{array}{l}\text { Process and equipment are relatively complex with moving parts that may } \\
\text { be difficult to maintain. }\end{array}$ \\
\hline Flexible (15) & 10 & $\begin{array}{l}\text { As proposed, this technology appears to be able to process most of the } \\
\text { materials in this category. }\end{array}$ \\
\hline Stability (5) & 4 & $\begin{array}{l}\text { Final product form is calcined plutonium oxide with very good stability, } \\
\text { although some chlorides also may be present. }\end{array}$ \\
\hline Effluent (5) & 5 & Should be only gaseous effluent. \\
\hline Worker Risk (20) & 10 & $\begin{array}{l}\text { High exposure to operators because of the manual operations and lack of } \\
\text { americium removal. }\end{array}$ \\
\hline Cost (5) & 4 & $\begin{array}{l}\text { Equipment is complex, but does not have many major equipment items; } \\
\text { should have a relatively low cost. }\end{array}$ \\
\hline & 20 & $\begin{array}{l}\text { Less than } 5 \text { years total duration--Implementation period estimated to be } \\
\text { less than } 2 \text { years; less than } 3 \text { years anticipated to process inventory. }\end{array}$ \\
\hline $\begin{array}{l}\text { Implementation } \\
\text { Operation }\end{array}$ & & \\
\hline
\end{tabular}




\section{Material Category: Solutions (Nitrates, Chlorides, Caustics, Filtrates)}

\section{Proposed Process: Ion Exchange/Calcination}

\section{Total Score: 66}

\begin{tabular}{|c|c|c|}
\hline Criteria & Rating & Reason \\
\hline Tech. Feasibility & & \\
\hline Maturity (20) & 12 & Fairly mature, can be in design in 2 years. \\
\hline Maintenance (10) & 3 & Relatively complex equipment with automated valves, sensors, pumps. \\
\hline Flexible (15) & 8 & Expected to be able to handle all of the solutions. \\
\hline Stability (5) & 5 & Final product form is calcined plutonium oxide with very good stability. \\
\hline Effluent (5) & 3 & Relatively high volumes of separation wastes would be sent to tank farm. \\
\hline Worker Risk (20) & 10 & $\begin{array}{l}\text { Americium removal would reduce exposure to operators during calcination } \\
\text { and packaging. Relatively easy to automate handling of solutions. }\end{array}$ \\
\hline Cost (5) & 3 & Higher costs than would be incurred by just thermal treatment. \\
\hline Duration (20) & 20 & $\begin{array}{l}\text { Less than } 5 \text { years total duration--Implementation period estimated to be less } \\
\text { than } 3 \text { years; less than } 2 \text { years anticipated to process inventory. }\end{array}$ \\
\hline $\begin{array}{l}\text { Implementation } \\
\text { Operation }\end{array}$ & & \\
\hline
\end{tabular}




\section{Material Category: Solutions (Nitrates, Chlorides, Caustics, Filtrates)}

\section{Proposed Process: Hydroxide Precipitation/Calcination}

Total Score: 57

\begin{tabular}{|c|c|c|}
\hline Criteria & Rating & Reason \\
\hline \multicolumn{3}{|l|}{ Tech Feasibility } \\
\hline Maturity (20) & 12 & Fairly mature, can be in design in 2 years. \\
\hline Maintenance (10) & 5 & Less complex than ion exchange. \\
\hline Flexible (15) & 8 & Expected to be able to handle all of the solutions. \\
\hline Stability (5) & 5 & Final product form is calcined plutonium oxide with very good stability. \\
\hline Effluent (5) & 4 & The volume of wastes to be sent to tank farm less than for ion exchange. \\
\hline Worker Risk (20) & 10 & $\begin{array}{l}\text { Americium not removed. Relatively easy to automate handling of } \\
\text { solutions. }\end{array}$ \\
\hline Cost (5) & 3 & Costs would be about same as for ion exchange. \\
\hline Duration (20) & 10 & More than 5 , but less than 10 years total duration. \\
\hline Implementation & & Implementation period estimated to be less than 3 years. \\
\hline Operation & & $\begin{array}{l}\text { More than } 2 \text { years anticipated to process inventory due to batch-type } \\
\text { operations. }\end{array}$ \\
\hline
\end{tabular}


Material Category: Solutions (Nitrates, Chlorides, Caustics, Filtrates)

Proposed Process: Molten Salt Oxidation/Dissolution/Thermal Treatment

Total Score: 48

\begin{tabular}{|c|c|c|}
\hline Criteria & Rating & Reason \\
\hline \multicolumn{3}{|l|}{ Tech. Feasibility } \\
\hline Maturity (20) & 0 & Limited experience with feeding liquids to the unit. \\
\hline Maintenance (10) & 5 & $\begin{array}{l}\text { Expected to be about the same as maintenance of the hydroxide precipita- } \\
\text { tion equipment. }\end{array}$ \\
\hline Flexible (15) & 15 & Expected to be able to handre all of the solutions. \\
\hline Stability (5) & 5 & Final product form is calcined plutonium oxide with very good stability. \\
\hline Effluent (5) & 1 & Dissolution would send salt water with halides to tank farm. \\
\hline Worker Risk (20) & 10 & $\begin{array}{l}\text { High exposure to operators due to the manual operations and lack of } \\
\text { Americium removal. }\end{array}$ \\
\hline Cost (5) & 2 & $\begin{array}{l}\text { Relatively complex equipment and enclosures estimated to have a relatively } \\
\text { high cost. }\end{array}$ \\
\hline Duration (20) & 10 & Five to 10 years total duration. \\
\hline Implementation & & Implementation period estimated to be 6 years. \\
\hline Operation & & Less than 4 years anticipated to process inventory. \\
\hline
\end{tabular}

B.4 


\section{Material Category: Organic Solutions (Tributyl phosphate, Carbon \\ Tetrachloride, Lard Oil)}

\section{Proposed Process: Thermal Stabilization (Vertical Calcination)}

Total Score: 34

\begin{tabular}{|c|c|c|}
\hline Criteria & Rating & Reason \\
\hline \multicolumn{3}{|l|}{ Tech. Feasibility } \\
\hline Maturity (20) & 0 & Not demonstrated for organic compounds. \\
\hline Maintenance (10) & 5 & $\begin{array}{l}\text { Process and equipment are relatively complex with moving parts that may } \\
\text { be difficult to maintain. }\end{array}$ \\
\hline Flexible (15) & 5 & $\begin{array}{l}\text { Serious doubts as to feasibility of this technology for these organic } \\
\text { solutions. }\end{array}$ \\
\hline Stability (5) & 1 & Final product may not meet definitions of stable product form. \\
\hline Effluent (5) & 1 & Gaseous effluent would contain chlorides and hydrocarbons. \\
\hline Worker Risk (20) & 8 & $\begin{array}{l}\text { Exposure to operators due to manual operations and lack of americium } \\
\text { removal, process could require considerable attention/adjustment. }\end{array}$ \\
\hline Cost (5) & 4 & $\begin{array}{l}\text { Equipment complex but not many major equipment items so should have a } \\
\text { relatively low cost. }\end{array}$ \\
\hline Duration (20) & 10 & Between 5 and 10 years total duration. \\
\hline Implementation & & $\begin{array}{l}\text { Implementation period estimated to be more than } 4 \text { years, new equipment } \\
\text { in a new glovebox. }\end{array}$ \\
\hline Operation & & About 1 year anticipated to process the two package inventories. \\
\hline
\end{tabular}




\section{Material Category: Organic Solutions (Tributyl phosphate, Carbon Tetrachloride, Lard Oil)}

\section{Proposed Process: Molten Salt Oxidation/Dissolution/Thermal Treatment}

\section{Total Score: 49}

\begin{tabular}{|c|c|c|}
\hline Criteria & Rating & Reason \\
\hline \multicolumn{3}{|l|}{ Tech. Feasibility } \\
\hline Maturity (20) & 0 & Limited experience with feeding either liquids or organics to the unit. \\
\hline Maintenance (10) & 5 & Process and equipment are relatively complex and difficult to maintain. \\
\hline Flexible (15) & 12 & Expected to be able to handle most of the solutions. \\
\hline Stability (5) & 5 & Final product is calcined plutonium oxide with good stability. \\
\hline Effluent (5) & 5 & $\begin{array}{l}\text { Dissolution would send very limited quantities of salt water with halides to } \\
\text { tank farm. }\end{array}$ \\
\hline Worker Risk (20) & 10 & $\begin{array}{l}\text { Exposure to operators due to the manual operations and lack of americium } \\
\text { removal small since limited quantities of plutonium are involved. }\end{array}$ \\
\hline Cost (5) & 2 & $\begin{array}{l}\text { Relatively complex equipment and enclosures estimated to have a relatively } \\
\text { high cost. }\end{array}$ \\
\hline Duration (20) & 10 & Five to 10 years total duration. \\
\hline Implementation & & Implementation period estimated to be 6 years. \\
\hline Operation & & Less than 1 year anticipated to process inventory. \\
\hline
\end{tabular}




\section{Material Category: Solids (Oxides, Fluorides, Sand Slag \& Crucible, Incinerator Ash)}

\section{Proposed Process: CEPOD/Separation/Calcination}

Total Score: 39

\begin{tabular}{|c|c|c|}
\hline Criteria & Rating & Reason \\
\hline \multicolumn{3}{|l|}{ Tech. Feasibility } \\
\hline Maturity (20) & 0 & Not demonstrated for several of these materials. \\
\hline Maintenance (10) & 2 & $\begin{array}{l}\text { Process and equipment are complex, are in a strong acid environment, and } \\
\text { are difficult to maintain. }\end{array}$ \\
\hline Flexible (15) & 5 & After dissolution, there will still be residues to process. \\
\hline Stability (5) & 5 & Final product form is calcined plutonium oxide with very good stability. \\
\hline Effluent (5) & 1 & Relatively high volumes of separation wastes would be sent to tank farm. \\
\hline Worker Risk (20) & 15 & $\begin{array}{l}\text { Americium removal would reduce exposure to operators during calcination } \\
\text { and packaging. }\end{array}$ \\
\hline Cost (5) & 1 & $\begin{array}{l}\text { Major installation costs would be incurred to provide the equipment and } \\
\text { enclosures for these processes. }\end{array}$ \\
\hline Duration (20) & 0 & Over 10 years total duration. \\
\hline Implementation & & Implementation period estimated to be more than 6 years. \\
\hline Operation & & More than 4 years anticipated to process inventory. \\
\hline
\end{tabular}




\section{Material Category: Solids (Oxides, Fluorides, Sand Slag \& Crucible, Incinerator Ash)}

\section{Proposed Process: Molten Salt Oxidation/Dissolution/Thermal Treatment}

\section{Total Score: 48}

\begin{tabular}{|c|c|c|}
\hline Criteria & Rating & Reason \\
\hline \multicolumn{3}{|l|}{ Tech. Feasibility } \\
\hline Maturity (20) & 0 & Not demonstrated for most of these materials. \\
\hline Maintenance (10) & 5 & Process and equipment are relatively complex and difficult to maintain. \\
\hline Flexible (15) & 15 & $\begin{array}{l}\text { As proposed, process appears to be able to process all of the materials in } \\
\text { this category. }\end{array}$ \\
\hline Stability (5) & 5 & Final product form is calcined plutonium oxide with very good stability. \\
\hline Effluent (5) & 1 & Dissolution would send salt water with halides to tank farm. \\
\hline Worker Risk (20) & 10 & $\begin{array}{l}\text { High exposure to operators due to the manual operations and lack of } \\
\text { americium removal. }\end{array}$ \\
\hline Cost (5) & 2 & $\begin{array}{l}\text { Relatively complex equipment and enclosures estimated to have a relatively } \\
\text { high cost. }\end{array}$ \\
\hline Duration (20) & 10 & Five to 10 years total duration. \\
\hline Implementation & & Implementation period estimated to be 6 years. \\
\hline Operation & & Less than 4 years anticipated to process inventory. \\
\hline
\end{tabular}




\section{Material Category: Solids (Oxides, Fluorides, Sand Slag \& Crucible, Incinerator Ash)}

\section{Proposed Process: Thermal Stabilization in Muffle Furnace}

Total Score: $\mathbf{5 2}$

\begin{tabular}{||c|c|l||}
\hline \multicolumn{1}{|c|}{ Criteria } & Rating & \multicolumn{1}{|c|}{ Reason } \\
\hline \hline Tech. Feasibility & & \\
Maturity (20) & 20 & Fully mature process; no development required. \\
Maintenance (10) & 10 & Simple equipment that is easily maintained or replaced. \\
Flexible (15) & 10 & Is expected to be able to handle most of the materials in this category. \\
Stability (5) & 2 & $\begin{array}{l}\text { Just dries material, does not convert halides to oxides. } \\
\text { Only gaseous effluent uniess scrubber is used in which case liquid effluent } \\
\text { would be low volume. }\end{array}$ \\
Effluent (5) & 4 & $\begin{array}{l}\text { High exposure to operators due to the manual operations and lack of ameri- } \\
\text { cium removal. } \\
\text { Worker Risk (20) }\end{array}$ \\
Cost (5) & 4 & $\begin{array}{l}\text { Relatively low costs due to simplicity of equipment. } \\
\text { Over 10 years total duration. } \\
\text { Duration (20) }\end{array}$ \\
Implementation & 0 & $\begin{array}{l}\text { Implementation period estimated to be very short, less than 1 year. } \\
\text { More than 10 years anticipated to process inventory. }\end{array}$ \\
Operation & &
\end{tabular}




\section{Material Category: Solids (Oxides, Fluorides, Sand Slag \& Crucible, Incinerator Ash)}

\section{Proposed Process: Thermal Stabilization in Continuous Calciner}

\section{Total Score: 82}

\begin{tabular}{|c|c|c|}
\hline Criteria & Rating & Reason \\
\hline \multicolumn{3}{|l|}{ Tech. Feasibility } \\
\hline Maturity (20) & 20 & Fully mature process; no development required. \\
\hline Maintenance (10) & 8 & Equipment more complex than muffle furnace option. \\
\hline Flexible (15) & 15 & Is expected to be able to handle most of the materials in this category. \\
\hline Stability (5) & 2 & Just dries material, does not convert halides to oxides. \\
\hline Effluent (5) & 4 & $\begin{array}{l}\text { Only gaseous effluent unless scrubber is used in which case liquid effluent } \\
\text { would be low volume. }\end{array}$ \\
\hline Worker Risk (20) & 10 & $\begin{array}{l}\text { Exposure should be equivalent to MSO option since no americium } \\
\text { removal. }\end{array}$ \\
\hline Cost (5) & 3 & Relatively lost costs due to simplicity of equipment. \\
\hline Duration (20) & 20 & Less than 5 years total duration. \\
\hline Implementation & & $\begin{array}{l}\text { Implementation period estimated to be short, approximately } 2 \text { years. New } \\
\text { equipment in existing glovebox. }\end{array}$ \\
\hline Operation & & About 2 years anticipated to process inventory. \\
\hline
\end{tabular}




\section{Material Category: Metals and Alloys}

\section{Proposed Process: Thermal Stabilization in Muffle Furnace}

\section{Total Score: 67}

\begin{tabular}{|c|c|c|}
\hline Criteria & Rating & Reason \\
\hline \multicolumn{3}{|l|}{ Tech. Feasibility } \\
\hline Maturity (20) & 20 & Fully mature process; no development required. \\
\hline Maintenance (10) & 10 & Simple equipment that is easily maintained or replaced. \\
\hline Flexible (15) & 10 & May have difficulties with some of the alloys in this category. \\
\hline Stability (5) & 3 & Not all material may be converted to an oxide form. \\
\hline Effluent (5) & 5 & Only gaseous effluent. \\
\hline Worker Risk (20) & 5 & $\begin{array}{l}\text { High exposure to operators due to the manual operations and lack of } \\
\text { americium removal. }\end{array}$ \\
\hline Cost (5) & 4 & Relatively low costs due to simplicity of equipment. \\
\hline Duration (20) & 10 & Less than 10 years total duration. \\
\hline Implementation & & Implementation period estimated to be very short, less than 1 year. \\
\hline Operation & & More than 4 years anticipated to process inventory. \\
\hline
\end{tabular}


Material Category: Metals and Alloys

\section{Proposed Process: Repackage}

Total Score: 95

\begin{tabular}{||l|r|l||}
\hline \multicolumn{1}{|c|}{ Criteria } & Rating & \multicolumn{1}{|c||}{ Reason } \\
\hline \hline Tech. Feasibility & & \\
Maturity (20) & 15 & Package concept needs development work. \\
Maintenance (10) & 10 & Simple equipment that is easily maintained or replaced. \\
Flexible (15) & 15 & All material can be repackaged. \\
Stability (5) & 5 & Metal is a stable form. \\
Effluent (5) & 5 & No repackaging effluent generated. \\
Worker Risk (20) & 20 & Minimal exposure to workers since operations are simple enough that tongs \\
& 5 & can be used to minimize exposure. \\
Relatively low costs due to simplicity of equipment. \\
Cost (5) & 20 & Less than 5 years total duration. \\
Duration (20) & Implementation period estimated to be very short, less than 1 year. \\
Implementation & Less than 4 years anticipated to process inventory. \\
Operation &
\end{tabular}


Material Category: Combustibles/Polycubes

Proposed Process: Molten Salt Oxidation/Dissolution/Thermal Treatment

Total Score: 48

\begin{tabular}{|c|c|c|}
\hline Criteria & Rating & Reason \\
\hline \multicolumn{3}{|l|}{ Tech. Feasibility } \\
\hline Maturity (20) & 0 & Not demonstrated for these materials. \\
\hline Maintenance (10) & 5 & Process and equipment are relatively complex and difficult to maintain. \\
\hline Flexible (15) & 15 & $\begin{array}{l}\text { As proposed, process appears to be able to process all of the materials in } \\
\text { this category. }\end{array}$ \\
\hline Stability (5) & 5 & Final product form is calcined plutonium oxide with very good stability. \\
\hline Effluent (5) & 1 & Dissolution would send salt water with halides to tank farm. \\
\hline Worker Risk (20) & 10 & $\begin{array}{l}\text { High exposure to operators due to the manual operations and lack of } \\
\text { americium removal. }\end{array}$ \\
\hline Cost (5) & 2 & $\begin{array}{l}\text { Relatively complex equipment and enclosures estimated to have a relatively } \\
\text { high cost. }\end{array}$ \\
\hline Duration (20) & 10 & Five to 10 years total duration. \\
\hline Implementation & & Implementation period estimated to be 6 years. \\
\hline Operation & & Less than 4 years anticipated to process inventory. \\
\hline
\end{tabular}




\section{Material Category: Combustibles/Polycubes}

\section{Proposed Process: Thermal Stabilization in Muffle Furnace}

\section{Total Score: 54}

\begin{tabular}{|c|c|c|}
\hline Criteria & Rating & Reason \\
\hline \multicolumn{3}{|l|}{ Tech. Feasibility } \\
\hline Maturity (20) & 0 & $\begin{array}{l}\text { Doubt as to whether a muffle furnace is suitable for use as a pyrolysis } \\
\text { unit. }\end{array}$ \\
\hline Maintenance (10) & 8 & $\begin{array}{l}\text { Due to presence of hydrocarbons, maintenance of furnace would be more } \\
\text { difficult than for other solids. }\end{array}$ \\
\hline Flexible (15) & 10 & Is expected to be able to handle most of the materials in this category. \\
\hline Stability (5) & 5 & Product stability should be better than for other solids. \\
\hline Effluent (5) & 3 & $\begin{array}{l}\text { Only gaseous effluent unless scrubber is used in which case liquid effluent } \\
\text { would be low volume. }\end{array}$ \\
\hline Worker Risk (20) & 5 & $\begin{array}{l}\text { Less exposure to operators than for other solids because less plutonium is } \\
\text { involved. }\end{array}$ \\
\hline Cost (5) & 3 & $\begin{array}{l}\text { Slightly higher than for other solids since a secondary chamber or off-gas } \\
\text { scrubber may be required. }\end{array}$ \\
\hline Duration (20) & 20 & Less than 5 years total duration. \\
\hline Implementation & & Implementation period estimated to be very short, less than 1 year. \\
\hline Operation & & Less than 4 years anticipated to process inventory. \\
\hline
\end{tabular}




\section{Distribution}

No. of

Copies

\section{OFFSITE}

12 DOE Office of Scientific and Technical Information

L. L. Zahn

PO Box 111

Concrete, WA 98237

R. L. Nass

Nuclear Fuel Services, Inc.

1205 Banner Hill Rd.

Erwin, TN 37650

M. Muller

195 East Road

Los Alamos, NM 87544

W. Sumner

Westinghouse Savannah River Co.

Aiken, SC 29802

J. V. Robinson,

J. V. Robinson \& Associates 19503 Welch Rd.

Snohomish, WA 98290
No. of

Copies

\section{ONSITE}

DOE Richland Operations Office
B. F. Burton (5)
T4-18

2 MACTEC
D. J. Swanberg
K8-50
D. J. Guzzetta
B1-42

12 Westinghouse Hanford Company
E. V. Weiss (10)
T3-01
G. P. Miller
T3-01

25 Pacific Northwest Laboratory
R. H. Gallucci
(K8-07)
S. M. Garrett
J.G.H. Geeting
(P7-43)
R. S. Goheen
(P7-43)
L. K. Holton
(K9-73)
T. Y. Hosaka
(B1-40)
G. A. Jensen
P. M. Molton
(K7-94)
D. K. Peeler
(P8-44)
M. H. Schlender
G. J. Sevigny
(5) $\quad(\mathrm{P} 7-33)$
N. J. Stratton
(K8-14)
K. J. Templeton
(K7-94)
A. J. Villegas
(K7-97)
Information Release Office (7) 